\title{
Identity and Dynamics of the Microbial Community Responsible for Carbon Monoxide Oxidation in Marine Environments
}

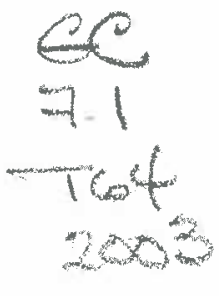

\author{
By
}

Tolli, John D.

B.S. Biology, emphasis in Marine Biology

San Diego State University, 1997

Submitted in partial fulfillment of the requirements of the degree of

DOCTOR OF PHILOSOPHY

at the

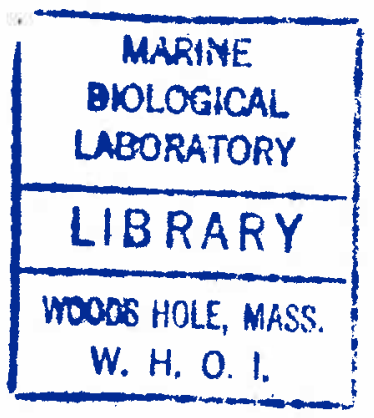

MASSACHUSETTS INSTITUTE OF TECHNOLOGY
and the
WOODS HOLE OCEANOGRAPHIC INSTITUTION

September 2003

(C) 2003 John D. Tolli. All rights reserved.

The author hereby grants WHOI and MIT permission to reproduce and distribute publicly paper and electronic copies of this thesis document in whole or in part.

Signature of Author

Joint Program in Oceanography/Biological Oceanography

Massachusetts Institute of Technology

Woods Hole Oceanographic Institution

July 2003

Certified by

Craig D. Taylor

Thesis Supervisor

Accepted by

Chair, Joint Committee for Biological Oceanography

Massachusetts Institute of Technology

Woods Hole Oceanographic Institution 


\title{
Identity and Dynamics of the Microbial Community Responsible for Carbon Monoxide Oxidation in Marine Environments \\ By
}

Tolli, John D.

Submitted to the Department of Biological Oceanography on June 24, 2003

in partial fulfillment of the requirements for the Doctor of Philosophy in

Biological Oceanography

\begin{abstract}
As colored dissolved organic matter in seawater absorbs UV solar radiation, a variety of simple chemical species are produced, including carbon monoxide $(\mathrm{CO})$. The ocean surface water is saturated with respect to $\mathrm{CO}$, and is thus a source of $\mathrm{CO}$ to the atmosphere. CO reacts with and removes free-radical compounds, and may itself contribute to the 'greenhouse' gas content of the atmosphere. An important sink for $\mathrm{CO}$ in seawater is the biological oxidation of $\mathrm{CO}$ to $\mathrm{CO}_{2}$ by marine microorganisms. The objectives of this study are to identify component members of the microbial community responsible for the oxidation of $\mathrm{CO}$ in coastal marine environments through a combination of recent microbiological and molecular approaches, and to estimate their contributions to total in situ $\mathrm{CO}$ bio-oxidation. We utilize an enrichment method that involves cultivation of bacteria on membrane filters, subsequent incubation with radiolabeled $\mathrm{CO}$, and the use of autoradiography to screen colonies with the desired phenotype. Cell-specific CO-oxidation activity is determined for selected purified strains with a time-series ${ }^{14} \mathrm{CO}$-oxidation method. Molecular phylogeny based on 16S-rDNA gene sequence information within the context of the large and growing $16 \mathrm{~S}$ database determines the phylogenetic relatedness and identity of marine CO-oxidizing bacteria that result from our cultivation program. The $\mathrm{CO}$ oxidizing organisms isolated in this study with greatest activity are closely related to the Roseobacter and Paracoccus genera of the alpha-proteobacteria, collectively known as the "marine alpha group". Other microorganisms found to oxidize CO at environmentally relevant rates are members of beta- and gamma-proteobacteria, and one in the Cytophaga-Flavobacterium-Bacteroides group.

A collective CO-oxidation activity was calculated from physiological measurements of purified isolates and abundance estimates of $\mathrm{CO}$-oxidizing marine alpha group organisms. Relative proportions of $\mathrm{CO}$ oxidizing Roseobacter and Paracoccus cells were resolved microscopically by microautoradiography in combination with DAPI and fluorescent-labeled oligonucleotide probes (Substrate Tracking AutoRadiography - Fluorescent In Situ Hybridization (STAR-FISH)). Marine alpha group organisms were a major component of total cell numbers (45.7\%) at the time of sampling (March 2003), and CO-oxidizing members of the marine alpha group contributed up to $40.7 \%$ of total $\mathrm{CO}$ oxidation occurring in coastal waters.
\end{abstract}

Thesis supervisor: Craig D. Taylor 


\section{CONTENTS}

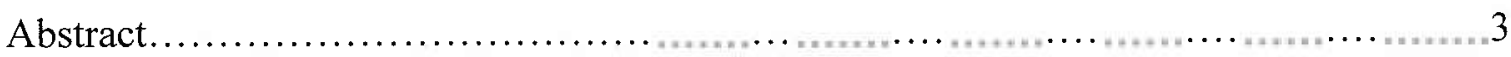

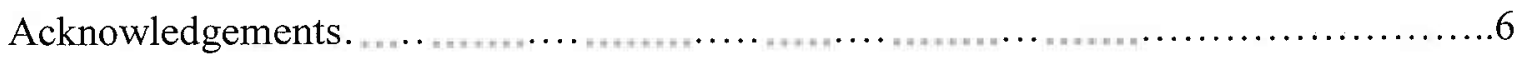

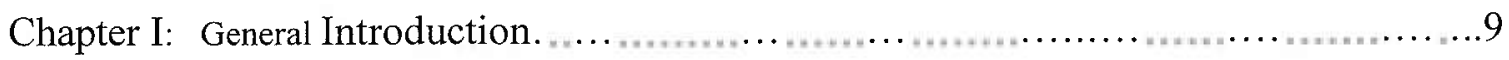

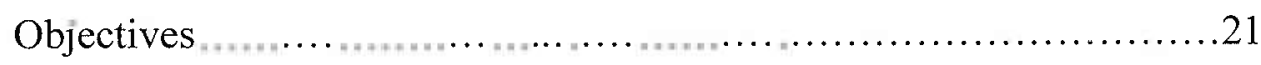

Chapter II: Biological CO Oxidation Rates in the Sargasso Sea and in

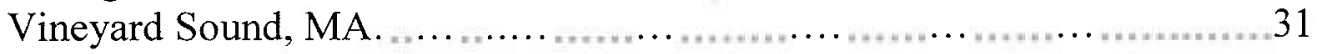

Chapter III: Characterization of Marine Carbon Monoxide Oxidizing Microorganisms Isolated from a Coastal Marine Environment...............69

Chapter IV: Abundance and activity of CO-oxidizing microorganisms in natural samples by Substrate Tracking Microautoradiography - Fluorescent In Situ Hybridization (STARFISH) ...................................115

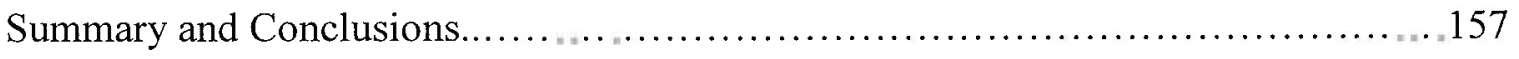

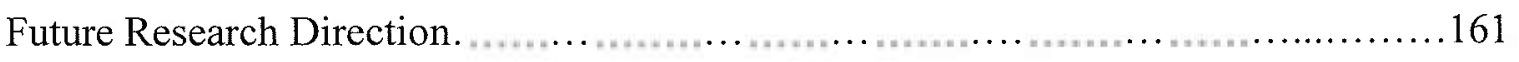

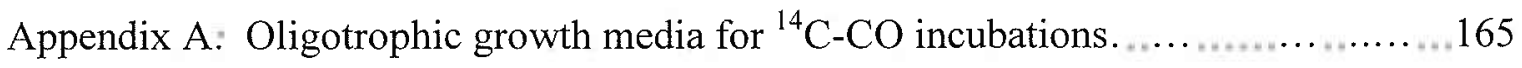

Appendix B: Autoradiographic plates for pure culture isolates.................... 167

Appendix C: Characterizations of CO oxidizing isolates (from Bergey's Manual of

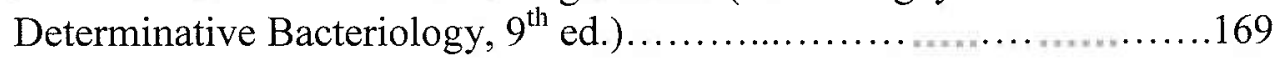

Appendix D: Aligned 16S-rDNA sequences for CO-oxidizing isolates................173 


\section{ACKNOWLEDGEMENTS}

I am grateful to several past and present members of the WHOI Department of Biology for their patience and willingness to teach me the skills that I required to conduct this research. These include Steve Molyneaux, Konstantinos Kormas, Ken Halanych, Mike Atkins, Frederica Valois and Bruce Woodin. Thanks also to Dr. Mary Ann Moran of the University of Georgia for her generous contribution of experimental Roseobacter strains for my analysis. The Captain and crew of the R/V Weatherbird II, of Bermuda Biological Station for Research, deserve special recognition for allowing me to conduct radiological experiments during the BATS166 cruise amidst their already-filled schedule and laboratory space.

I would like to thank each of my committee members Carl Wirsen, Stefan Sievert, John Waterbury, Oliver Zafiriou, Martin Polz, and Andreas Teske, for contributing their time and highly individual expertise to every phase of this research. Most of all, I must thank my advisor, Craig Taylor, for his continuous assistance, patience, and support through some difficult times.

To my wife Ofelia, and my son Douglas, goes my infinite love and gratitude for having such faith in me.

Financial support was provided by the WHOI Education office and the wonderful people who work there, NSF grant \#OCE-0136876, and the Coastal Ocean Institute and Rinehart Coastal Research Center grant \#BI10918. 
"Microbial ecology, the interaction of species with the environment and one another, is process-based, and the phylogenetic positioning of a phylotype can only give hints of the organism's actual function in its environment. Discarding pure culture approaches as too difficult, too slow or unnecessary, or using the term unculturable microbes means throwing the baby out with the bathwater. All those key microbes that make the phylogenetic tree useful appeared to be unculturable until they were cultured, at that point disclosing a wealth of new physiological and biochemical information needed in microbial ecology."

Holger Jannasch, 1927 - 1998 


\section{Chapter I:}

\section{General Introduction}

Carbon monoxide (CO) is the third most abundant carbon species in the atmosphere, after $\mathrm{CO}_{2}$ and methane. It is one of the most important reactive gasses in the atmosphere because of its reaction with the hydroxyl radical $\left(\mathrm{OH}^{*}\right)$, which forms a major sink for both atmospheric $\mathrm{CO}$ and $\mathrm{OH}^{*}$ (Logan et al., 1981; Johnson \& Bates, 1996; Pos et al., 1998; Zuo et al., 1998). Although the dominant sources of atmospheric CO are anthropogenic (Müller, 1992; Conrad \& Seiler, 1982a), it is well documented that sunlight-initiated photodegradation of colored dissolved organic matter (CDOM) is primarily responsible for producing $\mathrm{CO}$ in sunlit waters, thus the surface waters of the world's oceans are saturated with $\mathrm{CO}$ with respect to the atmosphere and are a source of atmospheric CO (Swinnerton et al., 1970; Conrad et al., 1982).

It is likely that most of the $\mathrm{CO}$ produced in situ is consumed by microbial activities (Conrad et al., 1982). Great uncertainty exists regarding the source strength of 
$\mathrm{CO}$ derived from the photodegradation of $\mathrm{CO}$; past studies focused on open ocean water have suggested that the oceanic CO flux may be as high as $200 \mathrm{Tg} / \mathrm{y}$ (Kieber et al., 1990; Mopper et al., 1991; Conrad et al., 1982). A more recent study has estimated a global "blue-water" photochemical source of $\mathrm{CO}, 50 \pm 10 \mathrm{Tg}$ carbon from $\mathrm{CO}$ per year (CO-C $\mathrm{a}^{-1}$ ) and its microbial sink, $32 \pm 18 \mathrm{Tg} \mathrm{CO}-\mathrm{C} \mathrm{a}^{-1}$ (Zafiriou et al., 2002), suggesting that $\mathrm{CO}$ processes are a non-trivial component of the oceanic carbon budget, and most photolytically produced $\mathrm{CO}$ is cycled internally by microbial processes. The global CO gas exchange flux has been estimated by Bates et al., (1995) as $\sim 5.5 \mathrm{Tg} \mathrm{CO}-\mathrm{C} \mathrm{a}^{-1}$; the flux of $\mathrm{CO}$ from the ocean into the atmosphere would therefore represent a minor fraction ( $9 \%-14 \%)$ of the total CO produced in the ocean (Conrad \& Seiler, 1980; Conrad et al., 1982). Whether the $\mathrm{CO}$ is transferred into the atmosphere or oxidized to $\mathrm{CO}_{2}$ it represents a direct loss of otherwise refractory DOM carbon in natural waters (Zuo \& Jones, 1997).

While CO-processes (production and consumption) have been measured on a gross scale in bulk seawater samples for nearly three decades in oligotrophic oceanic waters, there have been no definitive investigations concerning the identity of the microbes responsible for $\mathrm{CO}$ bio-oxidation in the marine environment; only circumstantial evidence for $\mathrm{CO}$ metabolizing marine organisms based on ancillary ability of certain bacteria to also metabolize CO. This will be the first attempt to both quantitatively and qualitatively describe the organisms responsible for oceanic COmetabolism, and illuminate the 'black box' regarding $\mathrm{CO}$ consumption in seawater that has been up to now overlooked in studies of ocean-atmosphere flux of trace gasses and carbon budget models in the oceanic environment. 
CO distribution and diel variability

The major source of $\mathrm{CO}$ in the surface waters of the ocean is the abiotic photooxidation of chromophoric dissolved organic material (CDOM) initiated by UV or nearUV light (Zuo \& Jones, 1995, 1997; Pos et al., 1998; Valentine \& Zepp, 1993; Mopper et al., 1991). The quantum yields for $\mathrm{CO}$ formation were found to decrease in an exponential manner between $280 \mathrm{nM}$ to $550 \mathrm{~nm}$. Although the highest quantum yields were observed in the UV-B region (280-320 nm), longer wavelengths of solar radiation, principally in the UV-A region (320-390 nm) and blue spectral region, are most important in inducing $\mathrm{CO}$ formation because a greater amount of radiation in these ranges reach the earth's surface (Valentine \& Zepp, 1993). A light-induced $\alpha$-cleavage of carbonyl compounds, a major constituent of natural DOM, may play a primary role in the photoproduction of CO (Pos et al., 1998; Zuo \& Jones, 1997). The dependence of CO production of the presence of CDOM, short-wavelength light, and oxygen (Zuo \& Jones, 1997; Conrad et al., 1982) and its independence of the presence of plankton or bacteria indicates that $\mathrm{CO}$ production is a photochemical rather than photometabolic process. At night photoproduction of $\mathrm{CO}$ ceases, thus the nighttime decrease in $\mathrm{CO}$ concentration results from two primary mechanisms: sea-to-air exchange and oxidation by microbes (Conrad \& Seiler, 1980; Jones, 1991; Johnson \& Bates, 1996).

Carbon monoxide concentration in the upper mixed layer in oligotrophic water exhibits a diurnal cycle with increasing concentrations of $\mathrm{CO}$ from dawn to a maximum (2-3 $\mathrm{nM})$ in middle to late afternoon, followed by a rapid decline in the early evening to a minimum (0.25 - $0.5 \mathrm{n} M)$ just before dawn (Johnson \& Bates, 1996; Conrad et al., 1982; 
Xie et al., 2001). This implies that $\mathrm{CO}$ is short-lived and is strongly coupled to the day/night cycle via photoproduction and biology (Conrad et al., 1982; Jones, 1991). Daytime vertical profiles of dissolved [CO] show maximum values in the surface water and decreasing $[\mathrm{CO}]$ with depth as light in the UV wavelengths is attenuated (Seiler \& Shmidt, 1974; Seiler, 1978; Jones, 1991; Xie et al., 2001). The lowest concentration of $\mathrm{CO}$ is found below the euphotic zone in depths beyond $100 \mathrm{~m}$ where $[\mathrm{CO}]$ varies between 1-12 $\mathrm{nl} \mathrm{l}^{-1}(0.044-0.53 \mathrm{nM})($ Conrad et al., 1982, lower detection limit of technique was $0.5 \mathrm{nl} \mathrm{l}^{-1}$ or $0.022 \mathrm{nM}$ ), and below detection limits at $200 \mathrm{~m}(<0.03 \mathrm{nM}$ ) (Xie et al., 2002b). The diel variation of dissolved $\mathrm{CO}$ occurs in the entire euphotic zone, with decreasing amplitude at greater depths reflecting decreasing light intensity. A phase lag of the diel variation within the euphotic zone - indicative of vertical CO transport - is lacking. In contrast with conditions within the euphotic zone, $\mathrm{CO}$ concentration varies little with time below the mixed layer. This indicates that the net exchange of $\mathrm{CO}$ between the euphotic zone and the underlying deep ocean water is very small and cannot account for the observed diurnal variation within the euphotic zone (Zuo \& Jones, 1997; Conrad et al., 1982; Jones, 1991; Zuo et al., 1998).

\section{Microbial groups implicated in CO oxidation}

Several biogeochemical studies have estimated the diel, annual, and global rates of microbial CO oxidation as an oceanic CO sink (Conrad \& Seiler, 1980, 1982b; Conrad et al. 1982, Johnson \& Bates, 1996; Jones, 1991; Xie et al., 2002; Zafiriou et al., 2002; and citations within) but few have attempted to investigate beyond the "black-box" 
level of the phenomena occurring in marine environments (Jones \& Amador, 1993; Jones $\&$ Morita, 1983b, 1984). There are no definitive investigations concerning the identity of the microbes responsible for $\mathrm{CO}$ bio-oxidation in the open-water marine environment; only circumstantial evidence for CO metabolizing marine organisms based on ancillary ability of certain bacteria to also metabolize CO. Two strains of ammonium-oxidizing microbes (Nitrosococcus oceanus and Nitrosomonas europaea) isolated from seawater and strains of methanotrophic (Pseudomonas methanica) bacteria isolated from brackish sediments have been shown to possess the ability to oxidize trace amounts of $\mathrm{CO}$ to $\mathrm{CO}_{2}$ in pure-culture studies, though aerobic methane and ammonium-oxidizing bacteria catalyze the oxidation of $\mathrm{CO}$ only when metabolizing other substrates and at the expense of the cell's reducing power (Ferenci et al., 1975; Jones \& Morita, 1983a, b).

A phylogenetically diverse group of microorganisms isolated from terrestrial and freshwater soils has been identified as having the ability to survive high concentrations of $\mathrm{CO}$ and a metabolism that allows growth with $\mathrm{CO}$ as their sole source of carbon and energy (Meyer and Schlegel, 1983; Meyer et al., 1986; Nozhevnikova \& Yurganov, 1978; Zavarzin \& Nozhevnikova, 1977). While CO-utilizing or "carboxydotrophic" bacteria have been successfully isolated from marine hydrothermal environments (Svetlichny et al., 1991a, 1991b; Sokolova et al., 2001; Gerhardt et al., 1991), these organisms, without exception, are strictly anaerobic and extremely thermophilic. These are therefore unlikely contributors to the observed CO consumption in marine surface waters. 


\section{Microbial Metabolism of $C O$}

Bacteria apparently contribute to $\mathrm{CO}$ consumption rather than production. Size fractionation experiments with ocean and lake water have shown that the $\mathrm{CO}$ oxidizing microorganisms are in a size range of 0.2-3.0 $\mu \mathrm{m}$ (Conrad et al., 1982; Conrad \& Seiler, 1982b; Olson, 1981) that excludes most of the eucaryotic phytoplankton population (Williams, 1981). There are two opposing views concerning the organisms responsible for the oxidation of CO in natural samples. Conrad and Seiler (1982b) suggest that the utilization of $\mathrm{CO}$ (in eutrophic lake water) is due to specific organisms that gain distinct advantage from the oxidation of CO. Evidence for this comes from low $K_{\mathrm{m}}$ values (7 - 9 $\mathrm{nM})$ and use of $\mathrm{CO}$ at trace levels $(\sim 0.04 \mathrm{nM})$ by the organisms reported in their studies. Bartholomew \& Alexander (1979) suggested that CO oxidation (in soil suspensions) is due to microorganisms that utilize $\mathrm{CO}$ gratuitously by co-oxidation or co-metabolism, that is, the transformation of a non-growth substrate in the obligate presence of a growth substrate (Dalton \& Stirling, 1982). This view is supported by their findings that essentially no radioactivity from ${ }^{14} \mathrm{C}-\mathrm{CO}$ appeared in the organic fraction under their experimental growth conditions and that ${ }^{14} \mathrm{C}-\mathrm{CO}_{2}$ fixation was not enhanced in the presence of $\mathrm{CO}$. These concepts are not mutually exclusive; groups of organisms that satisfy one or the other of these criteria may contribute jointly to total $\mathrm{CO}$ oxidation observed in natural waters.

Several workers have suggested that nitrifying bacteria contribute to $\mathrm{CO}$ oxidation in the oceans (Jones \& Amador, 1993; Conrad \& Seiler, 1980). A number of marine ammonium- and methane-oxidizing proteobacteria are identified as having a $K_{\mathrm{m}}$ for $\mathrm{CO}$ 
in the nanomolar range and the ability to oxidize $\mathrm{CO}$ at $n M$ concentrations in pure or enriched cultures. Methanotrophic bacteria are able to oxidize $\mathrm{CO}$ at trace levels and this oxidation is linked to the lack of specificity of the enzyme methane monooxygenase (MMO) (Ferenci et al., 1975). Due to the close similarity of the ammonium monooxygenase (AMO) and MMO enzymes, ammonium-oxidizing bacteria are also capable of $\mathrm{CO}$ oxidation at low $\mathrm{CO}$ concentrations in the environment. Jones and Morita (1983a) demonstrated that methane is a utilizable substrate for ammonium oxidizing bacteria, further demonstrating the similarity. $\mathrm{CO}$ is known to be a competitive substrate for $\mathrm{AMO}$, and inhibits $\mathrm{NH}_{4}{ }^{+}$oxidation in the marine environment at concentrations ranging from $2 n M$ to $11.4 \mu M$ (Ferenci, 1974; Jones \& Morita, 1983b; Vanzella et al., 1989). The ammonia oxidizers Nitrosomonas europaea and Nitrosococcus oceanus are able to oxidize $\mathrm{CO}$ to $\mathrm{CO}_{2}$ in the presence and absence of ammonium, but attempts to grow ammonium oxidizers on $\mathrm{CO}$ as the sole source of carbon and energy failed. None of the organisms tested incorporated any of the carbon from $\mathrm{CO}$ into cellular components in the absence of ammonium, but all were able to oxidize $\mathrm{CO}$ at trace concentrations $(<0.5 \mathrm{n} M)$. Although ammonia oxidizers can oxidize $\mathrm{CO}$ in the absence of ammonium, the oxidation can be considered to be a co-metabolism or "co-oxidation" (Dalton \& Stirling, 1982) since carbon from CO is not incorporated into cell material (Jones \& Morita, 1983b, 1984). CO oxidation in these organisms is a gratuitous process that actually drains the cell's supply of reducing power and does not support the growth of either methane- or ammonium-oxidizing organisms. 
Terrestrial aerobic microorganisms able to utilize carbon from $\mathrm{CO}$ include the chemolithoautotrophic carboxydobacteria (Zavarzin \& Nozhevnikova, 1977; Meyer, 1985; Meyer \& Schlegel, 1983), and other species of fungi and algae (Bartholomew \& Alexander, 1979; Inman et al., 1971). "Carboxydotrophic bacteria" or "carboxydobacteria" is a convenient operational term for the designation of organisms capable of oxidizing $\mathrm{CO}$ and growing chemolithotrophically. The group of carboxydotrophic bacteria defined by physiological characteristics is taxonomically diverse and is comprised of species of many different genera, e.g. Pseudomonas, Alcaligenes (Hydrogenomonas), Bacillus, Arthrobacter, Azomonas, and Azotobacter, Achromobacter, Comamonas, Seliberia (Nozhevnikova \& Zavarzin, 1974). From the diversity of carboxydobacteria observed it follows that it is unreasonable to revive a separate genus for lithotrophs oxidizing CO. The genus Hydrogenomonas was rejected by Davis et al. (1970) and the habit of grouping organisms according to similarity of physiological characteristics has disappeared (Nozhevnikova \& Zavarzin, 1974).

Enrichment and isolation of carboxydotrophic bacteria from natural habitats are traditionally done in liquid batch cultures incubated aerobically in desiccators supplied with $\mathrm{CO}_{2}$ and $\mathrm{CO}$ as carbon and energy sources. Such conditions are highly specific for the development of carboxydotrophs because of the inability of the contaminating microflora to utilize $\mathrm{CO}$, and inhibition of respiratory oxidases by irreversible binding of $\mathrm{CO}$ in the vast majority of organisms results in inhibition of their growth (Meyer \& Schlegel, 1983). Carboxydotrophic bacteria have been isolated from various freshwater soil and water sources and are able to utilize $\mathrm{CO}$ as an energy and carbon source, and are 
also able to grow like hydrogen bacteria on $\mathrm{H}_{2}, \mathrm{O}_{2}$, and $\mathrm{CO}_{2}$ (Zavarzin \& Nozhevnikova, 1977; Wood, 1991, Meyer \& Schlegel, 1983). Many possible habitats for carboxydobacteria are identical to those of hydrogen bacteria (Nozhevnikova \& Yurganov, 1978), including geothermal environments (Lilley et al., 1982), composting materials (Conrad, 1988) and submerged soils or soils with stagnant water (Inman et al., 1971; Rich et al., 1998). When pure cultures of other hydrogen bacteria were studied for their ability to utilize $\mathrm{CO}$, the results were negative; hydrogen bacteria were generally very sensitive to CO (Zavarzin \& Nozhevnikova, 1977).

The ability of the known carboxydobacteria to tolerate high [CO] stems from a branched respiratory chain, the autotrophic branch of which contains a $\mathrm{CO}$ insensitive $o$ type cytochrome (Meyer \& Schlegel, 1983, Kim \& Hegeman, 1983) or cytochrome $b_{653}$ (Meyer et al., 1986) functioning as terminal oxidase. CO:acceptor oxidoreductase [carbon monoxide oxidase (COX) (Meyer \& Schlegel, 1983) or çarbon monoxide dehydrogenase (CO-DH) (Meyer et al., 1986, Kim \& Hegeman, 1983)], the key enzyme in energy metabolism of these bacteria, is a selenium-containing molybdo-iron-sulfurflavin hydroxylase. COX or CO-DH serves three functions: $(a)$ to feed electrons into the respiratory chain for electron transport phosphorylation, $(b)$ to provide the carbon source as $\mathrm{CO}_{2}$, and (c) to provide ATP and, by inverse electron transfer, $\mathrm{NADH}$ for $\mathrm{CO}_{2}$ assimilation via the reductive pentosephosphate cycle. Carboxydotrophs oxidize CO for generation of energy, $5 \mathrm{CO}+2.5 \mathrm{O}_{2} \rightarrow 5 \mathrm{CO}_{2}$, and of reducing equivalents, $2 \mathrm{CO}+2$ $\mathrm{H}_{2} \mathrm{O} \rightarrow 2 \mathrm{CO}_{2}+2 \times 2[\mathrm{H}]=\mathrm{CO}_{2}$ derives from the oxidation of $\mathrm{CO}$ and is assimilated via the ribulosebisphosphate cycle: $\mathrm{CO}_{2}+2 \times 2[\mathrm{H}] \rightarrow\left(\mathrm{CH}_{2} \mathrm{O}\right)+\mathrm{H}_{2} \mathrm{O}$. The sum of these 
equations, $7 \mathrm{CO}+2.5 \mathrm{O}_{2}+\mathrm{H}_{2} \mathrm{O} \rightarrow 6 \mathrm{CO}_{2}+\left(\mathrm{CH}_{2} \mathrm{O}\right)$, indicates one-seventh of the COborn carbon being assimilated and is in accordance with the actual stoichiometry of uptake and fixation of $\mathrm{CO}$ by growing cells of Pseudomonas carboxydovorans and other carboxydotrophs:

$$
\mathrm{O}_{2}+2.19 \mathrm{CO} \rightarrow 1.83 \mathrm{CO}_{2}+0.36 \text { cell carbon }+ \text { energy }
$$

Under these conditions, the electrons derived from the oxidation of $\mathrm{CO}$ are channeled into the $\mathrm{CO}$ insensitive branch of the respiratory chain. The amount of $\mathrm{CO}$ used for energy generation may be much higher under oligotrophic or nutrient-poor growth: conditions; therefore, the amount of $\mathrm{CO}$-born $\mathrm{CO}_{2}$ assimilated by different strains ranges from $2-16 \%$ (Meyer \& Schlegel, 1983, for review).

There seems to be considerable variation in the efficiency with which CO-derived $\mathrm{CO} 2$ is assimilated according to growth conditions and among different strains of carboxydobacteria. This range indicates poor coupling in some strains between the CO oxidation and $\mathrm{CO} 2$ fixation processes and may reflect some variation among the electron transport systems of carboxydobacteria. It seems clear that CO-dependent growth is not very efficient in most cases, although the highest assimilation ratios agree well with the theoretically expected values (Meyer \& Schlegel, 1979, 1983; Hegeman, 1984)

In isotopic experiments with ${ }^{14} \mathrm{C}-\mathrm{CO},{ }^{14} \mathrm{C}-\mathrm{HCO}_{3}{ }^{-}$, and ${ }^{14} \mathrm{C}-\mathrm{CO}_{2}$, various species of carboxydobacteria incorporated labeled carbon into acid-stable products within the cells. However, the kinetics of accumulation of the label by the cells differed. The cells incubated in an atmosphere of unlabelled $\mathrm{CO}$ and ${ }^{14} \mathrm{C}-\mathrm{HCO}_{3}{ }^{-}$began to assimilate carbon dioxide at once and at a constant rate; moreover, the presence of $\mathrm{CO}$ as an energy 
substrate was necessary. The labeled carbon from ${ }^{14} \mathrm{C}-\mathrm{CO}$, in the absence of exogenous bicarbonate, was incorporated in the acid-stable products of the cells after a lag period, with the formation of acid-unstable intermediate(s). The addition of unlabeled carbon dioxide reduced the rate of incorporation of the label from ${ }^{14} \mathrm{C}-\mathrm{CO}$. The same was observed when ${ }^{14} \mathrm{C}-\mathrm{CO}_{2}$ formed from labeled $\mathrm{CO}$ was absorbed by $\mathrm{NaOH}$ or $\mathrm{KOH}$ (Nozhevnikova \& Yurganov, 1978; Zavarzin \& Nozhevnikova, 1977).

The key enzymes of the Calvin cycle have been found to be active in different strains of carboxydotrophic bacteria grown on CO. That carboxydotrophic bacteria growing on $\mathrm{CO}$ actually use the Calvin cycle for $\mathrm{CO}_{2}$ fixation in vivo and that $\mathrm{CO}$ is assimilated after its conversion to $\mathrm{CO}_{2}$ is evident from the following findings: (a) The activities of rubulosebisphosphate carboxylase and phosphoribulosekinase are in the same order of magnitude during growth with $\mathrm{CO}$ or $\mathrm{H}_{2}+\mathrm{CO}_{2}$ (Kiessling \& Meyer, 1982) and are, therefore, high enough to allow the observed growth rates with CO. (b) Very thin suspensions of carboxydotrophic bacteria do not grow with $\mathrm{CO}$ unless $\mathrm{CO}_{2}$ is present (Meyer \& Schlegel, 1978). (c) Growth with $\mathrm{CO}$ and the rate of ${ }^{14} \mathrm{C}-\mathrm{CO}$ assimilation are decreased by the presence of KOH (Nozhevnikova \& Yurganov, 1978; Zavarzin \& Nozhevnikova, 1977). (d) Labeled CO was assimilated after a lag period only, whereas ${ }^{14} \mathrm{C}_{-} \mathrm{CO}_{2}$ was incorporated instantaneously (Nozhevnikova \&Yurganov, 1978; Zavarzin \& Nozhevnikova, 1977). (e) Dilution of ${ }^{14} \mathrm{C}-\mathrm{CO}$ by $\mathrm{CO}_{2}$ resulted in a significant decrease of label incorporated into cell material (Nozhevnikova \& Yurganov, 1978; Zavarzin \& Nozhevnikova, 1977). Furthermore, the analysis of early fixation products from ${ }^{14} \mathrm{C}-\mathrm{CO}$ and ${ }^{14} \mathrm{C}-\mathrm{CO}_{2}$ of Pseudomonas carboxydohydrogena, Pseudomonas gazotropha, and 
Alcaligenes carboxydus were identical; after $3 \mathrm{sec}$ of incubation, about $40 \%$ of the radioactivity was found in phosphoglycerate, the rest was found in phosporylated sugars (Zavarzin \& Nozhevnikova, 1977).

The carboxydobacterium Pseudomanos carboxydoflava is remarkable because it has a constitutive $\mathrm{CODH}$ and oxidizes $\mathrm{CO}$ during heterotrophic growth, i.e. mixotrophically (Kiessling \& Meyer, 1982). Under these conditions, which approximate natural conditions better than purely autotrophic growth at the expense of $\mathrm{CO}$, there is little or no assimilation of $\mathrm{CO}$-derived $\mathrm{CO}_{2}$, apparently owing to repression of the reductive pentose cycle. However, the presence of $\mathrm{CO}$ increases the cell yield, demonstrating that there is at least an energetic benefit to the oxidation of $\mathrm{CO}$.

The question of which organisms are performing $\mathrm{CO}$ bio-oxidation observed in coastal or oceanic surface waters has not been satisfactorily resolved. As the marine microflora are thought to be actively oxidizing $\mathrm{CO}$, the main problem is to find out if there exists a specialized group of microorganisms that is capable of utilizing $\mathrm{CO}$ at environmental concentrations, or if $\mathrm{CO}$ at environmental concentrations is oxidized by all or most members of the microbial assemblage present in the environment. This work provides the first definitive identification of the $\mathrm{CO}$ metabolizing microorganisms that exist in a coastal marine environment. Through a combination of recent microbiological and molecular techniques, some component members of the $\mathrm{CO}$ metabolizing community are identified and their phylogenetic relationships determined in the context of the large and growing 16S-rRNA database. 


\section{OBJECTIVES}

The following investigations undertook the isolation, identification and phylogeny of important members of the microbial community responsible for oxidation of $\mathrm{CO}$ in the coastal marine environment, and determined the relative contributions of these organisms to total $\mathrm{CO}$ oxidation observed in natural waters in a multi-phase research program (figure 1.1).

\section{Objective 1: Isolation and Culture of marine $\mathrm{CO}$ oxidizing microorganisms.}

Our isolation protocol allowed the simultaneous recovery of $\mathrm{CO}$ metabolizing organisms with different growth rates and nutritional requirements. While there is ample evidence for the existence of carboxydotrophic bacteria in terrestrial soils and wetlands, there have been no documented attempts to obtain or enumerate CO-utilizing microbes in marine (non-hydrothermal) environments. Growth conditions were provided for the cultivation of marine organisms capable of $\mathrm{CO}$ metabolism under elevated $(\sim 40 \mathrm{nM})$ dissolved $\mathrm{CO}$ concentrations relative to the natural environment. Microbial samples from the environment were incubated on separate mineral media containing either $\mathrm{NO}_{3}{ }^{-}$or $\mathrm{NH}_{4}{ }^{+}$as alternate nitrogen sources, permitting the discrimination of strains that incorporate carbon from $\mathrm{CO}$ from those that oxidize $\mathrm{CO}$ by co-oxidation. Autoradiography permitted rapid screening of CO metabolizing strains amidst a potential background of other colonies. Purified strains were tested individually for their COoxidizing phenotype and their activity rates determined. 


\section{Objective 2: Identification and phylogeny of $\mathrm{CO}$ oxidizing isolates based on small subunit ribosomal gene sequence.}

With $\mathrm{CO}$ metabolizing strains isolated during the cultivation phase, we determined their 16S-rDNA sequence information by PCR amplification using general eubacterial primers. We compared the sequence information obtained from selected isolates within the context of published $16 \mathrm{~S}$ rRNA gene sequences to determine their phylogenetic relationships.

\section{Objective 3: Enumerate $\mathrm{CO}$ oxidizing organisms in natural samples}

We estimated the proportion of cells in the natural marine environment that metabolize carbon from $\mathrm{CO}$, and furthermore determined the proportion of $\mathrm{CO}$ metabolizing cells on a group-(genus)-specific level, by combining microautoradiography with group-specific fluorescent in situ hybridization with oligonucleotide probes developed based on the genetic identity of resultant strains. The substrate-tracking

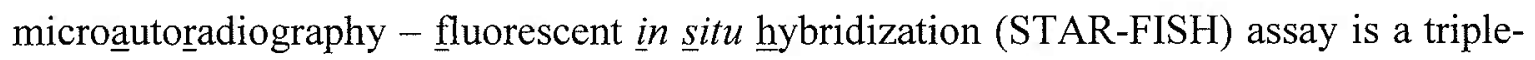
labeling technique that allowed simultaneous microscopic visualization of i) generally labeled cells (DAPI), ii) cells that have incorporated labeled carbon from $\mathrm{CO}$ and have exposed radiographic emulsion, and iii) cells which have hybridized with group-specific fluorescent-labeled oligonucleotide probes. 
Figure 1.1: Flow scheme of overall thesis program, showing the methods that allow isolation, specific activity measurement, and differential quantification of phenotype in natural samples. Major research areas are separated into Chapters. 


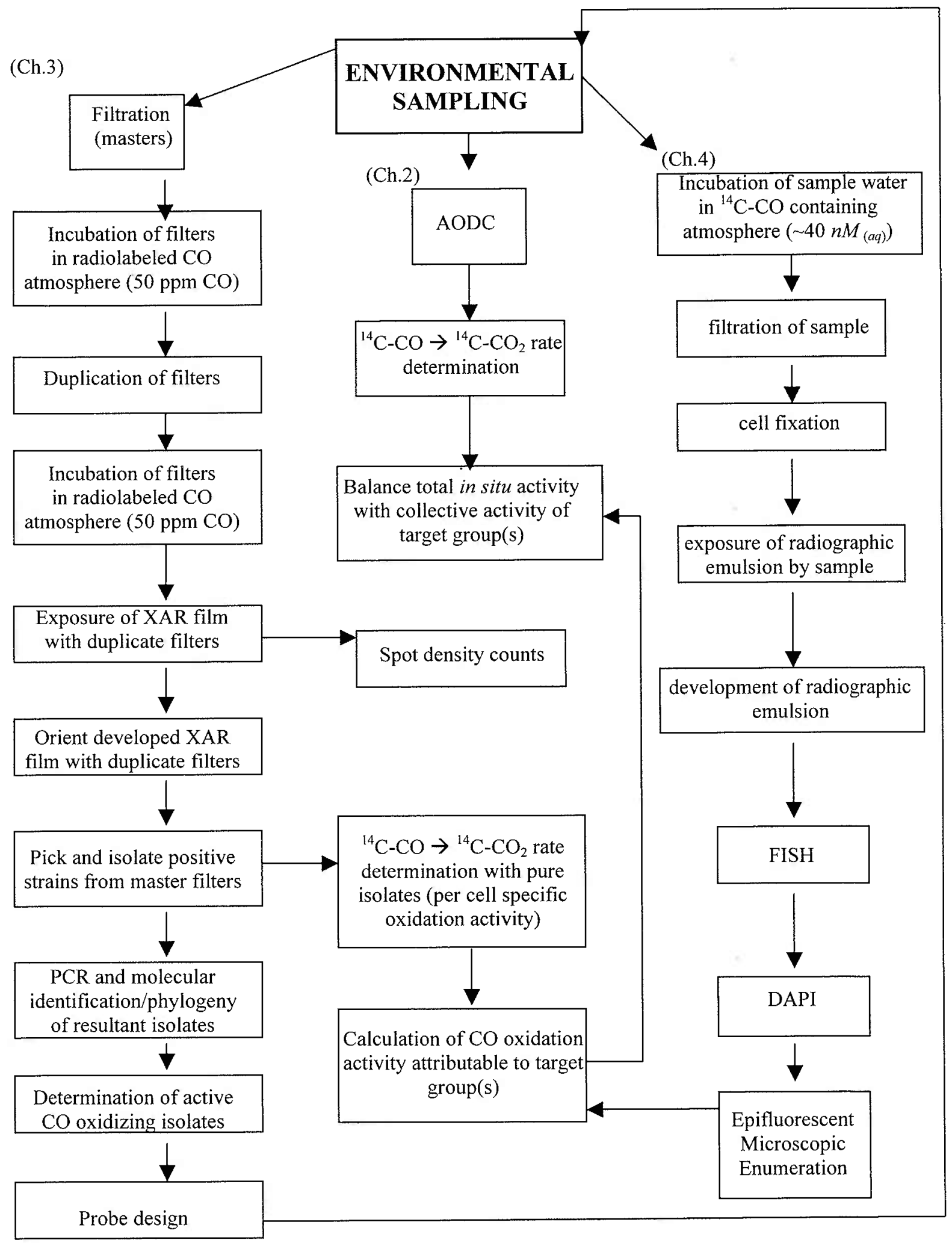




\section{BIBLIOGRAPHY}

Bartholomew, G.W. and Alexander, M. (1979). Microbial metabolism of carbon monoxide in culture and in soil. Appl. Environ. Microbiol. 37(5): 932-937

Bates, T.S., Kelly, K.C., Johnson, J.E., and Gammon, R.H. (1995). Regional and seasonal variations in the flux of oceanic carbon monoxide to the atmosphere. J. Geophys. Res. 100: 23,093-23,101

Conrad, R. and Seiler, W. (1980). Photooxidative production and microbial consumption of carbon monoxide in seawater. FEMS Microbiology Letters 9: 61-64

Conrad, R., Seiler, W., Bunse, G., and Giehl, H. (1982). Carbon Monoxide in Seawater (Atlantic Ocean) Journ. Geophys. Res. 87(C11): 8839-8852

Conrad, R., and Seiler, W. (1982a). Arid soils as a source of atmospheric carbon monoxide. Geophys. Res. Lett. 9: 1353-1356

Conrad, R., and Seiler, W. (1982b). Utilization of traces of carbon monoxide by aerobic oligotrophic microorganisms in ocean, lake, and soil. Arch. Microbiol. 132: $41-46$

Conrad, R. (1988). Biogeochemistry and ecophysiology of atmospheric $\mathrm{CO}$ and $\mathrm{H}_{2}$, in: Advances in Microbial Ecology Vol. 10 (K.C. Marshall, ed.) pp. 231-283 Plenum Press, New York.

Dalton, H. and Stirling, D.I. (1982). Co-Metabolism. Phil. Trans. R. Soc. Lond. B 297:481-496

Davis S.H., Stanier, R.Y., and Doudoroff, M. (1970). Arch Mikrobiol. 70:1-13

Ferenci, T. (1974). Carbon monoxide-stimulated respiration in Nitrosomonas europaea. FEBS Lett. 41: 94-98

Ferenci, T., Strom, T., and Quayle, J.R., (1975). Oxidation of carbon monoxide and methane by Pseudomonas methanica. J. Gen. Microbiol. 91: 79-91

Gerhardt, M., Svetlichny, V., Sokolova, T.G., Zavsarzin, G.A., and Ringpfeil, M., (1991). Bacterial $\mathrm{CO}$ utilization with $\mathrm{H}_{2}$ production by the strictly anaerobic lithoautotrophic thermophilic bacterium Carboxydothermus hydrogenus DSM 6008 isolated from a hot swamp. FEMS Microbiol. Lett. 83:267-272 
Hegeman, G. (1894). Oxidation of Carbon monoxide by aerobic bacteria. (In: Microbial Growth ON $\mathrm{C}_{1}$ Compounds. R.L. Crawford and R.S. Hanson, eds.) $A S M$, Washington, DC

Inman, R.E., Ingersoll, R.B., and Levy, E.A. (1971). Soil: a natural sink for carbon monoxide. Science 172: 1229-1231

Johnson, J. E. and Bates, T. S. (1996). Sources and sinks of carbon monoxide in the mixed layer of the tropical South Pacific Ocean. Global Biogeochemical Cycles. 10(2): $347-359$

Jones, R.D. (1991). Carbon monoxide and methane distribution and consumption in the photic zone of the Sargasso Sea. Deep-Sea Research 38(6): 625-635

Jones, R.D. and Amador, J.A (1993). Methane and carbon monoxide production, oxidation, and turnover times in the Caribbean Sea as influenced by the Orinoco River. J. Geophys. Res. 98:2353-2359

Jones, R.D. and Morita, R.Y. (1983a). Methane oxidation by Nitrosococcus oceanus and Nitrosomonas europaea. Appl. Environ. Microbiol. 45(2): 401-410

Jones, R.D. and Morita, R.Y. (1983b). Carbon monoxide oxidation by chemolithotrophic ammonium oxidizers. Can. J. Microbiol. 29: 1545-1551

Jones, R.D. and Morita, R.Y. (1984). Effects of various parameters on carbon monoxide oxidation by ammonium oxidizers. Can. J. Microbiol. 30: 894-899

Kieber, R.J., Zhou, X., and Mopper, K. (1990). Formation of Carbonyl Compounds from UV-Induced Photodegradation of Humic Substances in Natural Waters: Fate of Riverine Carbon in the Sea Limnol. Oceanogr. 35:1503-1515

Kiessling, M., and Meyer, O. (1982). Profitable oxidation of carbon monoxide or hydrogen during heterotrophic growth of Pseudomonas carboxydoflava, FEMS Microbiol. Lett. 13: 333-338

Kim, Y.M., and Hegeman, G.D. (1983). Oxidation of carbon monoxide by bacteria. Int. Rev. Cytol. 81: 1-31

Lilley, M.D., De Angelis, M.A., and Gordon, L.I. (1982). $\mathrm{CH}_{4}, \mathrm{H}_{2}, \mathrm{CO}$, and $\mathrm{N}_{2} \mathrm{O}$ in submarine hydrothermal vent waters. Nature 300: $38-49$

Logan, J.A., Prather, M.J., Wofsy, S.C., and McElroy, M.B. (1981). Tropospheric chemistry: a global perspective. J. Geophys. Res. 86: 7210-7254 
Meyer, O. and Schlegel, H.G. (1978). Reisolation of the carbon monoxide utilizing bacterium Pseudomonas carboxydovorans (Kistner) comb nov. Arch Microbiol. 118. $35-43$

Meyer, O. and Schlegel, H. (1979). Oxidation of carbon monoxide in cell extracts of Pseudomonas carboxydovorans. J. Bacteriol. 137:811-817

Meyer, O., and Schlegel, H.G., (1983). Biology of aerobic carbon monoxide oxidizing bacteria. Annu. Rev. Microbiol. 37: 277-310

Meyer, O. (1985). Metabolism of aerobic carbon monoxide utilizing bacteria, in: Microbial Gas Metabolism (R.K. Poole and C.S. Dow, eds.), pp. 131-151, Academic Press, London

Meyer, O., Jacobitz, S., and Kruger, B. (1986). Biochemistry and physiology of aerobic carbon monoxide-utilizing bacteria. FEMS Microbiol. Rev. 39:161-179

Mopper, K., Zhou. X., Kieber, R.J., Kieber, D.J., Sikorski R.J., and Jones, R.D. (1991). Photochemical degradation of dissolved organic carbon and its impact on the oceanic carbon cycle. Nature 353: 60-62

Müller, J.F., (1992). Geographical distribution and seasonal variation of surface emissions and deposition velocities of atmospheric trace gases. J. Geophys. Res., 97: $3787-3804$

Nozhevnikova, A. N., and Yurganov, L.N. (1978). Microbial aspects of regulating the carbon monoxide content of the earth's atmosphere, in: Adv. Microbial Ecol., $2: 203-244$

Olson, R.J. (1981). ${ }^{15} \mathrm{~N}$ tracer studies of the primary nitrite maximum. J. Mar. Res. 39(2): 203-226

Pos, W.H., Riemer, D.D., and Zika, R. (1998). Carbonyl sulfide (OCS) and carbon monoxide $(\mathrm{CO})$ in natural waters: evidence of a coupled production pathway. Mar. Chem. 62: 89-101

Rich, J.J., and King, G.M. (1998). Carbon monoxide consumption and production by wetland peats. FEMS Microbiol. Ecol. 28:215-224

Seiler, W., (1978). The influence of the biosphere on the atmospheric $\mathrm{CO}$ and $\mathrm{H}_{2}$ cycles, in Environmental Biogeochemistry and Geomicrobiology, 3: 773-810, edited by W. E. Krumbein, Ann Arbor Science Publishers, Ann Arbor, Michigan 
Seiler, W., and Shmidt, U. (1974). Dissolved nonconservative gases in seawater, in The Sea, 5: 219-243, edited by E. D. Goldberg, John Wiley, New York.

Sokolova, T.G., Gonzalez, J.M., Kostrikina, N.A., Chernyh, N.A., Tourova, T.P., Kato, C., Bonch-Osmolovskaya, E.A., and Robb, F.T. (2001). Carboxydobrachium pacificum gen. nov., sp. nov., a new anaerobic, thermophilic, CO-utilizing marine bacterium from Okinawa Trough. Int. J. Syst. Evol. Microbiol. 51:141-149

Svetlichny, V.A., Sokolova, T.G., Gerhardt, M., Ringpfeil, M., Kostrikina, N.A., and Zavarzin, G.A. (1991a). Carboxydothermus hydrogenoformans gen. nov., sp. nov., a CO-utilizing thermophilic anaerobic bacterium from Hydrothermal Environments of Kunashir Island. System. Appl. Microbiol. 14:254-260

Svetlichny, V.A., Sokolova, T.G., Gerhardt, M., Kostrikina, N.A., and Zavarzin, G.A. (1991b). Anaerobic extremely thermophilic carboxydotrophic bacteria in hydrotherms of Kuril Islands. Microb. Ecol. 21:1-10

Swinnerton, J.W., Linnenbom, V.J., Lamontagne, R.A. (1970). The Ocean: A natural source of carbon monoxide. Science 167: 984-986

Valentine, R.L. and Zepp, R.G. (1993). Formation of carbon monoxide from photodegradation of terrestrial dissolved organic carbon in natural waters. Environ. Sci. Technol. 27: 409-412

Vanzella, A., Guerrero, M.A., and Jones, R.D. (1989). Effect of CO and light on ammonium and nitrite oxidation by chemolithotrophic bacteria. MEPS, 57: 69-76

Williams, P. J. LeB., (1981). Microbial contribution to overall marine plankton metabolism: Direct measurement of respiration. Oceanol. Acta 4: 359-364

Wood, H.G. (1991). Life with $\mathrm{CO}$ or $\mathrm{CO}_{2}$ and $\mathrm{H}_{2}$ as a source of carbon and energy. FASEB J., 5: 156-163

Xie, H, Zafiriou, O.C., Wang, W., and Taylor, C.D. (2001). A simple automated continuous flow equilibrium method for measuring carbon monoxide in seawater. Environ. Sci. Technol. 35(7):1475-1480

Xie, H., Goldstone, J., Taylor, C.D., Wang, W, Ziolkowski, L., and Zafiriou, O.C. (2002). Diurnal cycling of carbon monoxide in Sargasso Sea surface waters. In prep. for submission to Limnol. Oceanog.

Zafiriou, O.C., Andrews, S.S., and Wang, W. (2003). Concordant estimates of oceanic carbon monoxide source and sink processes in the Pacific yield a balanced global "blue-water" CO budget. Global Biogeochemical Cycles 17(1):1015 
Zavarzin, G.A. and Nozhevnikova, A.N. (1977). Aerobic carboxydobacteria. Microb. Ecol. 3: 305-326

Zuo, Y., and Jones, R.D. (1995). Formation of carbon monoxide by photolysis of dissolved marine organic material and its significance in the carbon cycling of the oceans. Naturwissenschaften 82: 472-474

Zuo, Y., and Jones, R.D. (1997). Photochemistry of natural dissolved organic matter in lake and wetland waters - production of carbon monoxide. Wat. Res. 31(4): 850858

Zuo, Y., Guerrero. M.A, and Jones, R.D. (1998). Reassessment of the ocean-toatmosphere flux of carbon monoxide. Chemistry and Ecology 14: 241-257 


\title{
CHAPTER II:
}

\author{
Biological CO Oxidation Rates in the Sargasso Sea and in Vineyard Sound, MA.
}

\begin{abstract}
Needed in microbial ecology are improved methods for measurement of microbial metabolic activity in natural waters under conditions approaching those in situ. Here we report kinetic parameters for $\mathrm{CO}$ oxidation for microbial assemblages in open ocean (Sargasso Sea) and coastal marine environments (Vineyard Sound, MA), and directly compare techniques to measure CO loss rates and CO oxidation rates in natural samples. Gross CO oxidation rates in the surface waters of the Sargasso Sea in the summer 1999 cruise (dark incubation rate coefficient) ranged between 0.019 to $0.028 \mathrm{hr}^{-1}$. These rates were significantly higher than the in situ rates for that season $\left(0.0017-0.0025 \mathrm{hr}^{-1}\right)$, and also both the dark incubation and in situ rates for the spring 2002 season which ranged between 0.0083 and $0.017 \mathrm{hr}^{-1}$ and $0.0041-0.0062 \mathrm{hr}^{-1}$, respectively. We find that oxidation of CO in the Sargasso Sea obeys first order kinetics up to $3.5-4.5 \mathrm{nM}$ $[\mathrm{CO}]$ in closed incubations; incubations containing higher [CO] obey zero-order or saturation kinetics. Furthermore, $\mathrm{CO}$ oxidation rates obtained in dark incubations are not applicable to the entire photic period; the rates of $\mathrm{CO}$ oxidation determined in situ in daytime are depressed by up to an order of magnitude compared with dark incubations. This may result in overestimating the diel rate by up to $85 \%$ if it is based on solely on dark incubations, as has been the common practice. The specific $\mathrm{CO}$ oxidation activity of the Sargasso Sea assemblage averaged $1.3 \times 10^{-11} \pm 2.9 \times 10^{-12} \mathrm{nmol} \mathrm{CO}$ oxidized cell ${ }^{-1} \mathrm{hr}^{-1}$ in the summer and $2.8 \times 10^{-11} \pm 3.2 \times 10^{-12} \mathrm{nmol} \mathrm{CO}$ oxidized cell ${ }^{-1} \mathrm{hr}^{-1}$ in the spring.
\end{abstract}

\section{INTRODUCTION:}

The diurnal scale of variability in aquatic $\mathrm{CO}$ in the surface waters of the world's oceans is imposed primarily by the source, i.e. production by solar photolysis of chromophoric dissolved organic matter (CDOM). Large diurnal amplitudes require fast acting sinks that are provided by microbial oxidation (Conrad \& Seiler, 1980; Conrad \& Seiler, 1982b; Conrad et al., 1982; Jones \& Morita, 1984; Jones \& Amador, 1993), and gas exchange (Conrad et al., 1982; Conrad \& Seiler, 1982b; Zuo \& Jones, 1995; and many others). CO concentration increases from dawn to a maximum (2-3 $\mathrm{n} M)$ in middle

to late afternoon, followed by a rapid decline in the early evening to a minimum $(0.25$ $0.5 \mathrm{nM}$ ) just before dawn (Johnson \& Bates, 1996; Conrad et al., 1982; Xie et al., 2001) 
(Figure 2.14). This implies that $\mathrm{CO}$ is short-lived and is strongly coupled to the day/night cycle via photoproduction and biology (Conrad et al., 1982; Jones, 1991).

Microbial $\mathrm{CO}$ loss rates have typically been measured in dark incubations spanning 12 - 20 hours (Jones, 1991, Jones \& Amador, 1993, Jones et al., 1984, Johnson \& Bates, 1996). Dissolved [CO] within each subsample is measured by a headspace method using a Trace Analytical RGA-3 detector (Xie et al., 2002a). Since CO loss kinetics are first-order (Jones \& Morita, 1984; Jones \& Amador, 1993; Johnson \& Bates, 1996), exponential decays are fitted to the time series data to obtain a CO loss rate constant, $k_{c o}$ (Zafiriou et al., 2002). This method yields net CO loss rate constants at $[\mathrm{CO}]$ slightly below the sample's initial concentration. The more commonly used ${ }^{14} \mathrm{C}$ CO method (Jones, 1991; Jones \& Amador, 1993, Griffiths et al., 1982) yields potential $\mathrm{CO}$ oxidation rates when dissolved $[\mathrm{CO}]$ within the incubation is two- to ten-fold above oceanic values, as additional $\mathrm{CO}$ is introduced as a tracer substrate. If these incubations have elevated [CO] within the region of first-order kinetics, they are hence applicable to calculating $k_{c o}$ values.

In this study, we compare the results of two different methods of determining microbial $\mathrm{CO}$ oxidation rate. We report environmental $\mathrm{CO}$ oxidation rates by microorganisms in an oceanic oligotrophic environment (Bermuda Atlantic Time Series site), and in a coastal environment in southeastern Massachusetts. We utilize a new ${ }^{14} \mathrm{C}$ $\mathrm{CO}$ tracer technique that allows the determination of $\mathrm{CO}$ oxidation rates in the presence of $\mathrm{CO}$ photoproduction, and compare traditional dark-incubation $\mathrm{CO}$ oxidation rates with rates determined in situ in daytime incubations. 


\section{METHODS/MATERIALS}

Fieldwork was conducted during cruises EN327 and EN335 in waters near the BATS site in August, 1999 and March 2000, respectively. The ship was intended to remain approximately in the same water masses by following a free-drifting drogue and optical buoy array for in situ incubations (described below). EN327 was occupied from Year Day (YD) 218 at $31.37^{\circ} \mathrm{N}, 64.00^{\circ} \mathrm{W}$ to $\mathrm{YD} 229$ at $31.50^{\circ} \mathrm{N}, 64.03^{\circ} \mathrm{W}$, and $\mathrm{EN} 335$ started on YD 77 at $32.01^{\circ} \mathrm{N}, 64.02^{\circ} \mathrm{W}$ and ended on YD 88 at $32.03^{\circ} \mathrm{N}, 64.01^{\circ} \mathrm{W}$. Front passage or deviation from the Langrangian mode was monitored by continually profiling sea surface temperature (SST), salinity, and chlorophyll fluorescence and by recording the current vector vs. depth and time via an ADCP. The timing of the two cruises (winter vs. summer) was intended to maximize expected differences in CDOM quantity and the range of key variables, such as wind speed, biology, mixed layer and euphotic zone depths (Xie et al., 2001).

\section{Coastal sampling; Vineyard Sound, $M A$}

The primary coastal sampling site for this study was at the WHOI Shore Lab pier located $1 \mathrm{~km}$ east of Nobska Light, Woods Hole, on a southeast-facing beach on Vineyard Sound, Cape Cod, in Massachusetts (Figure 2.1). This location was chosen for its proximity to the laboratory, ease of sampling, and distance from coastal pond- and freshwater discharge. Syringe or bottle samples were collected $0.5 \mathrm{~m}$ below the surface to avoid atmospheric $\mathrm{CO}$ contamination, in water depths of approximately $1 \mathrm{~m}$. 


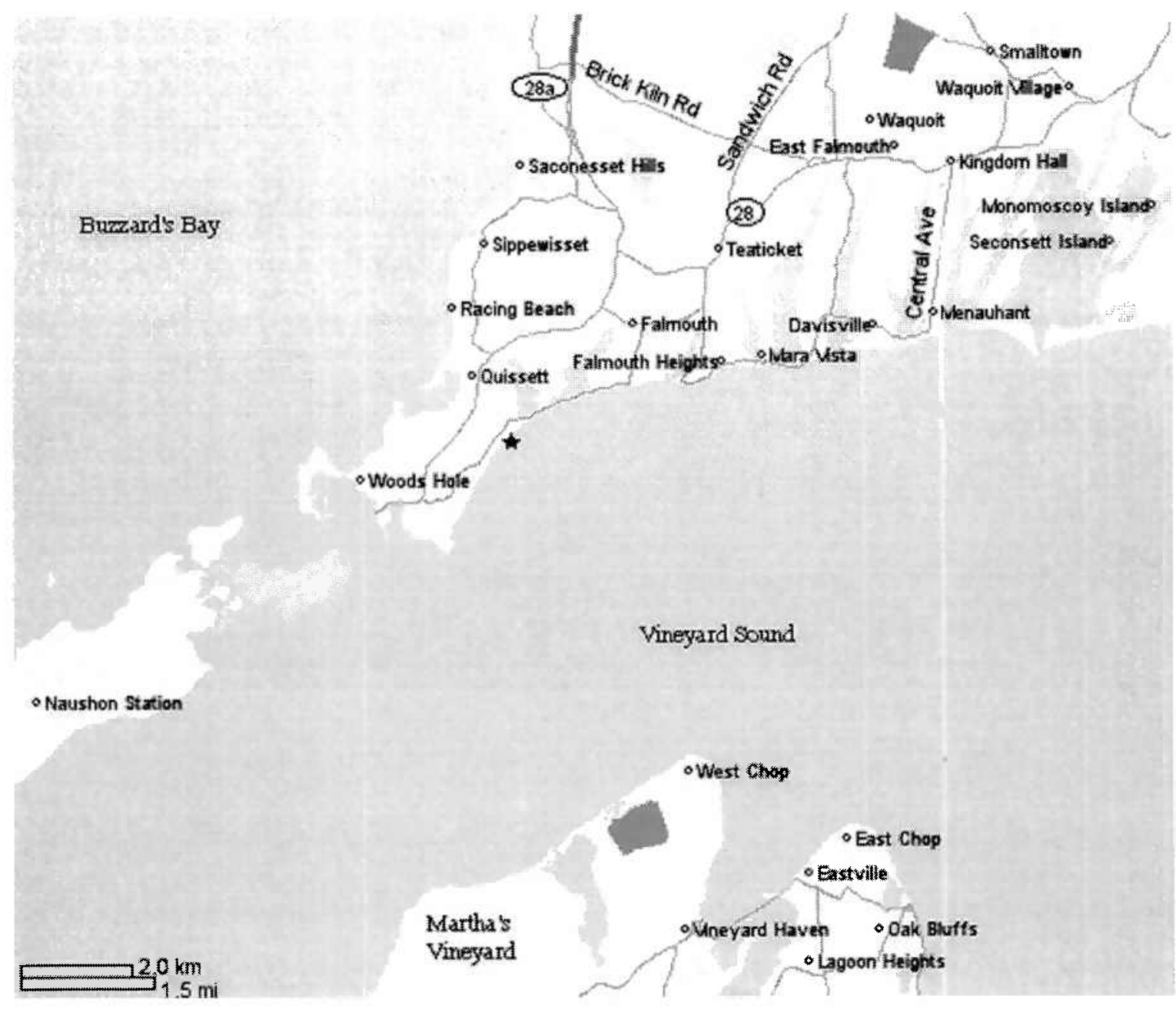

Figure 2.1 Coastal sampling site (Chemotaxis Dock) in Vineyard Sound, MA denoted by star ( $\star$ ) 
Generation of ${ }^{14}$ C-labeled CO.

${ }^{14} \mathrm{C}$-labeled $\mathrm{CO}$ was generated aboard ship by dehydration of $100 \mu \mathrm{Ci}$ of ${ }^{14} \mathrm{C}$ labeled formate $(56 \mathrm{mCi} / \mathrm{mmole}$, 7:3 ethanol:water, ICN Biomedical) with $1.0 \mathrm{ml} \mathrm{36 \textrm {N }}$ anhydrous sulfuric acid in a sealed $120 \mathrm{ml}$ serum vial. The formate/acid mixture was kept at room temperature with frequent agitation, and the reaction proceeded to completion after 24 hours. The mixture in the serum vial was made alkaline with the addition of $5.0 \mathrm{ml} 10 \mathrm{~N} \mathrm{NaOH}$ to sequester ${ }^{14} \mathrm{C}$-labelled $\mathrm{CO}_{2}$ that may have been produced during the acid-dehydration procedure. ${ }^{14} \mathrm{C}$ - $\mathrm{CO}$ activity in the stock bottle was monitored periodically (after every $15-20 \mathrm{ml}$ removed) by injecting a $1 \mathrm{ml}$ aliquot with a gas-tight syringe into $\mathrm{a}>400^{\circ} \mathrm{C}$ heated copper column $(.6 \mathrm{~cm}$ ID $\times 20 \mathrm{~cm})$ containing copper oxide chaff as a catalyst to oxidize $\mathrm{CO}$ to $\mathrm{CO}_{2}$. Zero-grade compressed air was used as the carrier gas, with flow-rate of approximately $60 \mathrm{ml} \mathrm{min}{ }^{-1}$. The ${ }^{14} \mathrm{C}^{-} \mathrm{CO}_{2}$ product was captured quantitatively by bubbling through a paired series of scintillation vials containing a mixture of $10.0 \mathrm{ml}$ scintillation cocktail (Scintiverse II) and $0.2 \mathrm{ml}$ hyamine hydroxide (ICN Biomedical, Inc.) downstream from the catalyst. Vial activities were measured via liquid scintillation spectroscopy in the ship'ṣ or shore-based laboratory. Most labeled $\mathrm{CO}_{2}$ product $(>99 \%)$ was captured in the first vial of the series, and the activity of the two vials was summed for total activity. Activities in the second vial were often indistinguishable from background levels (30-40 DPM) of activity. The linear decrease in activity in the fixed-volume stock vessel with successive gas aliquot removal was applied to calculate the activity (DPM) injected into each sample incubation vessel, and therefore the ${ }^{14} \mathrm{C}-\mathrm{CO}$ specific activity within the incubation $(\mu \mathrm{Ci} / \mu \mathrm{mol})$. 


\section{${ }^{14}$ C-CO oxidation assay}

Samples were collected in standard 10-L Niskin bottles fitted with silicon O-rings and Teflon $^{\circledR}$ coated springs, or in custom-built titanium bottles (Doherty et al., 2003) mounted on a CTD rosette. Water was drawn from the bottles without contact with the atmosphere in $100 \mathrm{ml}$ ground-glass syringes after three complete flushes with sample water. Sub-samples $(25.0 \mathrm{ml})$ were dispensed into $130 \mathrm{ml}$ quartz vials for the in situ incubations and into $75 \mathrm{ml}$ borosilicate glass serum vials for dark incubations. The bottles were sealed with rubber septa. Aliquots $(1.0 \mathrm{ml})$ of ${ }^{14} \mathrm{C}-\mathrm{CO}$ stock were withdrawn with a gas-tight syringe and injected into replicate pairs of sample-incubation vials. The quartz bottles for in situ incubations provided a relatively large $(>100 \mathrm{ml})$ headspace that provided a large reservoir of $\mathrm{CO}$ that was in equilibrium with $\mathrm{CO}$ that was dissolved in the aqueous phase. A potential doubling of aqueous [CO] due to photoproduction, when equilibrated into the gas reservoir, resulted in $<5 \%$ change in ${ }^{14} \mathrm{C}-\mathrm{CO}$ specific activity and hence, measured rates. Ambient $\mathrm{CO}$ concentration in the room air at the time of sealing was determined with a reduced gas analyzer (Trace Analytical). Samples were incubated in the dark within $2^{\circ} \mathrm{C}$ of the in situ temperature. The incubation was stopped by injecting $1.0 \mathrm{ml}$ of $10 \mathrm{~N} \mathrm{NaOH}$ to raise the $\mathrm{pH}$ of the sample to $>9$, and shaken to sequester any $\mathrm{CO}_{2}$ present in solution or the headspace. Zero-time bottles were fixed by injecting $\mathrm{NaOH}$ within 5 minutes of injecting with ${ }^{14} \mathrm{C}-\mathrm{CO}$, and for dark-incubated samples, time-point samples (duplicates) were fixed with $\mathrm{NaOH}$ at three-hour intervals. The $\mathrm{NaOH}$-stabilized samples were then stored until ${ }^{14} \mathrm{C}$-activity could be assessed at a shore-based laboratory. On shore, sample incubation vials were opened to allow 
unreacted ${ }^{14} \mathrm{C}$-CO to exchange overnight. The vials were resealed with a $\mathrm{CO}_{2}$-trapping wick (fluted filter paper treated with $0.2 \mathrm{ml}$ hyamine hydroxide) suspended in the headspace above the liquid. The samples were acidified by injection of $1.0 \mathrm{ml} 3.6 \mathrm{~N}$ $\mathrm{H}_{2} \mathrm{SO}_{4}$ to lower the pH below 2, and left overnight on a shaker-table at $100 \mathrm{rpm}$. The $\mathrm{CO}_{2}$-traps containing the product of microbial oxidation of ${ }^{14} \mathrm{C}-\mathrm{CO}$ were placed in a scintillation vial containing $10.0 \mathrm{ml}$ Scintiverse II and measured for activity by liquid scintillation spectroscopy (figure 2.2). DPM for each vial was corrected for the mean tzero background $(n=2)$, and nanomoles of $\mathrm{CO}_{2}$ produced in each vial was calculated by dividing by the specific activity of the ${ }^{14} \mathrm{C}-\mathrm{CO}$. This was converted to a nanomolar value (in $25 \mathrm{ml}$ sample), and the rate of oxidation over the incubation period was determined (Griffiths et al., 1982; Jones et al., 1984). First order rate coefficients were calculated by normalizing the time-series rate of $\mathrm{CO}$ oxidation to $\mathrm{CO}_{2}(\mathrm{nM} / \mathrm{hr})$ by the total dissolved [CO] $(\mathrm{nM})$ within each incubation vessel to yield the rate coefficient $\left(k_{c o}\right)$ expressed in reciprocal hours $\left(\mathrm{hr}^{-1}\right)$. Determining the total dissolved [CO] required the Bunsen solubility coefficient ( $\beta$ ) for $\mathrm{CO}$ (Weisenburg \& Guinasso, 1979), which is a function of temperature and salinity during the incubation*.

${ }^{*} \ln \beta=A_{1}+A_{2}(100 / T)+A_{3} \ln (T / 100)+S \%\left[B_{1}+B_{2}(T / 100)+B_{3}(T / 100)^{2}\right]$

where $A_{\mathrm{i}}$ and $B_{\mathrm{i}}$ are constants, $\mathrm{T}$ is the temperature in degrees Kelvin, and $S \%$ is the salinity in parts per thousand.

$A_{1}=-47.6148, A_{2}=69.5068, A_{3}=18.7397$

$B_{1}=0.045657, B_{2}=-0.040721$

(Weisenburg \& Guinasso, 1979) 
Figure 2.2: Scheme of $\mathrm{CO}$ oxidation rate assay. ${ }^{14} \mathrm{C}$ - $\mathrm{CO}$ is produced by acid dehydration of ${ }^{14} \mathrm{C}$-formate, and injected into the headspace of sealed sample vessels to incubate. The product of CO oxidation is quantitatively captured and counted for activity by liquid scintillation spectroscopy (figure courtesy C. Taylor). 

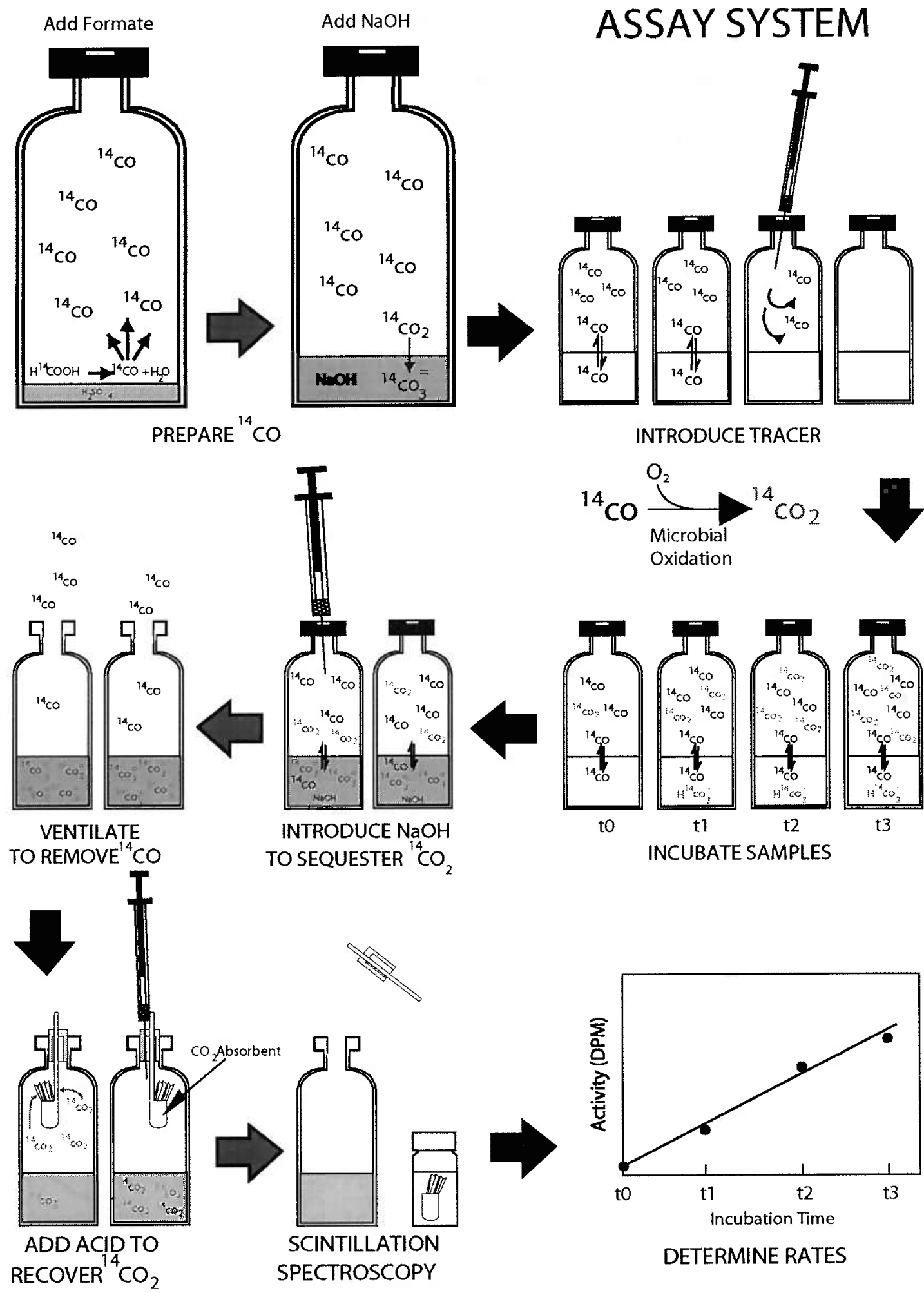

INTRODUCE TRACER
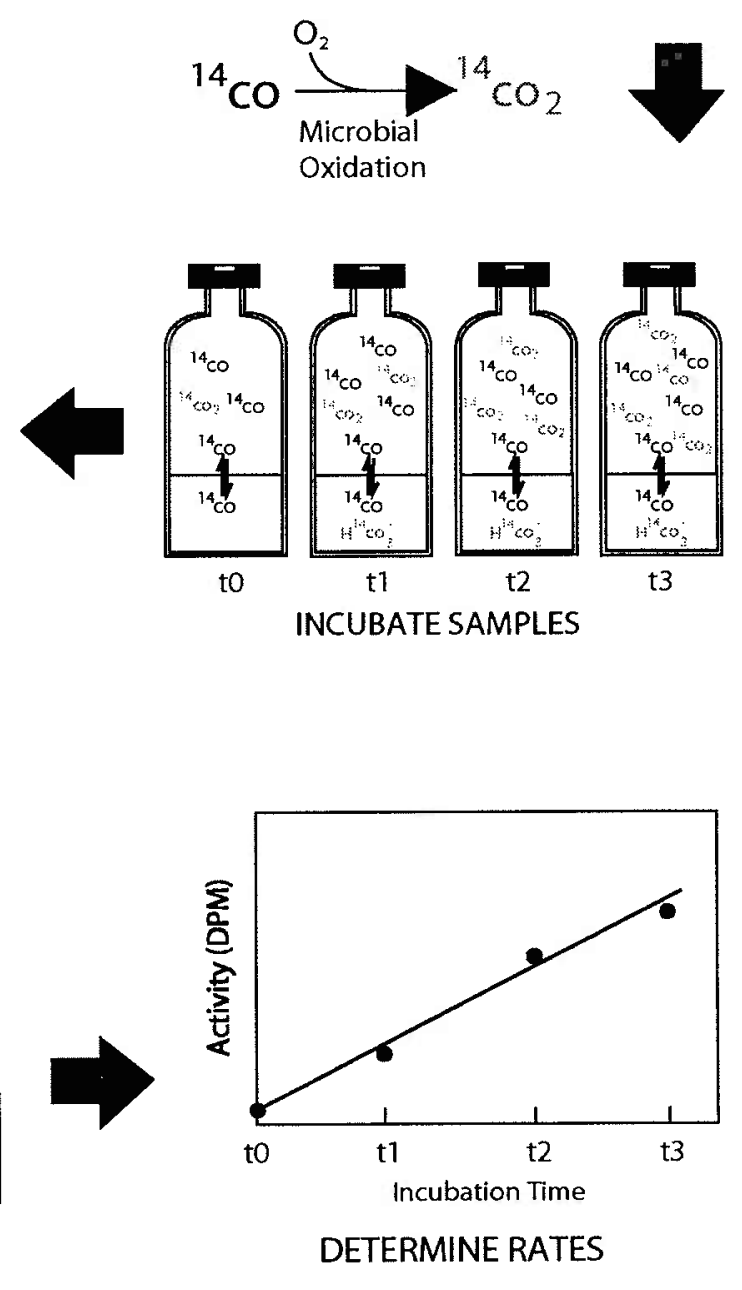
Total CO within each incubation vessel included the in situ dissolved [CO], the ambient $\mathrm{CO}$ of the lab atmosphere when the vial was sealed, and the labeled CO injected prior to incubation. Where it was determined that $\mathrm{CO}$ oxidation activity was at maximum velocity because of the effects of $\mathrm{CO}$ saturation, all rates from incubations containing higher total $[\mathrm{CO}]$ concentrations than at $\mathrm{V}_{\max }$ were normalized by [CO] at $\mathrm{V}_{\max }(4.5 n M$ $\mathrm{CO}$ and $3.5 n M \mathrm{CO}$ for EN327 and EN335, respectively). This correction zero order kinetics is further explained in the Discussion.

\section{In Situ CO Measurements.}

[CO] in surface water supplied by a retractable boom (Donoghue et al., 2001), Niskin bottle, or ship's pumping system was continuously monitored by an automated air-segmented continuous-flow-equilibration system developed by Xie et al. [2002a]. In brief, precisely regulated flows of $\mathrm{CO}$-free air and of seawater or an aqueous $\mathrm{CO}$ standard were injected into two temperature-buffered glass coils $(6.1 \mathrm{~m}$ in length and $4 \mathrm{~mm}$ in I.D.) (figure 2.3-A) in a manner forming discrete gas/liquid segments (figure 2.3-B). The volume ratio of gas to liquid in the coil was $\sim 1: 11$, and the coil residence time was $\sim 7$ min. The partially CO-equilibrated gas was automatically injected into a Trace Analytical Reduction Analyzer (RGA3) for CO quantification. The analytical blank and precision were $0.02 n M$ and $\pm 2.5 \%(\mathrm{n}=10$, at $\sim 1 n M$ level $)$, respectively and the accuracy of this method was better than 5\%. The system was able to process 4-6 samples per hour. Operation of the system and data acquisition were automated using a LabView ${ }^{\circledR}$-coded program (Wei Wang, WHOI Dept. Chemistry; Xie et al., 
2002a).Discrete samples from CTD casts, in-situ, and laboratory incubations were analyzed using a head-space method [Xie et al., 2002a]. Briefly, 5-mL of CO-free air was dosed into the water-filled syringes, forming a 1:18 gas/water ratio. Equilibration between gas and water was achieved by vigorous mechanical shaking for $4 \mathrm{~min}$. and the equilibrated head-space gas was injected into a modified RGA3 for CO quantification. The system was standardized using a moisturized (100\% relative humidity) $1.23-\mathrm{ppm}$ gaseous CO standard. The analytical precision and accuracy were $\pm 0.02 n M( \pm 2 \%)$ and better than $\pm 10 \%$, respectively. The system responded linearly up to $\sim 12 \mathrm{n} M$, and could process $\sim 4-6$ samples per hour. The RGA3 had a $2.0 \mathrm{ml}$ loop which was flushed by direct injection of $5.0 \mathrm{ml}$ gas samples.

In situ CO oxidation rate determination: Optical Buoy.

For the in situ daytime incubations, pairs of quartz vials were prepared as previously described and incubated at discrete depths using an optical buoy developed for this purpose (figure 2.4). The buoy was a cross-braced tetrahedron of 1 " Al pipe $3 \mathrm{~m}$ on a side whose base corners were floated by small, paired Norwegian floats. The apex bears a radio transmitter beacon, strobe light, and pennant. A central sample-line attachment point was $\sim 0.7 \mathrm{~m}$ above the water surface and $2 \mathrm{~m}$ from the floats, minimizing shadowing. Samples in paired $130 \mathrm{ml}$ quartz flasks were attached neck-down in light, strong stainless steel cages at adjustable, known depths to a weighted wire rope. Light-shadowing was estimated to average $<5 \%$. Buoy deployment occurred at dawn and recovery at dusk. 


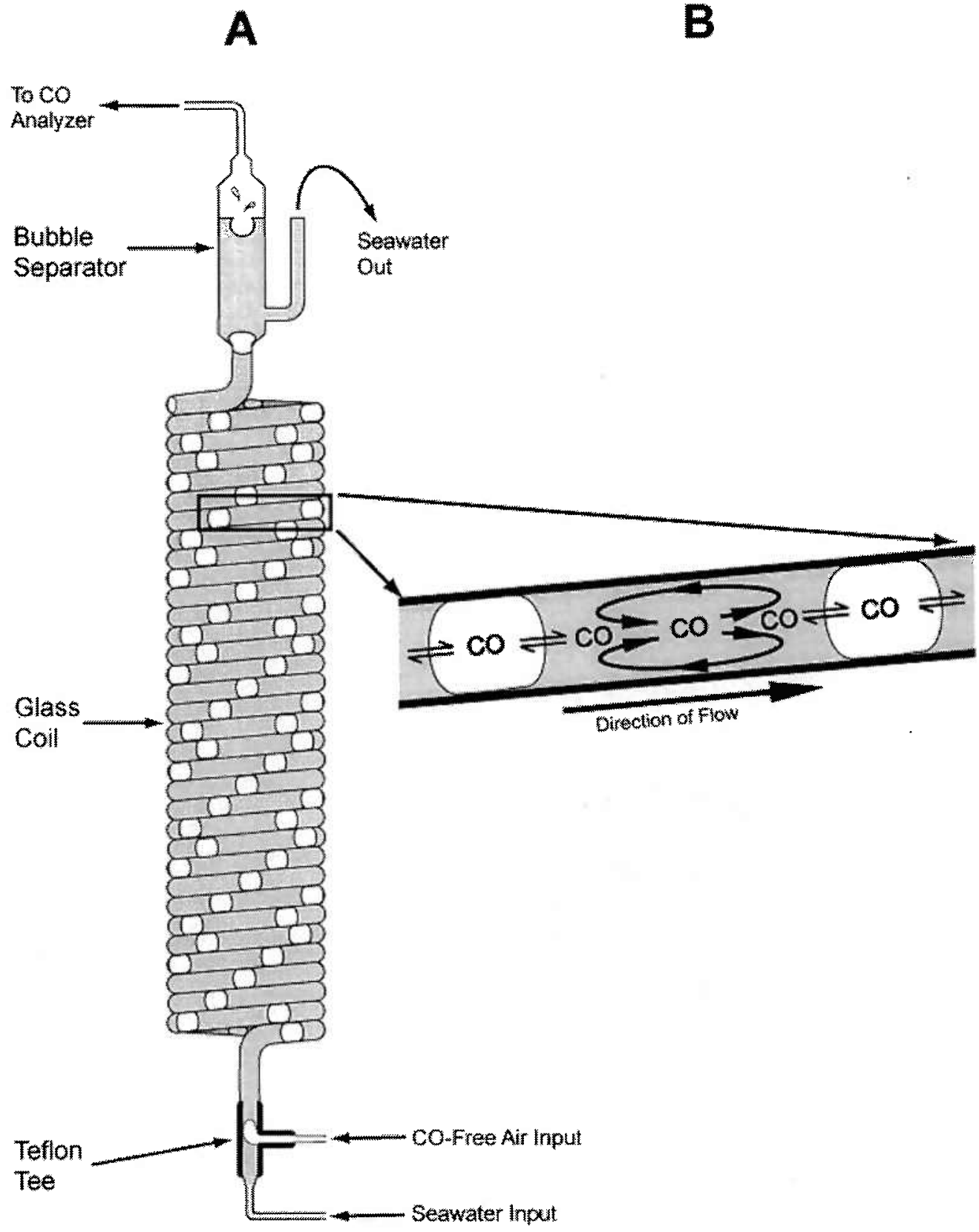

Figure 2.3: Automated air-segmented continuous-flow-equilibration system to monitor [CO] in oceanic surface water ( from Xie et al., 2002a). The system was able to process 4-6 samples per hour. 


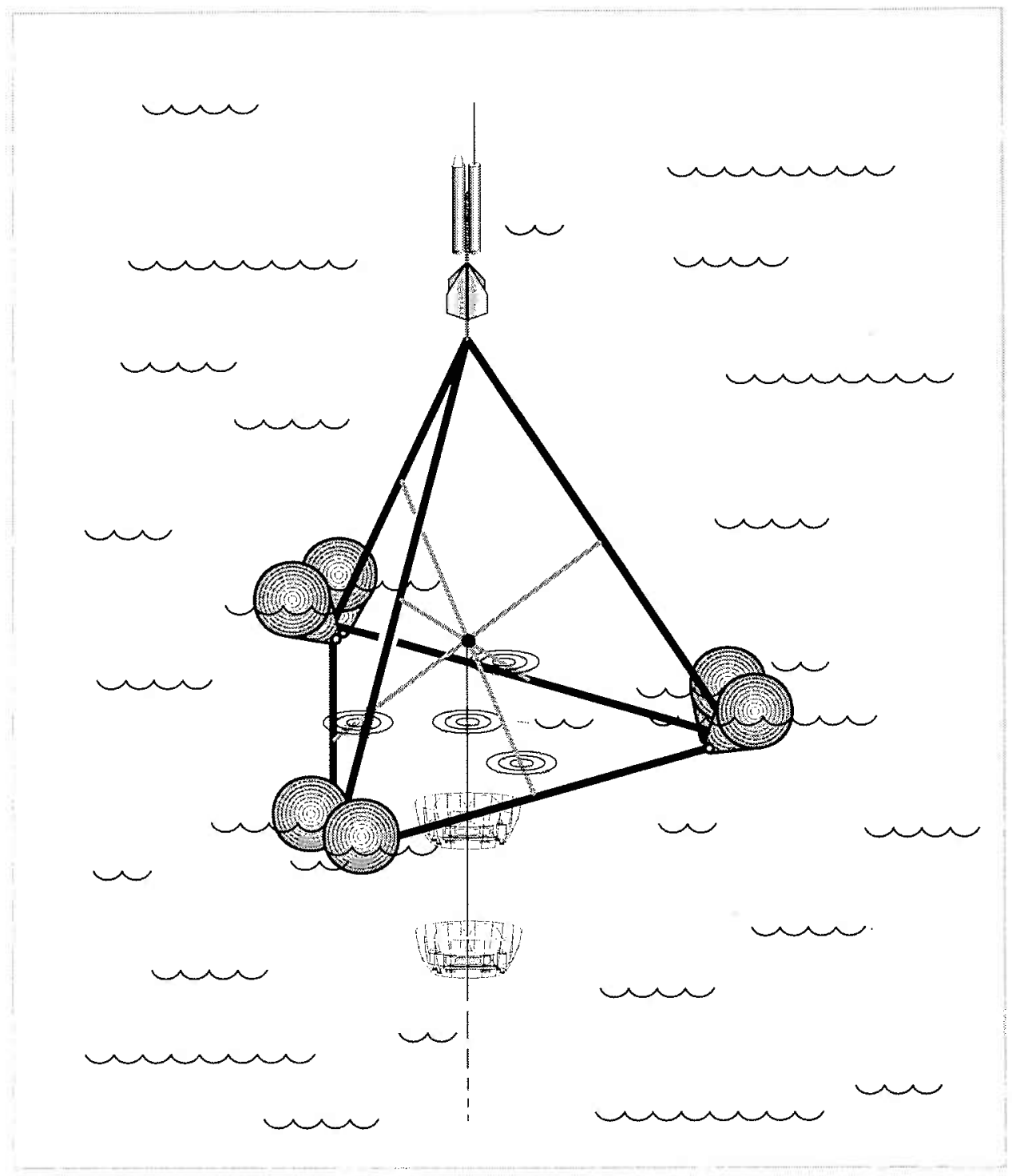

Figure 2.4: Optical Buoy. The optical buoy allows the end-point incubation of samples under in situ light and temperature conditions for $\mathrm{CO}$ production and $\mathrm{CO}$ oxidation rate measurements. The buoy is easily deployable and free-drifts within the water-mass, and maintains samples at discrete and predetermined depths. Deployment occurs at dawn and recovery at dusk, thus the incubation period spans the entire photoperiod. Buoy design by O. Zafiriou. 


\section{BATS166 substrate-series.}

Sample water was collected by Niskin flask on a Kevlar wire and drawn into an acidcleaned 2 liter Erlenmeyer flask. The sample water was sparged for 30 minutes with zero-grade air passed through a heated $\mathrm{CuO}$ catalyst designed to oxidize all environmental $\mathrm{CO}$, allowing a tightly constrained specific activity of the label to be used in the assay. Stock label was produced by acid dehydration of formate (as previously described) in $100 \mu \mathrm{Ci}$ batches in $120 \mathrm{ml}$ serum vials. The labeled product was transferred to an evacuated Tedlar $^{\circledR}$ gas sample bag by displacement with $\mathrm{CO}$-free distilled water injected into the $120 \mathrm{ml}$ vial, connected to the Tedlar ${ }^{\mathbb{B}}$ bag with $2 \mathrm{~mm}$ Teflon $^{\circledR}$ tubing with $22 \mathrm{~g}$ hypodermic needles attached at either end. The flexible $\mathrm{Tedlar}^{\circledR}$ container removed the need to monitor volume/pressure effects with gas removal, as was required with rigid glass stock bottles. $25.0 \mathrm{ml}$ of sparged (CO-free) sample water was pipetted into $70 \mathrm{ml}$ serum vials that had been flushed with $\mathrm{CO}$-free air for 30 seconds at a flow rate of $5.0 \mathrm{ml} \mathrm{sec}$. Headspaces were continuously flushed with CO-free air until each vial was sealed. Labeled $\mathrm{CO}$ was injected with a gas-tight syringe into each vial set. The dissolved $[\mathrm{CO}]$ in different incubation sets increased incrementally from low $(0.095$ $n M$ dissolved CO from $20 \mu$ injected) to high [CO] (9.493 $n M$ from $1000 \mu$ injected). 


\section{RESULTS and DISCUSSION}

\section{COASTAL CO STUDIES: Vineyard Sound, MA}

CO consumption measurement comparison.

Water collected from Vineyard Sound in March, April, and June 2001 underwent a direct comparison of two different $\mathrm{CO}$ process measurements, (dark CO consumption in sealed syringe incubations and ${ }^{14} \mathrm{C}$-CO-oxidation) which are shown to closely agree. Via the equation $[\mathrm{CO}]_{\mathrm{t}}=[\mathrm{CO}]_{0} \times e^{k \mathrm{t}}$, the first order rate coefficient $k_{c o}\left(\mathrm{hr}^{-1}\right)$ calculated in the syringe assay was used to calculate $\mathrm{CO}_{2}$ produced during the incubation. The calculated $\mathrm{CO}_{2}$ production calculated from $k_{c o}$ determined by gas analysis was plotted together with actual ${ }^{14} \mathrm{C}-\mathrm{CO}_{2}$ during the incubation (figure 2.5). The theoretical rate of $\mathrm{CO}_{2}$ production based $k_{c o}$ from syringe incubations agreed with actual $\mathrm{CO}_{2}$ production measured in the ${ }^{14} \mathrm{C}-\mathrm{CO}$ oxidation assay within $12 \%$ in March, $3 \%$ in April, and $8 \%$ in June. This indicates that most if not all $\mathrm{CO}$ disappearing from natural water is being oxidized to $\mathrm{CO}_{2}$, and the dominant sink of $\mathrm{CO}$ is accounted for.

We confirmed that $\mathrm{CO}$ oxidation was biologically mediated by a series of ${ }^{14} \mathrm{C}-\mathrm{CO}$ incubations with three separate killed controls (autoclaved, $0.22 \mu \mathrm{m}$-filtered, and cyanide) and a live natural sample (figure 2.6). The live sample oxidized $\mathrm{CO}$ at a rate of $0.516 n M \mathrm{CO} \mathrm{hr}^{-1}\left(k_{c o}=0.018 \mathrm{hr}^{-1}\right)$. The three killed samples showed no measurable COoxidation activity after 5 hours of incubation with ${ }^{14} \mathrm{C}-\mathrm{CO}$, and supports the findings of Conrad and Seiler (1980) that azide poisoning, boiling, and filter sterilization abolished CO consumption in seawater. The autoclaved and cyanide treated samples had 

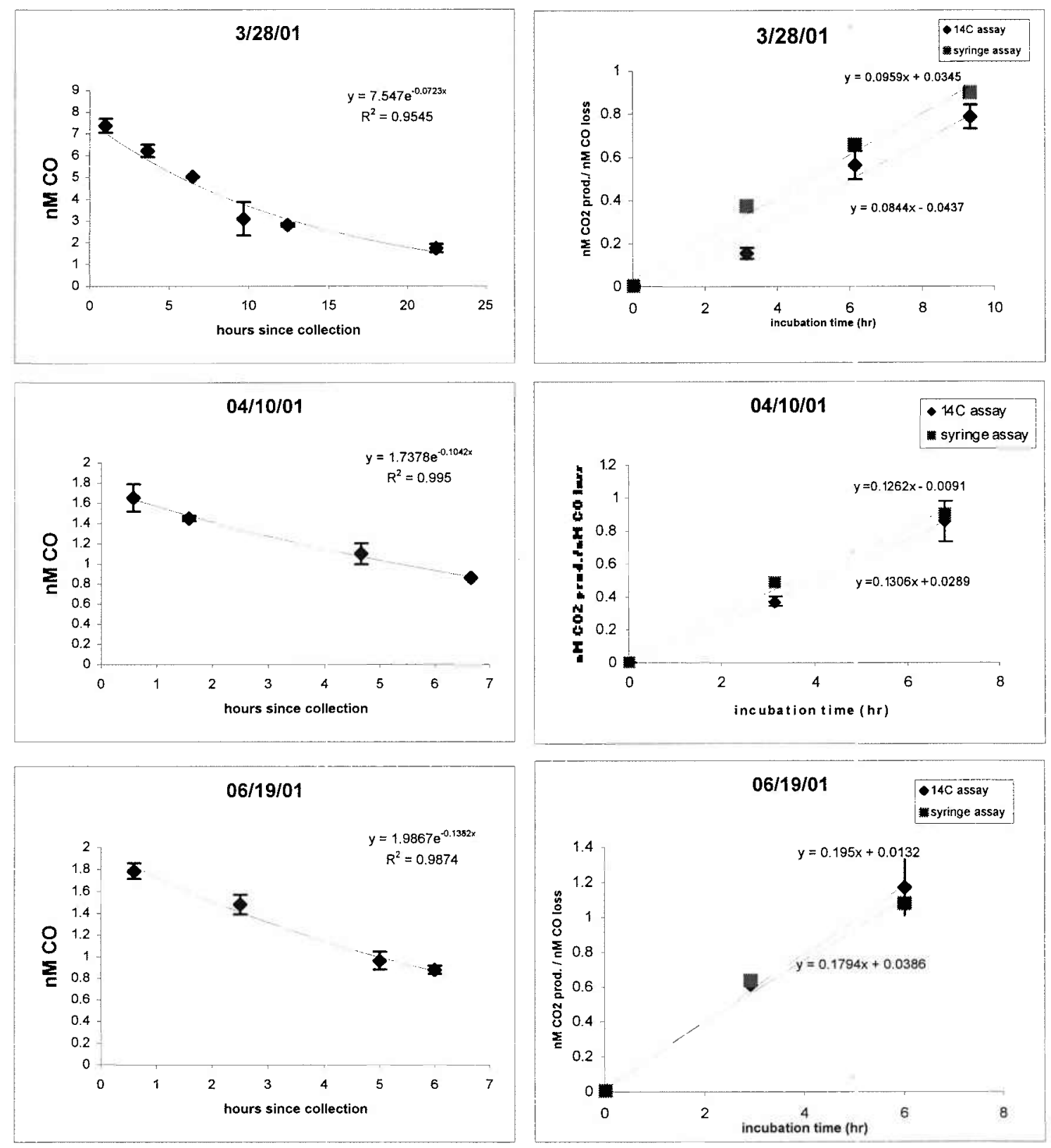

Figure 2.5: Comparison of $\mathrm{CO}$ assays. (left column) Syringe assays to monitor $\mathrm{CO}$ decay from closed samples result in a determination of rate constant $\left(k_{c o}\right)$. (right column) Theoretical $\mathrm{CO}_{2}$ production (-) calculated using $k_{c o}$ from syringe assay was directly compared with actual $\mathrm{CO}_{2}$ production determined by the ${ }^{14} \mathrm{C}$-CO oxidation assay $(\bullet)$. 


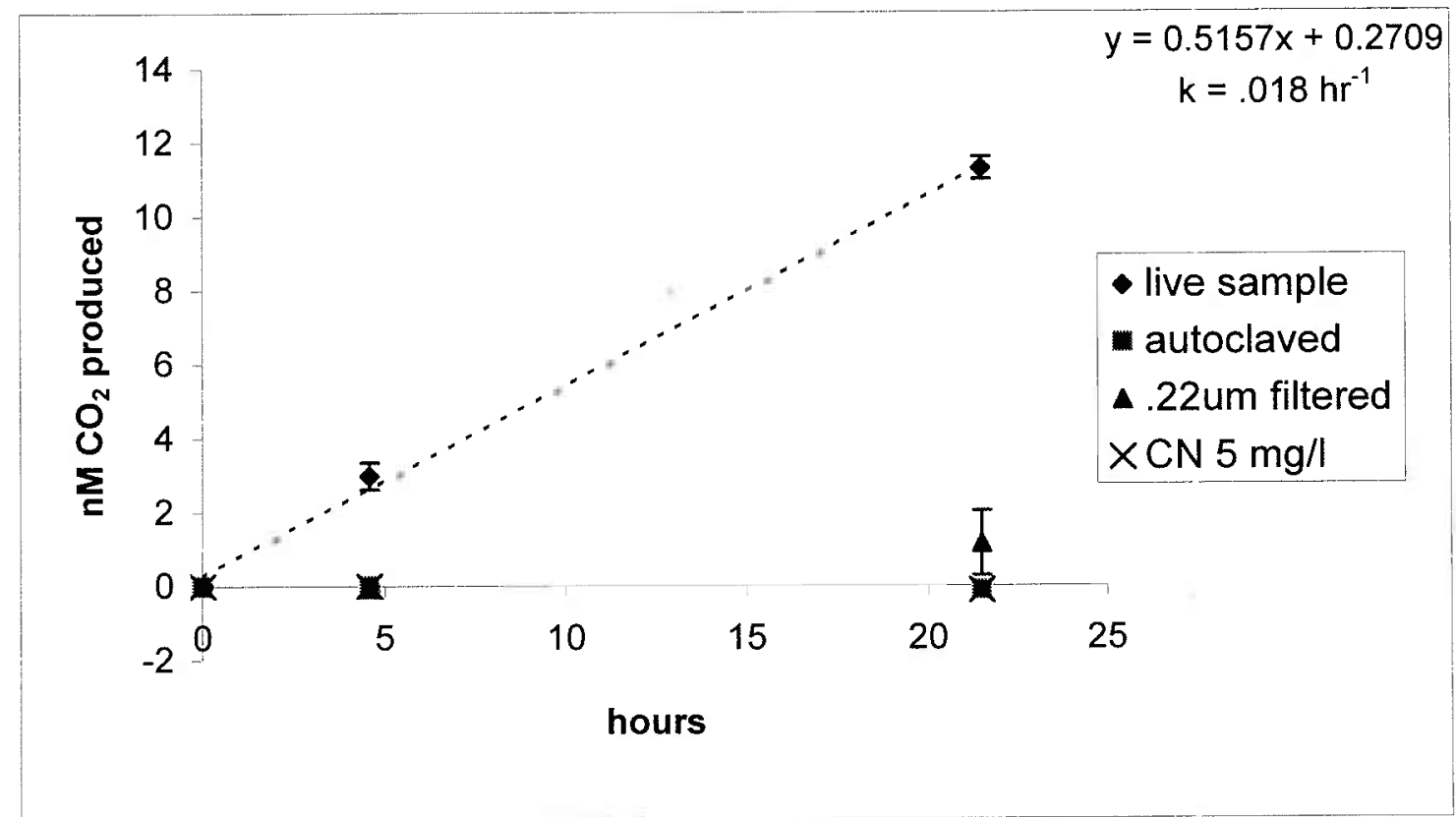

Figure 2.6: $\mathrm{CO}$ oxidation is biologically mediated. $\mathrm{CO}$ consumption is abolished when variety of sterilization treatments applied to natural seawater samples, compared with the untreated (live) control $(\diamond) .(02 / 20 / 02)$ 
no measurable activity after 21 hours of ${ }^{14} \mathrm{C}$-CO incubation, however, there was low level oxidation activity detected in the $0.22 \mu \mathrm{m}$ filter-sterilized sample after 21 hours, perhaps due to extremely small cells that had passed through the filter, or by filter blow-by into the filtrate.

Compartmentalization of carbon derived from ${ }^{14} \mathrm{C}-\mathrm{CO}$ was investigated by timeseries measurements of ${ }^{14} \mathrm{C}$ activity in acid-unstable products $\left({ }^{14} \mathrm{C}-\mathrm{CO}_{2}\right.$ in headspace gas $)$ and acid-stable ${ }^{14} \mathrm{C}$-POM and ${ }^{14} \mathrm{C}-\mathrm{DOM}$ on filters and in filtrate. Time-series $\mathrm{CO}$ consumption within syringe samples (natural seawater) was measured directly with a Trace Analytical reduction gas analyzer. To determine the fraction of $\mathrm{CO}$ that is oxidized to $\mathrm{CO}_{2}$, the ${ }^{14} \mathrm{C}$-CO-oxidation assay was employed. The fraction of $\mathrm{CO}$-born $\mathrm{CO}_{2}$ that was incorporated in organic material (acid-stable products) was determined with ${ }^{14} \mathrm{C}$ liquid-scintillation-counting of filtered material (POM) and filtrate (DOM). It was determined that the filters and liquid filtrate from these incubations contained only background levels of activity ( $<50 \mathrm{DPM})$ (figure 2.7 ). As the harsh chemical treatment during sample processing likely destroyed the cells, filter activity was expected to be minimal. Neither the filter nor the filtrate retained any labeled carbon fixed as recalcitrant organic material, and all labeled carbon that had been metabolized by the microbial community was captured quantitatively at the acidification step. A modified ${ }^{14} \mathrm{C}$-CO oxidation experiment to determine ${ }^{14} \mathrm{C}-\mathrm{CO}$ incorporation into particulate material was performed with pure cultures and without the destructive $\mathrm{pH}$ treatments, and will be discussed in detail in Chapter 3. 


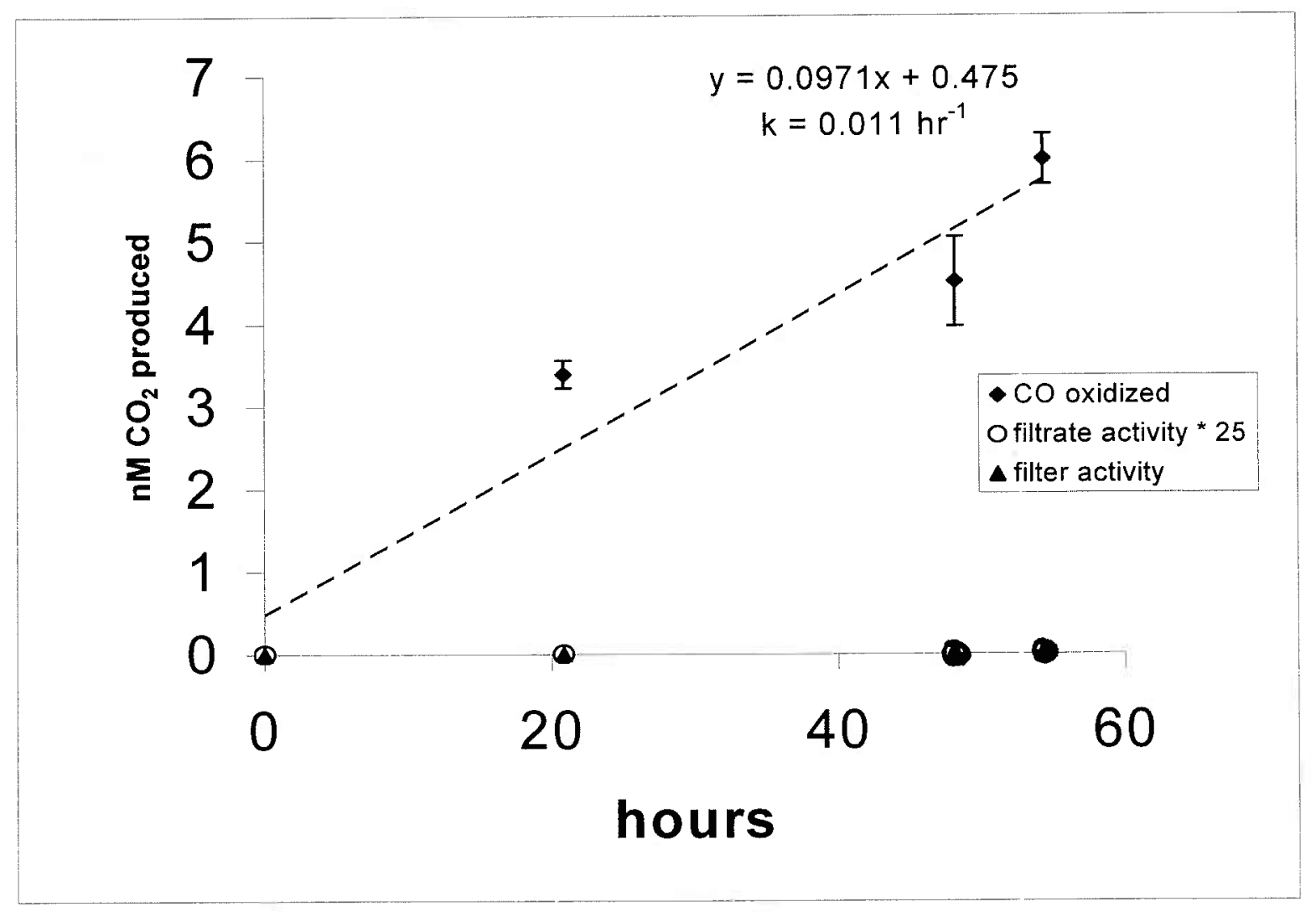

Figure 2.7: $\mathrm{CO}$ is oxidized rather than incorporated into particulate matter. In a long-term parallel incubation $(01 / 25 / 01), \mathrm{CO}_{2}$ product and filtered particulates were measured for ${ }^{14} \mathrm{C}$ activity after incubation with ${ }^{14} \mathrm{C}$-CO. All measured activity was in the form of bicarbonate or other acidvolatile products. 
Reduced gas analysis (Trace Analytical RGA) of in situ [CO] and rates of $\mathrm{CO}$ oxidation (figure 2.5 ) at the coastal sampling location are consistent with other coastal CO oxidation measurements in similar environments (Jones \& Amador, 1993; Jones, 1991). CO production is typically greater near coastal waters than open-ocean sites, probably due to larger CDOM content. The mid-day peak of $\mathrm{CO}$ concentration (figure 2.8), for example, is $3-5$ fold higher than the maximum measured in the Sargasso Sea (Jones, 1991; Xie et al., 2002b)(figure 2.14). CO-oxidation rates in coastal waters are approximately an order of magnitude greater than those measured in oligotrophic environments, suggesting an active CO-oxidizing microbial community near-shore.

In a study to determine kinetic parameters in coastal water samples in December 2000 , we estimated $V_{\max }$ and half-saturation constant $\left(\mathrm{K}_{\mathrm{M}}\right)$ by graphic determination (figure 2.9) and by Lineweaver-Burke calculation (figure 2.10). The approximate $\mathrm{K}_{\mathrm{M}}$ of the coastal assemblage for $\mathrm{CO}$ is $1.55 \mathrm{nMCO}$, and is in agreement with the approximate $\mathrm{K}_{\mathrm{M}}$ for the oceanic assemblage (figure 2.18).

The CO-oxidation rate constants measured at the coastal sampling location are highly variable on a seasonal or annual scale (figure 2.12). The mean value for all coastal measurement of $k$ is $0.064 \pm 0.021 \mathrm{hr}^{-1}(\mathrm{n}=9$, mean $\pm \mathrm{SEM})$. The mean coastal value for $k_{c o}$ is 6 -fold greater than the mean oceanic value for $k_{c o}$ during the winter EN327 cruise, and $\sim 2.8$-fold greater than the summer EN335 value. This greater rate of CO oxidation in coastal waters reflects either a faster specific CO-oxidation activity on a per-cell basis (figure 2.13), a higher cell density (figure 2.11), or both. Per-cell specific activity for CO oxidation was calculated for the coastal assemblage with $\mathrm{CO}$ oxidation rates and AODC 


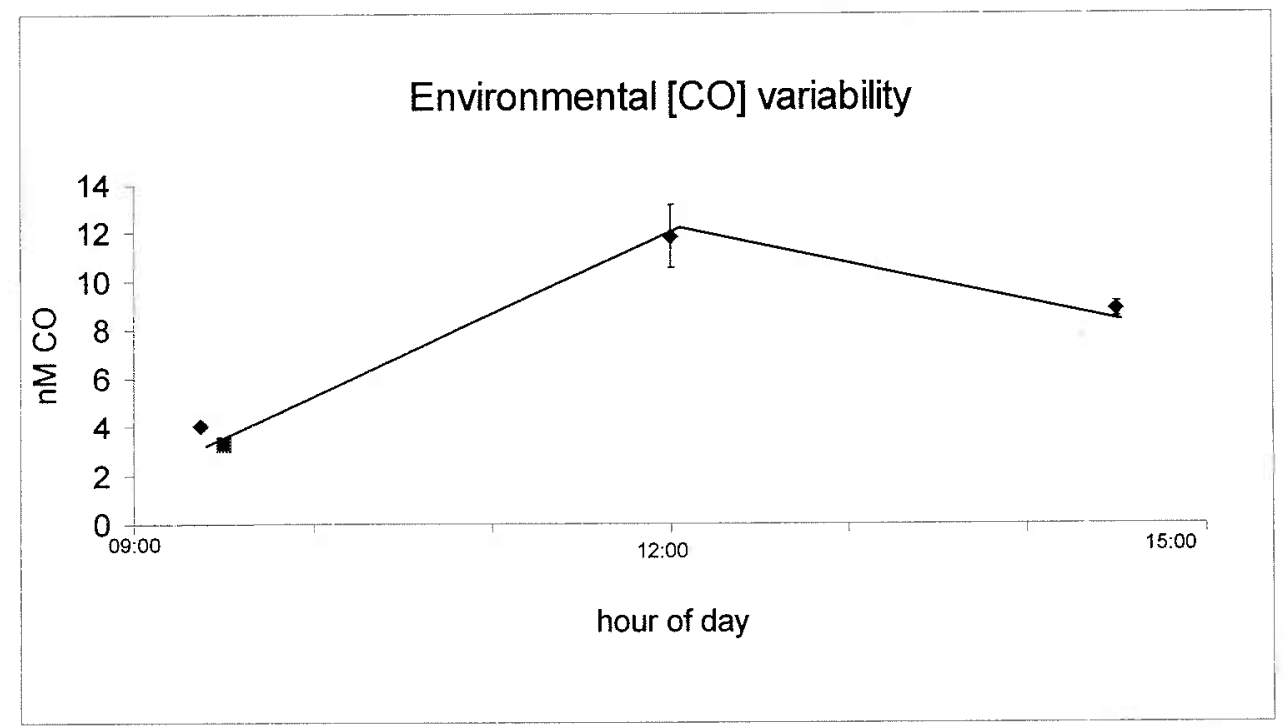

Figure 2.8: Diel [CO] variability was measured with a reduced-gas analyzer. In situ $[\mathrm{CO}]$ was determined at three sampling times on 10/20/00. 


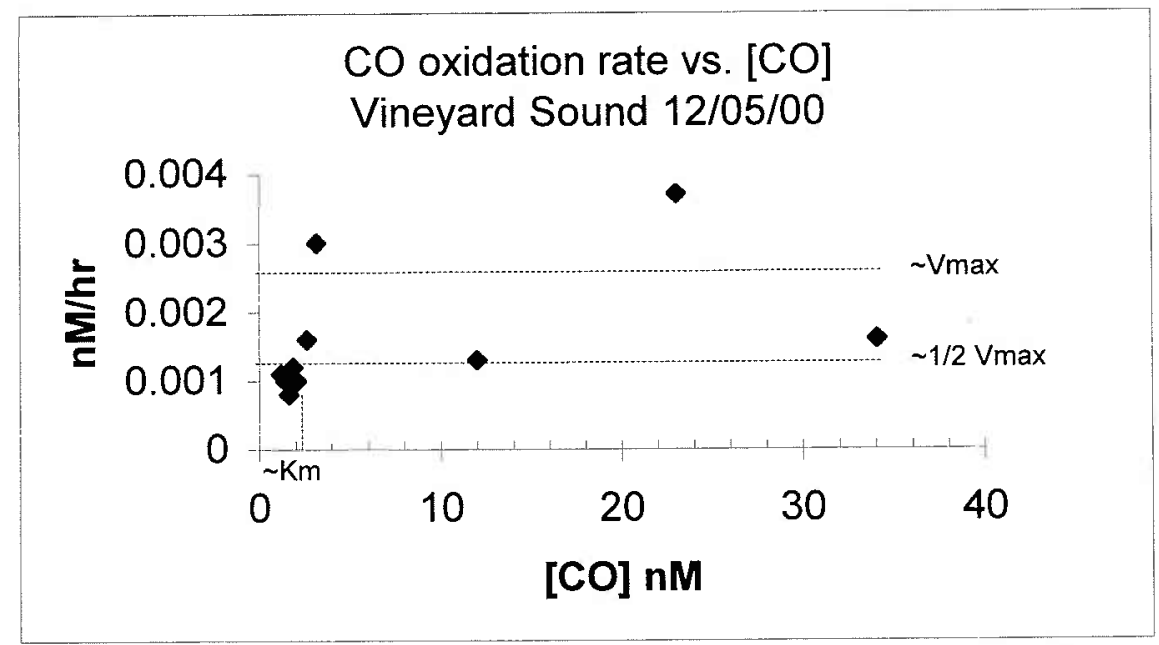

Figure 2.9: Kinetics experiment to estimate $\mathrm{V}_{\max }$ and $\mathrm{K}_{\mathrm{M}}$ for coastal microbial assemblage for CO. Dissolved [CO] results from injected tracer only.

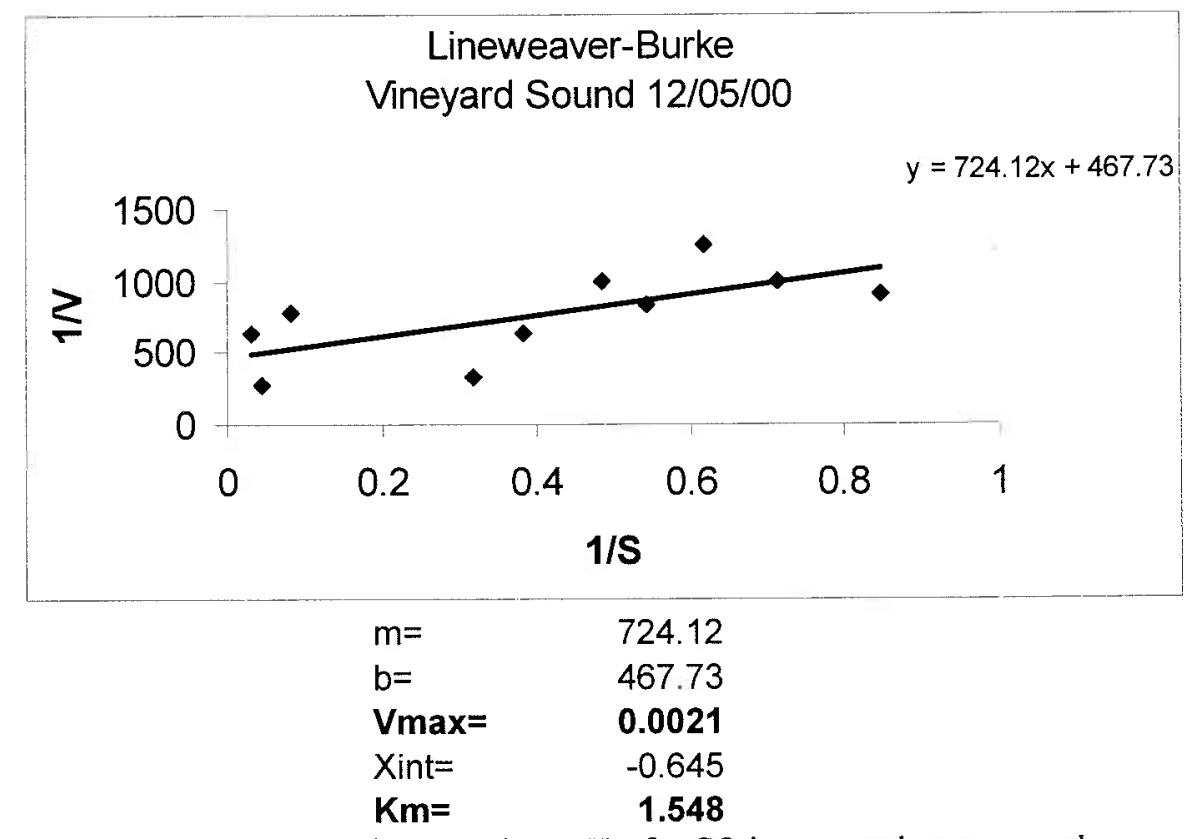

Figure 2.10: Lineweaver-Burke calculation to estimate $K_{M}$ for $C O$ in a coastal water sample. 


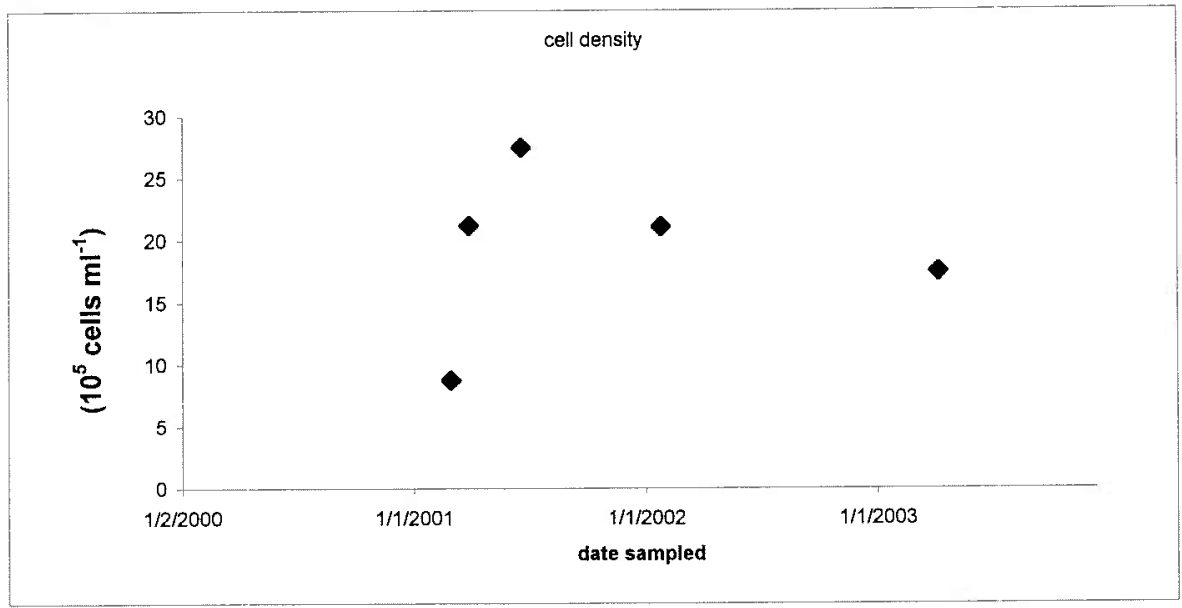

Figure 2.11: Cell density over time at Vineyard Sound, MA

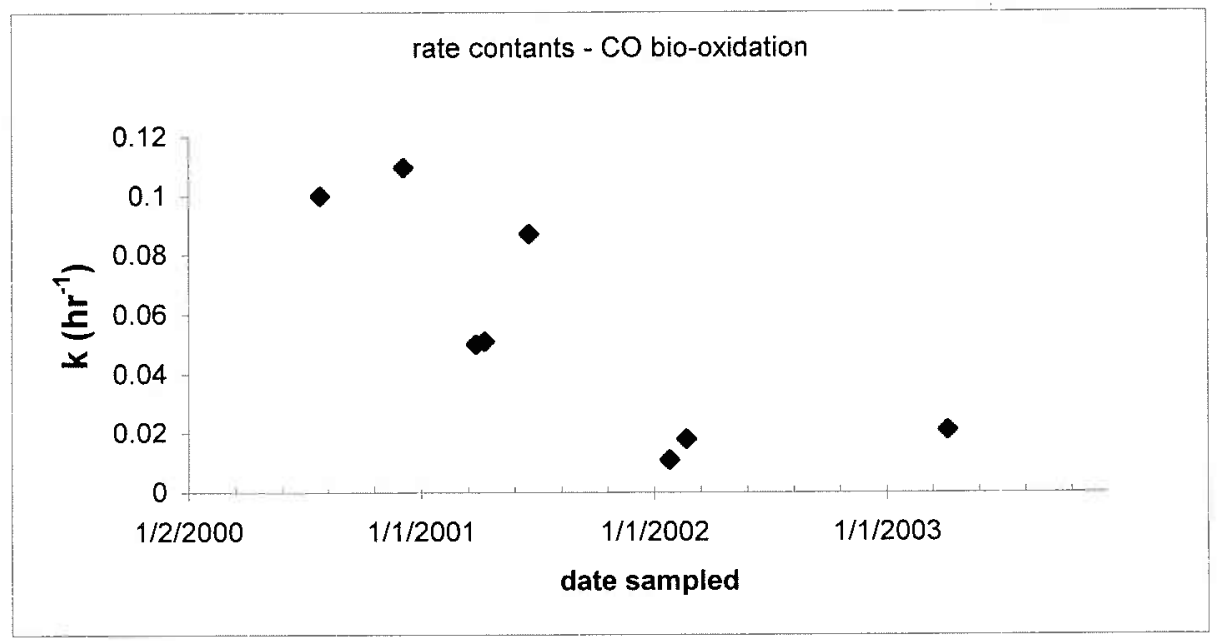

Figure 2.12: Rate constants $\left(k_{c o}\right)$ measured at the coastal sampling locations at several times over three years.

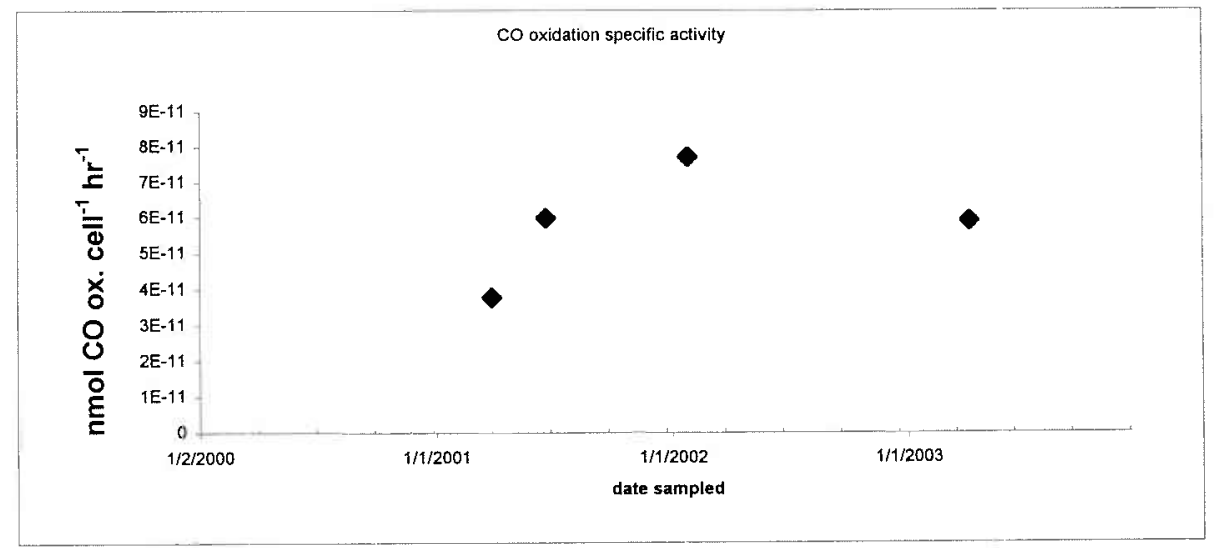

Figure 2.13: CO oxidation per-cell specific activities at the coastal sampling location, calculated from $\mathrm{CO}$ oxidation activity and in situ cell density at various sampling dates. 
data, and is in the range of $4.5 \times 10^{-11}-6 \times 10^{-11}$ nmol CO oxidized cell ${ }^{-1} \mathrm{hr}^{-1}$. This value should be regarded as the minimum value of activity by environmental isolates to designate them as environmentally important $\mathrm{CO}$ oxidizing strains, since this calculation assumes that every cell in total assemblage oxidizes $\mathrm{CO}$ at the same rate. Organisms of interest should have at least this rate of cell-specific activity.

Since dissolved [CO], biological $\mathrm{CO}$ oxidation rates and rate constants, cell density, and per-cell specific $\mathrm{CO}$ oxidation activities are all several-fold to an order of magnitude greater in a coastal environment compared with an oligotrophic environment, the coastal waters are therefore a promising source of CO-metabolizing microbial isolates, to be explored in Chapter 3.

Sargasso Sea CO bio- oxidation studies:

Six in situ optical buoy incubations were performed in collaboration with $\mathrm{O}$. Zafiriou (WHOI Dept. Chemistry) over an eight-day period in August, 1999 (EN327), and seven over an eight-day period in March, 2000 (EN335). Each buoy was deployed at dawn and recovered at dusk. Sample water was collected from a single depth $(20 \mathrm{~m})$ early in the morning $(0100-0300)$ for dispensation and incubated at five to seven discrete depths with end-points spanning the integrated photic period. Additionally, dark time-series rate measurements were performed with samples collected via Niskin bottles at various depths and at times around the clock to compare with the in situ measurements to establish whether in situ light intensity may inhibit biological CO oxidation. Cruise data were divided into four groups: summer buoy (in situ), summer dark, spring buoy, 

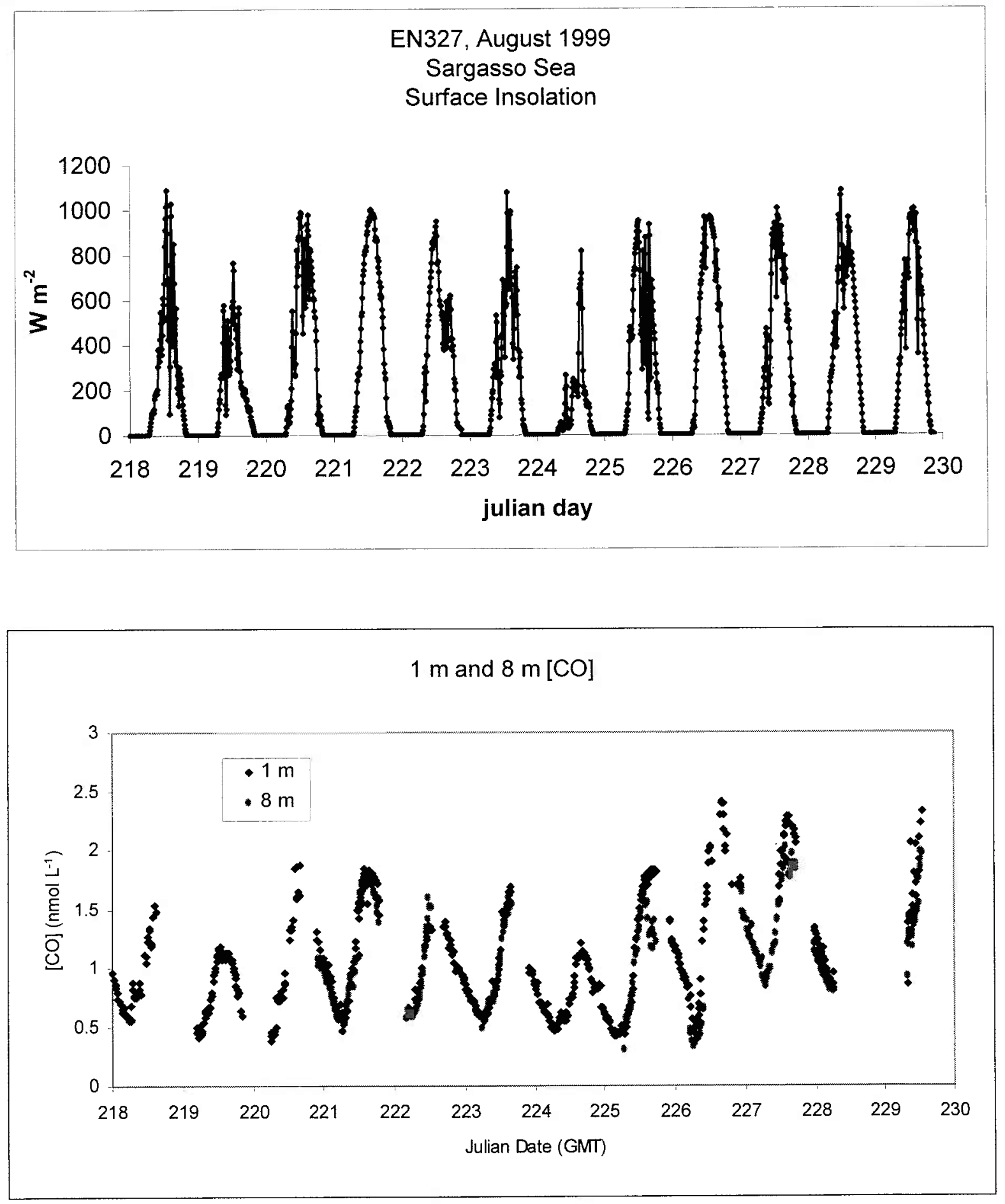

Figure 2.14: Diel monitoring of dissolved [CO] in oceanic (BATS) surface waters. Top: Daily solar intensity, sampling interval $15 \mathrm{~m}$. Bottom: dissolved [CO] at $1 \mathrm{~m}(\bullet)$ and $8 \mathrm{~m}(\bullet)$ depth ( from Xie et al., 2001, 2002a, 2002b). 
and spring dark. Initially, rate coefficients $\left(k_{c o}\right)$ were determined by normalizing the observed rates by the concentration of total dissolved [CO] within the sample. Dissolved $[\mathrm{CO}]$ varied in samples of a given cruise because of differences in in situ $[\mathrm{CO}]$ depending on the time of day sampled, and differences in injected ${ }^{14} \mathrm{C}$ activity that arose because of the fixed-volume stock vessels. In principle, if first order rate kinetics are in effect, then the average rate coefficient $k_{c o}$ should remain stable with increasing [CO]. However, when all dark rate coefficients were plotted versus $[\mathrm{CO}]$, we observed a trend of decreasing rate coefficients with increasing dissolved $\mathrm{CO}$ in both cruises (figure 2.15). At some level of dissolved [CO], first order rate kinetics is no longer followed and zero order (saturation) kinetics takes effect. The microbial assemblage in the surface Sargasso Sea is typically subjected to low $\mathrm{CO}$ concentrations with maximum exposures of $\sim 2-2.5$ $n M \mathrm{CO}$ for a brief period during mid-afternoon during peak photoproduction. The injection of labeled $\mathrm{CO}$ to each sample vial was sufficient to raise the dissolved [CO] within the sample to exceed environmental levels (figure 2.17) for an extended period of time (12-14 hours). This long period of higher than- environmental CO levels may cause inhibition of $\mathrm{CO}$ oxidation of the microbial assemblage, and may account for the depressed rate coefficients observed in many of our measurements. More likely, however, is the $\mathrm{CO}$ oxidizing enzymes of the active microorganisms became saturated at high $[\mathrm{CO}]$, and normalization of the rate in obeisance to first order kinetics resulted in an underestimate of the rate coefficient in incubations containing [CO] higher than the saturation level. 


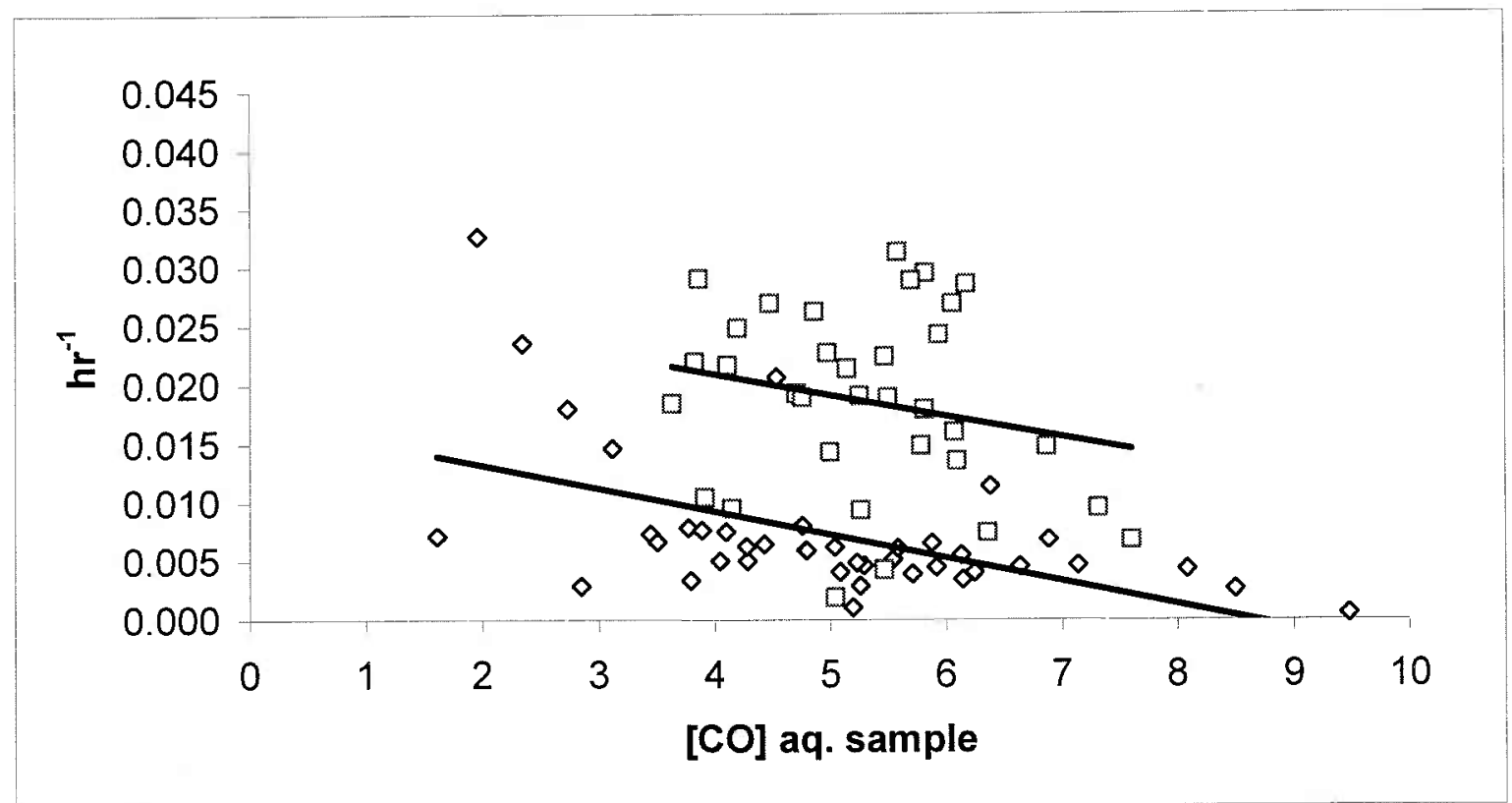

Figure 2.15: Empirically derived rate coefficients from all incubations during EN327 ( $\square$ ) (summer) and EN335 $(\diamond)$ (spring) suggest rate saturation at higher [CO].

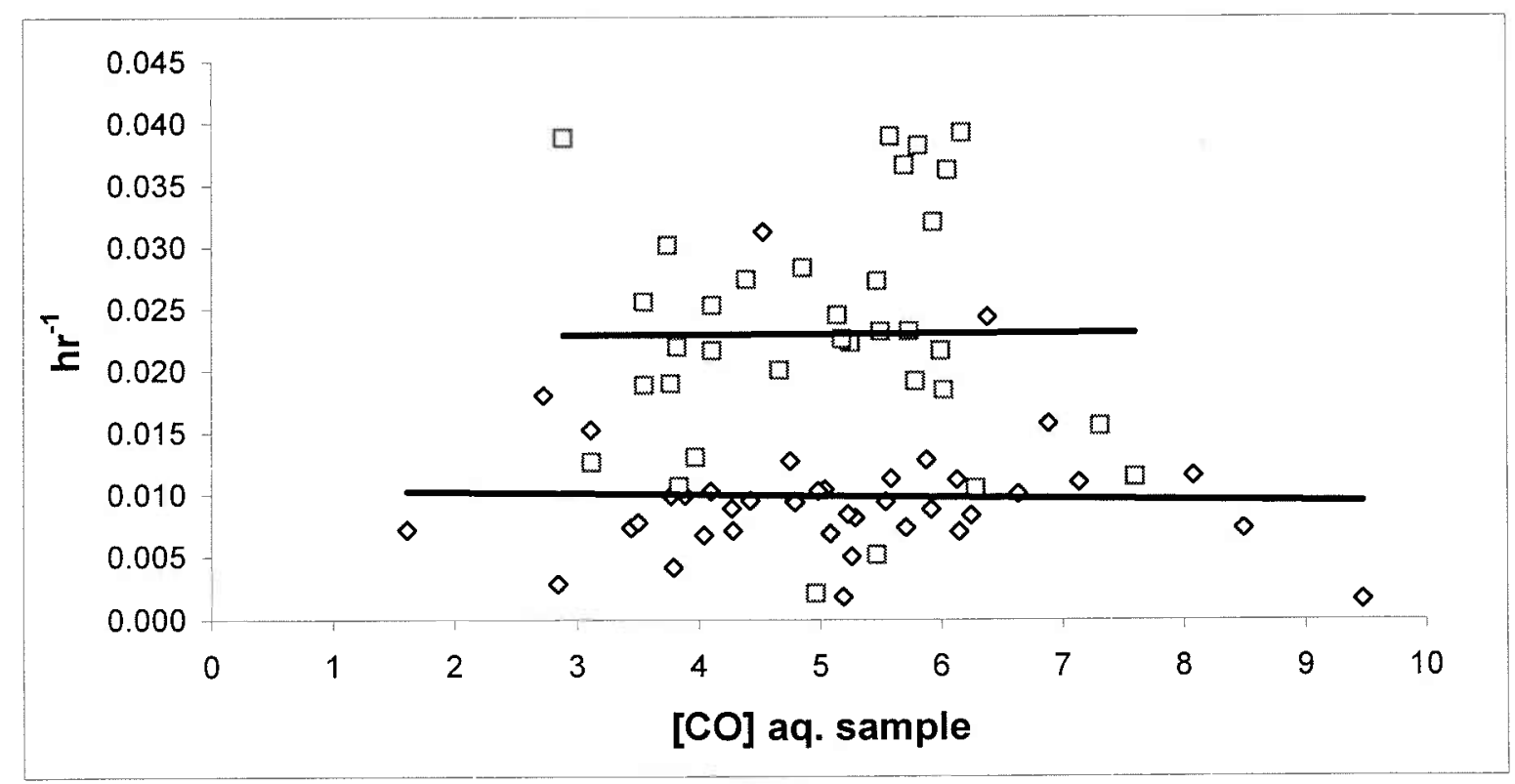

Figure 2.16: Depressed rate coefficients from high-[CO] incubations corrected by normalization by inhibitory [CO] value; $4.5 n M$ during EN327 (D) and $3.5 n M$ during EN335 $(\diamond)$. Average corrected rate coefficients $\left(k_{c o}\right)$ for $\operatorname{EN} 327=0.023 \mathrm{hr}^{-1}$, and EN335 $=0.010 \mathrm{hr}^{-1}$. 
In the dataset for each cruise, we inferred the saturating [CO] levels by applying a fixed normalization factor ( $\mathrm{CO}$ concentration) in incubations where the dissolved [CO] was higher than peak environmental levels. In incubations having total dissolved CO below the saturation level, each rate constant was calculated simply by normalizing the measured rate $(\mathrm{n} M / \mathrm{hr})$ by the total dissolved $[\mathrm{CO}](\mathrm{n} M)$ within the incubation set, obeying first order kinetics. In incubations containing dissolved [CO] greater than the inferred saturation concentration, rate constants were normalized by the single [CO] value where first order kinetics gives way to zero order. These transition points were determined by observing where the average value of $k_{c o}$ remained constant across all [CO] (figure 2.16), and were 4.5 nM CO during EN327 and $3.5 n M \mathrm{CO}$ during EN335. The average rate constant for $\mathrm{CO}$ oxidation after this correction was applied to the data was $0.023 \pm 0.0017 \mathrm{hr}^{-1}(($ mean $\pm \mathrm{SEM})$ in the summer cruise (EN327), and $0.010 \pm$ $0.00090 \mathrm{hr}^{-1}$ in the early spring (EN335).

We validated this correction approach to apply to the 1999 and 2000 rate data in a substrate-series experiment conducted in July 2002 aboard the R/V Weatherbird (Bermuda Biological Station for Research, Inc.) in the vicinity of the BATS site (BATS166) and the previous EN cruises. A careful and systematic series of time of series incubations under aqueous $\mathrm{CO}$ concentrations ranging between 0.01 and $10 n M$ were performed $(0.1 \mathrm{n} M$-intervals between $0-1.0 \mathrm{n} M$, and approximately $1 \mathrm{n} M$-intervals between 1.0 and $10 \mathrm{n} M)$ ] to establish the [CO] where saturation of $\mathrm{CO}$ oxidation occurs (Figure 2.17). The time-series consisted of paired samples sacrificed approximately 2 hours apart in 8-hour incubations. Incubations and processing of samples were 

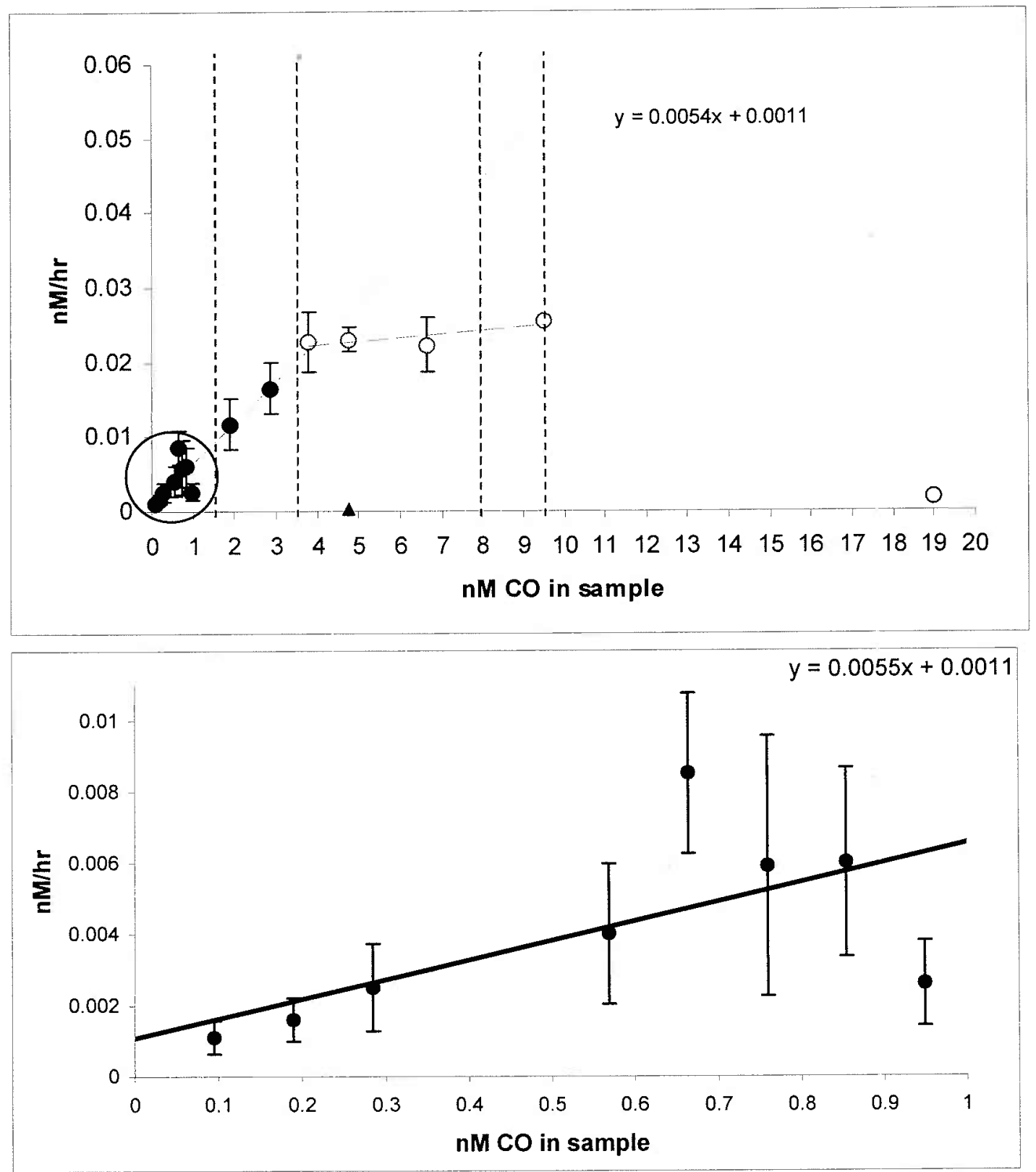

Figure 2.17: Substrate series performed on microbial samples near BATS, July 2002.

(upper panel) Area between outer dashed vertical bars is the range of dissolved [CO] in incubations performed during EN335, and during EN327 between inner dashed vertical bars. Closed circles (O) designate the region obeying first-order kinetics. Open circles $(O)$ designate the inhibitory region or deviation from first-order kinetics. Black triangle $(\mathbf{A})$ is a killed control $(\mathrm{CN})$.

(lower panel) Linear relationship of rate and dissolved [CO] at [CO] less than $1 \mathrm{nM}$ (region encircled in top panel is expanded in lower panel) 


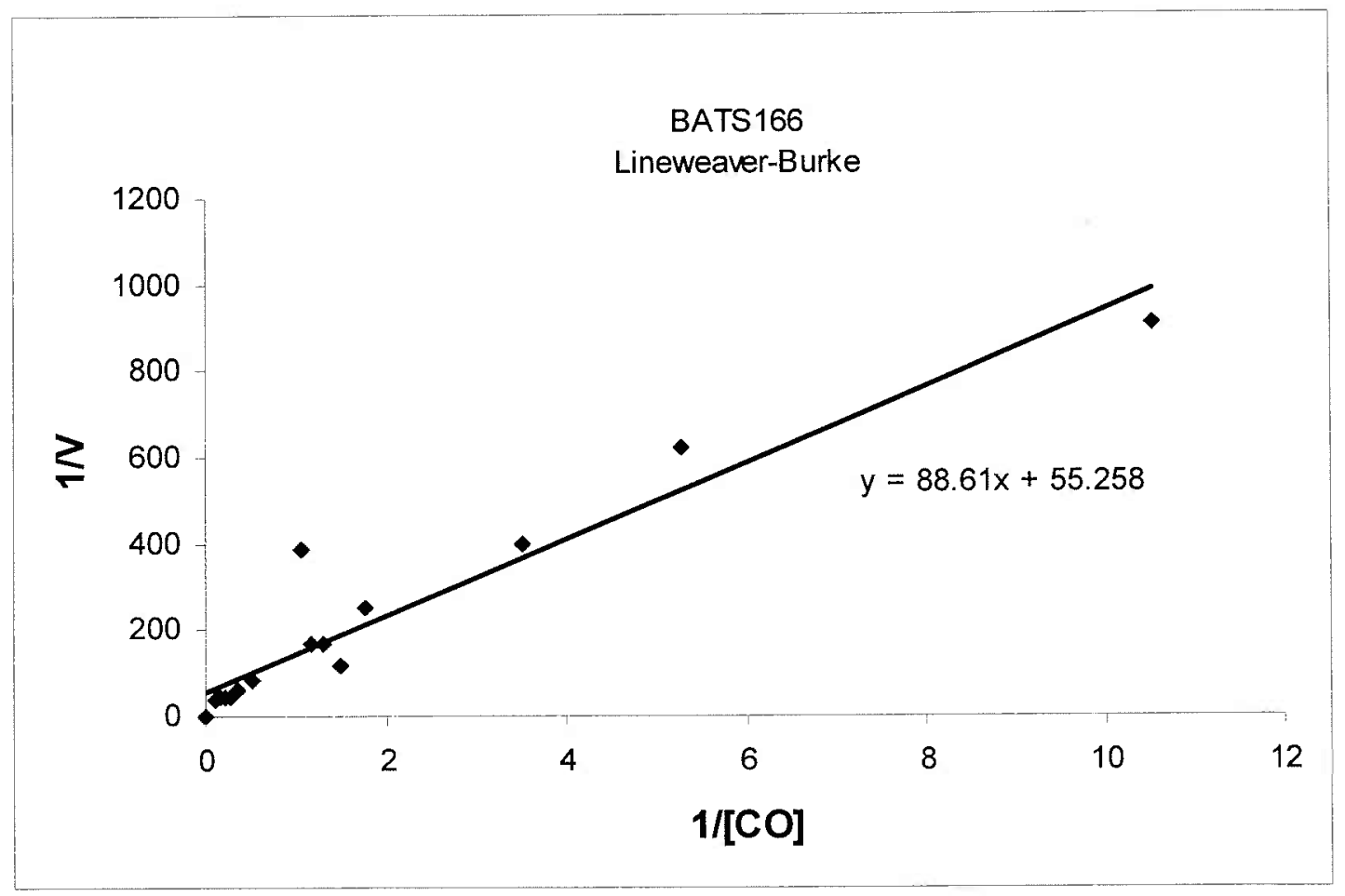

Figure 2.18: Kinetic analysis of BATS 166 substrate series. $V \max =(1 / \mathrm{b})=0.020 \mathrm{nM} / \mathrm{hr}$. $\mathrm{Km}=(-1 / \mathrm{X}$ intercept $)=1.793 n M \mathrm{CO}$. 
performed as previously described. Lineweaver-Burke analysis of the substrate series experiment showed a maximum velocity for the $\mathrm{CO}$ oxidation reaction $\left(\mathrm{V}_{\max }\right)$ of 0.020 $n M \mathrm{CO}$ oxidized $\mathrm{hr}^{-1}$ and the apparent half-saturation constant $\left(\mathrm{K}_{\mathrm{M}}\right)$ was $1.793 n M \mathrm{CO}$ (figure 2.18). We observed deviation from the straight-line typically observed in the analytical procedure used to calculate $\mathrm{K}_{\mathrm{M}}$ and $\mathrm{V}_{\max }$ in incubations having dissolved $\mathrm{CO}$ concentrations greater than $4.0 \mathrm{nM}$ in the BATS166 experiment, which is bracketed within the two saturation [CO] concentrations inferred from the EN327 and EN335 cruise data. Incubations containing greater than $4 n M$ dissolved $\mathrm{CO}$ did not result in increasing $\mathrm{CO}$ oxidation rates. $\mathrm{CO}$ oxidation activity was nearly abolished in an incubation containing $19 n M \mathrm{CO}$, or six-fold greater [CO] than experienced in situ $\left(4 \times 10^{-4} \mathrm{hr}^{-1}\right)$. This suggests that saturation kinetics gives way to inhibition kinetics at [CO] between 10 $n M$ and $19 \mathrm{nM}$ and possibly at even lower [CO]. There are no data to interpolate between these two [CO] values in the BATS166 cruise because our objective was to determine the transition point between first and zero-order kinetics at low [CO], therefore the transition between $\mathrm{CO}$ saturation and inhibition is poorly constrained.

When the EN cruise data were corrected for substrate saturation effects due to high $[\mathrm{CO}]$ in ${ }^{14} \mathrm{C}-\mathrm{CO}$ incubations, the highest observed $\mathrm{CO}$ oxidation rates were observed during the summer 1999 cruise where the dark incubation rate constant ranged between 0.019 to $0.028 \mathrm{hr}^{-1}$ (figure 2.19) with the maximum occurring at $15 \mathrm{~m}-20 \mathrm{~m}$. These rates were $\sim 10$-fold higher than the in situ rates for that season $\left(0.0017-0.0025 \mathrm{hr}^{-1}\right)$, and also higher than both the dark incubation and in situ rates for the spring season (figure 2.20), which ranged between $0.0083-0.017 \mathrm{hr}^{-1}$ and $0.0041-0.0062 \mathrm{hr}^{-1}$, 


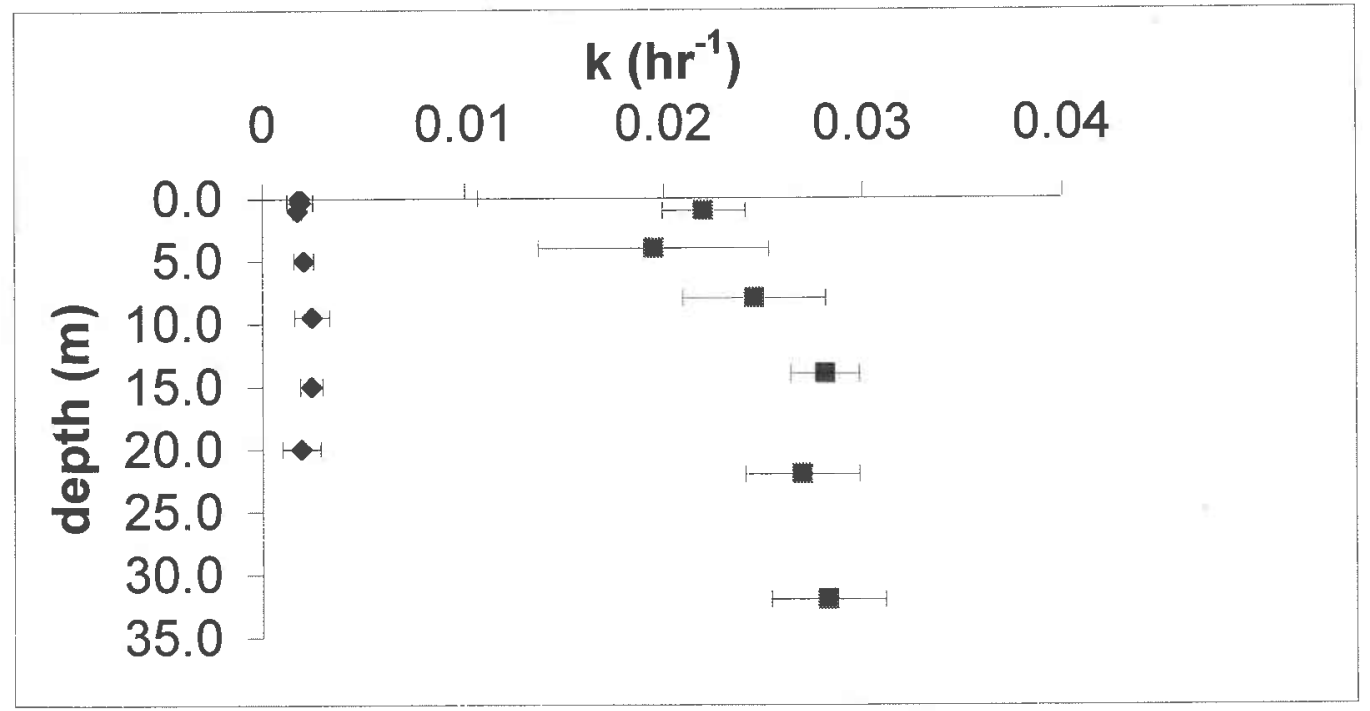

Figure 2.19: EN327 (summer) buoy ( $\bullet$ ) and dark incubation $(*)$ rate coefficients.

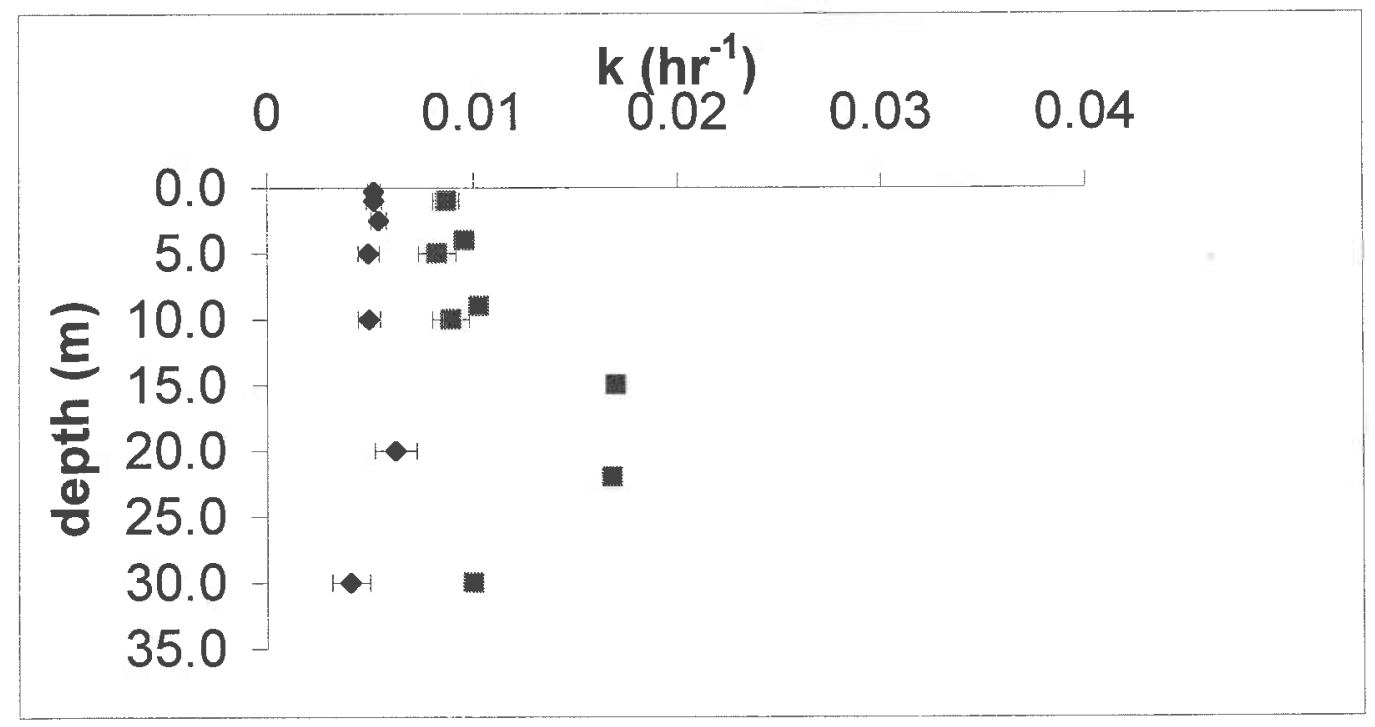

Figure 2.20: EN335 (spring) buoy $(\diamond)$ and dark incubation $($ ( $)$ rate coefficients 
respectively. We did not observe increasing $\mathrm{CO}$ oxidation rates with increasing depth in any in situ incubations. The in situ CO-oxidation rates are depressed relative to the dark incubations during both cruises. The light field at all in situ incubation depths may have been inhibitory to $\mathrm{CO}$ oxidation by the microbial assemblage, and thus depressed the COoxidation rates at all in situ depths tested $(0-30 \mathrm{~m})$ relative to dark incubations at corresponding depths. This suggests that daytime dissolved [CO] increases rapidly from the combined effects of photoproduction and light-induced inhibition of the microorganisms that consume $\mathrm{CO}$. Similarly, nighttime dissolved [CO] decreases rapidly when photoproduction ceases and activity of $\mathrm{CO}$ metabolizing microorganisms resumes.

Specific CO-oxidation activities for the spring and summer seasons were estimated using the CO-oxidation rate constants measured in this study and the bacterioplankton standing stock estimates of Carlson et al., (1996). Their estimates were $4 \times 10^{8}$ cells $1^{-1}$ in spring and $5 \times 10^{8}$ cells $^{-1}$ in summer in the surface mixed layer. The summer and spring mean cell-specific CO oxidation rates were $1.3 \times 10^{-11} \pm 2.9 \times 10^{-12}$ nmol CO oxidized cell ${ }^{-1} \mathrm{hr}^{-1}$ and $2.8 \times 10^{-11} \pm 3.2 \times 10^{-12} \mathrm{nmol} \mathrm{CO}$ oxidized cell $^{-1} \mathrm{hr}^{-1}$, respectively. These activities are calculated using our measured values for total $\mathrm{CO}$ oxidation rate and literature values for bacterial cell density, and represent a minimum value of per-cell $\mathrm{CO}$ oxidation activity and environmental relevance since not all cells oxidize CO.

Our estimates of oceanic and coastal CO consumption rates in the surface water are consistent with prior studies that have investigated this parameter with syringe assays (Conrad \& Seiler, 1982), ${ }^{14} \mathrm{C}-\mathrm{CO}$ oxidation methods (Jones \& Amador, 1993; Jones, 
1991) or by calculation using numerical models (Johnson \& Bates, 1996). Conrad et al. (1982) and Conrad \& Seiler (1982) measured the decay of CO in surface samples from the equatorial Atlantic Ocean, and reported rate constants on the order of $0.03-0.05 \mathrm{hr}^{-1}$ in dark incubations, and $K_{\mathrm{m}}$ values for $\mathrm{CO}$ to be $7 n M \mathrm{CO}$, only slightly higher than our estimates for these parameters in oceanic waters. Jones (1991), using the ${ }^{14} \mathrm{C}-\mathrm{CO}$ oxidation method in dark incubations, measured rate coefficients for CO consumption in the Sargasso Sea surface waters that were $0.012-0.018 \mathrm{hr}^{-1}$ in July, and $0.0045-0.011$ $\mathrm{hr}^{-1}$ in September. Jones and Amador, (1993), in a study to determine the impact of the Orinoco River on the consumption of $\mathrm{CO}$ and $\mathrm{CH}_{4}$ and the photoproduction of $\mathrm{CO}$ in the southeastern Caribbean Sea, reported CO oxidation rates were minimum at a station in Mona Passage $\left(0.028 \mathrm{hr}^{-1}\right)$, increased with proximity to the Orinoco River outflow, and were highest near the mouth of the river $\left(0.199 \mathrm{hr}^{-1}\right)$. Johnson \& Bates (1996) estimated CO loss rate constants by an exponential fit method, and reported mean $k_{c o}$ values as $0.032 \pm 0.0071 \mathrm{hr}^{-1}$ in April, and $0.009 \pm 0.0052 \mathrm{hr}^{-1}$ in December. Rate estimates in our study, in both oceanic and coastal waters, nicely fit with CO loss rates previously determined by a variety of methods. One assumption common to the aforementioned studies, however, is that the $\mathrm{CO}$ oxidation rate at a given station does not vary between day and night; all direct measurements of $\mathrm{CO}$ consumption rates have thus been made with dark incubations. Our daytime in situ incubations indicate that there may be a lightrelated inhibition of CO oxidation. CO turnover times commonly reported in "days" (the reciprocal of the rate constant in terms of "day "1") may not be accurate if in situ $\mathrm{CO}$ oxidation is retarded in daytime light regimes. If $\mathrm{CO}$ oxidation is slower during daylight 


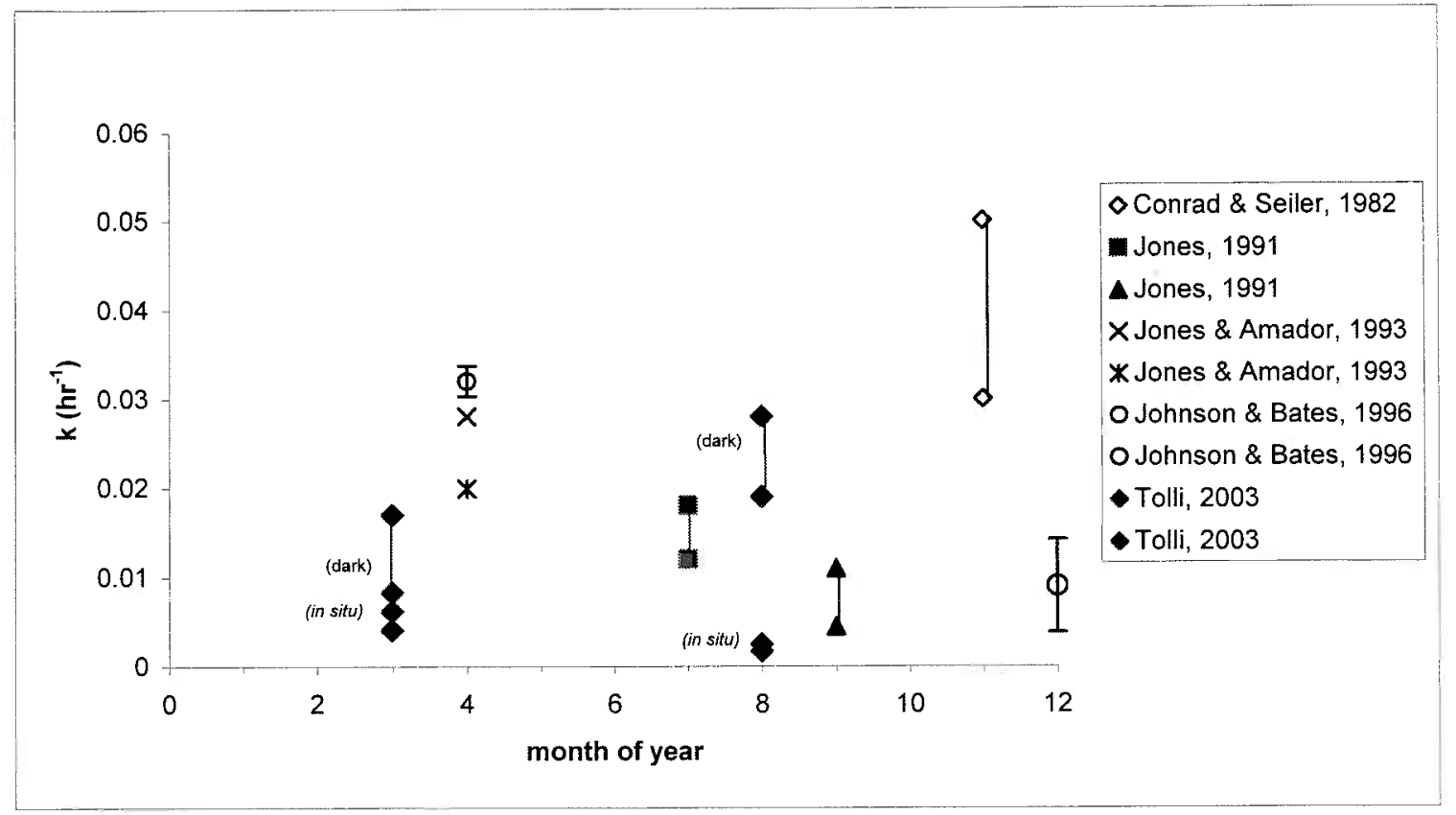

Figure 2.21: Comparison of oceanic rate coefficients $\left(k_{c o}\right)$ measured in this study $(\bullet)$ with literature values. Literature values of $k_{c o}\left(\mathrm{hr}^{-1}\right)$ were calculated from values reported as "day" reciprocal, "days" (turnover time). All literature values of oceanic $k_{\mathrm{co}}$ are based on dark incubations, and do not account for potential daytime rate inhibition. 
hours, then the diel rate coefficients $k_{c o}$ are high and $\mathrm{CO}$ turnover times reported previously are underestimated (figure 2.21). Turnover time calculated using our summertime dark incubation values integrated over 24 hours is 1.67 days. If daytime rates are inhibited by an order of magnitude over the photic period (12 hours), then the integrated turnover time (12 hours daytime, 12 hours dark) is 3.07 days, or $83 \%$ higher.

Prior studies of $\mathrm{CO}$ processes in oceanic and coastal waters, while lending support to our results, still do not provide insight to the microbial species that are responsible for the observed $\mathrm{CO}$ oxidation. The phylogeny and identity of cells responsible for $\mathrm{CO}$ oxidation in the Sargasso Sea remains enigmatic; Chapters 3 and 4 of this study are concerned with the identities of coastal $\mathrm{CO}$ oxidizing organisms, where organisms belonging to the genus Roseobacter and Paracoccus were found to be important CO oxidizers. Giovannoni et al. (1990), using PCR-assisted sequence retrieval and fairly general bacterial primers, retrieved partial 16S-rRNA sequences that are affiliated to the alphaproteobacteria from the Atlantic Sargasso Sea, among many others. Sequences of the so-called SAR83 cluster had only a few percent difference to those of members of the Roseobacter group (Amann, 2000, for review) that were found to be active CO oxidizers in this study. The metabolic importance of Roseobacter and other marine-alpha organisms in $\mathrm{CO}$ oxidation will be discussed in subsequent chapters. 


\section{BIBLIOGRAPHY}

Amann, R. (2000). Who is out there? Microbial aspects of biodiversity. Syst. Appl. Microb. 23:1-8

Carlson, C.A., Ducklow, H.W., and Sleeter, T.D. (1996). Stocks and dynamics of bacterioplankton in the northwestern Sargasso Sea. Deep-Sea Research II 43(2-3):491-515

Conrad, R. and Seiler, W. (1980). Photooxidative production and microbial consumption of carbon monoxide in seawater. FEMS Microbiology Letters 9: 61-64

Conrad, R., and Seiler, W. (1982). Utilization of traces of carbon monoxide by aerobic oligotrophic microorganisms in ocean, lake, and soil. Arch. Microbiol.

132: $41-46$

Conrad, R., Seiler, W., Bunse, G., and Giehl, H. (1982). Carbon Monoxide in Seawater (Atlantic Ocean) Journ. Geophys. Res. 87(C11): 8839-8852

Doherty, K.W., C.D. Taylor and O.C. Zafiriou. (2003). A titanium bottle design for contamination-free sampling of carbon monoxide and other possible chemical, biological, and geological materials. Deep-Sea Research. 50: 249-255.

Donoghue, T.G., O.C. Zafiriou and C.D. Taylor. (2001). Retractable surface-following sampler. Marine Technology Society Journal. 35(2): 29-35.

Giovannoni, S., Britschgi, T., Moyer, C., and Field, K. (1990). Genetic diversity is Sargasso Sea bacterioplankton. Nature 345:60-63

Griffiths, R.P., Caldwell, B.A., Cline, J.D., Broich, W.A., and Morita, R.Y. (1982). Field observations of methane concentrations and oxidation rates in the southeastern Bering Sea. Appl. Environ. Microbiol. 44(2): 435-446

Johnson, J. E. and Bates, T. S. (1996). Sources and sinks of carbon monoxide in the mixed layer of the tropical South Pacific Ocean. Global Biogeochemical Cycles. 10(2): $347-359$

Jones, R.D. (1991). Carbon monoxide and methane distribution and consumption in the photic zone of the Sargasso Sea. Deep-Sea Research 38(6): 625-635

Jones, R.D. and Amador, J.A (1993). Methane and carbon monoxide production, oxidation, and turnover times in the Caribbean Sea as influenced by the Orinoco River. J. Geophys. Res. 98:2353-2359 
Jones, R.D. and Morita, R.Y. (1984). Effects of various parameters on carbon monoxide oxidation by ammonium oxidizers. Can. J. Microbiol. 30: 894-899

Jones, R.D. and Morita, R.Y., and Griffiths, R.P. (1984). Method for estimating in situ chemolithotrophic ammonium oxidation using carbon monoxide oxidation. MEPS 17: 259-269

Wiesenburg, D.A and Guinasso, N.L. (1979). Equilibrium solubilities of methane, carbon monoxide, and hydrogen in water and seawater. J. Chem. Eng. Data.

24(4): $356-360$

Xie, H, Zafiriou, O.C., Wang, W., and Taylor, C.D. (2001). A simple automated continuous flow equilibrium method for measuring carbon monoxide in seawater. Environ. Sci. Technol. 35(7):1475-1480

Xie, H., Andrews, S., Martin, W., Miller, J., Ziolkowski, L., Taylor, C., and Zafiriou, O. (2002a). Validated methods for sampling and headspace analysis of carbon monoxide in seawater. Marine Chemistry 77(2-3):93-108.

Xie, H., Goldstone, J., Taylor, C.D., Wang, W, Ziolkowski, L., and Zafiriou, O.C. (2002b). Diurnal cycling of carbon monoxide in Sargasso Sea surface waters. In prep. for submission to Limnol. Oceanog.

Zafiriou, O.C., Andrews, S.S., and Wang, W. (2002). Concordant estimates of oceanic carbon monoxide source and sink processes in the Pacific yield a balanced global "blue-water" CO budget. Global Biogeochemical Cycles 17(1):1015

Zuo, Y., and Jones, R.D. (1995). Formation of carbon monoxide by photolysis of dissolved marine organic material and its significance in the carbon cycling of the oceans. Naturwissenschaften 82: 472-474 


\title{
CHAPTER III:
}

\section{Characterization of Marine Carbon Monoxide Oxidizing Microorganisms Isolated from a Coastal Marine Environment}

\begin{abstract}
For the purpose of isolating a specific phylogenetic group of microorganisms in natural seawater and determining their relative contribution to a gross metabolic feature found in seawater (CO oxidation), we utilize a direct isolation method for obtaining $\mathrm{CO}$ oxidizing microbes under conditions approximating the natural environment. The method involves cultivation of bacteria on membrane filters placed atop an oligotrophic liquid mineral medium, subsequent incubation with radiolabeled $\mathrm{CO}$ at near-environmental levels, and the use of macroautoradiography to screen colonies with the desired phenotype amidst a potential background of other colonies. Since this method spatially separates otherwise competing populations, simultaneous recovery of organisms with different growth rates and nutritional requirements is possible, and large numbers of bacteria can be screened rapidly at one time. Cell-specific CO-oxidation activities were determined for selected strains with time-series ${ }^{14} \mathrm{CO}$-oxidation rate measurments. Nine of 30 resulting isolates oxidize $\mathrm{CO}$ at environmentally relevant rates, and were taxonomically diverse with representatives in the $\alpha, \beta$, and $\gamma$-subclasses of the Proteobacteria, and in the Cytophaga-FlavobacteriumBacteroides group. Three isolates with the highest specific rates of CO metabolism $\left(1.0 \times 10^{-10}-2.0 \times 10^{-}\right.$

${ }^{10} \mathrm{nmol} \mathrm{CO} \mathrm{cell}^{-1} \mathrm{hr}^{-1}$ ) cluster within the Roseobacter and Paracoccus groups of the $\alpha$-Proteobacteria, collectively known as the "marine alpha group", CO oxidizing isolates resulting from this study are not related to bacterial groups previously implicated in environmental $\mathrm{CO}$ oxidation, rather, they represent a hitherto unreported metabolic function in several diverse microbial types.
\end{abstract}

\section{INTRODUCTION}

Selective liquid culture enrichment techniques have been used to isolate bacteria to study their microbial ecology and physiology. These techniques typically involve incubation of mixed populations in a medium designed to foster the growth of those microorganisms exhibiting a particular phenotype. Serial transfers of the enrichment culture to fresh medium are continued until the microbial culture appears to consist mainly of one or very few types of microorganisms exhibiting the desired properties. 
Undesired organisms are eliminated from the culture through competitive exclusion or dilution, or streaking on selective agar media. Although selective enrichment techniques have historically been used with great success, the diversity of organisms in enrichment cultures is not likely to reflect that found in the natural environment. Dominant organism(s) in the enrichment culture may or may not be important players in the natural environment.

Enrichment and isolation of pure cultures of "carboxydotrophic" bacteria, microorganisms that are capable of gaining both energy and carbon from carbon monoxide, from natural habitats have traditionally employed liquid batch cultures incubated aerobically in desiccators supplied with $\mathrm{CO}_{2}$ and high levels of $\mathrm{CO}$ as carbon and energy sources. Such conditions are highly specific for the development of carboxydotrophs because of the inability of the contaminating microflora to use $\mathrm{CO}$ for growth, and binding of $\mathrm{CO}$ to the terminal respiratory oxidases of most organisms results in inhibition of their growth (Meyer \& Schlegel, 1983). Carboxydotrophic bacteria possess specialized metabolic machinery for the oxidation of $\mathrm{CO}$, and attempts to isolate them from marine environments (other than hydrothermal sites) are conspicuously absent in the primary marine literature.

In enrichment programs using very high $\mathrm{CO}$ concentrations, the resulting isolates generally have a low affinity for that substrate. The reported $K_{\mathrm{M}}$ for $\mathrm{CO}$ of carboxydotrophic isolates obtained by these methods from terrestrial enrichments containing >500 nM CO (Conrad et al., 1981; Meyer, 1985) have been 1-2 orders of magnitude higher than the average $K_{\mathrm{m}}$ for CO consumption in soil or water $(5-50 \mathrm{n} M)$ 
(Conrad \& Seiler, 1982b, Conrad et al., 1981; Bartholomew \& Alexander, 1981; Jones \& Morita, 1983), or marine environments (1-2 $\mathrm{n} M$ ) (this study). The observed high $K_{\mathrm{M}}$ for CO by several terrestrial carboxydotrophic strains is likely a bias created by the high [CO] used in the enrichments and for their isolation (Zavarzin \& Nozhevnikova, 1977). This highlights the importance of cultivating $\mathrm{CO}$ metabolizing bacteria under $\mathrm{CO}$ concentrations close to that encountered in situ for obtaining microbes that are more representative of those active in the environment.

To this end, we utilized a method that does not rely on the use of liquid batchculture techniques for screening and isolating microorganisms with particular phenotypes. The method involves cultivation of bacteria on membrane filters atop a combusted glass-fiber filter saturated with an oligotrophic liquid mineral medium, subsequent incubation with radiolabelled $\mathrm{CO}$, and the use of autoradiography to identify colonies with desired phenotypes amidst a potential background of other colonies. Since this method spatially separates otherwise competing populations, simultaneous recovery of organisms with different growth rates and nutritional requirements is possible, and large numbers of bacteria can be screened rapidly at one time. The defined mineral media (Appendix A) used in this study supports growth of carboxydotrophic bacteria and other microorganisms able to metabolize $\mathrm{CO}$, and selects against diverse heterotrophs that cannot survive elevated [CO] or cannot utilize $\mathrm{CO}$ for growth. Cell-specific rates of CO oxidation from ${ }^{14} \mathrm{C}$-CO oxidation studies of selected pure isolates are used to estimate the CO oxidation that is attributable to these organisms in situ. We attempt to show that these organisms' apparent abundance and metabolic activity is sufficient to account for a 
significant fraction of $\mathrm{CO}$ bio-oxidation in natural samples that is measured independently by time-series gas analysis and ${ }^{14} \mathrm{C}-\mathrm{CO}$ oxidation techniques.

CO production is typically greater near coastal waters than open-ocean sites, probably due to greater colored dissolved organic matter (CDOM) content (Jones \& Amador, 1993). The mid-day CO concentration (12 $\mathrm{n} M)$ at our coastal sampling location (figure 2.8), for example, is $3-5$ fold higher than the maximum measured in the Sargasso Sea (Jones, 1991; Xie et al., 2001). CO oxidation rates in coastal waters $(0.01-$ $0.11 \mathrm{hr}^{-1}$, this study, fig. 2.12) can be up to an order of magnitude greater than those measured in oligotrophic environments, suggesting an active $\mathrm{CO}$ oxidizing microbial community near-shore. The coastal waters are therefore a promising source of $\mathrm{CO}$ metabolizing microbial isolates. Our field sampling procedures include i) sampling water for the screening and isolation program in sterile borosilicate glass bottles, ii) sampling water in sterile glass syringes for analysis of $\mathrm{CO}$ oxidation rates (reduced gas analyzer and ${ }^{14} \mathrm{C}-\mathrm{CO} \rightarrow{ }^{14} \mathrm{C}-\mathrm{CO}_{2}$ methods), and iii) maintaining in situ temperature and salinity for incubation temperatures and calculation of the Bunsen solubility coefficient $(\beta)$ for $\mathrm{CO}$, necessary for determining the dissolved [CO] when $\mathrm{CO}$ is provided in the gas phase at a given mixing ratio.

The phylogenetic relationships of $\mathrm{CO}$ oxidizing isolates were determined based on their 16S-rDNA sequences. Strain-specific 16S-rDNA sequence information allows the identification of these organisms and the examination of their phylogenic relationships within the framework of published sequences. Here, we focus on the $16 \mathrm{~S}$ rRNA-based phylogeny of strains resulting from our cultivation program, and an early 
estimation as to whether the apparent abundance and activity of recovered strains are sufficient to support the $\mathrm{CO}$ oxidation that is measured by independent means in water that is sampled at the same time and location as the microbial assemblage. The ability to both identify strains and determine phylogenetic relationships that $16 \mathrm{~S}-\mathrm{rRNA}$ sequence information provides, combined with cell-specific $\mathrm{CO}$-oxidation rate information from physiological studies of those organisms in pure cultures, are two component data necessary to determine the relative contributions of $\mathrm{CO}$-metabolizing community members to the total CO-oxidation that is observed in natural waters.

\section{METHODS/MATERIALS}

\section{Sampling:}

Seawater samples for isolation of microbes and for CO-oxidation measurements were collected from the coastal location described in Chapter 2 (Vineyard Sound, MA) and by the sampling methods described therein.

\section{Isolation program.}

Screening of microbial colonies grown from natural seawater by macroautoradiography at once allows detection and isolation of cells utilizing ${ }^{14} \mathrm{C}$-CO-born carbon, as well as initial estimates of their abundance. Using the method of Dunbar et al. (1996) modified for our experiment, sampled microbial assemblages were serially diluted (triplicate per dilution level) into defined, sterilized oligotrophic artificial seawater media (see appendix A) and deposited on autoclaved 47-mm diameter, $0.22 \mu \mathrm{m}$ polycarbonate 
membrane filters that have been previously washed with methanol and distilled water to remove potential organic contaminants, and autoclaved. The filter was placed atop a washed and combusted glass-fiber filter saturated with liquid oligotrophic growth medium in a sterile polystyrene petri plate. The growth requirements of known carboxydotrophic bacteria are simple; Meyer and Schlegel (1983) recommend an improved trace element solution, which includes molybdenum and selenium for the formation of fully active $\mathrm{CODH}$ in carboxydotrophic bacteria. To support the growth of lithoautotrophic organisms that may incorporate CO-born carbon only when $\mathrm{NH}_{4}{ }^{+}$is available as an energy source, $\mathrm{NH}_{4}{ }^{+}$is supplied in separate plate sets. Because of the potential for heterotrophic growth on trace vitamin additives to the medium $\left(\mathrm{B}_{12}\right.$, niacin, and biotin) these vitamins are omitted in duplicate plate sets (preliminary experiments suggest possible need for vitamins at trace levels for some $\mathrm{CO}$ metabolizers). In the event that there exists a group of organisms that co-oxidize $\mathrm{CO}$ while obtaining their energy requirements from unknown heterotrophic substrates present in natural coastal seawater, a set of membrane incubations were run using natural $0.22 \mu \mathrm{m}$ filtered coastal seawater from the sampling site as media to supply environmental DOC to this group.

The membranes are incubated in a ${ }^{14} \mathrm{C}-\mathrm{CO}$-containing atmosphere for sufficient time (2-3 weeks) to allow for the induction of enzymes necessary for $\mathrm{CO}$ metabolism by the presence of $\mathrm{CO}$ and visible colony formation on the membranes. The atmosphere is maintained by injecting the ${ }^{14} \mathrm{C}-\mathrm{CO}$ and air mixture into an evacuated dessicator containing the samples. A slight negative pressure maintained within the chamber provided a tight seal. Providing an atmosphere enriched with $\mathrm{CO}$ and removing 
dissolved organic substances specifies the conditions for the growth of $\mathrm{CO}$ metabolizing bacteria that are able to utilize $\mathrm{CO}$ as their sole source of carbon and energy, while selecting against $\mathrm{CO}$-sensitive and other heterotrophic organisms. We provided growth conditions for the cultivation of organisms capable of $\mathrm{CO}$ metabolism under elevated environmental levels of $\mathrm{CO}(50 \mathrm{ppmv} \mathrm{CO}: \mathrm{air}=\sim 42 n M \mathrm{CO}(\mathrm{aq}))$.

A series of four sample concentration levels $(0.1,1.0,10.0,100.0 \mathrm{ml}$ per membrane) were included in the first incubation. For subsequent sample incubations, we selected the concentration level (undiluted, $1.0 \mathrm{ml}$ per membrane) that resulted in membrane colony densities that were sufficient for statistical analysis and appropriate to macro-autoradiography and replicate plating. Further refinement of the experimental treatment regime included a reduction of different $[\mathrm{CO}]$ atmospheres from three concentration levels to only one, dispensing with the high $\mathrm{CO}$ atmospheres after one cultivation round when no visible colonies resulted.

\section{Macro-autoradiographic screening protocol.}

After the master filters had incubated and supported visible colonies, replicas of the masters were made. First, the master was removed from its media and placed colony-side-up on a sterile square of Whatman \#1 paper (figure 3.1). Then, a sterile, wet $0.22 \mu \mathrm{m}$ nucleopore filter was placed on top of the master filter, covered with another square of Whatman filter paper, and evenly compressed with a surface-sterilized Plexiglas weight. Reference notches were cut on the stacked master and duplicate filters with a sterile razorblade to record the orientation of the two filters relative to one-another. 
Following duplication, the filters were carefully separated and each was placed cell-side-up on fresh mineral media and re-grown for several days in $\mathrm{a}^{14} \mathrm{C}$-CO-containing atmosphere. Following the second growth period, the duplicate filters were removed from the supporting media and allowed to air-dry. When dry, the duplicate filters were spotted with $\mathrm{NaH}^{14} \mathrm{C}-\mathrm{CO}_{3}$ tracer with a sterile toothpick at the location of the registration notches. The dry duplicate filters were attached to 8 " $\mathrm{x} 10$ " sheets of absorbent BenchKote paper with small pieces of transparent tape at the edges of the filter, sample-side up. In a photographic darkroom, an autoradiography cassette was loaded in the following order: filter page within a Kodak BioMax LE (low energy) intensifying screen, followed by Kodak XAR paper placed on top of the intensifying screen. The cassette assembly was closed and allowed to expose for $5-7$ days at $-80^{\circ} \mathrm{C}$. The film was developed under darkroom conditions following standard procedure for X-ray film (3 min. developer, 30 sec. rinse, $3 \mathrm{~min}$. fixer, $20 \mathrm{~min}$. wash). The ${ }^{14} \mathrm{C}$-label-spotted orientation notches visible on the autoradiograph (figure 3.3) were used to orient the master filters with the developed autoradiographic images. When viewed on a light table, the exposed autoradiographic signals reveal the location of ${ }^{14} \mathrm{C}$-containing colonies on the overlaid master filter. The duplicate filter sheets were wrapped with cellophane and archived.

Exposed spots on the autoradiographic plates result from colonies that have incorporated carbon from ${ }^{14} \mathrm{C}-\mathrm{CO}$, and correspond to live colonies on the master filter. Selected colonies from the master filter were test-streaked on solid media (marine agar 2216) for purification, in anticipation that $\mathrm{CO}$ oxidizers are also heterotrophs. In this initial streaking, several colonies were obtained from each autoradiographically positive 
colony sampled from the master membrane. Each of these were further isolated into pure cultures. Because at this point it was unknown which isolate conferred the positive signal in the initial autoradiography, each of these monocultures underwent another round of ${ }^{14} \mathrm{C}-\mathrm{CO}$ incubation and autoradiography (Appendix B) to determine which pure-culture isolates incorporate labeled $\mathrm{CO}$ and conferred the original autoradiographic signal. Each of these isolates was given an alphanumeric designation and was noted for the media from which it was isolated in the initial incubation. Once positive CO-metabolizing isolates were determined, these were cross- tested for growth on alternate nitrogen-source media in a subsequent ${ }^{14} \mathrm{C}-\mathrm{CO}$ incubation. This growth and screening protocol allowed the isolation of strains of organisms that incorporate label from $\mathrm{CO}$ when growing on carbon-rich media, and others that may incorporate label from $\mathrm{CO}$ when growing under oligotrophic conditions with either ammonium or nitrate as nitrogen source.

\section{Specific CO oxidation rates of environmental isolates}

Cell-specific CO-oxidation activity was determined with suspensions of selected strains at cell-densities measured by acridine orange direct counting (AODC) and incubated with ${ }^{14} \mathrm{C}-\mathrm{CO}$. Purified isolates were transferred from discrete colonies on 2216 agar and grown 1-2 days in $15 \mathrm{ml} 2216$ marine broth to a light turbidity $\left(\sim 10^{7}\right.$ cells $\left./ \mathrm{ml}\right)$. Liquid cultures were centrifuged for $10 \mathrm{~min}$. at 10,000 RPM, and the broth was decanted leaving the pellet intact. The pellet was resuspended in $15 \mathrm{ml} 0.22 \mu \mathrm{m}$ filtered seawater to rinse, and centrifuged for $10 \mathrm{~min}$. The rinse was repeated twice, and the pellet was 
Figure 3.1: Autoradiographic procedure for isolating CO-metabolizing organisms from natural samples. Cells are deposited onto filters and incubated in a ${ }^{14} \mathrm{C}-\mathrm{CO}$ atmosphere. After colony formation, duplicate filters are created and re-incubated with ${ }^{14} \mathrm{C}-\mathrm{CO}$. ${ }^{14} \mathrm{C}$-containing colonies expose XAR film, and colonies are harvested from the master filters when oriented with the film. 


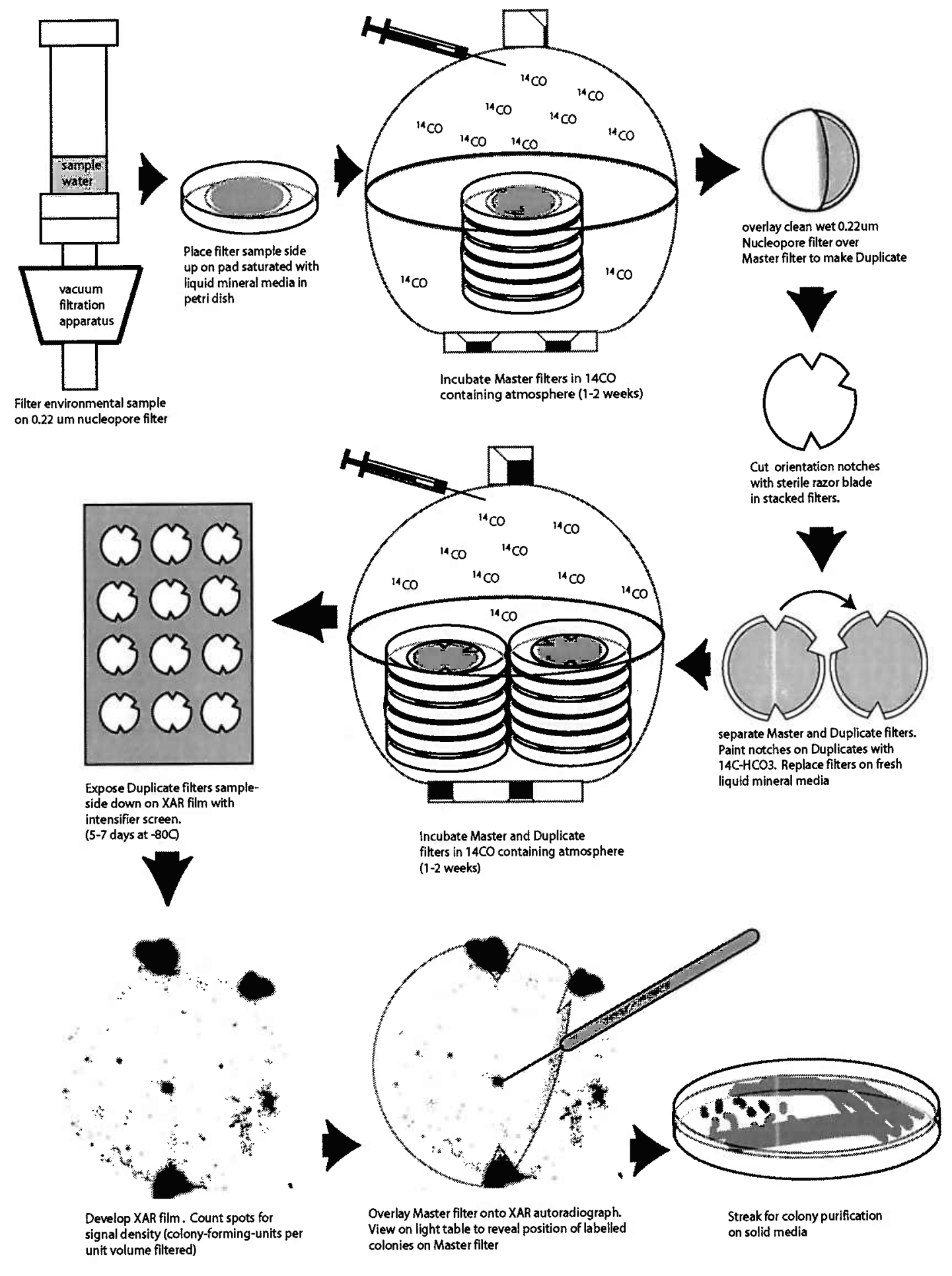


finally re-suspended in $150 \mathrm{ml}$ of aged and $0.22 \mu \mathrm{m}$ filtered seawater $\left(\sim 10^{6} \mathrm{cell} \mathrm{ml}^{-1}\right.$ final density). CO was injected into the headspace of each sealed bottle sufficient to maintain a dissolved [CO] of approximately $40 \mathrm{nM}$ in order to induce $\mathrm{CO}$ metabolic enzymes in each isolate. Cell density was determined after 2 days of $\mathrm{CO}$ induction and prior to the CO oxidation assay by direct microscopy (AODC). To measure the in situ rates of CO oxidation, to determine cell-specific rates of $\mathrm{CO}$ oxidation for selected isolates, and as a screening method to indicate ${ }^{14} \mathrm{C}$-CO-oxidizing strains, we utilized the ${ }^{14} \mathrm{C}-\mathrm{CO}$ oxidation method (Bartholomew \& Alexander, 1979; Griffiths et al. 1982) described previously (Chapter 2). CO oxidation activity was calculated on a per-cell basis for each isolate (nmol CO oxidized cell ${ }^{-1} \mathrm{hr}^{-1}$ ).

\section{Molecular analysis.}

CO metabolizing microorganisms isolated as pure cultures were picked and the $16 \mathrm{~S}$ rRNA gene was amplified by PCR by a variety of treatments. In general, the universal bacterial primers $8 \mathrm{f}$ and 1492r were used in PCR amplification, resulting in a 1484 base-pair segment. The correct size of the product was confirmed by electrophoresis in $2 \%$ agarose gel run at 100 volts for $25-30$ minutes, with either a Low DNA MASS Ladder or Amplisize Molecular Ruler 50-2,000 bp ladder. The gel was stained in ethidium bromide for 15-20 minutes, and viewed under UV and photographed using a ChemiImager low light imaging system (Alpha Innotech Corporation).

Most strains provided amplifiable template after picking solitary colonies from solid 2216 marine agar with a sterile toothpick and placed into $5 \mu$ Lyse-N-Go PCR 
reagent (Pierce), and a $2 \mathrm{~min}$. heating period at $95^{\circ} \mathrm{C}$ prior to the addition of primers, nucleotides, and Taq polymerase. Other strains required a more stringent lysing procedure: $10 \mu \mathrm{l}$ of liquid broth culture were centrifuged at 13,000 rpm for $4 \mathrm{~min}$., and the supernatant removed. The pellet was washed once with MilliQ ultrafiltered water and resuspended into $5 \mu$ Lyse-N-Go. The combination of osmotic shock and the Lyse-N-Go treatment of these more recalcitrant strains resulted in amplifiable template DNA. With one isolate (JT-10), rapid freeze-fracturing of cells in liquid nitrogen followed by treatment with $\mathrm{CTAB}$ and phenol/chloroform/isoamyl extraction (A. Teske, personal communication) was necessary to obtain a PCR product. In all amplification runs, a negative control containing no template and a positive control with $0.5 \mu 1 \mathrm{E}$. coli liquid culture were run to control for contamination and reagent quality. Amplified template was frozen or kept on ice. Template products were cleaned using the QIAquick PCR purification kit (Qiagen) protocol designed to purify fragments from $100 \mathrm{bp}$ to $10 \mathrm{~kb}$ from primers, nucleotides, polymerases, and salts using spin columns in a microcentrifuge. Cleaned DNA was eluted with $50 \mu \mathrm{l} \mathrm{H}_{2} \mathrm{O}$.

In preparation for sequencing, the amount of PCR product needed was estimated by visual comparison of product band intensity $(4 \mu \mathrm{l})$ to a low DNA mass ladder standard. Product volume required for sequencing reactions were adjusted to yield approximately $50 \mathrm{ng}$ of DNA per reaction. The sequencing reactions were performed with the Big Dye Terminator (BDT) sequencing kit (Applied Biosystems) using 3 different bacterial primers in separate reactions. For each reaction, $1 \mu \mathrm{l}$ BDT, $1 \mu \mathrm{l}$ primer (8f, 1492r, or 519f), $50 \mathrm{ng}$ DNA, and $\mathrm{H}_{2} 0$ were combined to a total volume of $6 \mu \mathrm{l} .32$ 
isolates and 3 separate primer reactions filled a 96-well microplate. The thermocycler was set for 25 cycles: $96^{\circ} \mathrm{C}$ for $10 \mathrm{sec} ., 50^{\circ} \mathrm{C}$ for $5 \mathrm{sec}$., and $60^{\circ} \mathrm{C}$ for $4 \mathrm{~min}$.

The product was cleaned by isopropanol precipitation. The 96-well plate was removed from the thermocycler and spun briefly. Thirty $\mu 175 \%$ IPA was added to each well, the plate was sealed well, and inverted to mix thoroughly. The plate was allowed to rest at room temperature for $15 \mathrm{~min}$. The plate was centrifuged at 4170 RPM for $30 \mathrm{~min}$. The sealant tape was removed and the plate was inverted carefully onto a paper towel to absorb IPA, taking care not to disturb the pellet. The pellet was washed by adding $50 \mu 1$ $70 \%$ IPA. The plate was resealed and spun at $3450 \mathrm{RPM}$ for $10 \mathrm{~min}$. The tape was removed and the plate inverted again to remove IPA. The inverted plate was centrifuged at 1950 RPM for $1 \mathrm{~min}$. to bump down residual IPA. The plate was allowed to air dry for $20 \mathrm{~min}$. Each pellet was resuspended in $7 \mu \mathrm{l} \mathrm{Hi-Di}$ formamide. The plate was resealed with aluminum tape and stored at $-20^{\circ} \mathrm{C}$ before sequencing with a ABI PRISM 3700 DNA Analyzer/Sequencer located at the Josephine Bay Paul Center, MBL. Sequences from 30 isolates were edited and assembled using Sequencher 4.0.5 (Gene Codes Corporation, Ann Arbor, MI). Sequencing resulted in double-stranded sequence fragments that were checked against the NCBI database using the BLAST search program (Altschul et al., 1990) for initial identification. 


\section{RESULTS and DISCUSSION}

Positive signals on XAR film were counted after two weeks of incubating in a ${ }^{14} \mathrm{C}-\mathrm{CO}$ containing atmosphere at environmentally relevant levels of $\mathrm{CO}(40-50 \mathrm{ppm})$ (figure 3.4). Differential media plates were counted separately, and counts of colonies grown separately on nitrate and ammonium were combined to yield the cell density (cells $\mathrm{ml}^{-1}$ ) that had incorporated ${ }^{14} \mathrm{C}$ from $\mathrm{CO}$. The presence or absence of vitamins in the growth media made no significant difference in colony density counts (figure 3.4). Therefore, vitamin condition ("with vitamins" and "without vitamins") values were averaged. Total plate counts were thus $395 \pm 55$ cells ml$^{-1}$ in Vineyard Sound water (mean $\pm \mathrm{SEM}, \mathrm{n}=6$ ). Acridine orange direct counts $(\mathrm{AODC})$ of Vineyard Sound water at

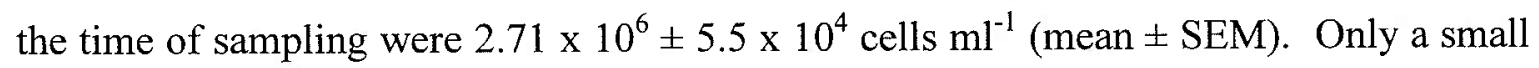
fraction of cells present in the sample grew to visually distinct colonies under the experimental growth conditions $(0.01 \%$ of total). Colonies that were able to grow under these conditions necessarily had respiratory adaptations that allowed them to grow in elevated [CO] conditions. It is possible that other cells having $\mathrm{CO}$ tolerance did not form colonies on the "solid" substrate (the membrane); therefore, our autoradiographic plate counts may underestimate $\mathrm{CO}$ metabolizing cells in coastal seawater due to this limitation.

To test the feasibility of this direct isolation approach to determine whether our acquired CO-metabolizing isolates are significant contributors to measured $\mathrm{CO}$ oxidation rate, we searched the primary literature sources to find specific activities of known COoxidizing strains. A range of published activities were selected for comparison with our 
calculated CO-oxidation activities based on autoradiographic colony count. In an initial estimate of the proportion of total $\mathrm{CO}$ oxidation that can be attributed to organisms that produced colonies in a CO-containing atmosphere, our calculation used literature values for uptake efficiency (4\% (Zavarzin \& Nozhevnikova, 1977)), cellular carbon content (20 fg C cell $^{-1}$ (Cho \& Azam, 1990)), and protein:dry weight conversion factor (1.4 mg protein per $3.1 \mathrm{mg}$ dry weight (Cypionka et al., 1980)). The amount of CO oxidized in a $25 \mathrm{ml}$ liquid culture of these characterized strains at cell density of $1 \times 10^{6}$ cells ml$^{-1}$ can be compared with $\mathrm{CO}$ oxidation rates we have observed in natural seawater samples (Table 3.2). Measurements of the $\mathrm{CO}$ oxidation rate of the coastal in situ assemblage are from 1-10 pmol $\mathrm{CO} \mathrm{hr}^{-1} 10^{-6}$ cells (total $\mathrm{CO}$ oxidation rate / total cell density by direct count), which is as active as the $\mathrm{CO}$ oxidation rate of one known carboxydotrophic organism, Pseudomonas carboxydohydrogena (Cypionka et al., 1980). If 400 cells ml $^{-1}$ are actively metabolizing $\mathrm{CO}$ in the environmental samples, then the rate of $\mathrm{CO}$ oxidation by these cells increases to $2.5-25 \mathrm{nmol} \mathrm{CO} \mathrm{hr}{ }^{-1}$ per $10^{6}$ cells, which is in the same order of magnitude as the most active described carboxydotrophic organisms.

Several strains carried over when colonies corresponding with the XAR film signal were picked from master filters and streaked on solid media for purification. To verify $\mathrm{CO}$ oxidizing activity for all membrane isolates, we reanalyzed purified cultures of each isolate by macroautoradiography, following the same method as the first round with few modifications concerning filter size and orientation. In autoradiographic exposures of purified isolates on different growth media (broth, low organic - $\mathrm{NO}_{3}$, and low organic $\mathrm{NH}_{4}$ ), we expected to see most carbon assimilation from labeled $\mathrm{CO}$ in organisms that are 


\begin{tabular}{|c|c|c|c|}
\hline strain & activity & $\frac{\text { CO oxidation rate }}{\text { (calculated) }}$ & reference \\
\hline $\begin{array}{l}\text { Pseudomonas } \\
\text { carboxydoflava }\end{array}$ & $2300 \mu \mathrm{l} \mathrm{CO} \mathrm{hr}{ }^{-1}$ mg protein $^{-1}$ & $18.12 \mathrm{nmol} \mathrm{hr}^{-1} / 10^{6}$ cells & $\begin{array}{l}\text { Cypionka et al. } \\
1980\end{array}$ \\
\hline $\begin{array}{l}\text { Comamonas } \\
\text { compransoris }\end{array}$ & $2000 \mu \mathrm{l} \mathrm{CO} \mathrm{hr}{ }^{-1} \mathrm{mg}$ protein $^{-1}$ & $15.8 \mathrm{nmol} \mathrm{hr}^{-1} / 10^{6}$ cells & $\begin{array}{l}\text { Cypionka et al. } \\
1980\end{array}$ \\
\hline $\begin{array}{l}\text { Pseudomonas } \\
\text { carboxydohydrogena }\end{array}$ & $100 \mu 1 \mathrm{CO} \mathrm{hr}^{-1} \mathrm{mg}$ protein $^{-1}$ & $0.788 \mathrm{pmol} \mathrm{hr}^{-1} / 10^{6}$ cells & $\begin{array}{l}\text { Cypionka et al. } \\
1980\end{array}$ \\
\hline $\begin{array}{l}\text { Vineyard Sound } \\
\text { assemblage }\end{array}$ & & $\begin{array}{c}0.5-10 \mathrm{pmol} \mathrm{hr}^{-1} / 10^{6} \text { cells } \\
\text { (measured) }\end{array}$ & This study \\
\hline
\end{tabular}

Table 3.2: Literature values for specific $\mathrm{CO}$ oxidation rates of pure cultures of carboxydobacteria and of natural assemblages. 

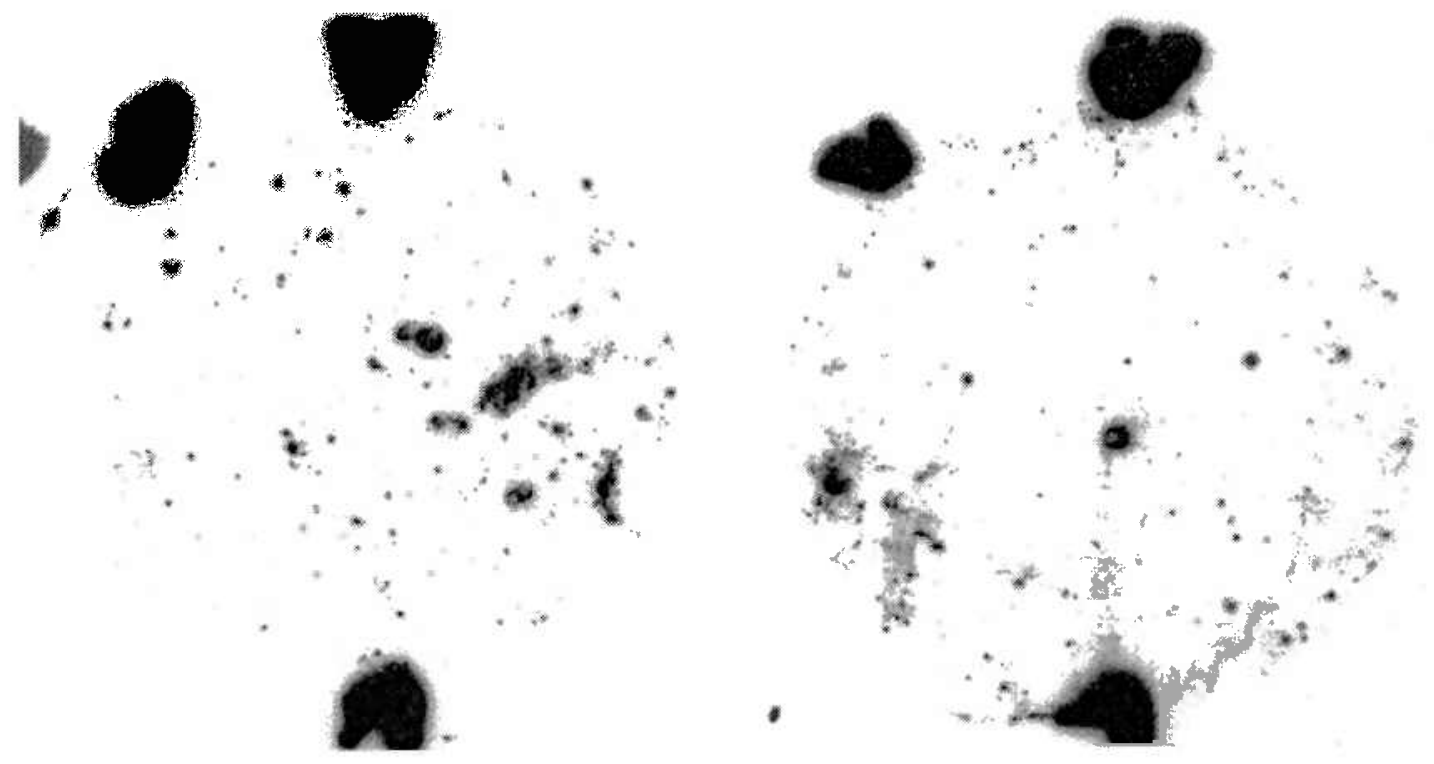

Figure 3.3: Representative autoradiographs of duplicate-filter holding colonies that incorporated labeled carbon from ${ }^{14} \mathrm{C}-\mathrm{CO}$. Volume filtered: $1 \mathrm{ml}$, Vineyard Sound. Large painted notches are registration marks to allow alignment of master filters to film.

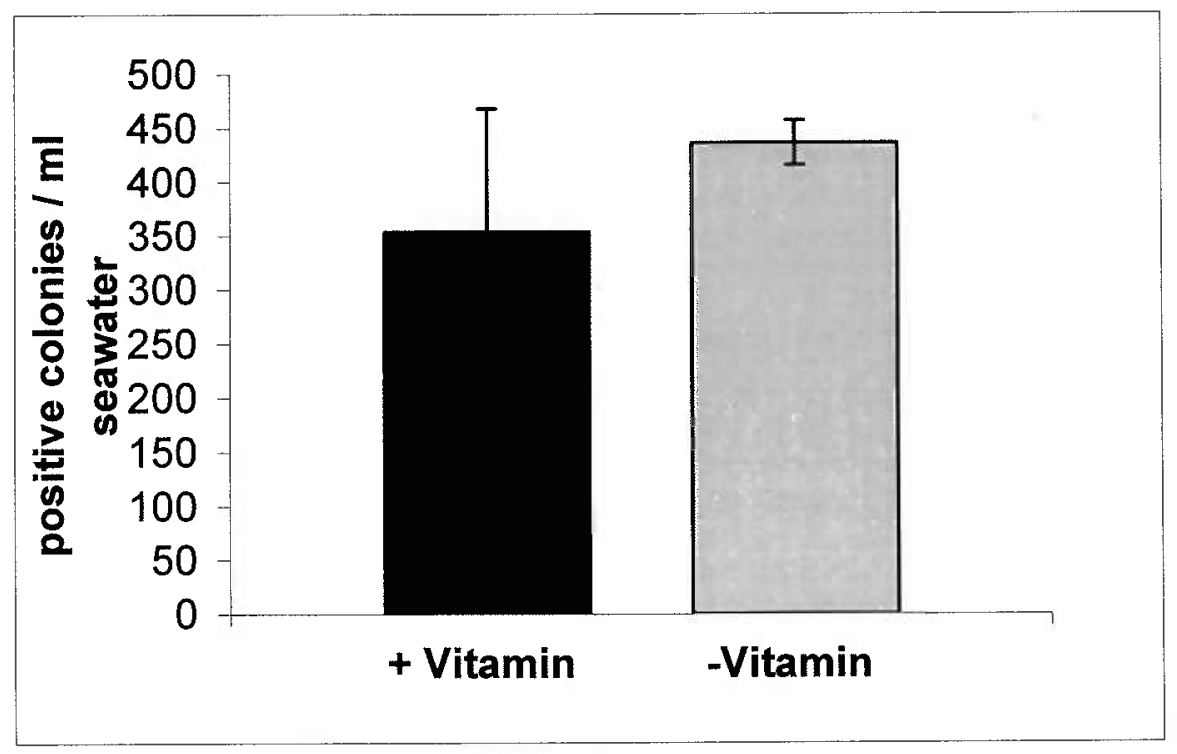

Figure 3.4: Uptake signals were counted separately on differential media. Nitrogen source values were combined, and ultimately the vitamin source values were averaged to yield $395 \pm 55$ positive colony-forming units per ml seawater. 


\begin{tabular}{|c|c|c|c|}
\hline ISOLATE & BROTH & NO3 & NH4 \\
\hline JT-01 & + & ++ & $\overline{++}$ \\
\hline JT-02 & + & + & + \\
\hline JT-03 & + & & \\
\hline JT-04 & $\sim$ & + & + \\
\hline JT-05 & + & $\sim$ & + \\
\hline JT-06a & ++ & & \\
\hline JT-06b & + & & \\
\hline JT-07 & $\sim$ & & \\
\hline JT-08 & + & & \\
\hline JT-09 & ++ & + & + \\
\hline JT-10 & + & & \\
\hline JT-11 & + & & $\sim$ \\
\hline JT-12 & + & $\sim$ & $\sim$ \\
\hline $\mathrm{JT}-13 \mathrm{a}$ & + & + & + \\
\hline $\mathrm{JT}-13 \mathrm{~b}$ & ++ & & \\
\hline JT-14 & $\sim$ & + & $\sim$ \\
\hline JT-15 & + & + & \\
\hline JT-16 & ++ & + & \\
\hline JT-17 & + & & \\
\hline JT-18 & + & & \\
\hline JT-19 & ++ & $\sim$ & $\sim$ \\
\hline JT-20 & + & & \\
\hline JT-21 & $\sim$ & & \\
\hline JT-22 & + & & \\
\hline JT-23 & + & & + \\
\hline JT-24 & + & & + \\
\hline $\mathrm{JT}-25$ & ++ & & \\
\hline JT-26 & ++ & $\sim$ & \\
\hline JT-27 & ++ & $\sim$ & $\sim$ \\
\hline JT-28 & ++ & $\sim$ & $\sim$ \\
\hline JT-29 & ++ & $\sim$ & $\sim$ \\
\hline JT-30 & + & & \\
\hline E. coli & & & \\
\hline
\end{tabular}

Table 3.5: results of autoradiography of purified isolates incubated in a ${ }^{14} \mathrm{C}-\mathrm{CO}$-containing atmosphere (50 ppm)and different growth conditions (Appendix 2 for plates) 
able to utilize $\mathrm{CO}$ in media that was poor in organic carbon, that is, heterotrophic organisms that induce $\mathrm{CO}$-metabolic genes in response to an oligotrophic and $\mathrm{CO}$ containing environment to supplement their carbon source. The surprising result of this second round of autoradiography with pure isolates was that every isolate strongly incorporated label from $\mathrm{CO}$ while growing under heterotrophic conditions (table 3.5). We searched the literature for precedents and possible explanations for this result.

In ${ }^{14} \mathrm{C}-\mathrm{CO}_{2}$ uptake experiments on the metabolically versatile heterotroph, Sandaracinobacter sibiricus [previously Erythrobacter sibiricum (renamed in Yurkov et al., 1997)], by Yurkov and Beatty, 1998, a low level of $\mathrm{CO}_{2}$ fixation was attributed to the enzyme phosphoenolpyruvate carboxylase. When intermediates of the citric acid cycle are removed during rapid biosynthesis, they are replaced by the anaplerotic fixation of $\mathrm{CO}_{2}$ by this enzyme. If these organisms (our isolates) are oxidizing $\mathrm{CO}$ to $\mathrm{CO}_{2}$ with $\mathrm{CO}$ induced enzymes, then labeled $\mathrm{CO}_{2}$ is readily available to fill these anaplerotic reactions, and therefore the cells produce a strong autoradiographic signal when grown in heterotrophic conditions.

Profitable oxidation of carbon monoxide during heterotrophic growth has also been reported in Pseudomonas carboxydoflava, a bacterium characterized as carboxydotrophic when growing autotrophically in mineral medium in the presence of CO (Kiessling and Meyer, 1982). However, the authors report that virtually none of the carbon from $\mathrm{CO}$ was incorporated while growing in heterotrophic media; the oxidation of CO provided the organism with additional energy and stimulated growth rate and greater uptake of organic carbon compared to cultures grown in the absence of CO. Since $P$. 
carboxydoflava profited from CO oxidation, 'cooxidation' is not suitable to describe this process. The term "mixotrophic" seems to be applicable to describe the profitable oxidation of $\mathrm{CO}$ by heterotrophically growing cells of $P$ carboxydoflava.

${ }^{14} \mathrm{C}-\mathrm{CO}$ uptake experiments were conducted with pure isolates JT-01 and JT-08, the two most active CO-oxidizers resulting from our direct isolation program. The isolates were incubated in a ${ }^{14} \mathrm{C}$-CO-containing atmosphere in liquid media for six days, with subsamples withdrawn periodically to determine the activity levels of ${ }^{14} \mathrm{C}$ that had been incorporated into cell matter and ${ }^{14} \mathrm{C}-\mathrm{CO}$ oxidized into acid-volatile product. Two different liquid media were aged $0.22 \mu \mathrm{m}$-filtered seawater (collected $39^{\circ} 32^{\prime} \mathrm{N}, 68^{\circ} \mathrm{W}$, 100m, E. Horgan) and 2216 marine broth (Difco), to compare the cells' label-uptake characteristics while growing under heterotrophic conditions versus carbon-limited conditions. Both CO-oxidizing isolates showed strong CO-oxidation activity when incubated either in seawater or in 2216 marine broth. When grown in seawater, ${ }^{14} \mathrm{C}$ incorporation into particulate matter was undetectable over the entire six-day incubation period (figure 3.6, figure 3.7). When incubated in broth media, $\mathrm{CO}$-oxidation reached a peak activity within 2 days (JT-01) or 3 days (JT-08) and label incorporation in particulate matter began to increase. When the relative fraction of total $\mathrm{CO}$ metabolized captured on filters was compared between the two isolates and their two different growth media, carbon from $\mathrm{CO}$ only become incorporated into particulate matter when the cells were in heterotrophic media. Cells grown in low-carbon media do not exhibit ${ }^{14} \mathrm{C}$ accumulation from $\mathrm{CO}$ (figure 3.8), but oxidize $\mathrm{CO}$ rapidly. This is in 

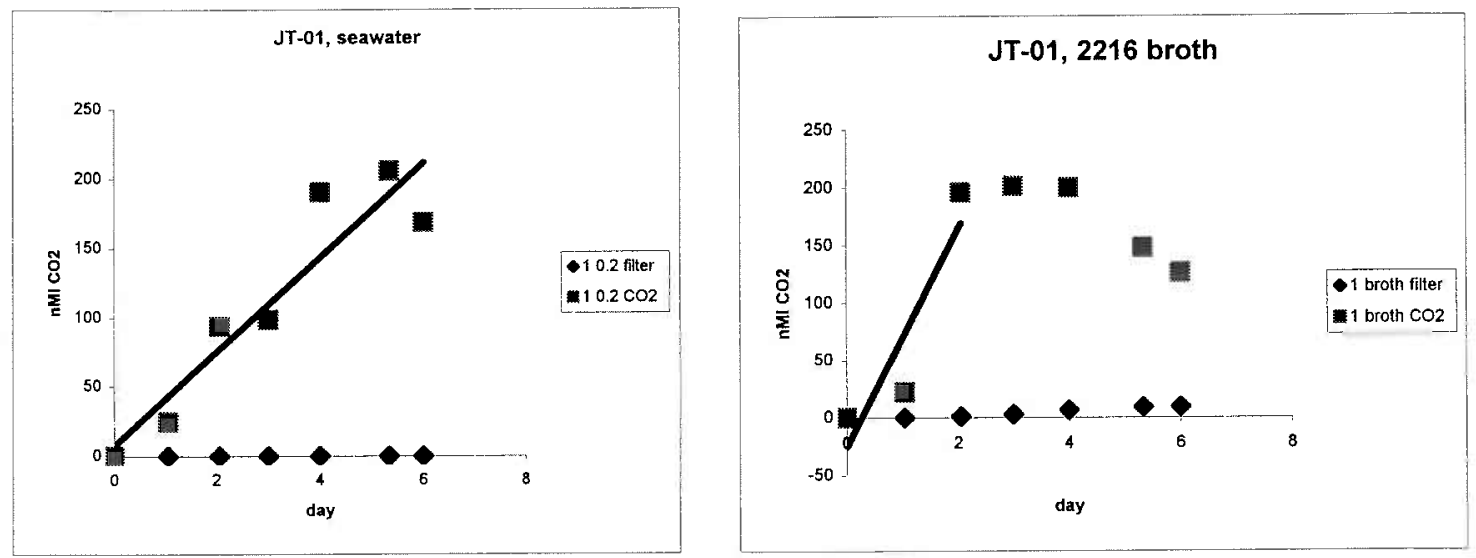

Figure 3.6: $\mathrm{CO}$ incorporated by isolate JT-01 over time while growing in carbon-limited media (left) or heterotrophic conditions (right). Filter activity $(\bullet)$ and ${ }^{14} \mathrm{C}_{-}-\mathrm{CO}_{2}(\boldsymbol{\square})$ were measured separately at each time point.
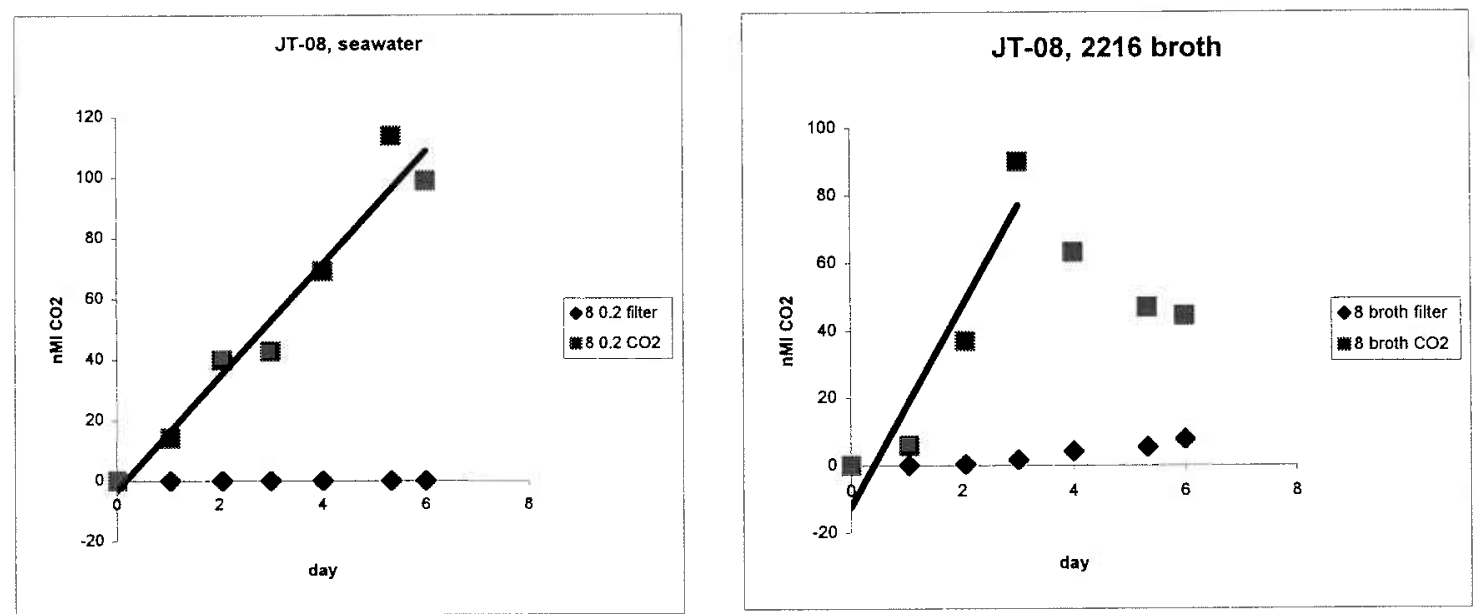

Figure 3.7: $\mathrm{CO}$ incorporated by isolate JT-08 over time while growing in carbon-limited media (left) or heterotrophic conditions (right). Filter activity $(\bullet)$ and ${ }^{14} \mathrm{C}-\mathrm{CO}_{2}(\boldsymbol{\square})$ were measured separately at each time point. 


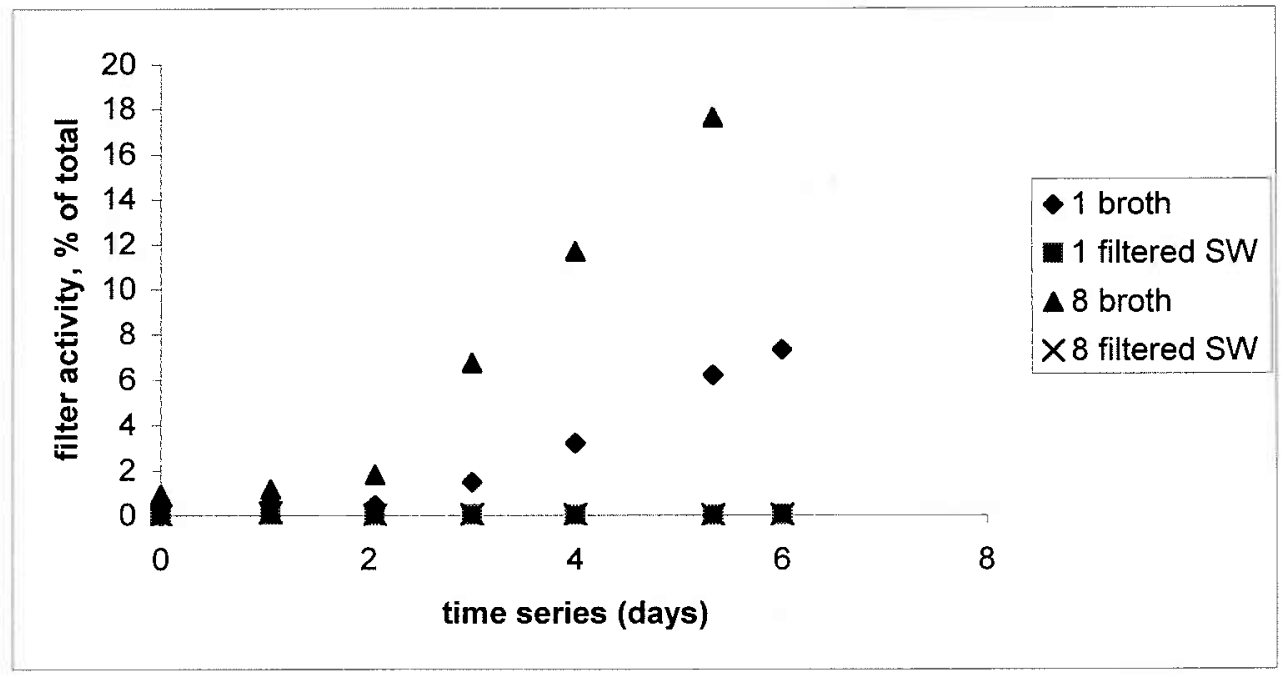

Figure 3.8: Fraction of total CO metabolism captured on filters for both JT-01 and JT-08, growing under two carbon conditions. JT-01 in filtered seawater ( $\boldsymbol{\square})$, JT-01 in 2216 marine broth (•), JT-08 in filtered seawater $(\times)$, and JT-08 in 2216 marine broth $(\mathbf{A})$. 
agreement with the autoradiographic observations that isolates exhibit strong uptake of label when in broth as opposed to mineral media, and supports the hypothesis that carbon is entering the citric acid cycle as $\mathrm{CO}_{2}$ in anaplerotic reactions to replace cycle intermediates that are removed during rapid biosynthesis.

Since the in situ microbial community did not incorporate label from $\mathrm{CO}$ when incubated in native seawater over the course of more than two days (figure 2.7), and two seawater isolates known to oxidize $\mathrm{CO}$ rapidly did not incorporate label from $\mathrm{CO}$ when grown in a carbon-poor seawater medium for up to six days (figure 3.8 ), we conclude that nearly all of the environmental $\mathrm{CO}$ that is acted upon by the microbial assemblage is oxidized to $\mathrm{CO}_{2}$ and remains in solution as bicarbonate, and is not specifically incorporated into organic biomass other than indirectly by autotrophic organisms. Labeled bicarbonate need not be retained within the cells to confer a positive signal to XAR film, rather, it may be extracellular but still within the colony on the membrane.

To estimate the potential energetic benefit to mixotrophic cells oxidizing $\mathrm{CO}$ while utilizing environmental DOC, we searched primary literature sources for environmental concentrations of two bioavailable organic substrates, acetate and glucose, and calculated the energy advantage that mixotrophic organisms deriving energy from oxidation of $\mathrm{CO}$ at environmental levels (12 $\mathrm{n} M$, this study) would have over organisms that lack this metabolic feature (Table 3.9). Free energy for each reaction was calculated as $\Delta \mathrm{G}^{0}=\Sigma \Delta \mathrm{G}_{\mathrm{f}}^{0}$ (products) $-\Sigma \Delta \mathrm{G}_{\mathrm{f}}^{0}$ (reactants). The calculated standard free energy yield was scaled down to the environmental concentration of the substrate. Energetic advantage was then calculated by dividing the free energy yield of CO oxidation at 12 


\begin{tabular}{|l|l|l|l|}
\hline $\begin{array}{l}\text { Organic } \\
\text { substrate }\end{array}$ & $\begin{array}{l}\text { Environmental } \\
\text { concentration } \\
(\mathrm{n} M)\end{array}$ & $\Delta \mathrm{G}(\mathrm{kJ})$ & $\begin{array}{l}\text { Energy } \\
\text { advantage with } \\
\text { CO oxidation }\end{array}$ \\
\hline Acetate & $20($ Wu et al., 1994) & $3.26 \times 10^{-5}$ & $19 \%$ \\
\hline Glucose & $8($ Lee, 1992) & $2.3 \times 10^{-5}$ & $27 \%$ \\
\hline
\end{tabular}

Table 3.9: Energetic advantage of mixotrophs utilizing trace DOM as carbon sources and CO-oxidation as a supplemental energy source. Energy advantage is calculated by dividing the energy yield of $\mathrm{CO}$ oxidation at $12 \mathrm{nM}[\mathrm{CO}]$ by the energy yield of individual DOM species at their environmental concentrations (coastal). 


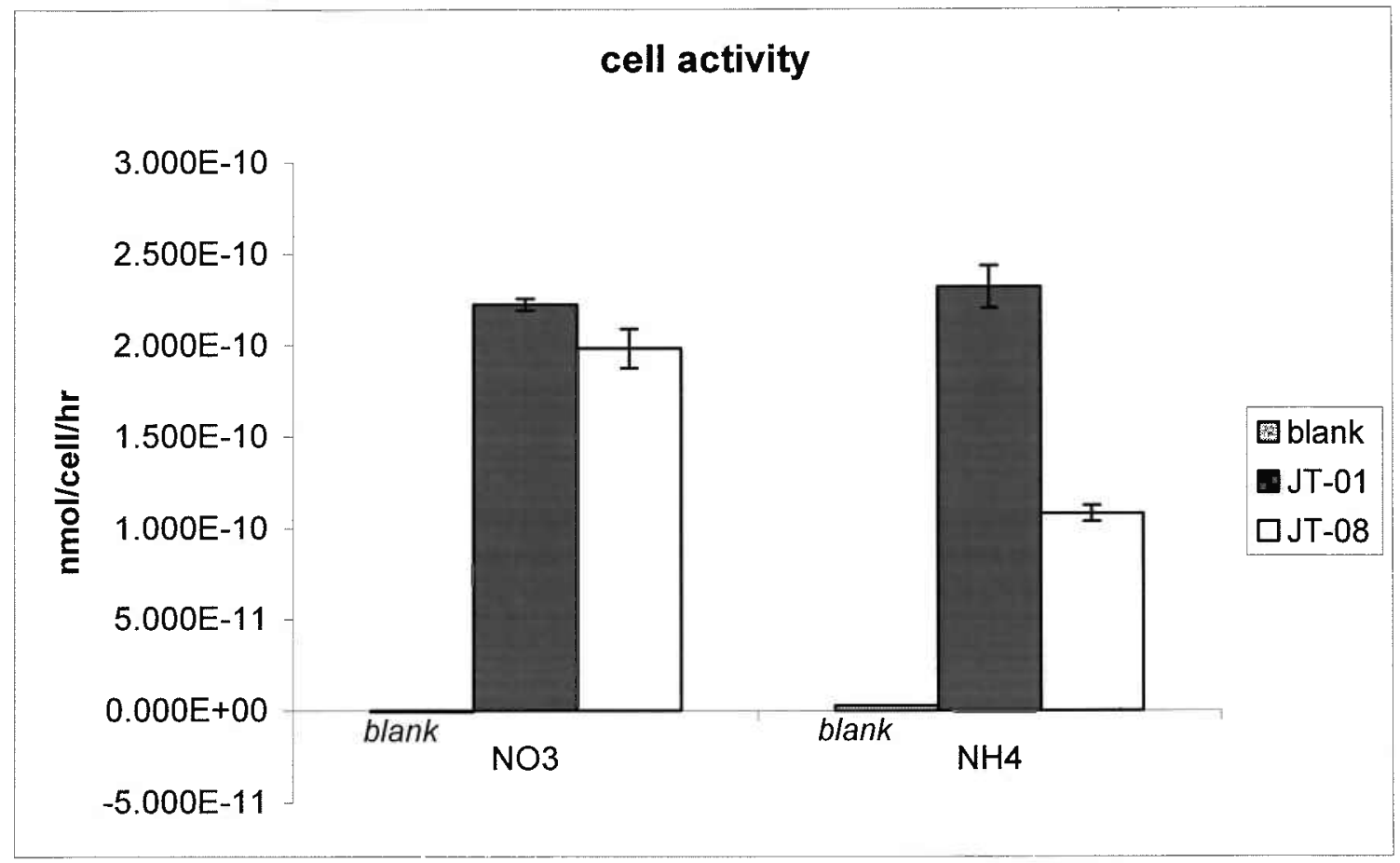

Figure 3.10: Cell-specific $\mathrm{CO}$ oxidation activity. The statistic used for comparing activities between isolates is specific activity in terms of nanomoles CO oxidized cell ${ }^{-1}$ hour ${ }^{-1}$, and is obtained by normalizing the $\mathrm{CO}$ oxidation rate by the cell density obtained by AODC. Error bars represent standard error of the mean. Isolates shown here are the most active $\mathrm{CO}$ oxidizers resulting from this study. 


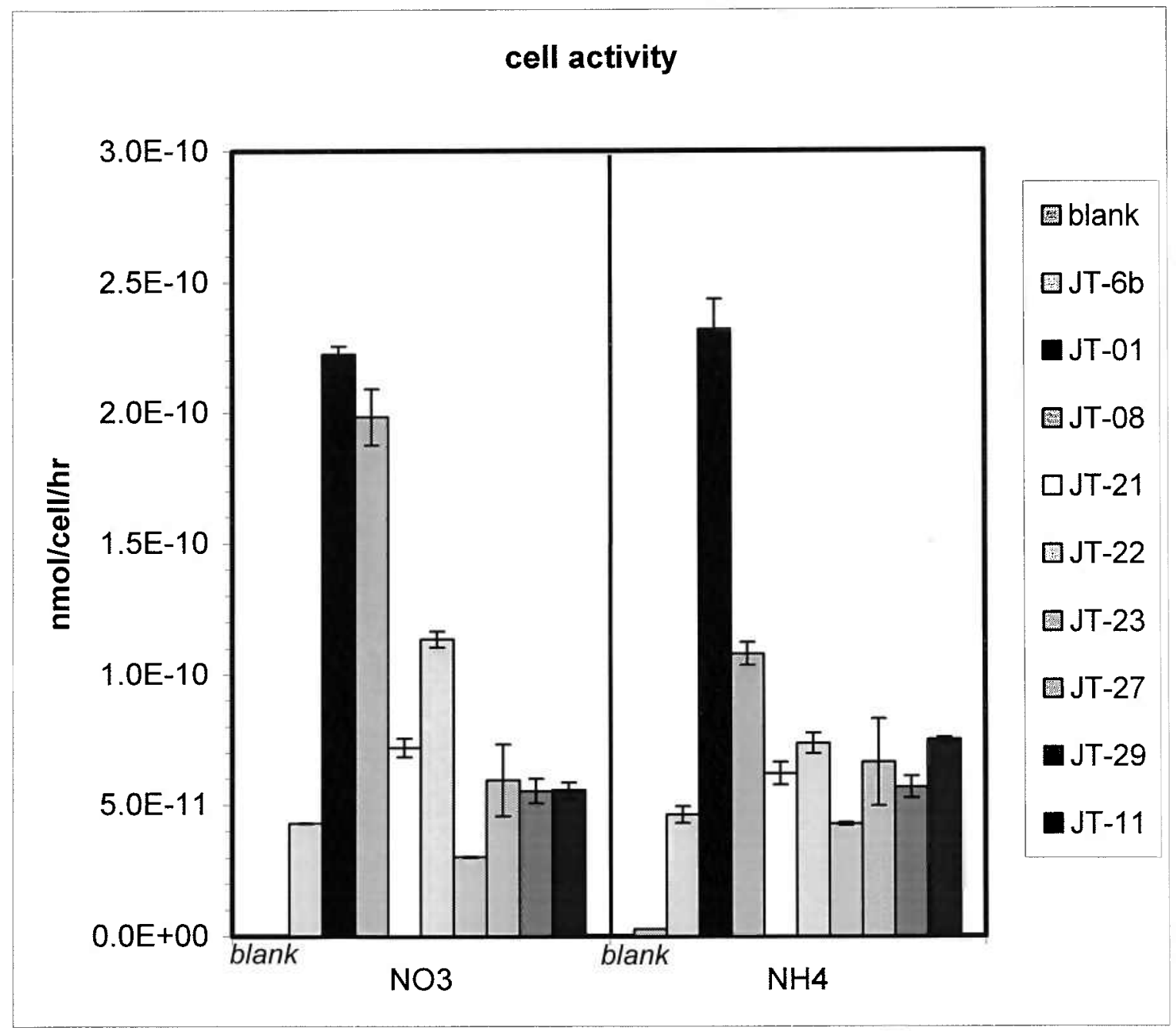

Figure 3.11 Environmental isolates tested for $\mathrm{CO}$ oxidation activity that have $\mathrm{CO}$-oxidation greater than the average specific activity of the microbial assemblage in Vineyard Sound surface water $\left(4.53 \times 10^{-11}\right.$ to $5.99 \times 10^{-11} \mathrm{nmol} \mathrm{CO}$ oxidized cell ${ }^{-1} \mathrm{hr}^{-1}$. Nine of 30 isolates oxidize carbon monoxide at significant rates. Error bars represent SEM. Close relatives based on BLAST returns of the isolate sequences are as follows: JT-6b, Alteromonas sp.; JT-01, Ruegeria sp., JT-08, Roseobacter sp.; JT-21, Cyclobacterium sp.; JT-22, Roseovarius sp.; JT-23, $\gamma$-Proteobacter; JT-27, Halomonas sp.; JT-29, Halomonas sp., JT-11, Pseudomonas sp. 
$\mathrm{n} M$ by the free energy yield of the organic substrate oxidation. In each case, there is significant energy advantage to utilizing the energy from $\mathrm{CO}$ oxidation, even if CO-born carbon is not utilized and incorporated as biomass.

\section{Isolate specific CO-oxidation rates}

The specific rates of $\mathrm{CO}$ oxidation by the CO-oxidizing isolates recovered during this study were measured by the ${ }^{14} \mathrm{C}$-CO oxidation assay performed with pure cultures. The direct measurement of the rate of $\mathrm{CO}$ oxidation ( $\mathrm{n} M / \mathrm{hr}$ ) could not be used to compare between isolates because of differences in cell density between incubations. This raw statistic was normalized to cell density for each incubation (AODC) to yield a specific cell CO-oxidation activity that could be used to compare activities of separate isolates (nmol CO oxidized cell $^{-1} \mathrm{hr}^{-1}$ ) (figure 3.10). Specific CO oxidation activity was measured for every isolate in two different nitrogen-source conditions in mineral media (figure 3.11). In most cases, nitrogen source did not make a difference in whether organisms oxidized $\mathrm{CO}$, or the magnitude of $\mathrm{CO}$-oxidation activity if it existed. One isolate, (JT-08), oxidized $\mathrm{CO}$ at a higher rate while grown with nitrate as nitrogen source; this is the sole exception among 30 isolates and nine positive $\mathrm{CO}$ oxidizers. The overall mean $\mathrm{CO}$ oxidation activity for all positive isolates $(\mathrm{n}=9)$ was $8.953 \times 10^{-11} \mathrm{nmol} \mathrm{CO}$ oxidized cell ${ }^{-1} \mathrm{hr}^{-1}$. The average $\mathrm{CO}$ oxidation activity of the two most active isolates (JT-01 and JT-08) was more than 2-fold faster than the others $(\mathrm{n}=7)$ at $1.9 \times 10^{-10} \mathrm{nmol}$ $\mathrm{CO}$ oxidized cell $\mathrm{hr}^{-1}$, and within range of the $\mathrm{CO}$ oxidation activity of one characterized carboxydotroph, Pseudomonas carboxydohydrogena (Cypionka et al., 1980). 
Identity and Phylogeny.

After 16S-rDNA sequencing of 30 isolated strains, putative identifications based upon sequence and BLAST search returns were compiled (Table 3.12). It is important to note that while all isolates are $\mathrm{CO}$ tolerant to elevated concentrations of $\mathrm{CO}(40-50 \mathrm{nM})$, and are phylogenetically diverse, none of the 21 "carboxydotrophic" organisms described in literature are represented in our isolation program, which is consistent with the absence of any described carboxydotrophic organisms ever having been isolated from marine environments. Furthermore, all known carboxydotrophic organisms to date have been enriched under extremely high $[\mathrm{CO}]$ conditions $(20 \%-80 \%)$., where our direct isolation approach has used modestly high $\mathrm{CO}$ concentrations relative to those in the marine environment.

None of our 30 isolates are closely related to known ammonium-oxidizing organisms; nitrogen source did not affect $\mathrm{CO}$ oxidation rates in most cases except for JT08, where CO-oxidation rate was reduced by half when the cells were in an $\mathrm{NH}_{4}{ }^{+}$ medium compared to those in a nitrate medium (Figure 3.11). The contribution of ammonium oxidizing bacteria $(\mathrm{AOB})$ in $\mathrm{CO}$ oxidation in ocean water remains enigmatic. Prior work on these organisms to determine their role in environmental $\mathrm{CO}$ oxidation has been based mainly on comparisons of their $\mathrm{K}_{\mathrm{M}}$ values in pure culture incubations with $\mathrm{CO}$ with kinetic values for $\mathrm{CO}$ consumption in ocean, soil, and lake samples. The ability of $\mathrm{AOB}$ to oxidize $\mathrm{CO}$ and their rates of $\mathrm{CO}$ consumption are negatively affected by the presence of ammonium, suggesting that $\mathrm{CO}$ and ammonium are competitive substrates and that $\mathrm{CO}$ is oxidized incidentally by ammonium monooxygenase. Furthermore, in the 


\begin{tabular}{|c|c|c|c|c|c|}
\hline \multicolumn{2}{|c|}{ ISOLATE fragment } & \multicolumn{2}{|c|}{ length (bp) } & \multirow{2}{*}{$\frac{\text { database match (BLAST) }}{\text { Paracoccus marcusii }}$} & \multirow{2}{*}{$\frac{\% \text { identity }}{96 \%}$} \\
\hline \multirow[t]{2}{*}{1} & $8 f-519 r$ & $(316)$ & alphaproteobacteria & & \\
\hline & $907 f-1492 r$ & (316) & alphaproteobacteria & Paracoccus marcusii & $96 \%$ \\
\hline 2 & $8 f-519 r / 519 f-1492 r$ & (689) & gammaproteobacteria & Pseudomonas aeruginosa & $99 \%$ \\
\hline 3 & $8 \mathrm{f}-519 \mathrm{r} / 519 \mathrm{f}-1492 \mathrm{r}$ & $(800)$ & gammaproteobacteria & Vibrio Harveyi & $99 \%$ \\
\hline 4 & $8 f-519 r / 519 f-1492 r$ & $(784)$ & alphaproteobacteria & Marinobacter aquaeolei & $99 \%$ \\
\hline 5 & $8 f-519 r / 519 f-1492 r$ & & gammaproteobacteria & Pseudomonas aeruginosa & \\
\hline \multirow[t]{3}{*}{$6 b$} & $8 f-519 r / 519 f-1492 r$ & $(746)$ & gammaproteobacteria & Glaciecola sp. & $95 \%$ \\
\hline & & & gammaproteobacteria & alteromonas $\mathrm{sp}$. & $95 \%$ \\
\hline & & & gammaproteobacteria & nonas alvinellae & $95 \%$ \\
\hline \multirow[t]{3}{*}{7} & $8 \mathrm{f}-519 \mathrm{r} / 519 \mathrm{f}-1492 \mathrm{r}$ & $(785)$ & alphaproteobacteria & Ruegeria atlantica & $99 \%$ \\
\hline & & & alphaproteobacteria & Agrobacterium atlanticum & $98 \%$ \\
\hline & & & alphaproteobacteria & & $97 \%$ \\
\hline \multirow[t]{4}{*}{8} & $8 f-519 r / 519 f-1492 r$ & (729) & alphaproteobacteria & Roseobacter sp. & $96 \%$ \\
\hline & & & alphaproteobacteria & Ruegeria atlantica & $96 \%$ \\
\hline & & & alphaproteobacteria & Agrobacterium atlanticum & $95 \%$ \\
\hline & & & alphaproteobacteria & Agrobacterium meteori & \\
\hline \multirow[t]{3}{*}{10} & $8 f-519 r / 519 f-1492 r$ & $(738)$ & gammaproteobacteria & Pseudoalteromonas flavipulchra & $99 \%$ \\
\hline & & & gammaproteobacteria & Ps. piscicida & $99 \%$ \\
\hline & & & gammaproteobacteria & Ps. maricaloris & $99 \%$ \\
\hline 11 & $8 f-519 r / 519 f-1492 r$ & & gammaproteobacteria & Pseudomonas aeruginosa & $99 \%$ \\
\hline 12 & $8 f-519 r / 519 f-1492 r$ & $(687)$ & gammaproteobacteria & Pseudomonas aeruginosa & $99 \%$ \\
\hline $13 a$ & $8 \mathrm{f}-519 \mathrm{r} / 519 \mathrm{f}-1492 \mathrm{r}$ & $(1398)$ & gammaproteobacteria & Pseudomonas aeruginosa & $98 \%$ \\
\hline \multirow[t]{3}{*}{$13 b$} & $8 f-519 r / 519 f-1492 r$ & $(732)$ & epsilonproteobacteria & Micrococcus luteus & $99 \%$ \\
\hline & & & epsilonproteobacteria & Arthrobacter sp. & $99 \%$ \\
\hline & & & epsilonproteobacteria & Micrococcus psychrophilum & $98 \%$ \\
\hline \multirow[t]{3}{*}{14} & $8 f-519 r / 519 f-1492 r$ & $(821)$ & alphaproteobacteria & Ruegeria atlantica & $99 \%$ \\
\hline & & & alphaproteobacteria & Agrobacterium atlanticum & $98 \%$ \\
\hline & & & alphaproteobacteria & Agrobacterium meteori & $98 \%$ \\
\hline 15 & $8 f-519 r / 519 f-1492 r$ & $(740)$ & alphaproteobacteria & Silicibacter pomeroyi & $95 \%$ \\
\hline \multirow[t]{2}{*}{16} & $8 f-519 r / 519 f-1492 r$ & $(782)$ & Flavobacteria & Uncultured Cytophagales & $95 \%$ \\
\hline & & & Flavobacteria & Cytophaga sp. & $95 \%$ \\
\hline $17 / 18$ & $8 f-519 r / 519 f-1492 r$ & $(683)$ & Flavobacteria & Oceanomonas baumannii & $98 \%$ \\
\hline 19 & $8 \mathrm{f}-519 \mathrm{r} / 519 \mathrm{f}-1492 \mathrm{r}$ & $(584)$ & gammaproteobacteria & Halomonas marina & $100 \%$ \\
\hline \multirow[t]{3}{*}{20} & $8 \mathrm{f}-519 \mathrm{r} / 519 \mathrm{f}-1492 \mathrm{r}$ & $(779)$ & alphaproteobacteria & Ruegeria atlantica & $99 \%$ \\
\hline & & & alphaproteobacteria & Agrobacterium atlanticum & $98 \%$ \\
\hline & & & alphaproteobacteria & Agrobacterium meteori & $98 \%$ \\
\hline 21 & $8 \mathrm{f}-519 \mathrm{r} / 519 \mathrm{f}-1492 \mathrm{r}$ & (279) & Flavobacteria & Cyclobacterium marinum & $99 \%$ \\
\hline 22 & $8 \mathrm{f}-519 \mathrm{r}$ & $(741)$ & alphaproteobacteria & Roseobacter sp. & $97 \%$ \\
\hline \multirow[t]{3}{*}{23} & $8 \mathrm{f}-519 \mathrm{r} / 519 \mathrm{f}-1492 \mathrm{r}$ & $(270)$ & gammaproteobacteria & Uncultured Neptunomonas & $91 \%$ \\
\hline & & & gammaproteobacteria & Thiomicrospira sp. & $91 \%$ \\
\hline & & & gammaproteobacteria & Methylomonas methanica & $91 \%$ \\
\hline 25 & $8 f-519 r / 519 f-1492 r$ & (804) & Flavobacteria & CFB group bacterium & $100 \%$ \\
\hline 26 & $8 \mathrm{f}-519 \mathrm{r} / 519 \mathrm{f}-1492 \mathrm{r}$ & (725) & Methanobacterium & Zobellia uliginosum & $96 \%$ \\
\hline \multirow[t]{2}{*}{27} & $8 f-519 r$ & $(592)$ & gammaproteobacteria & Halomonas alimentaria & $96 \%$ \\
\hline & & $(552)$ & gammaproteobacteria & & $97 \%$ \\
\hline 28 & $8 \mathrm{f}-519 \mathrm{r} / 519 \mathrm{f}-1492 \mathrm{r}$ & $(686)$ & gammaproteobacteria & Halomonas marina & $100 \%$ \\
\hline 29 & $8 \mathrm{f}-519 \mathrm{r} / 519 \mathrm{f}-1492 \mathrm{r}$ & (679) & gammaproteobacteria & Halomonas marina & $100 \%$ \\
\hline 30 & $8 \mathrm{f}-519 \mathrm{r} / 519 \mathrm{f}-1492 \mathrm{r}$ & (316) & Flavobacteria & Uncultured Cytophagales & $97 \%$ \\
\hline
\end{tabular}

Table 3.12: BLAST Identification of Isolates Bold text denotes CO-oxidizing isolates. 
Type strain tested

Source collection

Accession number

\begin{tabular}{|c|c|c|}
\hline Paracoccus versatus & DSMZ & 582 \\
\hline $\begin{array}{c}\text { Ruegeria atlantica }= \\
\text { Agrobacterium atlanticum }\end{array}$ & DSMZ & 5823 \\
\hline Ruegeria gelatinovorans & & \\
\hline Paracoccus denitrificans & DSMZ & 5887 \\
\hline Roseobacter litoralis & DSMZ & 7001 \\
\hline Paracoccus alcaliphilus & DSMZ & 6996 \\
\hline Paracoccus aminophilus & DSMZ & 8512 \\
\hline Ruegeria algicola & DSMZ & 8538 \\
\hline Paracoccus pantotrophus & DSMZ & 10253 \\
\hline Silicibacter lacuscaerulensis & DSMZ & 11072 \\
\hline Sulfitobacter brevis & DSMZ & 11314 \\
\hline Roseovarius tolerans & DSMZ & 11443 \\
\hline Sulfitobacter mediterraneus & DSMZ & 11457 \\
\hline Roseobacter gallaeciensis & DSMZ & 12244 \\
\hline Pseudomonas aeruginosa & DSMZ & 12440 \\
\hline LFR (Ledyard et al., 1993) & ATCC & 10145 \\
\hline EE-36 & ATCC & 51258 \\
\hline Silicibacter lacuscaerulensis & M.A.Moran (UGA) & \\
\hline Silicibacter pomeroyi DSSS-3: & M.A.Moran (UGA) & \\
\hline ISM & M.A.Moran (UGA) & \\
\hline NF18 & Jannasch collection (WHOI) & \\
\hline TB66 & Jannasch collection (WHOI) & \\
\hline AIII3 & A. Teske (WHOI) & \\
\hline DI4 & A. Teske (WHOI) & \\
\hline DIII4 & A. Teske (WHOI) & \\
\hline & & \\
\hline
\end{tabular}

Table 3.13: Type cultures tested for CO-oxidation activity, their source, and accession numbers where applicable. 
experiments performed by Jones and Morita (1983) with Nitrosococcus oceanus and Nitrosomonas europaea, they were unable to obtain $\mathrm{K}_{\mathrm{M}}$ values as low as those reported for ocean, soil, or lake samples (4-9 $\mathrm{n} M)($ Conrad and Seiler, 1982), even after 24 hours of nutrient starvation (222 $\mathrm{nM}$ for $N$. europaea, $889 \mathrm{nM}$ for $N$. oceanus). It is not known what advantage the ammonium oxidizers get from their cooxidation of $\mathrm{CO}$, if any, since they do not incorporate CO-born carbon and the energy of $\mathrm{CO}$ oxidation by AMO is not coupled to the electron transport system.

Phylogenetic analysis based on the 16S-rDNA sequences of positive COoxidizing isolates places the most active strains (JT-01, JT-08, JT-22) in the Roseobacter group (González et al., 1999) and Paracoccus group of the $\alpha$-subclass of the Proteobacteria (Figure 3.14). We obtained and tested type strains belonging to the Roseobacter and Paracoccus groups (Table 3.13) for CO-oxidation activity using the ${ }^{14} \mathrm{C}-\mathrm{CO}$ oxidation assay, and discovered that four Roseobacter type organisms oxidized $\mathrm{CO}$ at environmentally relevant levels: Roseobacter litoralis, Ruegeria atlantic, Ruegeria gelatinovora, and Silicibacter pomeroyi (Figure 3.14).

Organisms belonging to the Roseobacter group (including the genera Rhodovulum, Roseivivax, Roseobacter, Roseovarius, Rubrimonas, Ruegeria, Sagittula, Stayelam Stappia Silicibacter, and Sulfitobacter) have been reported by Gonzalez and Moran (1997) as contributing up to $28 \%$ of the total $16 \mathrm{~S}$ ribosomal DNA (rDNA) sequences in seawater samples from the coast of the southeastern United States. Roseobacter species have been reported as being a dominant microbial component during a North Sea coccolithophore bloom, contributing $24 \%$ of the bacterioplankton numbers 
and up to $50 \%$ of the biomass (Zubkov et al., 2001). Roseobacter has also been determined to contribute greater than $30 \%$ of total SSU rDNA in the surface waters of the Monterey Bay upwelling plume (Suzuki et al., 2001). Given the rate of CO-oxidation by some Roseobacter group isolates and their probable numerical density in the study location, Roseobacter group organisms are likely important contributors to total $\mathrm{CO}$ oxidation in coastal waters. Many members of the Roseobacter group acquired from various sources (Table 3.13) tested for CO-oxidation activity were negative for that phenotype (Figure 3.15); CO oxidation is therefore not a characteristic phenotype of the marine alpha, Roseobacter, or Paracoccus clades. However, the most active of the organisms isolated in this study are representatives of Roseobacter and Paracoccus. While our CO-oxidizing isolates are phylogenetically very diverse, they all are aerobic heterotrophs and halotolerant. Descriptions of the of genera to which the CO oxidizing isolates resulting from this study belong are excerpted from Bergey's Manual of Determinative Bacteriology, $9^{\text {th }}$ ed. and may be found in Appendix C.

To estimate the fraction of total CO-oxidation activity measured in natural seawater that can be attributed to organisms of the Roseobacter group, the specific activities of Roseobacter group organisms obtained from our isolation program and the CO-oxidizing Roseobacter type cultures were averaged. The average specific activity of the seven Roseobacter CO oxidizing strains (JT-01, JT-08, JT-22, Roseobacter litoralis, Ruegeria gelatinovora, Silicibacter pomeroyi, Ruegeria atlantica) was $1.07 \times 10^{-10} \mathrm{nmol}$ $\mathrm{CO}$ cell $^{-1} \mathrm{hr}^{-1}$. The average cell density of the Vineyard Sound coastal sampling location is $1.96 \times 10^{6}$ cells $\mathrm{ml}^{-1}$. As Roseobacter group organisms have been found to compose 
Figure 3.14: Neighbor-joining tree including positive CO-oxidizing isolates from this study (JT-*) in their phylogenetic context. Bold type denotes strains that have tested positive for $\mathrm{CO}$ oxidation. Italicized type denotes type cultures that have been tested and found negative for $\mathrm{CO}$ oxidation. 


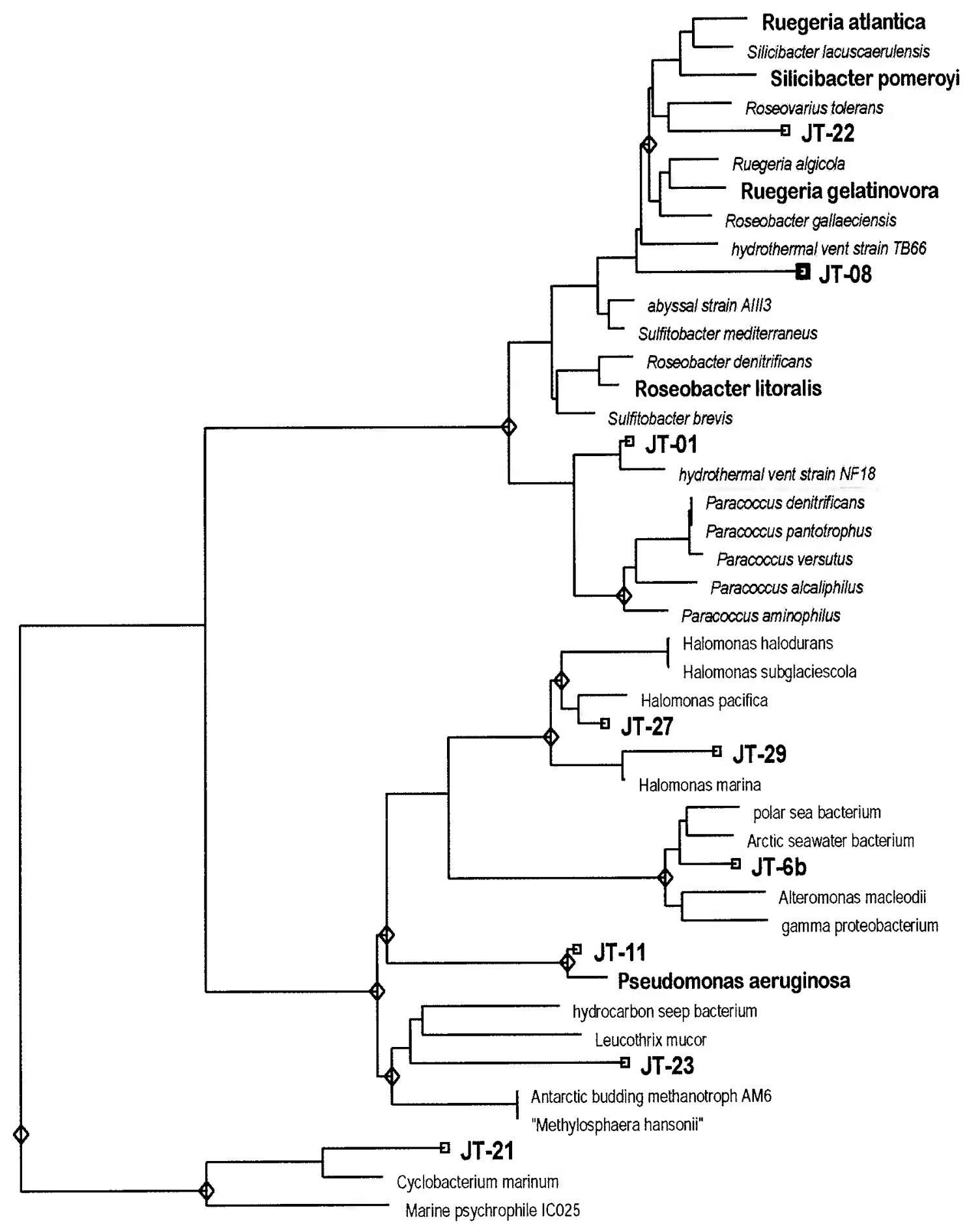




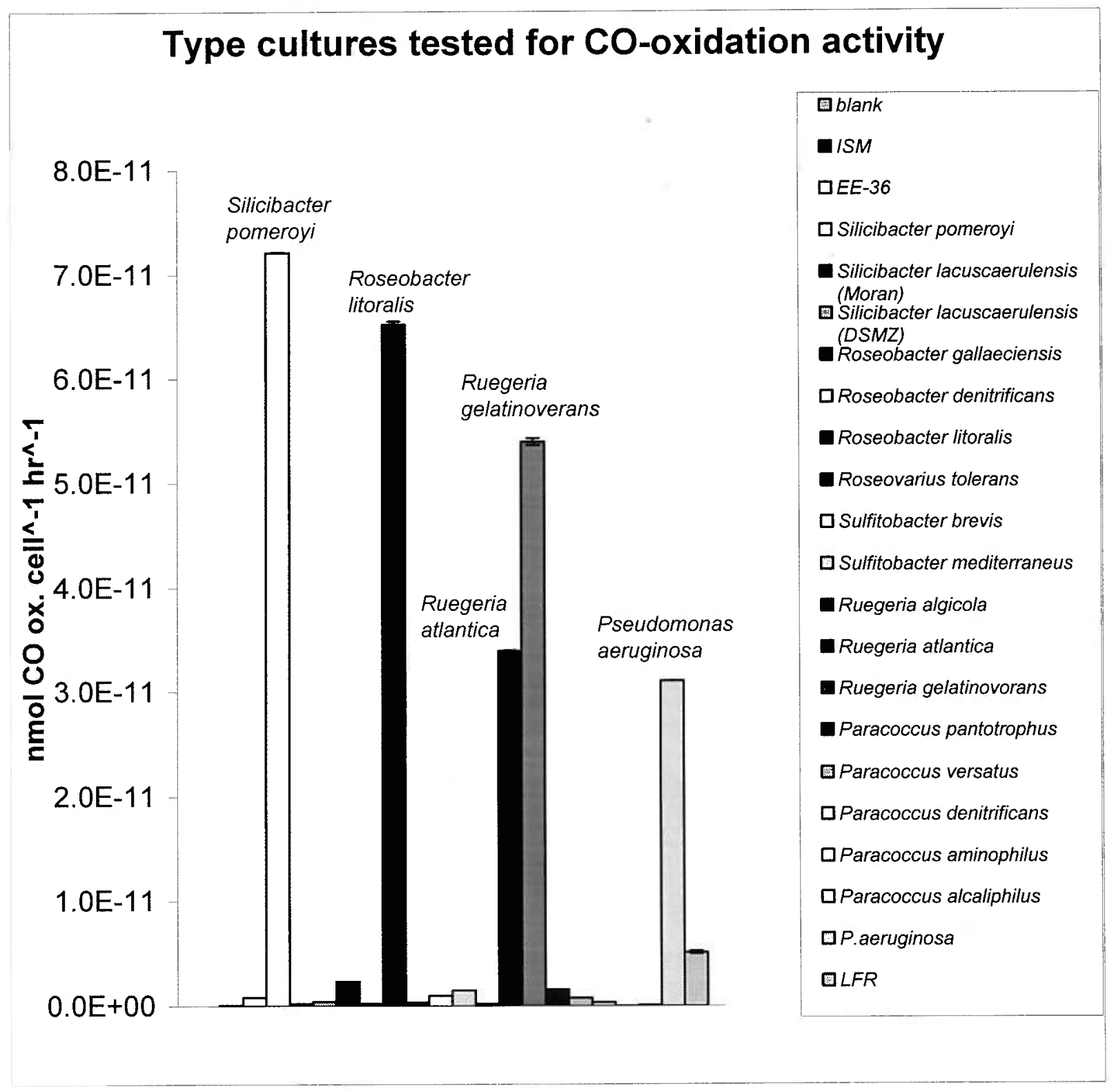

Figure 3.15: Type culture CO-oxidation specific activities. Four of 12 type species tested in the Roseobacter group and one strain of $P$. aeruginosa oxidize carbon monoxide with environmentally relevant specific activities. 
$28 \%$ of a natural coastal microbial population (Gonzalez and Moran, 1997) and greater in other environments, this percentage is a conservative value for the relative abundance of Roseobacter at our sampling site. The rate of $\mathrm{CO}$ oxidation that would result from this average specific activity at this relative cell density would be $0.06 n M$ CO oxidized $\mathrm{hr}^{-1}$. This rate value, once normalized to $1 n M$ incubation [CO] yields a rate constant $k=0.033$ $\mathrm{hr}^{-1}$. The average rate constant measured in bulk water samples from Vineyard Sound in $0.064 \pm 0.021 \mathrm{hr}^{-1}$. Therefore, members of the marine alpha subgroup of the Proteobacteria may potentially contribute $50 \%$ of the total $\mathrm{CO}$ oxidation that was measured in natural seawater samples. The sole parameter in this calculation not directly measured was the relative abundance of marine-alpha group cells at our sampling location; to further constrain the contribution of Roseobacter (or other specific groups) to environmental $\mathrm{CO}$ oxidation, it was necessary to enumerate these cells in the local environment and determine their relative proportion to the total assemblage, and to determine the relative proportion of Roseobacter that are CO-metabolically active. This topic is addressed in Chapter 4 and will consist of a triple-labeling technique (SubstrateTracking AutoRadiography / Fluorescent In Situ Hybridization, or STARFISH) that will allow the simultaneous quantification and discrimination of total cell density, COmetabolizing cells, and marine alpha-type cells in the same microscopic field.

The Class alphaproteobacteria currently contains several organisms that have been previously identified as "carboxydotrophic", though many were originally members of different taxonomic classes because of their metabolic features and have since been reclassified based on their molecular phylogeny. An example is the reclassification and 
renaming of Pseudomonas carboxydovorans, formerly in the gamma subdivision of Proteobacteria, to Oligotropha carboxidovorans, currently in the alpha subdivision (Meyer et al., 1993b). O. carboxidovorans has become a model species for studies of the CODH enzyme and cox genes that confer CO metabolism. Carbophilus and Zavarzinia, are two other examples of genera that are carboxydotrophic and currently classified within alphaproteobacteria that were formerly misclassified as Alcaligenes (betaproteobacteria) and Pseudomonas (gammaproteobacteria), respectively.

The key enxyme in the aerobic utilization of $\mathrm{CO}$ by many described carboxydotrophic microorganisms is carbon monoxide dehydrogenase (CODH), which catalyzes the oxidation of $\mathrm{CO}$ to $\mathrm{CO}_{2}$ (Meyer et al., 1982, 1993a). The CODH structural genes coxMSL of Oligotropha carboxidovorans, an alphaproteobacteria (formerly Pseudomonas carboxydovorans [Meyer et al., 1993b]), have been sequenced (Schübel et al., 1995) and are part of a cox gene cluster coxBCMSLDEFGHIK (Santiago et al., 1999), which resides on the 128-kb megaplasmid pHCG3. The crystal structure of CODH has been solved at a 2.2 Angstöm resolution (Dobbek et al., 1999). CODH is composed of an 88.7-kDa molybdoprotien (L), a 30.2-kDa flavoprotein (M) (Gremer et al., 2000), and a 17.8-kDa iron-sulfur protein (S) in a (LMS $)_{2}$ subunit structure. The cox genes are specifically and coordinately transcribed under chemolithoautotrophic conditions in the presence of $\mathrm{CO}$ as carbon and energy source. All deduced products of the cox genes of O. carboxidovorans have counterparts in so far uncharacterized gene clusters of Pseudomonas thermocarboxydovorans, Hydrogenophaga pseudoflava, Bradyrhizobium japonicum, and Mycobacterium tuberculosis. In addition to the clustered cox genes, 
mutational analyses have identified the genes $l o n, c y c H$ and $\operatorname{orf} X$ which reside on the plasmid pHCG3. The Lon protease, the $\mathrm{CycH}$ protein and the unknown orf gene product have essential functions in the utilization of CO (Santiago et al., 1999).

The similarity among the CODH from otherwise phenotypically diverse carboxydobacteria is striking (Meyer \& Schlegel, 1983; Kim et al., 1982) and suggests a common evolutionary origin for the $\mathrm{CODH}$ genes and relatively recent dispersal of the trait, perhaps by plasmid-mediated genetic exchange. Plasmids are readily mobilizable between taxa and represent the most common method of acquiring selectable traits (e.g. antibiotic resistance determinants). Plasmids are rarely integrated into the chromosome, therefore the acquired trait(s) must confer an advantage sufficient to overcome not only inactivation by mutation, but also elimination by segregation. There are, however, several proposed mechanisms for DNA assimilation into the bacterial genome, including a) persisting as a episome; b) homologous recombination, which is likely to serve primarily to re-assort variation among closely related taxa and is unlikely to allow introduction of novel traits; $c$ ) integration mediated by bacteriophage integrases or mobile elment transposases; and d) illegitimate incorporation through chance double-strand break repair (Ochman et al., 2000).

In a genome sequencing project for the Roseobacter isolate Silicibacter pomeroyi strain DSS-3, preliminary sequence data have shown the cox genes coxS, coxL, and coxM, plus many of the accessory cox proteins (D, E, F. G), arranged in an operon (M.M. Moran, personal communication). The genes have greatest similarity to those of $O$. carboxidovorans, but also high similarity to $H$. pseudoflava and $B$. fungorum genes. 
Silicibacter posesses a 500-kb megaplasmid similar to Oligotropha (along with a number of other alphaproteobacteria), however, the cox gene cluster is not located there. The phenotype may be transmissible to other species through lateral gene transfer even if the operon is not carried on a plasmid, but rather in a transposable element within the chromosome flanked by two insertion sequences. It may be mobilized as a complex transposon that can integrate into the chromosomes of phylogenetically diverse bacterial species (Kleckner, 1989). This mode of lateral gene transfer is consistent with the appearance of the $\mathrm{CO}$ oxidation phenotype in widely diverse organisms but not as a characteristic shared within or between closely related taxa, and the presence of the cox gene cluster in the genome rather than in a plasmid in Silicibacter pomeroyi.

Lateral gene transfer involves the introduction of DNA into a single lineage, and the acquired trait is limited to the descendents of the recipient strain and absent from closely related taxa, thereby producing a scattered phylogenetic distribution. Lateral gene transfer need not be invoked to explain the sporadic occurrence of certain phenotypic traits, such as antibiotic resistance, because these properties can originate through point mutations in existing genes and therefore may evolve independently in divergent lineages (Ochman et al., 2000). Thus, additional information is needed to discriminate between convergent evolution and lateral gene transfer. Clearly, the strongest evidence for (or against) lateral gene transfer of the cox operon derives from a molecular genetic analysis of the cox gene sequences themselves.

Primer sequences specific for cox genes required for active $\mathrm{CODH}$ and the ability to oxidize CO may be designed and used to amplify and confirm the presence of these 
genes in marine isolates known to oxidize environmental $\mathrm{CO}$. If the $\mathrm{CO}$ oxidation phenotype correlates with the presence of cox genes and their products, then the biochemical mechanism of $\mathrm{CO}$ oxidation in marine environments will be better understood. Phylogentic distribution of the phenotype may also be explained by sequence analysis of the $c o x$ genes in $\mathrm{CO}$ oxidizing isolates or cloned from environmental samples. Furthermore, molecular probes specific for conserved cox genes may enable a direct quantification of diverse CO-oxidizing cells in marine environments. 


\section{BIBLIOGRAPHY}

Altschul, S.F., Gish, W., Miller, W., Myers, E.W. \& Lipman, D.J. (1990) "Basic local alignment search tool." J. Mol. Biol. 215:403-410.

Bartholomew, G.W. and Alexander, M. (1981). Soil as a sink for atmospheric carbon monoxide. Science. 212: 1389-1391

Bergey's Manual ${ }^{\circledR}$ of Determinative Bacteriology, $9^{\text {th }}$ edition (2000). Holt, John, Krieg, N., Sneath, P., Staley, J., and Williams, S., eds. Lippincott Williams \& Wilkins, New York.

Brock, T (1997). Biology of Microorganisms, $8^{\text {th }}$ Edition. (Madigan, M., Martinko, J., and Parker, J., Eds.) Prentice Hall, Upper Saddle River, NJ

Cho, B.C., and Azam, F. (1990). Biogeochemical significance of bacterial biomass in the ocean's euphotic zone. MEPS. 63(2-3):253-259

Conrad, R., Meyer, O., and Seiler, W. (1981). Role of carboxydobacteria in consumption of atmospheric carbon monoxide by soil. Appl. Environ. Microbiol. 42: 211-215

Conrad, R., and Seiler, W. (1982). Utilization of traces of carbon monoxide by aerobic oligotrophic microorganisms in ocean, lake, and soil. Arch. Microbiol. 132: 4146

Cypionka, H., Meyer, O., and Schlegel, H.G. (1980). Physiological characteristics of various species of strains of carboxydobacteria. Arch. Microbiol. 127:301-307

Dobbek, H., Gremer, L., Meyer, O., Huber, R (2000). CO Dehydrogenase from Oligotropha carboxydoverans. Proc. Natl. Acad. Sci USA 275(3): 1864

Dunbar, J, Wong, D.C.L., Yarus, M.J., and Forney, L.J. (1996). Autoradiographic method for isolation of diverse microbial species with unique catabolic traits. Appl. Environ. Microbiol. 62(11):4180-4185

Gremer, L., Kellner, S., Dobbek., H., Huber, R, and Meyer, O. (2000). Binding of Flavin Adenine Dinucleotide to Molybdenum-containing Carbon Monoxide Dehydrogenase from Oligotropha carboxidovorans. J. Biol. Chem. 275:18641872

González, J.M. and Moran, M.A. (1997). Numerical dominance of a group of marine bacteria in the $\alpha$-subclass of the Class Proteobacteria in coastal seawater. Appl. Environ. Microbiol. 63(11):4237-4242 
González, J.M., Kiene, R.P., and Moran, M.A. (1999). Transformation of sulfur compounds by anabundant lineage of marine bacteria in the $\alpha$-subclass of the class Proteobacteria. Appl. Environ. Microbiol. 65:3810-3819

Griffiths, R.P., Caldwell, B.A., Cline, J.D., Broich, W.A., and Morita, R.Y. (1982). Field observations of methane concentrations and oxidation rates in the southeastern Bering Sea. Appl. Environ. Microbiol. 44(2): 435-446

Jones, R.D. and Amador, J.A (1993). Methane and carbon monoxide production, oxidation, and turnover times in the Caribbean Sea as influenced by the Orinoco River. J. Geophys. Res. 98:2353-2359

Jones, R.D. and Morita, R.Y. (1983). Carbon monoxide oxidation by chemolithotrophic ammonium oxidizers. Can. J. Microbiol. 29: 1545-1551

Jones, R.D. (1991). Carbon monoxide and methane distribution and consumption in the photic zone of the Sargasso Sea. Deep-Sea Research 38(6): 625-635

Kiessling, M., and Meyer, O. (1982). Profitable oxidation of carbon monoxide or hydrogen during heterotrophic growth of Pseudomonas carboxydoflava, FEMS Microbiol. Lett. 13: 333-338

Kim, Y., Kirkconnell, S., and Hegeman, G. (1982). Immunological relationships among carbon monoxide dehydrogenases of carboxydobacteria. FEMS Microbiol. Lett. 13:219-223

Kleckner, N. (1989) in Mobile DNA (Berg, D.E., and Howe, M.M., eds) 185-210 (American Society for Microbiology, Washington, DC.)

Ledyard, K., DeLong, E., and Dacey, J. (1993). Characterization of a DMSP-degrading bacterial isolate from the Sargasso Sea. Arch. Microbiol. 160:312-318

Lee, C. (1992). Controls on organic carbon preservation: The use of stratified water bodies to compare intrinsic rates of decomposition in oxic and anoxic systems. Geochem. Cosmochem. Acta. 56:3323-3335

Meyer, O. (1982). Chemical and spectral properties of carbon monoxide: methylene blue oxidoreductase. The molybdenum-containing iron-sulfur flavoprotein from Pseudomonas carboxydovorans J. Biol. Chem. 257:1333

Meyer, O., and Schlegel, H.G., (1983). Biology of aerobic carbon monoxide oxidizing bacteria. Annu. Rev. Microbiol. 37: 277-310 
Meyer, O. (1985). Metabolism of aerobic carbon monoxide utilizing bacteria, in: Microbial Gas Metabolism (R.K. Poole and C.S. Dow, eds.), pp. 131-151, Academic Press, London

Meyer, O., Frunzke, K., and Mörsdorf, G. (1993a) in Microbial Growth on $C_{I}$ Compounds. (Murrlee, J.C., and Kelly, D.P., eds) Intercept Scientific Publication, Andover, United Kingdom.

Meyer O., and Rohde, M (1984). Enzymology and Bioenergetics of Carbon MonoxideOxidizing Bacteria. In : Microbial Growth on $\mathrm{C}_{1}$ Compounds. (Crawford, R.L. and Hanson, R.S., Eds.) Am. Soc. Microbiol. Washington, D.C. pp.26-33

Meyer, O. , Stackebrandt, E., and Auling, G. (1993b). Reclassification of ubiquinone Q10 containing carboxidotrophic bacteria: transfer of '[Pseudomonas] carboxydovorans' OM5 to Oligotropha, gen. nov, and Oligotropha carboxidovorans, comb. nov., transfer of '[Alcaligenes]' carboxydus' DSM $1086^{\mathrm{T}}$ to Carbophilus, gen. nov., as Carbophilus carboxidus, comb. nov., transfer of '[Pseudomonas] compransoris' DSM $1231^{\mathrm{T}}$ to Zavarzinia, gen. nov., as Zavarzinia compransoris, comb. nov. and amended descriptions of the new genera. System. Appl. Microbiol. 16:390-395

Ochman, H., Lawrence, J.G., and Groisman, E.A. (2000) Lateral gene transfer and the nature of bacterial innovation. Nature 405:299-305

Santiago, B., Shubel, U., Egelseer, C., and Meyer, O. (1999). Sequence analysis, characterization and CO-specific transcription of the cox gene cluster on the megaplasmid pHCG3 of Oligotropha carboxidovorans Gene 236:115-124

Schübel, U., Kraut, M., Mörsdorf, G., and Meyer, O. (1995) Molecular characterization of the genecluster coxMSL encoding the molybdenum-containing carbon monoxide dehydrogenase of Oligotropha carboxidovorans J.Bacteriol. 177:2197

Suzuki, M., Preston., C., Chavez, F., and DeLong, E. (Quantitative mapping of bacterioplankton populations in seawater: field tests across an upwelling plume in Monterey Bay. Aquat. Microb. Ecol. 24:117-127

Wellsbury, P., Goodman, K., Barth, T., Cragg, B., Barnes, S, and Parkes, R. (1997). Nature. 388:573-576

Xie, H, Zafiriou, O.C., Wang, W., and Taylor, C.D. (2001). A simple automated continuous flow equilibrium method for measuring carbon monoxide in seawater. Environ. Sci. Technol. 35(7):1475-1480 
Yurkov, V., E. Stackebrandt, O. Buss, A. Vermeglio, V. M. Gorlenko, and J. T. Beatty. (1997). Reorganization of the genus Erythromicrobium: description of "Erythromicrobium sibiricum" as Sandaracinobacter sibiricus, gen. nov., sp. nov., and "Erythromicrobium ursincola" as Erythromonas ursincola, gen. nov., sp. nov. Int. J. Syst. Bacteriol. 47:1172-1178

Yurkov, V.V and Beatty, J.T. (1998). Aerobic Anoxygenic Phototrophic Bacteria. Microbiology and Molecular Biology Reviews 62(3):695-724

Zavarzin, G.A. and Nozhevnikova, A.N. (1977). Aerobic carboxydobacteria, Microb. Ecol. 3: 305-326

Zubkov, M., Fuchs, B., Archer, S., Kiene, R., Amann, R., and Burkill, P. (2002). Linking the composition of bacterioplankton to rapid turnover of dissolved dimethylsulphoniopropionate in an algal bloom in the North Sea. Environ. Microbiol. 3(5):304-311 


\title{
Chapter IV:
}

\section{Group-specific enumeration of $\mathrm{CO}$-oxidizing microorganisms in natural samples by Substrate Tracking Microautoradiography - Fluorescent In Situ Hybridization (STARFISH)}

\begin{abstract}
Fluorescent in situ hybridization (FISH) using oligonucleotide probes specific for the Roseobacter and other subclasses of the $\alpha$-Proteobacteria (the marine alpha group) was used in combination with microautoradiography to detect and enumerate microorganisms from natural seawater sources that are capable of metabolizing carbon from labeled carbon monoxide $(\mathrm{CO})$ and are members of a specified phylogenetic group. Marine alpha group organisms were a major component of total cell numbers $(45.7 \%)$ at the time of sampling (March 2003), and CO-oxidizing members of the marine alpha group contribute up to $40.7 \%$ of total CO oxidation in coastal waters.
\end{abstract}

\section{INTRODUCTION}

A challenge in microbial ecology is to link the metabolic activity of microorganisms in natural waters under conditions approaching those in situ with their phylogenetic identity. A composite microbial population may be studied by nonselective methods that measure gross metabolism, or by selective measurements such as the uptake of radiolabeled substrates or the growth of culturable bacteria. Quantifying the activity of microbial populations as a whole, however, yields no information on the structure of the population in terms of the number of microorganisms and the specific fraction of the total 
number engaged in the measured function. Specific activity indices, introduced by Wright (1978), express metabolic activity parameters per organism by dividing the activity term $\left({ }^{14} \mathrm{C}-\mathrm{CO}\right.$ oxidation rate, in our study) measured for the composite microbial population by total microscopic direct counts (DC) for samples. This approach represents a first approximation for the interpretation of the relationship between measured microbial activities and a structural component of the population, i.e., the number of microorganisms (Tabor \& Neihof, 1982).

Microautoradiography has the potential to address a number of specific questions relating to substrate uptake by natural populations of bacteria and has been applied to the study of bacterial activity in a number of distinct environments (Grey et al., 1999). The use of radiolabeled substrates in combination with microautoradiography does allow analysis of the metabolic activity of prokaryotes under conditions that approach in situ conditions by direct visualization of microorganisms with active substrate uptake systems within a complex community. A major limitation of microautoradiography has been an inability to correlate the activity detected with identification and detection of a responsible organism. One attempt to solve this problem has involved combining microautoradiography with fluorescent in situ hybridization.

In situ characterization of the marine picoplankton "black box" has been restricted mostly to determinations of community composition by a number of molecular techniques, including fluorescent in situ hybridization (FISH) (Amann et al., 1990, 1995; DeLong \& Shah, 1990, DeLong et al., 1999, Gonzolez \& Moran, 1997). In FISH fluorescently labeled oligunucleotide probes are used to identify and enumerate 
microorganisms in situ (Delong et al., 1989). Probe sequences can target organisms at various taxonomic levels; some probes are universal and target all organisms (Giovannoni et al., 1988), while others are for the domains Archaea (Massana et al., 1997) and Bacteria (Giovannoni et al., 1988). Other probes target intermediate levels, for example, the $\alpha$ subdivision of the class Proteobacteria (Manz et al., 1992; Ouverney \& Fuhrman, 1999).

The objective of this study was to utilize a method that involves a direct combination of FISH performed with rRNA gene-targeted oligonucleotide probes and microautoradiography for simultaneous in situ identification and determination of substrate uptake patterns of individual microbial cells within a natural microbial assemblage (Lee et al., 1999). Here FISH and microautoradiography are combined on a single slide to determine the proportion of the total microbial assemblage that has incorporated carbon from $\mathrm{CO}$ in specific picoplankton groups. The cells are triplelabeled with a ${ }^{14} \mathrm{C}$-labeled substrate, a group-specific oligonucleotide probe, and a general DNA stain. Within the same microscopic field it is possible to determine the percentage of a specific prokaryotic phylogenetic group in a mixed sample and the distribution of substrate uptake within the target subgroup (Ouverney \& Fuhrman, 1999).

In our program to isolate and cultivate $\mathrm{CO}$ metabolizing organisms in a coastal marine environment (Chapter 3), we discovered many of the active $\mathrm{CO}$ oxidizers belonged to the Roseobacter clade. The 'Roseobacter group' as recently referred to by González et al. (1999), encompasses a physiologically and geographically diverse group of bacteria within the $\alpha$-subclass of the Proteobacteria (Brinkmeyer et al., 2000), and 
together with Paracoccus composes the "marine alpha group". These heterotrophic bacteria are strongly implicated in the turnover of the climatically active gas, dimethylsulphide (DMS), and particularly its precursor, an algal osmolyte dimethylsulphionoproprionate (DMSP) (Ledyard et al., 1993; González et al., 1999). Roseobacter group organisms were found to be active in lignin transformation (González et al., 1997) and methyl and inorganic sulfur compound utilization (Sorokin et al., 1995; González et al., 1997). Bacteria of this clade have been discovered in a wide range of marine habitats including pelagic environments (Eilers et al., 2000; Zubkov et al., 2001; Bano \& Hollbaugh, 2002), coastal seawater (González \& Moran, 1997; Eilers et al., 2001; Pernthaler et al., 2002, Suzuki et al., 1997; this study), sediments (Sobecky et al., 1998), marine snow aggregates (Rath et al., 1998; Gram et al., 2002) and as endosymbionts or in association with microalgae (Ashen \& Goff, 1996, 2000; Shiba, 1991) and invertebrates (Barbieri et al., 1996; Ruiz-Ponte et al., 1998). Octadecabacter antarcticus and $O$. arcticus (Gosink et al., 1997) isolated from polar sea ice, Antarctobacter heliothermus (Labrenz et al., 1998), and Roseovarius tolerans (Labrenz et al., 1999) isolated from a hypersaline lake in Antarctica, and Silicibacter lacuscaerulensis (Petursdottir \& Kristjansson, 1997) isolated from a geothermal lake in Iceland represent members of this clade found in extreme environments. Roseobacter group bacteria have also been isolated from cultures of toxic dinoflagellates (Lafay et al., 1995). Furthermore, the SAR83 (Giovannoni et al., 1990) cluster of organisms detected in the oligotrophic gyre of the Sargasso Sea have very similar 16S-rDNA sequences to known Roseobacter organisms that are readily cultured in the laboratory (Amann, 2000). 
This seemingly ubiquitous group of microorganisms may play an important role in the bio-oxidation of photolytically produced $\mathrm{CO}$ in various marine environments, and their potential CO metabolic activity has previously been overlooked in other characterization studies.

\section{METHODS and MATERIALS}

Fluorescent In Situ Hybridization and stringency testing.

Liquid suspensions of type species Paracoccus denitrificans (DSMZ \#6610) and type strain Roseobacter litoralis (DSMZ \#6996) in 2216 marine broth grown for 24 hours at $20^{\circ} \mathrm{C}$ were used for FISH stringency testing. The cultures were centrifuged at 9000 rpm for 5 minutes, and the pellets were resuspended in $0.22 \mu \mathrm{m}$-filtered seawater to rinse. The suspension was again centrifuged at $9000 \mathrm{rpm}$ for $5 \mathrm{~min}$., and the pellets were resuspended in $250 \mu \mathrm{l} \mathrm{PBS}$ and $750 \mu \mathrm{l} 4 \%$ paraformaldehyde solution. FISH was performed under various hybridization conditions to empirically determine the formamide concentration of the hybridization buffer that would allow discrimination between Roseobacter target cells and Paracoccus cells, having a single and consistent mismatch in the probe sequence. The Roseobacter clade-specific oligonucleotide probe used for hybridization was ROSEO536R (Brinkmeyer et al., 2000). The probe sequence $\left(5^{\prime}-3^{\prime}\right)$ CAACGCTAACCCCCTCCG was constructed with a 5'-Cy3 label and HPLCpurified by Thermo Hybaid (former Interactiva, Ulm, Germany). At high formamide concentrations $(40 \%)$ in the hybridization buffer $(\mathrm{HB})$, we were able to discriminate between Roseobacter target cells and Paracoccus cells having the single mismatch to the 
labeled probe. $40 \%$ formamide was used in FISH HB in combination with the competitor probe ROSEOC536R $\left(\left(5^{\prime}-3^{\prime}\right)\right.$ CAACGCTAGCCCCCTCCG) to further suppress false positive signals. The ROSEO536R probe specificity was checked against the RDP II database (http://rdp.cme.msu.edu/html/analyses.html) using the "Probe Match" function, and was found highly specific for the Roseobacter group. Type discrimination was confirmed via FISH and a mixed binary culture of Roseobacter litoralis and Paracoccus denitrificans, and the ROSEO536R/ROSEOC536R combination.

In enumerating Paracoccus, the ROSEOC536R sequence was Cy3-labeled and designated "PARA536R", and the ROSEO536R sequence was non-labeled for use as competitor probe "PARAC536R". We assumed that the melting characteristics of the probe and competitor were not affected by the presence/absence of the 5 ' label, and that signal discrimination remained the same using PARA536R / PARAC536R at 40\% formamide in $\mathrm{HB}$, though this assumption was not explicitly tested. PARA536R specificity was checked against the RDP II database, and was inclusive of Paracoccus but also several other alphaproteobacteria sequences including marine strains of Rhodobacter, Rhodovulum, and Caulobacter. Therefore, specific counts of Roseobacter using the highly specific ROSEO536R probe are well supported, but specific counts of Paracoccus using the PARA536R probe may be overestimated due to lower specificity of PARA536R for Paracoccus, though the non-Paracoccus targets are still members of alphaproteobacteria. 
Filters were prepared by gentle vacuum (-5 psi) filtration of $20 \mu l$ sample in $1 \mathrm{ml}$ 1X PBS onto $0.22 \mu \mathrm{m}$ nucleopore filters. The filters were placed temporarily on Whatman \#4 filter paper pad saturated with 4\% PFA solution in filtered seawater and cut in half with a sterile razor blade. Wet filter-halves were mounted sample-side-down on EtOH-cleaned, 0.1\%-gelatin-coated slides, and allowed to completely air dry. The filters were gently peeled from the gelatin layer, leaving the filtered cells embedded partially in the gelatin layer.

The Hybridization Buffer (HB) consisted of $360 \mu \mathrm{l} 5 \mathrm{M} \mathrm{NaCl}, 40 \mu \mathrm{l} 1 \mathrm{M}$ TrisHCl (pH 7.5-8.0), $1.177 \mathrm{ml}$ formamide ( $40 \%$ final concentration), $2.0 \mathrm{ml} \mathrm{ddH_{2 }}$, and $2 \mu \mathrm{l} 10 \%$ SDS. Hybridizations were performed in $20 \mu \mathrm{l}$ volumes (18 $\mu$ l hybridization buffer (HB), $1 \mu \mathrm{l}$ ROSEO536R and $1 \mu \mathrm{l}$ ROSEOC536R (10 $\mathrm{ng} \mu \mathrm{l}^{-1}$ final probe concentration)) by application of hybridization buffer directly to the embedded sample and covered with a cover slip. Hybridizations (overnight, $46^{\circ} \mathrm{C}$ ) and washes $\left(15-20 \mathrm{~min}\right.$. at $48^{\circ} \mathrm{C}$ ) were performed as previously described by Stahl and Amann, 1991. Hybridization chambers consisted of $50 \mathrm{ml}$ centrifuge tubes containing $2.0 \mathrm{ml}$ of $\mathrm{HB}$ and a strip of Whatman filter paper. Sample slides were inserted into the centrifuge tubes and closed, and placed in an incubator maintained at $46^{\circ} \mathrm{C}$. Rinses were performed after the elapsed hybridization period by gently immersing each slide into $50 \mathrm{ml}$ centrifuge tubes containing wash buffer (WB) maintained at $48^{\circ} \mathrm{C}$ for $15-20 \mathrm{~min}$. WB consisted of $460 \mu \mathrm{l} 5 \mathrm{M} \mathrm{NaCl}, 1 \mathrm{ml} 1 \mathrm{M}$

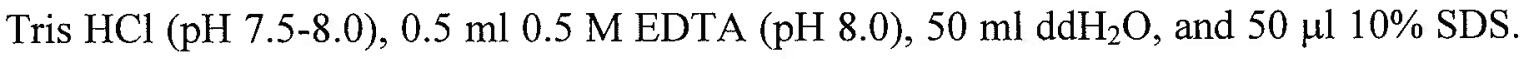
After the washing step, slides were gently immersed in $\mathrm{ddH}_{2} \mathrm{O}$ in a staining jar. The slides were not rinsed with a squirt bottle after it was found that cell retention was 
adversely affected by direct-stream rinsing. Slides were air-dried in the dark, treated with DAPI (4'-6-diamidino-2-phenylindole) (Hicks et al., 1992) with $20 \mu \mathrm{l}$ of a $1.0-\mu \mathrm{g} / \mu \mathrm{l}$ DAPI solution for $1 \mathrm{~min}$. in the dark, and a final rinse in $\mathrm{ddH}_{2} \mathrm{O}$ for $5 \mathrm{~min}$. in a staining jar. Higher DAPI concentrations and/or longer staining times resulted in large DAPI background on emulsion-coated slides as DAPI diffused into the gelatin/emulsion layer and resisted rinsing. After airdrying, the samples were mounted in Citifluor and covered with a glass cover slip. This FISH protocol was adopted for all further FISH and STARFISH assays.

\section{Fluorescent Microautoradiographic Microscopy}

Microscopic counts were made using a Zeiss Axioplan 2 imaging microscope with a Zeiss $\alpha$ Plan-FLUAR 100X oil objective. DAPI counts were made with a UV lamp and filter set (Chroma Technology Corp.) exciter D360/40, emitter GG420. Cy3 counts were made with Endow GFP long pass emission filter set (Chroma Technology Corp.) exciter HQ470/40, emitter HQ500lp. Autoradiographic counts were made with transmitted incandescent light simultaneously with epifluorescent fields. A $100 \times 100$ $\mu \mathrm{m}$ ocular counting grid was used to define fields for epifluorescent signal counting. For each microscopic field, Cy3 signals, DAPI signals, Cy3/emulsion exposures, and DAPI/emulsion exposures were counted and recorded. Ten random microscopic fields were counted on each slide for statistical purposes. 


\section{Cultured isolate testing}

Four pure isolates were selected from our isolation program (see Chapter 3) for use in testing the STAR-FISH staining protocol. JT-01 (Ruegeria atlantica), a member of the Roseobacter clade and a CO-oxidizer; JT-16, a non-CO-oxidizing unidentified Cytophaga species, and JT-21, a CO-oxidizing Cytophaga member most closely related to Cyclobacterium marinum. Liquid cultures were sealed in a vial under zero-grade air $(\sim 20 \mathrm{ppm} \mathrm{CO})$ and were incubated with injected ${ }^{14} \mathrm{C}-\mathrm{CO}$ for a final dissolved [CO] of 40 $n M$ for 1-4 days. The bottles were incubated on a rotary shaker table at 100 RPM for 24 48 hours. At the end of the incubation the sample was preserved by the addition of 0.22 $\mu \mathrm{m}$-filtered formaldehyde to $4 \%$ final concentration. This concentration of fixative was found to be sufficient to stop uptake of labeled organic substances (Meyer-Reil, 1978). The entire sample was centrifuged for $10 \mathrm{~min}$. at 9,000 rpm, and the pellet was transferred to a $2.0 \mathrm{ml}$ centrifuge tube. The pellet was resuspended in $250 \mu \mathrm{l} 1 \mathrm{X}$ PBS and $750 \mu \mathrm{l} 4 \%$ paraformaldehyde solution, and placed in $4^{\circ} \mathrm{C}$ for two hours. The samples were centrifuged for $5 \mathrm{~min}$. at 9,000 RPM, and the pellet was resuspended in a mixture containing $100 \mu \mathrm{l} 4 \% \mathrm{PFA}$ and $100 \mu \mathrm{l}$ ethanol $(98 \%)$. Samples were stored at $-20^{\circ} \mathrm{C}$ when not in use.

STARFISH ${ }^{14}$ C-CO incubation April 7, 2003

Coastal marine microbial assemblages were sampled at 0.5 -meter depth at the Vineyard Sound sampling location (see Chapter 2) in a sterile glass bottle affixed to a pole. The sample was subdivided in the laboratory to perform several parallel analyses: 
AODC or DAPI direct counting, rates of ${ }^{14} \mathrm{C}$-CO oxidation to ${ }^{14} \mathrm{C}-\mathrm{CO}_{2},{ }^{14} \mathrm{C}$-CO-carbon uptake for microautoradiographic analysis, and whole-cell hybridization (figure 4.2).

Seawater sample $(1.8 \mathrm{ml})$ was stained for $10 \mathrm{~min}$ by the addition of $0.2 \mathrm{ml} 0.1 \%$ acridine orange (final concentration $0.01 \%$ ) or alternatively for $1 \mathrm{~min}$. with DAPI (1.0 $\mu \mathrm{g} / \mathrm{ml}$ final concentration) within one hour of sample collection. The cells were gently vacuum filtered $(5 \mathrm{~mm} \mathrm{Hg}$ ) onto a Sudan Black-stained $0.22 \mu \mathrm{m}$ nucleopore membrane and enumerated by epifluorescence microscopy (Hobbie et al., 1977)).

${ }^{14} \mathrm{C}$-CO oxidation assay. (refer to Chapter 2 methods and materials)

Autoradiographic procedure.

Uptake of radioactivity by microorganisms was determined with a microautoradiographic technique based primarily on the "MARGE-E" procedure developed by Tabor and Neihof (1982), and the general procedures for autoradiography with liquid emulsions described by various authors (Andreasen \& Neilsen, 1997). LM-1 hypercoat emulsion was the photographic medium used in our STARFISH assays (Amersham Pharmacia biotech, 1999). Each gram of LM-1 hypercoat emulsion contains the equivalent of $0.09 \mathrm{~g}$ of silver $(\mathrm{Ag})$ with an average crystal diameter of $0.2 \mu \mathrm{m}$ (when exposed and developed), $0.023 \mathrm{~g}$ gelatin and $1 \%(\mathrm{w} / \mathrm{v})$ plasticiser. An ethanol-cleaned 3" x 1" glass microslide was dipped in $0.1 \%$ gelatin at $46^{\circ} \mathrm{C}$ to create a gelatin sublayer (figure 4.1). After the gelatin layer was dry, the coated slide was immersed for $15 \mathrm{sec}$. in diluted LM-1 ( 1 part emulsion to 1 part $0.1 \%$ gelatin solution improved cell adhesion 
compared to layering with emulsion only) (Amersham Pharmacia Biotech) maintained at $46^{\circ} \mathrm{C}$ under darkroom conditions (Kodak safelight filter GBX-2 placed $1 \mathrm{~m}$ away from the workspace). Later, a NightVision ${ }^{\mathrm{TM}}$ head-mounted IR illumination system was used in lieu of the safelight when manipulating unexposed emulsion-coated slides so as to further reduce autoradiographic background. The slide was drained horizontally for 20 sec. to produce a thin emulsion film. The emulsion was allowed to dry in the dark for 5 min. at room temperature.

Initial microautoradiographs showed large incidental radiographic exposures as a result of bioluminescent eucaryotic organisms present in the raw sample. To remove these organisms, sample watter was $10.0 \mu \mathrm{m}$ filtered. One hundred $\mathrm{ml}$ of $10 \mu \mathrm{m}$ - filtered sample water was sealed within a $120 \mathrm{ml}$ glass serum vial, and injected with ${ }^{14} \mathrm{C}-\mathrm{CO}$ to result in a dissolved [CO] of $20 \mathrm{nM}$. Subsamples were removed at $2 \mathrm{hr} ., 4 \mathrm{hr} ., 6 \mathrm{hr}$., and $24 \mathrm{hr}$. intervals and were fixed with formaldehyde to a final concentration of $4 \%$. These subsamples were filtered onto $0.22 \mu \mathrm{m}$ filters and transferred to emulsion coated glass microscope slides to undergo autoradiography, FISH, and DAPI staining. The wet sample filters were applied with the sample side placed on the emulsion film carefully to exclude bubbles and to avoid lateral movement of the filter against the semi-solid emulsion. The slides were placed in a light-tight slide box containing a packet of silicon desiccant and allowed to set for another $3 \mathrm{hr}$., following the manufacturer's recommendations. After the emulsion was completely dry, the wooden light-tight slide box was wrapped in aluminum foil and placed at $4^{\circ} \mathrm{C}$ for radiographic exposure. 


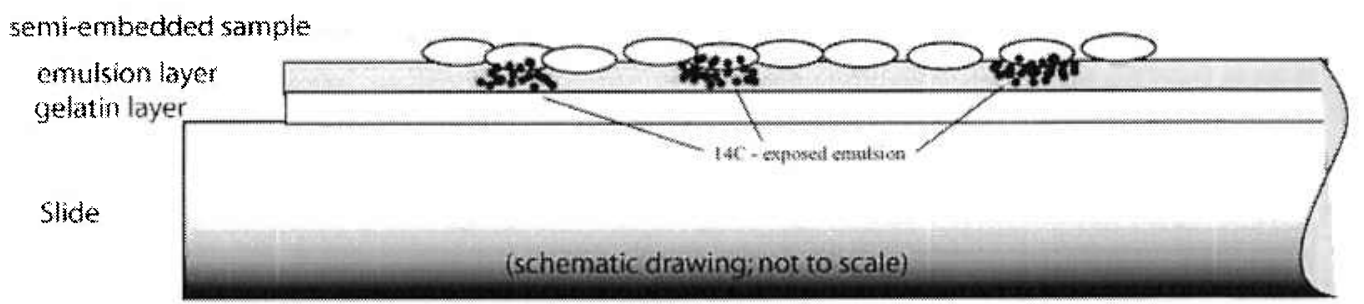

Figure 4.1: Side view of STARFISH cell adhesion protocol. Cells are partially embedded in the autoradiographic gelatin / emulsion mixture, so that silver grain exposure does not occlude fluorescence signal by either DAPI or Cy3 label. The gelatin sub-layer aids in cell retention throughout the process to within $90 \%$ of direct counts. 
After the emulsion slides had been exposed for 1-3 days, they were developed using a standard photographic procedure. In the dark, slides were immersed in a staining jar containing Kodak GBX developer at $20^{\circ} \mathrm{C}$ (ambient lab temperature) for $5 \mathrm{~min}$. They were transferred to $0.5 \%$ acetic acid in de-ionized water as a stop solution for 30 sec., and fixed for $10 \mathrm{~min}$. in Kodak GBX fixer solution. The developer and fixer solutions were diluted per manufacturer's directions. The slides were rinsed for $20 \mathrm{~min}$. in gently flowing tap water in a de-staining tray. After air-drying, the filter was gently peeled away from the emulsion film while gently breathing onto the backside of the filter. Attempting to peel the off the filter without humidifying resulted in tearing of the filter or removal of the emulsion film from the slide. Cells were dehydrated in an ethanol series $(50 \%, 80 \%, 98 \%$ aqueous ethanol, v/v, 3 min. each) (Stahl \& Amann, 1991). The slides may be stored at room temperature indefinitely, or FISH/DAPI processed immediately. Developed emulsion slides are FISH- and DAPI stained as previously described. 


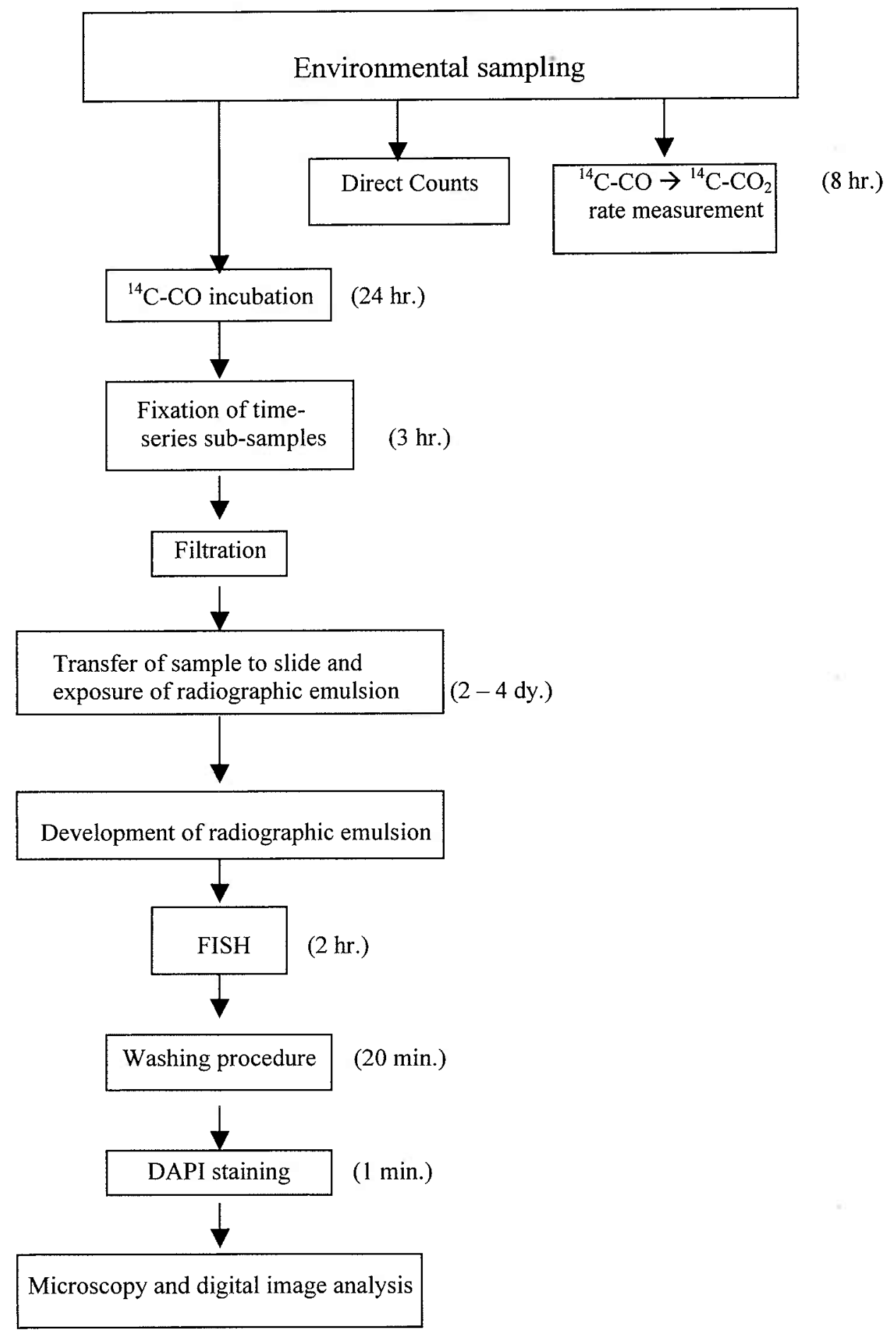

Figure 4.2: Order of staining operations for STARFISH triple-labeled samples. Times required for each step are included parenthetically. This sequence was found to minimize background silver grain exposure and DAPI absorption by the emulsion layer. 


\section{RESULTS and DISCUSSION}

Roseobacter and Paracoccus are phylogenetically closely related genera within the alpha subgroup of the Proteobacteria, therefore, fine scale discrimination between these two sister groups using oligonucleotide probes targeted to the same region of $16 \mathrm{~S}$ rDNA necessarily must occur under strict stringency conditions. A high formamide concentration in combination with non-labeled competitor probes during whole-cell hybridization enabled differentiation between these sister groups. One mismatch to the ROSEO536R probe sequence was found after searching all non-target eubacterial and archaebacterial 16S-rDNA sequence data accessible through the RDPII (http://rdp.cme.msu.edu) and Genbank (http://www.ncbi.nlm.nih.gov) databases. A competitor probe ROSEOC536R recognizing this single and consistent mismatch was used in hybridization experiments with natural samples in conjunction with probe ROSEO536R to maximize probe specificity of ROSEO536R by blocking this binding site of those species containing the single mismatch (Amann et al. 1990, Brinkmeyer et al., 2000). The use of the ROSEO536R probe and competitor ROSEOC536R, and PARA536R and competitor PARAC536R, allow separate enumeration of Roseobacter and Paracoccus, collectively the marine alpha group, in natural samples.

All hybridizations were performed at a uniform temperature. Several of the taxon-specific probes reported by Brinkmeyer et al. (2000) exhibited attenuation of fluorescent signal at the higher formamide concentrations necessary to achieve optimal stringency at $46^{\circ} \mathrm{C}$, and optimal formamide concentrations for ROSEO536R and ROSEOC $536 \mathrm{R}$ were reported as $15-18 \%$ at $50^{\circ} \mathrm{C}$. In following these recommendations, 
however, we found the opposite; fluorescence by target type cells hybridized at their modified temperature and formamide concentrations was barely visible and impossible to count. Therefore, the optimal hybridization conditions for this study were re-evaluated. Optimal formamide concentration for high probe specificity at a $46^{\circ} \mathrm{C}$ hybridization temperature was determined by a formamide series with pure cultures (figure 4.3) and mixed cultures (figure 4.4) of Roseobacter and Paracoccus cells, and visualization of fluorescent signal brightness in natural samples. In FISH hybridizations using only ROSEO536R without the competitor probe, we found that $40 \%$ formamide in the hybridization buffer created the stringency required to discriminate between Roseobacter-clade cells, and closely related cells having the single mismatch at E.coli position 545 (figure 4.3). We decided that the ROSEO/ROSEOC combination in combination with the formamide concentration would produce clearer and more consistent discrimination of target from non-target organisms.

General staining with DAPI remained as the last step (refer to figure 4.2). We found that pre-staining the STARFISH time-series subsamples with DAPI or acridine orange prior to emulsion exposure produced a large autoradiographic background, probably due to residual fluorescence of the fluorochrome after light exposure. DAPI concentration and staining time was further modified from literature values. Rapid diffusion of DAPI into the gel/emulsion layer and its resulting resistance to rinsing produced a strong fluorescent background in the microscopic field, making total cell counts difficult and inaccurate. One minute of direct staining using $1 \mu \mathrm{g} / \mathrm{ml}$ DAPI was sufficient to stain the cells without excess retention of DAPI in the emulsion layer. 
To calculate the $\mathrm{CO}$ that could potentially be oxidized by target group cells, the relative densities of these groups in natural samples were multiplied by specific $\mathrm{CO}$ oxidation rate measurements of the coastal CO oxidizing isolates (Chapter 3). Because these specific rate measurements were conducted at $19-20^{\circ} \mathrm{C}$ (laboratory ambient temperature), and the STARFISH experiment was conducted at in situ temperature $\left(6^{\circ} \mathrm{C}\right.$, March, 2003), a parallel CO oxidation experiment was conducted at two temperatures to determine the Arrhenius correction required. The rate of overall $\mathrm{CO}$ oxidation in the natural sample at $19^{\circ} \mathrm{C}$ was $0.077 n M \mathrm{hr}^{-1}$ greater than at $6^{\circ} \mathrm{C},(20 \%$ increase $)$, and the dissolved $[\mathrm{CO}]$ in the $6^{\circ} \mathrm{C}$ incubation was $21 \%$ greater than at $19^{\circ} \mathrm{C}$. Both samples had been stripped of natural $\mathrm{CO}$ before incubation with ${ }^{14} \mathrm{C}-\mathrm{CO}$, and injected with precise and equal volumes of labeled $\mathrm{CO}$. When the rate coefficient $k_{c o}$ was calculated from these values for rate and [CO], we determined that $k_{c o}$ was $54 \%$ higher at $19^{\circ} \mathrm{C}$ than at $6^{\circ} \mathrm{C}$ (figure 4.5). The rate coefficients and specific rates of $\mathrm{CO}$ oxidation that were measured for $\mathrm{CO}$ oxidizing isolates determined at $20^{\circ} \mathrm{C}$ were therefore adjusted for lower field temperature by application of the Arrhenius equation, $k=A e^{-E a / R T}$, where the frequency factor A was calculated for the rate coefficient for each isolate at $20^{\circ} \mathrm{C}$, the universal gas constant $\mathrm{R}=8.314$ joules $\mathrm{deg}^{-1} \mathrm{~mol}^{-1}$, and $\mathrm{T}=$ temperature in Kelvins. The activation energy $E_{a}=26.13 \mathrm{KJ} \mathrm{mol}^{-1}$ was calculated from the slope of a best fit line in a graph of $\log k_{c o}$ versus $1 / \mathrm{T}$ from the two temperature $\mathrm{CO}$ oxidation experiment $\left(E_{a}=\right.$ slope $\left.\times-2.303 \mathrm{R}\right)$ (figure 4.6) (Daniels \& Alberty, 1967). 
Figure 4.3: Formamide series. $40 \%$ formamide within the hybridization buffer (HB) was necessary to permit discrimination between Roseobacter family cells from Paracoccus having a single consistent mismatch from ROSEO536R, without use of a competitor probe having exact sequence compliment to the mismatch. Cy3 fluorescence signal in Paracoccus (right side in each pair) is absent at $40 \%$ formamide in the hybridization buffer (negative images). 


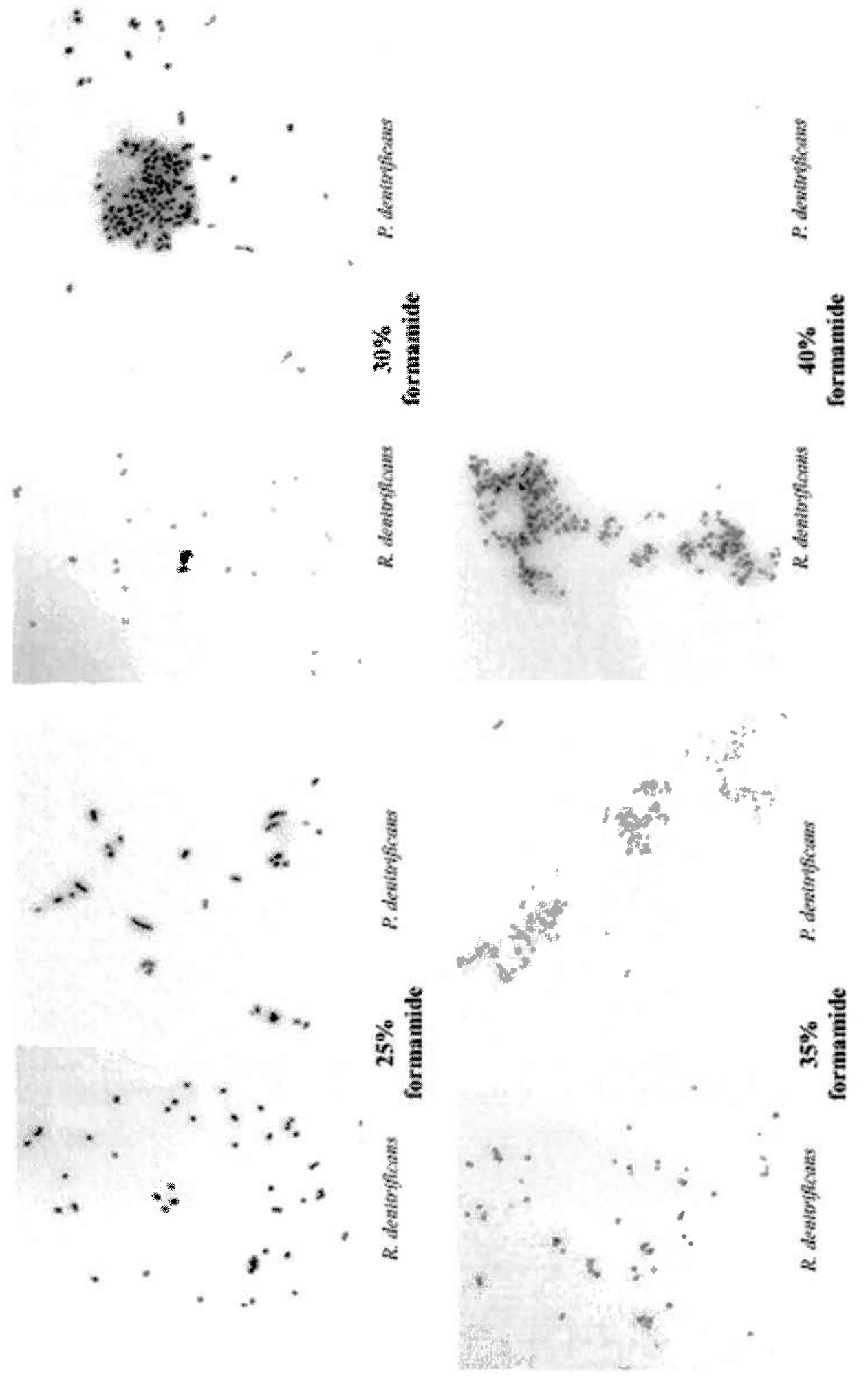


Figure 4.4: Mixed binary culture of Roseobacter litoralis and Paracoccus denitrificans. Digital overlay of microscopic fields viewed with UV to show DAPI stained cells, and $500 \mathrm{~nm}$ long pass filter to view Cy3-labeled target cells. Roseobacter cells are illuminated by ROSEO536R used in combination with the competitive probe ROSEOC536R and at $40 \%$ formamide stringency and appear pink, while Paracoccus stained only with DAPI appear blue. This demonstrates fine-scale discrimination between cells having exact and single-mismatch sequences to the ROSEO probe. 


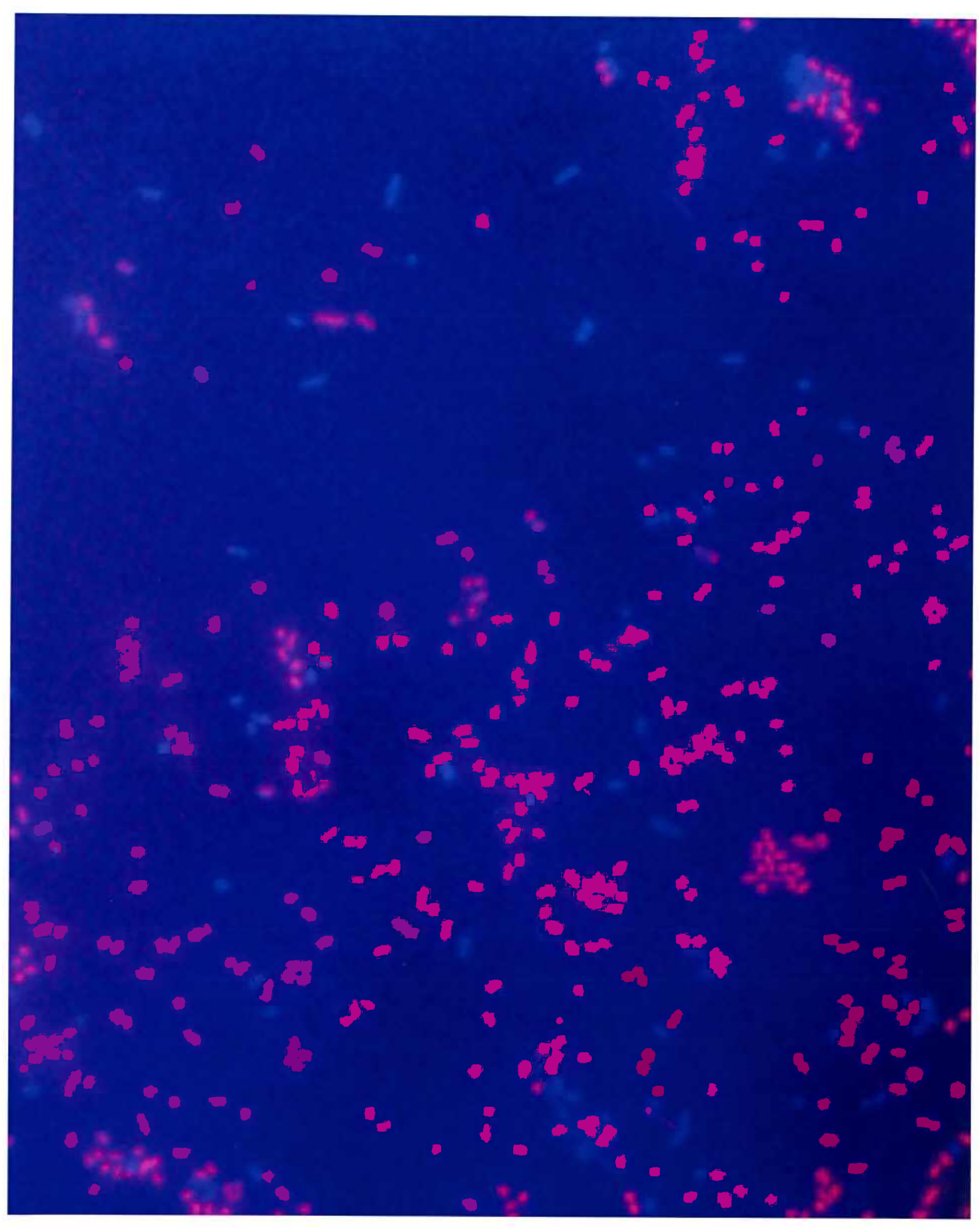




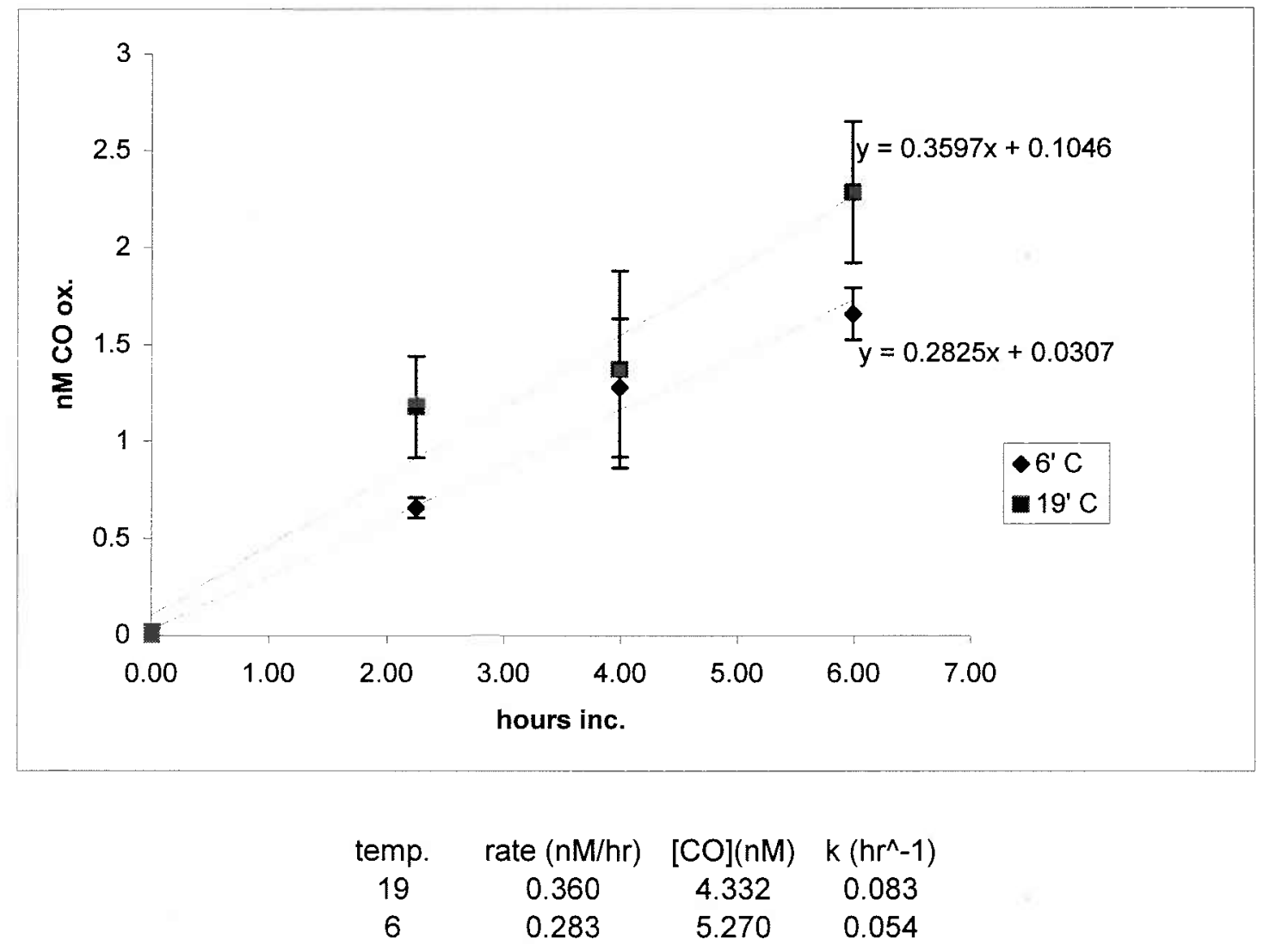

Figure 4.5: Two-temperature $\mathrm{CO}$ oxidation test. $\mathrm{CO}$ oxidation in natural seawater progressed at a lesser rate at in situ temperature $\left(6^{\circ} \mathrm{C}\right)$ than at laboratory ambient temperature $\left(19^{\circ} \mathrm{C}\right)$. Rate coefficients for pure isolates determined at $20^{\circ} \mathrm{C}$ require correction before application to in situ rate calculations. 


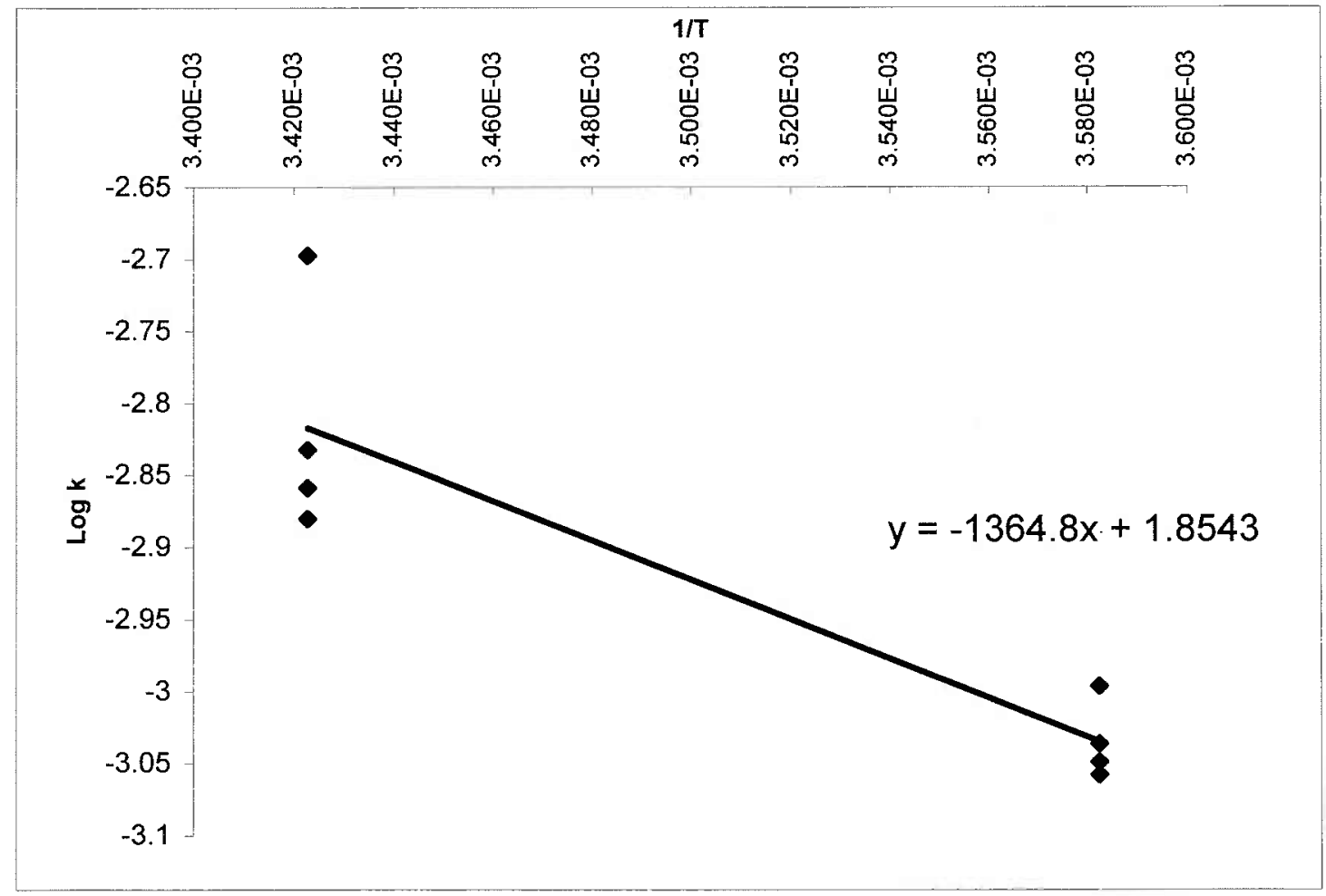

Figure 4.6: Graph of $\log k_{c o}$ versus 1/T for CO oxidation by in situ microbial assemblage, from which the Arrhenius activation energy $E_{a}$ was calculated from the slope. 


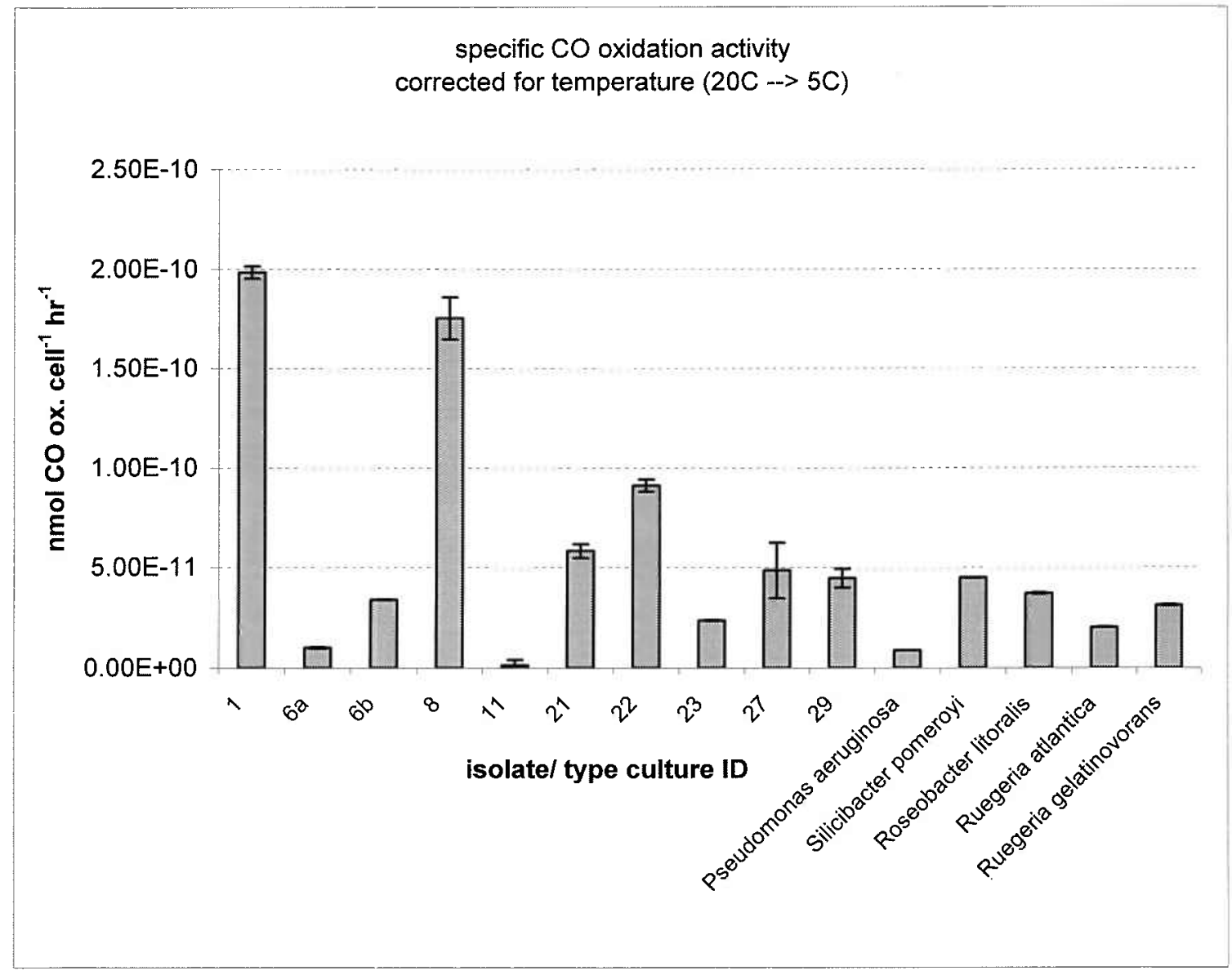

Figure 4.7: Specific $\mathrm{CO}$ oxidation activity for active $\mathrm{CO}$ oxidizing isolates and type cultures, corrected for temperature in rate coefficients $k_{c o}$ determined at $20^{\circ} \mathrm{C}$ for pure cultures and applied to incubations at $5^{\circ} \mathrm{C}$. 
The temperature-adjusted rate constants for the pure culture isolates were approximately $35 \%$ lower when applied to $5^{\circ} \mathrm{C}$ (figure 4.7) than at $20^{\circ} \mathrm{C}$ (figure $3.11,3.15$ ).

Two factors affect the value of $k_{c 0}$ : the temperature during incubation and dissolved [CO] that varies inversely with temperature. The pre-and post-correction $k_{c o}$ values yield $Q_{10}=1.2$, a departure from the general rule that reaction rates approximately double with every $10^{\circ}$ increase in temperature $\left(Q_{10}=\sim 2\right)$. If we postulate that $\mathrm{CO}$ behaves as a non-gaseous solute (concentration non varying with temperature), and adjust $k_{c o}$ only for temperature effect, then $Q_{10}$ becomes 1.73 , much nearer the rule-of-thumb value. Since both temperature and its effect on dissolved [CO] are in fact operative in this experiment, we will accept the low value of $Q_{10}$ and use the $k_{c o}$ values corrected for both variables in our rate calculations.

The STARFISH experiment began with a sample collected from the Vineyard Sound collection site (figure 2.1) on April 7, 2003. The gross rate of $\mathrm{CO}$ oxidation $\left(0.0882 n M\right.$ CO oxidized $\left.\mathrm{hr}^{-1}, k_{c o}=0.021 \mathrm{hr}^{-1}\right)$ was determined via ${ }^{14} \mathrm{C}-\mathrm{CO}$ oxidation assay (figure 4.8) begun within 1 hour of sampling. Microscopic direct counts of sample water showed a total cell density of $1.17 \times 10^{6} \pm 2.25 \times 10^{4}$ cells/ml (mean $\pm \mathrm{SEM}$, $\mathrm{n}=10$ ). After the STARFISH incubation sub-samples had been triple labeled and mounted, microscopic counts of cells in the same field under four different regimes of illumination per field were recorded. The UV 552/568 (absorb/emit) filter set illuminated cells that had reacted with $\mathrm{Cy3}$-labeled probes. Separate slide sets were prepared to enumerate Roseobacter (figure 4.9) and Paracoccus separately, by their respective probe sets. 


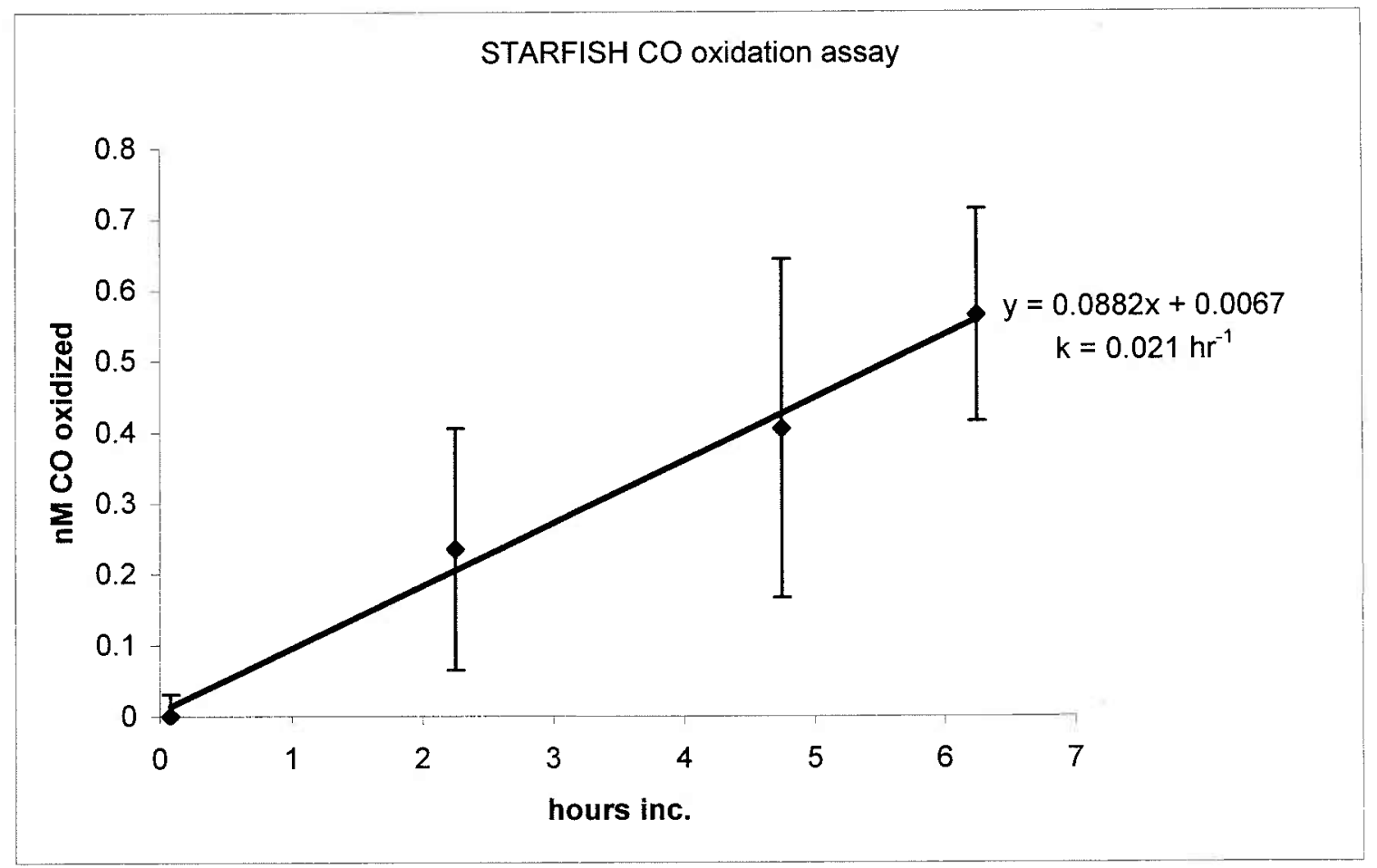

Figure 4.8: CO oxidation assay for STARFISH experiment. Four time-point incubation conducted at in situ $\left(6^{\circ} \mathrm{C}\right)$ temperature, $25 \mathrm{ml}$ volumes of natural sample, $\mathrm{n}=2$ for each time-point. 
Figure 4.9: Representative counting field for STARFISH enumeration of $\mathrm{CO}$ metabolizing Roseobacter cells in natural coastal sample. Cells fixed after 6 hours of incubation with ${ }^{14} \mathrm{C}-\mathrm{CO}$.

Upper Left: Cy3 signal from Roseobacter specific staining.

Upper Right: Cy3 and transmitted light image of Roseobacter and ${ }^{14} \mathrm{C}$-containing cells.

Lower Left: DAPI stained cells. (total)

Lower Right: DAPI and transmitted light image. 

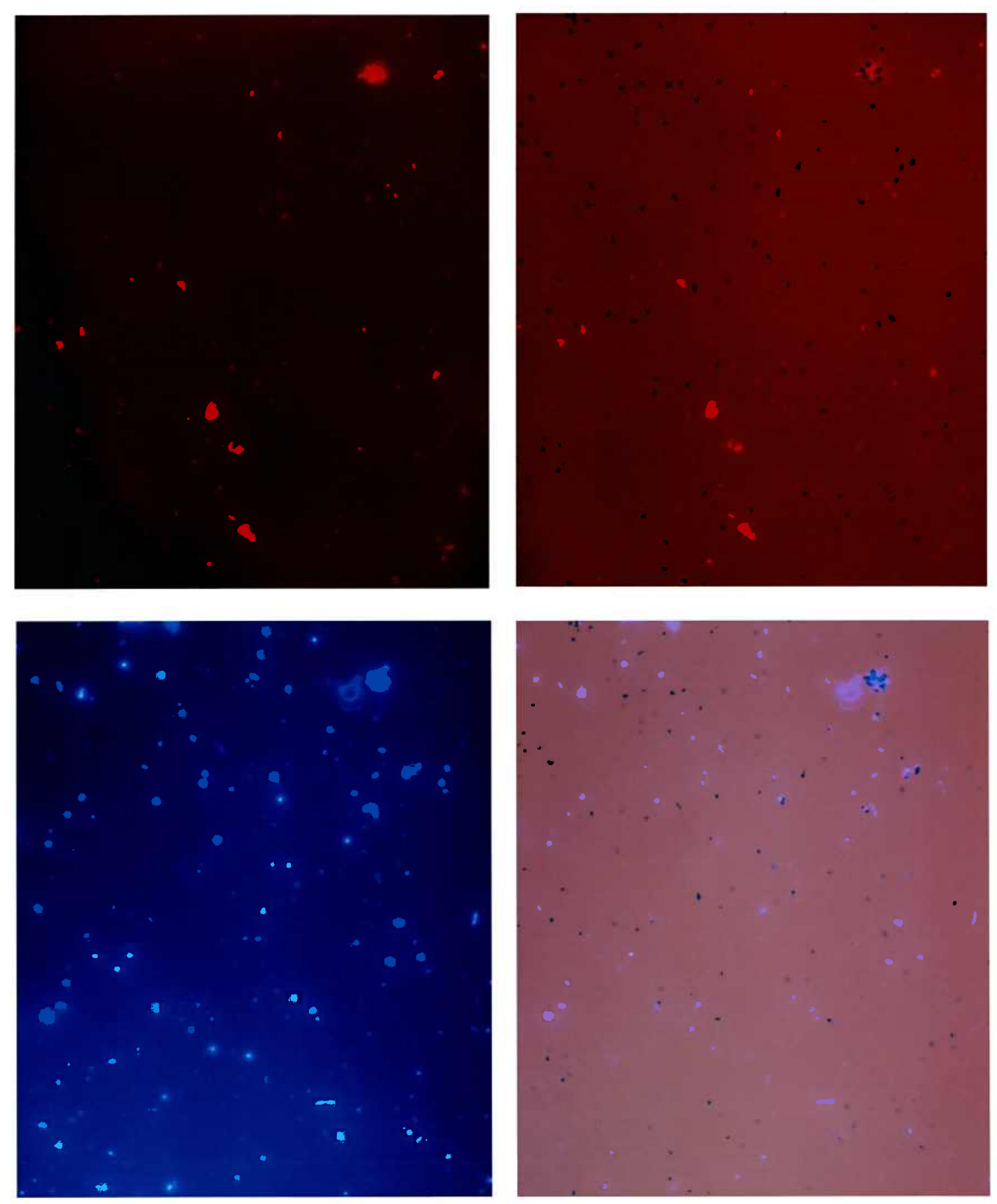
Simultaneous use of UV and transmitted light allowed visualization of Cy3-labeled cells that incorporated label from ${ }^{14} \mathrm{C}$-CO. The UV $360 / 420$ filter set allowed visualization of all cells stained with DAPI and a total cell count. A fourth enumeration was made of DAPI-stained cells that incorporated label from ${ }^{14} \mathrm{C}-\mathrm{CO}$ in each microscopic field.

Total cell counts on STARFISH slides were compared with direct filter counts to establish quantitative cell retention during the STARFISH preparations. Within experimental error, cells that were mounted on slide emulsions from filters and undergoing the multiple immersions and rinses in the STARFISH protocol were quantitatively retained on the slides. Early experiments possessed only $60 \%-70 \%$ cell retention after STARFISH treatments, until rinsing under flowing water was replaced with gentle static immersion in rinse fluid to avoid the mechanical removal of cells from the emulsion layer.

In situ cell density for each probe-targeted group was estimated by calculating the ratio of Cy3 signals to DAPI signals per microscopic field ( $\mathrm{n}=10$ per light field (4), per slide (2), per time-point (4)). This ratio was multiplied by DAPI direct count of the sample, resulting in a group-specific cell density for Roseobacter and Paracoccus cells in the natural sample (figure 4.10 ). The marine alpha group composed $45.7 \%$ of the total microbial assemblage at the time of sampling ( +2 hours), and increased to $65 \%$ of the assemblage after 24 hours of ${ }^{14} \mathrm{C}-\mathrm{CO}$ incubation at $5^{\circ} \mathrm{C}$. Approximately $10 \%$ of $\mathrm{Cy} 3-$ labelled Roseobacter cells also had an autoradiographic signal attached, and nearly $20 \%$ of Cy3-labelled Paracoccus were active in ${ }^{14} \mathrm{C}$-CO metabolism. 


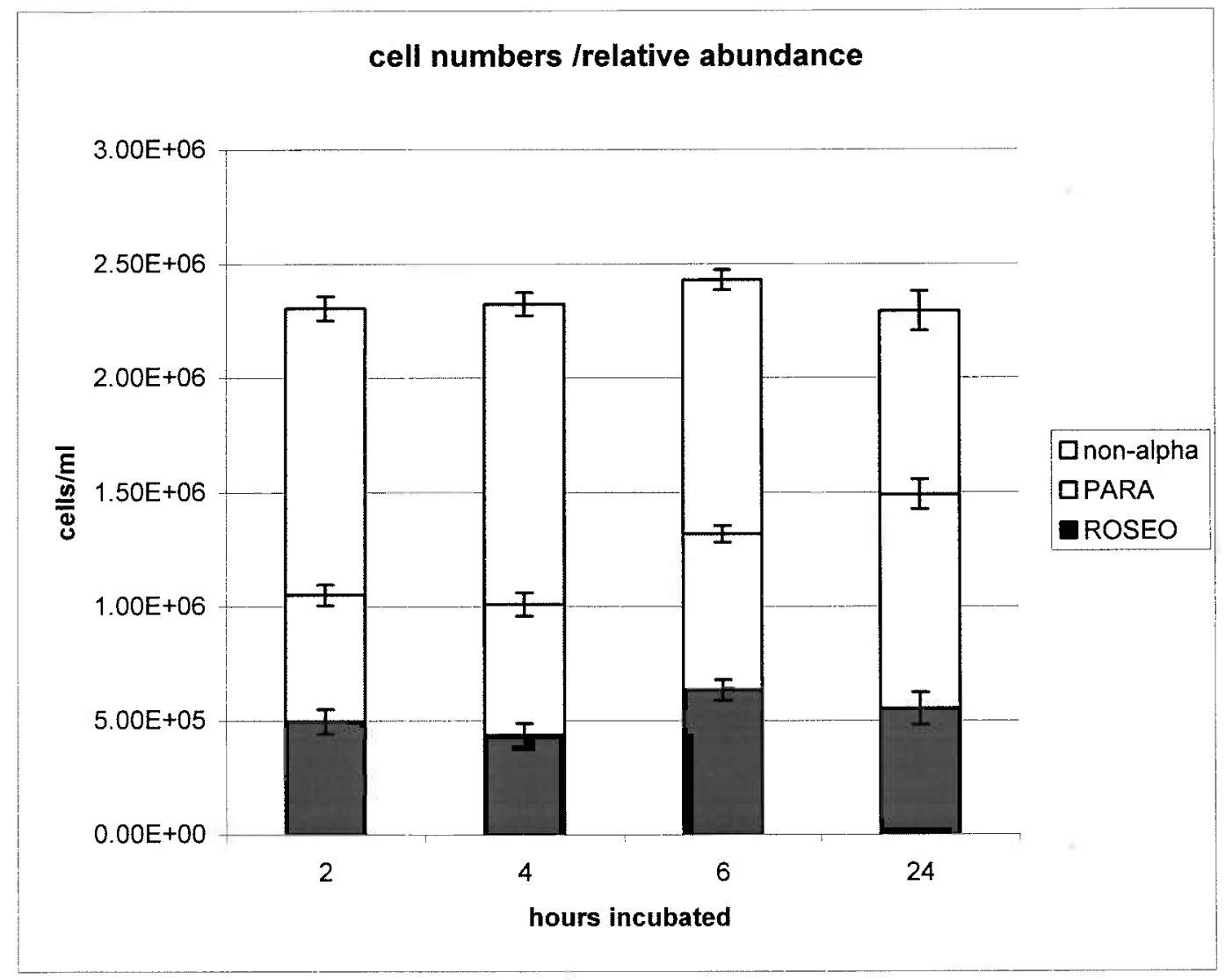

Figure 4.10: Differential cell counts in STARFISH preparations, (scaled). Roseobacter Cy3 signals (bottom), Paracoccus Cy3 signals (middle), and difference (total DAPI signal minus Cy3 signal) (top) 

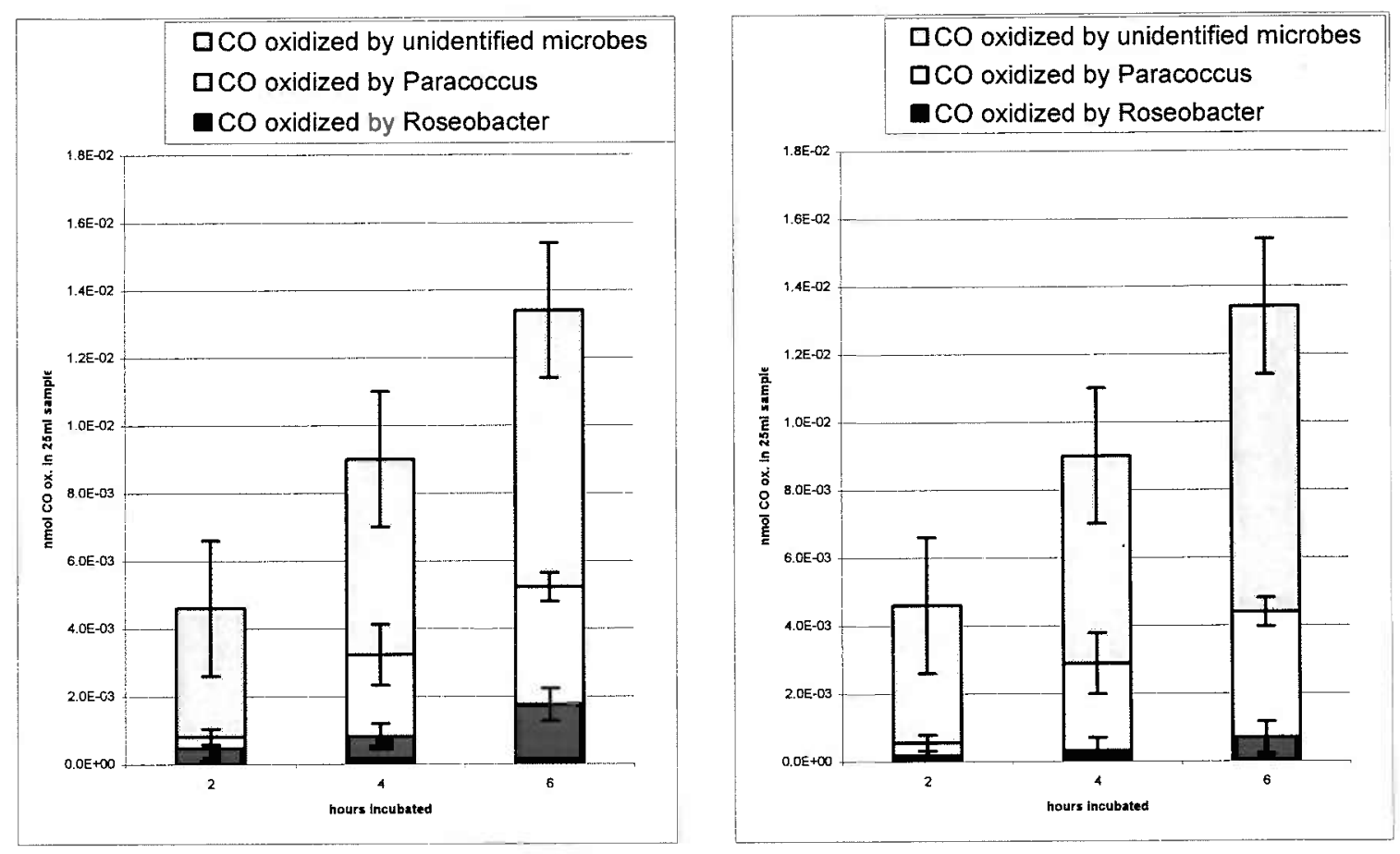

Figure 4.11: CO oxidized by target groups. Roseobacter(bottom), Paracoccus ( $2^{\text {nd }}$ from bottom), and unaccounted residual $\mathrm{CO}$ oxidized (top). Graph on left shows the maximum $\mathrm{CO}$ oxidation values based on isolates with greatest cell specific activities for Roseobacter (JT-08) and Paracoccus (JT$01)$. The graph on the left shows the average $\mathrm{CO}$ oxidation values based on average cell specific CO oxidation activities for Roseobacter (6 spp.) and Paracoccus (JT-01, 2 growth conditions) 
The ratio of Cy3- and ${ }^{14} \mathrm{C}$-positive cells to DAPI-positive cells on the STARFISH slides, multiplied by cell density determined by DAPI direct counts on separate slides, yielded the relative density of active CO-metabolizing cells belonging to Roseobacter or Paracoccus groups. These activity- and group-specific cell densities (cells $\mathrm{ml}^{-1}$ ) were multiplied by the specific CO-oxidation activity term (nmolCO oxidized $\mathrm{cell}^{-1} \mathrm{hr}^{-1}$, corrected for temperature difference), to estimate the molar amount of CO oxidized that could be attributed to Roseobacter and Paracoccus organisms.

A maximum estimate of $\mathrm{CO}$ oxidation activity attributed to Roseobacter and Paracoccus was determined by using the cell specific $\mathrm{CO}$ oxidation activities of the isolates exhibiting the highest specific CO oxidation activities of each group (JT-01, JT08; figure 4.7). A second, more conservative estimate was calculated using average values of $\mathrm{CO}$ oxidation activity by Roseobacter and Paracoccus (figure 4.11). The sole CO oxidizing Paracoccus strain in our study, JT-01, oxidized CO at a rate two-fold greater than other isolates except JT-08, a Roseobacter strain. Since the average specific $\mathrm{CO}$ oxidation activity value that can be calculated for Paracoccus pertains to only one strain grown in two different nitrogen-containing media $(n=2)$, the average CO oxidation attributed to Paracoccus is large since the maximum and average values are similar. The average activity for Roseobacter, however, is more certain as six isolates and type strains were confirmed as CO oxidizing organisms $(n=8)$ with only one having an anomalously high specific rate. 
Up to $40.7 \%$ of total $\mathrm{CO}$ oxidation at this sampling can be attributed to marine alpha group organisms isolated from the environment and their specific metabolic rates that we obtained in Chapter 3. After 2 hours of incubation with ${ }^{14} \mathrm{C}-\mathrm{CO}$, there is a low density of ${ }^{14} \mathrm{C}$-labeled cells of any variety, suggesting that there is a time dependence on label uptake before intracellular ${ }^{14} \mathrm{C}$ reaches a threshold activity sufficient to create an autoradiographic signal. ${ }^{14} \mathrm{C}$-positive signal ratio, the relative numbers of Roseobacter and Paracoccus, and thus, the CO-oxidation activity attributed each group, vary only slightly with time after 4 hours of ${ }^{14} \mathrm{C}$-CO incubation. After six hours of incubation with ${ }^{14} \mathrm{C}-\mathrm{CO}$, active $\mathrm{CO}$-metabolizing cells belonging to the Roseobacter group account for $5.2 \%-13.1 \%$ of total $\mathrm{CO}$ oxidation, and Paracoccus $\mathrm{CO}-\mathrm{metabolizing}$ cells account for $25.8 \%-27.6 \%$. Thus, $31 \%-40.7 \%$ of total in situ $\mathrm{CO}$ oxidation is attributed to the marine alpha group collectively. This value is less than the initial estimate that was based on rate coefficients, made in Chapter $3(50 \%)$, but is still a substantial fraction of the total activity.

The marine alpha group organisms are emerging as numerically dominant and metabolically versatile in various marine habitats. The ability of Roseobacter and its sister taxon Paracoccus to oxidize photolytically produced $\mathrm{CO}$, and the large relative proportion of total in situ $\mathrm{CO}$ oxidation for which they are accountable has been hitherto unreported.

We have in pure culture several microorganisms isolated from coastal seawater that are not closely related to the marine alpha group but are capable CO-oxidation at environmentally relevant levels. These have representatives in betaproteobacteria, 
gammaproteobacteria, and the phylum Bacteroidetes (Chapter 3). The relative proportion of total $\mathrm{CO}$ oxidation performed by these groups cannot yet be resolved in natural samples because we have not enumerated these component groups via the STARFISH assay. By using extant general oligonucleotide probes for these phylogenetic groups, it is a viable and practical endeavor to enumerate these groups in natural waters and determine their relative contributions to the total CO-metabolism occurring there. With use of group-specific probes in STARFISH, the efficacy of this assay has been demonstrated for quantifying a numerically and metabolically important phylogenetic group contributing to a natural chemical transformation that occurs in marine environments. A more complete picture of the $\mathrm{CO}$ oxidizing marine community may be obtained when more CO-oxidizing taxa have been quantified and included in the $\mathrm{CO}$ oxidation budget. 


\section{BIBLIOGRAPHY}

Amann, R.I., Krumholz, L., and Stahl, D.A. (1990). Fluorescent-oligonucleotide probing of whole cells for determinative, phylogenetic, and environmental studies in microbiology. J. Microbiol. 172:762-770

Amann, R.I., Ludwig, W., and Schleifer, K-H. (1995). Phylogenetic identification and in situ detection of individual microbial cells without cultivation. Microbiol. Rev. 59(1):143-169

Amann, R. (2000). Who is out there? Microbial aspects of biodiversity. System. Appl. Microbiol. 23:1-8

Amersham Pharmacia biotech (1999). Hypercoat emulsions: Micro autoradiography emulsions for the detection of radiolabeled compounds. Product information and guidelines for LM-1 and EM-1 emulsions. Amersham Pharmacia Biotech, Piscataway, NJ.

Andreasen, K and Nielsen P.H. (1997). Application of microautoradiography to the study of substrate uptake by filamentous microorganisms in activated sludge. Appl. Environ. Microbiol. 63(9):3662-3668

Ashen J.B. and Goff, L.J. (1996). Molecular identification of a bacterium associated with gall formation in the marine red algae Prionitis lanceolata. J. Phycol., 32:286297

Ashen J.B. and Goff, L.J. (2000). Molecular and ecological evidence for species specificity and coevolution in a group of marine algal-bacterial symbioses. Appl. Environ. Microbiol. 66:3024-3030

Bano, N., and Hollibaugh, J.T. (2002). Phylogenetic composition of bacterioplankton assemblages from the arctic ocean. Appl. Environ. Microbiol. 68:505-518

Barbieri, E., Gulledge, J., Moser, D., and Chien, C.-C.; (1996). New evidence for bacterial diversity in the accessory nidamental gland of the squid (Loligo pealei). Biol. Bull. 191:316-317

Brinkmeyer, R., Rappe, M., Gallacher, S., and Medlin, L. (2000). Development of clade (Roseobacter and Alteromonas) and taxon-specific oligonucleotide probes to study interactions between toxic dinoflagellates and their associated bacteria. Eur. J. Phycol. 35:315-329

Daniels, F. and Alberty, R. (1967). Physical Chemistry, $3^{\text {rd }}$ Ed. John Wiley \& Sons, Inc., New York 
Delong, E.F., Wickham, G.S., and Pace, N.R. (1989). Phylogenetic stains: ribosomal RNA-based probes for the identification of single cells. Science 243:1360-1363

DeLong, E.F. and Shah, J. (1990). Fluorescent, ribosomal RNA probes for clinical application: A research review. Diagn. Clin. Test. 28:41-44

DeLong, E.F, Taylor, L.T., Marsh, T.L., and Preston, C.M. (1999). Visualization and enumeration of marine planktonic archaea and bacteria by using polyribonucleotide probes and fluorescent in situ hybridization. Appl. Environ. Microbiol. 65(12):5554-5563

Eilers, H., Pernthaler, J., Glöckner, F.O., and Amann, R. (2000). Culturability and in situ abundance of pelagic bacteria from the North Sea. Appl. Environ. Microbiol. 66:3044-3051

Eilers, H., Pernthaler, J., Peplies, J., Glöckner, F.O., Gerdts, G., and Amann, R. (2001). Isolation of novel pelagic bacteria from the German Bight and their seasonal contributions to surface picoplankton. Appl. Environ. Microbiol. 67:5134-5142

Giovannoni, S.J., Britschgi, T.B., Moyer, C.L., and Field, K.G. (1990). Genetic diversity in Sargasso Sea bacterioplankton. Nature 345:60-64

Giovannoni, S.J., DeLong, E.F., Olsen, G.J., and Pace, N.R. (1988). Phylogenetic groupspecific oligodeoxynucleotide probes for identification of single microbial cells. J. Bacteriol. 170:720-726

González, J.M. and Moran, M.A. (1997). Numerical dominance of a group of marine bacteria in the $\alpha$-subclass of the Class Proteobacteria in coastal seawater. Appl. Environ. Microbiol. 63(11):4237-4242

González, J.M., Mayer, F., Moran, M.A., Hoson, R.E., and Whitman, W.B. (1997). Sagittula stellata gen. nov, sp. nov., a lignin-transforming bacterium from a coastal environment. Int. J. Syst. Bacteriol. 47:773-780

González, J.M., Kiene, R.P., and Moran, M.A. (1999). Transformation of sulphur compounds by an abundant lineage of marine bacteria in the $\alpha$-subclass of the class Proteobacteria. Appl. Environ. Microbiol. 65:3810-3819

Gosink, J.J., Herwig, R.P., and Stayley, J.T. (1997). Octadecabacter arcticus gen. nov., sp. nov. and $O$. antarcticus, sp. nov., nonpigmented, psychrophilic gas vacuolated bacteria from polar sea ice and water. Syst. Appl. Microbiol., 20:356-365 
Gram, L., Grossart, H-P., Schlingloff, A., and Kiørboe, T. (2002). Possible quorum sensing in marine snow bacteria: Production of acylated homoserine lactones by Roseobacter strains isolated from marine snow. Appl. Environ. Microbiol. 68:4111-4116

Grey, N.D., Howarth, R., Pickup, R.W., Jones, J.G., and Head, I.M. (1999). Substrate uptake by uncultured bacteria from the Genus Achromatium determined by microautoradiography. Appl. Environ. Microbiol 65(11):5100-5106

Hicks, R.E, Amann, R.I., and Stahl, D.A. (1992). Dual staining of natural bacterioplankton with 4',6-diamidino-2-phenylindole and fluorescent oligonucleotide probes targeting kingdom-level $16 \mathrm{~S}$ rRNA sequences. Appl. Environ. Microbiol. 58(7):2158-2163

Hobbie, J.E., Daley, R.J., and Jasper, S. (1977). Use of Nucleopore filters for counting bacteria by epifluorescence microscopy. Appl. Environ. Microbiol. 33:1225-1228

Kim, Y.M., and Hegeman, G.D. (1983). Oxidation of carbon monoxide by bacteria. Int. Rev. Cytol. 81: 1-31

Labrenz, M., Collins, M.D. , Lawson, P.A., Tindall, B.J., Braker, G., and Hirsh, P. (1998). Antarctobacter heliothermus gen. nov., sp. nov., a budding bacterium from hypersaline and heliothermal Ekho Lake. Int. J. Syst. Bacteriol., 48:13631372

Labrenz, M., Collins, M.D. , Lawson, P.A., Tindall, B.J., Schumann, P. and Hirsh, P. (1999). Roseovarius tolerans gen. nov., sp. nov., a budding bacterium with variable bacteriochlorophyll a production from hypersaline Ekho Lake. Int. J. Syst. Bacteriol., 49:137-147

Lafay, B., Ruimy, R., Rauch de Traubenberg, C., Breittmayer, V., Gauthier, M.J., and Christen, R. (1995). Roseobacter algicola sp. nov., a new marine bacterium isolated from the phycosphere of the toxin-producing dinoflagellate Prorocentrum lima. Int. J. Syst. Bacteriol. 45:290-296

Ledyard, K.M., DeLong, E.F., and Dacey, J.W.H. (1993). Characterization of a DMSPdegrading bacterial isolate from the Sargasso Sea. Arch Microbiol 160:312-318 
Lee, N., Nielsen, P.H., Andreason, K.H., Juretschko, S., Nielsen, J.L., Schleifer, K.H., and Wagner, M. (1999). Combination of Fluorescent ins situ hybridization and microautoradiography- a new tool for structure-function analyses in microbial ecology. Appl. Environ. Microbiol. 65(3):1289-1297

Massana, R., Murray, A.E., Preston, C.M., and DeLong, E.F. (1997). Vertical distribution and phylogenetic characterization of marine planktonic Archaea in the Santa Barbara Channel. Appl. Environ. Microbiol. 63:50-56

Manz, W., Amann, R., Ludwig, W., Wagner, M., and Schleifer, K.H. (1992). Phylogenetic oligonucleotide probes for the major subclasses of proteobacteria: problems and solutions. System. Appl. Microbiol. 15:593-600

Meyer-Reil, L-A. (1978). Autoradiography and epifluorescence microscopy combined for the determination of number and spectrum of actively metabolizing bacteria in natural waters. Appl. Environ. Microbiol. 36(3):506-512

Meyer, O., Jacobitz, S., and Kruger, B. (1986). Biochemistry and physiology of aerobic carbon monoxide-utilizing bacteria. FEMS Microbiol. Rev. 39:161-179

Ouverney, C.C, and Fuhrman, J.A. (1999). Combined microautoradiogfraphy-16S rRNA probe technique for determination of radioisotope uptake by specific microbial cell types. Appl. Environ. Microbiol. 65(4):1746-1752

Pernthaler, A., Pernthaler, J., Schattenhofer, M., and Amann, R. (2002). Identification of DNA-sythesizing bacterial cells in coastal North Sea Plankton. Appl. Environ. Microbiol. 68:5728-5736

Petursdottir, S.K., and Kristjansson, J.K. (1997). Silicibacter lacuscaerulensis gen. nov., sp. nov. a mesophilic moderately halophilic bacterium characteristic of the Blue Lagoon geothermal lake in Iceland. Extremophiles 1:94-99

Rath, J., Wu, K.Y., Herndl, G.J., and DeLong, E.F. (1998). High phylogenetic diversity in a marine snow-associated bacterial assemblage. Aquat. Microb. Ecol. 14:261269

Ruiz-Ponte, C., Cilia, V., Lambert, C., and Nicolas, J.L. (1998). Roseobacter gallaciensis sp. nov., a new marine bacterium isolated from rearings and collectors of the scallop Pecten maximum. Int. J. Syst. Bacteriol., 48:537-542.

Shiba, T. (1991). Roseobacter litoralis gen. nov., sp. nov., aerobic pink-pigmented bacteria which contain bacteriochlorophyll a. Syst. Appl. Microbiol., 14:140-145 
Sobecky, P.A., Mincer, T.J., Chang, M.C., Toukdarian, A., and Helinski, D.R. (1998). Isolation of broad-host-range replicons from marine sediment bacteria. Appl. Environ. Microbiol. 64:2822-2830

Sorokin, D.Y. (1995). Sulfitobacter pontiacus gen. nov., sp. Nov.: a new heterotrophic bacterium from the Black Sea, specialized on sulfite oxidation. Microbiolgy (Engl. Trans. Mikrobiologiya), 64: 354-36

Stahl, D.A and Amann, R. (1991). Development and application of nucleic acid probes. In Nucleic Acid Techniques in Bacterial Systematics (Stackebrandt, E. \& Goodfellow, M., editors, pp.205-248. Wiley, New York

Suzuki, M.T., Rappé, M.S., Haimberger, Z.W., Winfield, H., Adair, N., Ströbel, J., and Giovannoni, SJ. (1997). Bacterial diversity among small-subunit rRNA gene clones and cellular isolates from the same seawater sample. Appl. And Env. Microb. 63:983-989

Tabor, P. and Neihof, R.A. (1982). Improved microautoradiographic method to determine individual microorganisms active in substrate uptake in natural waters. Appl. Environ. Microbiol. 44(4):945-953

Wright, R.T. (1978). Measurement and significance of specific activity in the heterotrophic bacteria of natural waters. Appl. Environ. Microbiol. 36:297-305

Zubkov, M.V., Fuchs, B.M., Burkill, P.H., and Amann, R. (2001). Comparison of cellular and biomass specific activities of dominant bacterioplankton groups in stratified waters of the Celtic Sea. Appl. Environ. Microbiol. 67:5210-5218 


\section{SUMMARY and CONCLUSIONS}

This project has explored and described the biodiversity of organisms that contribute to a specific chemical transformation occurring in natural waters, one that mediates the flux of $\mathrm{CO}$ to the atmosphere and returns carbon to biological cycling. State-of-art methods in molecular biology in a novel application have resulted in a richer understanding of this important process in the ocean. Biological involvement in $\mathrm{CO}$ oxidation in natural seawater has long been acknowledged in studies of trace gasses in the ocean and atmosphere, but the identities of $\mathrm{CO}$ oxidizing microbes have remained obscure. A major thrust of our study has been to determine if there exists a specialized group of microorganisms that is responsible for $\mathrm{CO}$ metabolism at environmental concentrations, or if $\mathrm{CO}$ at environmental concentrations is oxidized and/or consumed by several members of the microbial assemblage present in the environment. We have isolated several pure strains of microorganisms from natural coastal seawater with a novel technique that involves macroautoradiography to target, isolate, and quantify microbial colonies that incorporate label from a ${ }^{14} \mathrm{C}$-CO-containing atmosphere, and have determined the cell-specific CO-metabolic rates of these organisms in pure cultures in laboratory experiments. Furthermore, we have provided the first definitive identification of some of the diverse $\mathrm{CO}$ metabolizing microorganisms that exist in a coastal environment. This research has begun to illuminate the rich phylogenetic diversity of microorganisms that utilize an inorganic carbon substrate in coastal waters. 


\section{Objective 1: Isolation and Culture of marine $\mathrm{CO}$ oxidizing microorganisms.}

1) Thirty CO-tolerant isolates result from the $\mathrm{CO}$ incubation program.

2) Nine isolates are positive for $\mathrm{CO}$ oxidation at environmentally relevant activities, at cell-specific activities ranging from $3.0 \times 10^{-11}-2.3 \times 10^{-10} \mathrm{nmol}$ CO oxidized cell $^{-1} \mathrm{hr}^{-1}$ at $20^{\circ} \mathrm{C}\left(2.37 \times 10^{-11}-1.75 \times 10^{-10} \mathrm{nmol} \mathrm{CO}\right.$ oxidized cell ${ }^{-1} \mathrm{hr}^{-1}$ at $\left.5^{\circ} \mathrm{C}\right)$.

3) In 8 of 9 isolates, nitrogen source had no effect on CO oxidation activity. JT-08 (a Roseobacter group organism) is the exception, where CO-oxidation activity with $\mathrm{NH}_{4}{ }^{+}$was $\sim 50 \%$ of activity with $\mathrm{NO}_{3}{ }^{-}$.

4) All isolates resulting from the incubation program are able to grow in heterotrophic media, and all incorporate ${ }^{14} \mathrm{C}$ from $\mathrm{CO}$ strongly while growing in heterotrophic conditions.

5) ${ }^{14} \mathrm{C}$ - incorporation was weak or absent in most CO-oxidizing isolates while in oligotrophic growth conditions. JT-01 (a Paracoccus group organism) is the exception, with strong label incorporation in all three growth media (2216 broth, $\mathrm{NO}_{3}{ }^{-}$mineral media, or $\mathrm{NH}_{4}^{+}$mineral media) 


\section{Objective 2: Identification and phylogeny of $\mathrm{CO}$ oxidizing isolates based on small subunit ribosomal gene sequence.}

1) The three most active $\mathrm{CO}$ oxidizing organisms isolated in our incubation program are phylogenetically clustered within the marine alpha group (Roseobacter and Paracoccus) of the alphaproteobacteria (JT-01, JT-08, JT-22).

2) Several type cultures of marine alpha organisms are positive and active $\mathrm{CO}$ oxidizers (Ruegeria atlantica, Silicibacter pomeroyi, Ruegeria gelatinovora, and Roseobacter litoralis), but $\mathrm{CO}$ oxidation is not a characteristic phenotype of Roseobacter, Paracoccus, or the marine alpha group.

3) The diversity of the CO-oxidizing isolates resulting from this program is broad, with representatives in the the alphaproteobacteria, betaproteobacteria, gammaproteobacteria, and Phylum Bacteroidetes.

\section{Objective 3: STARFISH assay to enumerate CO oxidizing organisms in natural samples}

1) The marine alpha group composed $45.7 \%$ of the total microbial assemblage in a coastal environment in early spring.

2) Oligonucleotide probes specific for Roseobacter and Paracoccus, in combination with microautoradiography, reveal that the marine alpha group contributes $31 \%$ $41 \%$ of total in situ $\mathrm{CO}$ oxidation, based on $\mathrm{Cy} 3$ probe- and ${ }^{14} \mathrm{C}$-labeled cell counts in natural samples. 


\section{Future Research Directions}

STARFISH with 16S-rDNA probes spanning the diversity of CO-oxidizing isolates

Our protocol to enumerate CO-metabolizing prokaryotic groups with environmentally relevant CO-metabolic activities on a per-cell basis in coastal waters and calculate their relative contributions to total in situ $\mathrm{CO}$ metabolism has been productive and successful in assigning the proportion of a natural chemical conversion in seawater to specific microbial groups. However, other diverse seawater microorganisms from our isolation program also have demonstrated the ability to metabolize $\mathrm{CO}$ and are likely important contributors to total measured biological $\mathrm{CO}$ oxidation in coastal seawater. These organisms must be quantified in natural samples in the same manner to determine their relative importance to total in situ $\mathrm{CO}$ metabolism.

To fulfill this objective we will utilize STAR-FISH for simultaneous in situ identification, quantification, and determination of substrate uptake patterns of individual microbial cells within a natural microbial assemblage. We will perform STAR-FISH experiments with coastal seawater samples collected locally to target and quantify a variety of phylogenetic groups, including Alteromonas-like species (Gammaproteobacteria), Halomonas- and Pseudomonas-like species (betaproteobacteria), and Cyclobacterium-like species (phylum Bacteroidetes), which we currently believe contribute to in situ CO metabolism based on laboratory studies of pure cultures. The STAR-FISH approach additionally will indicate other phylogenetic groups performing $\mathrm{CO}$ metabolism that are as yet unknown to us and absent in our culture collection, limited only by our breadth and depth of probe utilization. The STAR-FISH 
experiments in combination with existing specific metabolic measurements from pure cultures will allow simultaneous determination of relative abundance, relative importance to CO-consumption in coastal waters, and balancing the observed CO-consumption in bulk water samples. (Proposed, WHOI SeaGrant, WHOI proposal \# BI11269 denied; Ocean Life Institute, WHOI proposal \# BI11345 pending)

\section{Seasonal monitoring of community structure}

We will monitor the in situ community structure and $\mathrm{CO}$ metabolic rates at several sampling events throughout the year to determine seasonal shifts in abundance and activity of the major CO-metabolizing microbial groups, and how this relates to seasonal variability in $\mathrm{CO}$ bio-consumption that is observed in the coastal environment.

\section{STARFISH in an oceanic environment}

In an oceanic environment (BATS) during summer 1999 and early spring 2000, we monitored the diel variability of photolytically produced $\mathrm{CO}$ and its rate of microbial oxidation. While the question of which organisms are performing $\mathrm{CO}$ bio-oxidation in coastal surface waters is being resolved, the identities and relative abundances of the microorganisms responsible for in situ $\mathrm{CO}$ bio-oxidation in oceanic surface waters requires further investigation. There are many published studies concerning $\mathrm{CO}$ photoproduction, in situ consumption, and atmospheric flux in oceanic surface waters, but none concerning the identity of the microbes responsible for oceanic $\mathrm{CO}$ bio-oxidation. Our objectives are to (a) apply our field-proven techniques for direct isolation and identification of microorganisms to surface waters of the oligotrophic open ocean, (b) determine specific CO-oxidation activities of all resulting isolates, (c) develop molecular 
probes based on molecular phylogeny of resulting isolates and (d) apply STAR-FISH for simultaneous identification, quantification, and determination of substrate uptake patterns of individual microbial cells within an oceanic microbial assemblage. While COprocesses (production and consumption) have been measured on a gross scale in bulk seawater samples for nearly three decades in oligotrophic oceanic waters, this will be the first attempt to both quantitatively and qualitatively describe the organisms responsible for oceanic CO-metabolism, and illuminate the 'black box' regarding $\mathrm{CO}$ consumption in seawater that has been up to now overlooked in studies of ocean-atmosphere flux of trace gasses and carbon budget models in the oceanic environment. (proposed, Access to the Sea, WHOI proposal \# BI11285 denied)

\section{Amplification/probing of CO-DH genes}

Carbon monoxide dehydrogenase (CO-DH) (Meyer et al., 1986, Kim \& Hegeman, 1983) is a key enzyme in energy metabolism of many described CO-metabolizing bacteria isolated from terrestrial sources. CO-DH serves three functions: $(a)$ to feed electrons into the respiratory chain for electron transport phosphorylation, $(b)$ to provide the carbon source as $\mathrm{CO}_{2}$, and (c) to provide ATP and, by inverse electron transfer, $\mathrm{NADH}$ for $\mathrm{CO}_{2}$ assimilation via the reductive pentosephosphate cycle. It is possible that CO-metabolizing organisms isolated from marine sources may also possess this enzyme. Primers and probes for CO-DH are being currently being developed (Gary King, personal communication) and may be adapted for use in detecting this gene in marine environments and in STAR-FISH to directly enumerate CO-metabolizing cells that also contain the genes for $\mathrm{CODH}$. 
APPENDIX A: Mineral media for ${ }^{14} \mathrm{C}-\mathrm{CO}$ incubations

\begin{tabular}{ccc} 
6 salt base (Solution 1) & $\mathrm{g} / \mathrm{l} \mathrm{dH}_{2} \underline{0}$ \\
\hline $\mathrm{NaCl}$ & 20.0 \\
$\mathrm{MgCl}_{2}$ & $6 \mathrm{H}_{2} \mathrm{O}$ & 3.0 \\
$\mathrm{MgSO}_{4}$ & $7 \mathrm{H}_{2} \mathrm{O}$ & 6.0 \\
$\mathrm{KCl}$ & 0.5 \\
$\mathrm{NaHCO}_{3}$ & 0.2 \\
$\mathrm{CACl}_{2} \cdot 2 \mathrm{H}_{2} \mathrm{O}$ & 0.3
\end{tabular}

Autoclave to sterilize

Phosphate Solution 2 (autoclave separately from solution 1 )

$\mathrm{K}_{2} \mathrm{HPO}_{4}$

Trace Element Solution 3

$\mathrm{ZnCl}_{2}$

$\mathrm{MnCl}_{2} \cdot 4 \mathrm{H}_{2} \mathrm{O}$

$\mathrm{H}_{3} \mathrm{BO}_{3}$

$\begin{array}{llll}\mathrm{CoCl}_{2} & 6 \mathrm{H}_{2} \mathrm{O}\end{array}$

$\mathrm{CuCl}_{2} \cdot 2 \mathrm{H}_{2} \mathrm{O}$

$\mathrm{NiCl}_{2} \cdot 6 \mathrm{H}_{2} \mathrm{O}$

$\mathrm{Na}_{2} \mathrm{MoO}_{4} \quad 2 \mathrm{H}_{2} \mathrm{O}$

$\mathrm{Na}_{2} \mathrm{SeO}_{3}$

Adjust to $\mathrm{pH} 6.5$ with $\mathrm{HCl}, 0.22$ filter sterilize and refrigerate
$17.5 \mathrm{~g} / 500 \mathrm{ml} \mathrm{dH} \mathrm{H}_{2} \mathrm{O}$

$\mathrm{g} / 1 \mathrm{dH}_{2} \mathrm{O}$ (modified Pfennigs SL-8)

0.7

0.1

0.62

0.19

0.17

0.024

0.036

0.02

$\mathrm{g} / 500 \mathrm{ml} \mathrm{d} \mathrm{H}_{2} \mathrm{O}$

$5 \mathrm{mg}$

$2 \mathrm{mg}$

$\mathrm{B}_{12}$ (cobalamine) $5 \mathrm{mg}$

Do not autoclave. $0.22 \mu \mathrm{m}$ filter sterilize and refrigerate

Nitrate Solution 5

$\mathrm{NaNO}_{3}$

$65 \mathrm{~g} / 250 \mathrm{ml} \mathrm{dH}_{2} \mathrm{O}$

Autoclave to sterilize

Ammonium Solution 6

$\left(\mathrm{NH}_{4}\right)_{2} \mathrm{SO}_{4}$

$50 \mathrm{~g} / 250 \mathrm{ml} \mathrm{dH}_{2} \mathrm{O}$

autoclave to sterilize

FINAL SOLUTION

Add $1.0 \mathrm{ml}$ of Solutions 2, 3, and 4 to 1.016 -salt base (Solution 1) after cooling. For differential nitrogen media, add $1 \mathrm{ml}$ of either solution 5 or solution 6 .

Final concentrations:

$\begin{array}{ll}\mathrm{PO}_{4}{ }^{3-} & 0.245 \mathrm{mM} \\ \mathrm{NO}^{3-} & 3.06 \mathrm{mM} \\ \mathrm{NH}_{4}{ }^{+} & 3.04 \mathrm{mM}\end{array}$


APPENDIX B: autoradiographs - second round, purified isolates
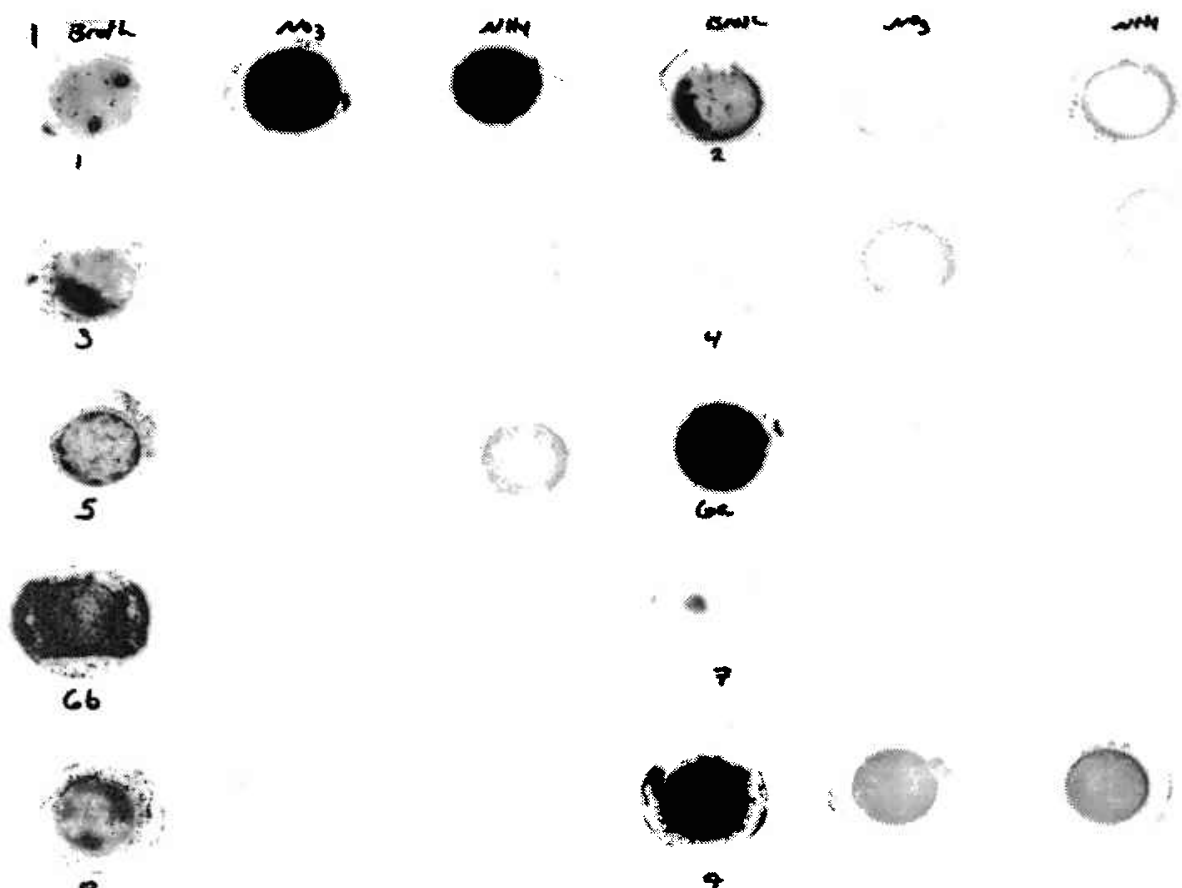

8
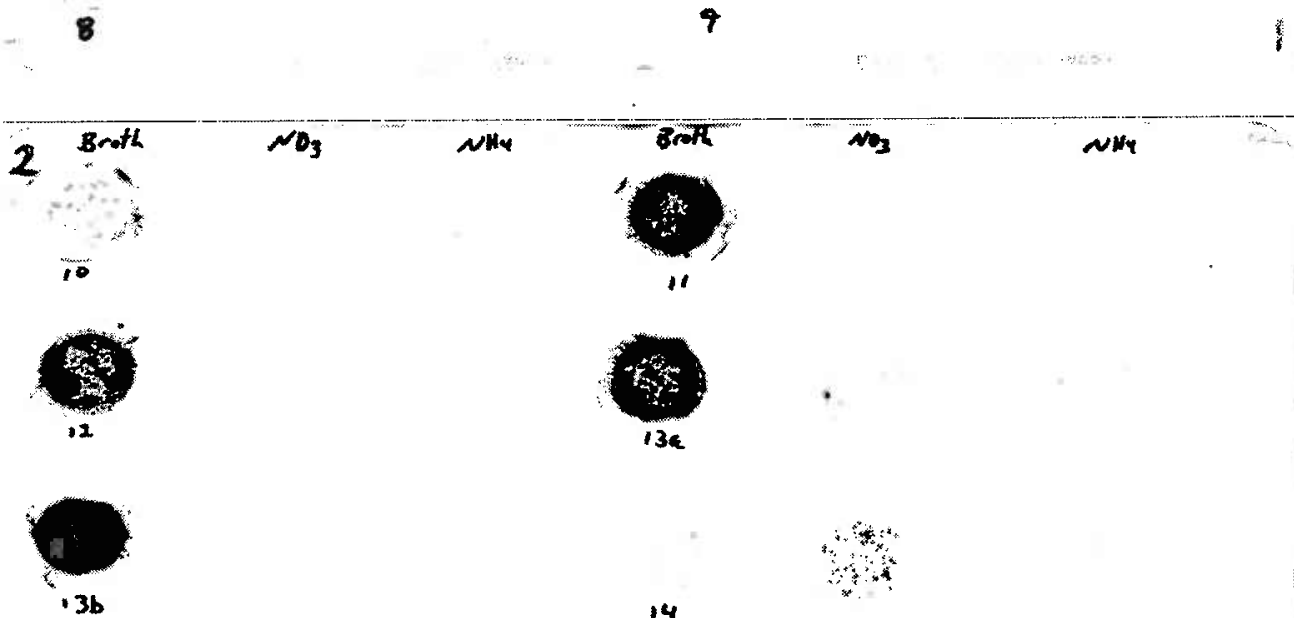

$+4$

NHY

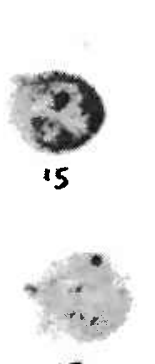

17
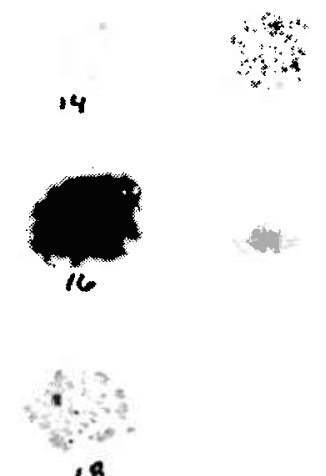

18 


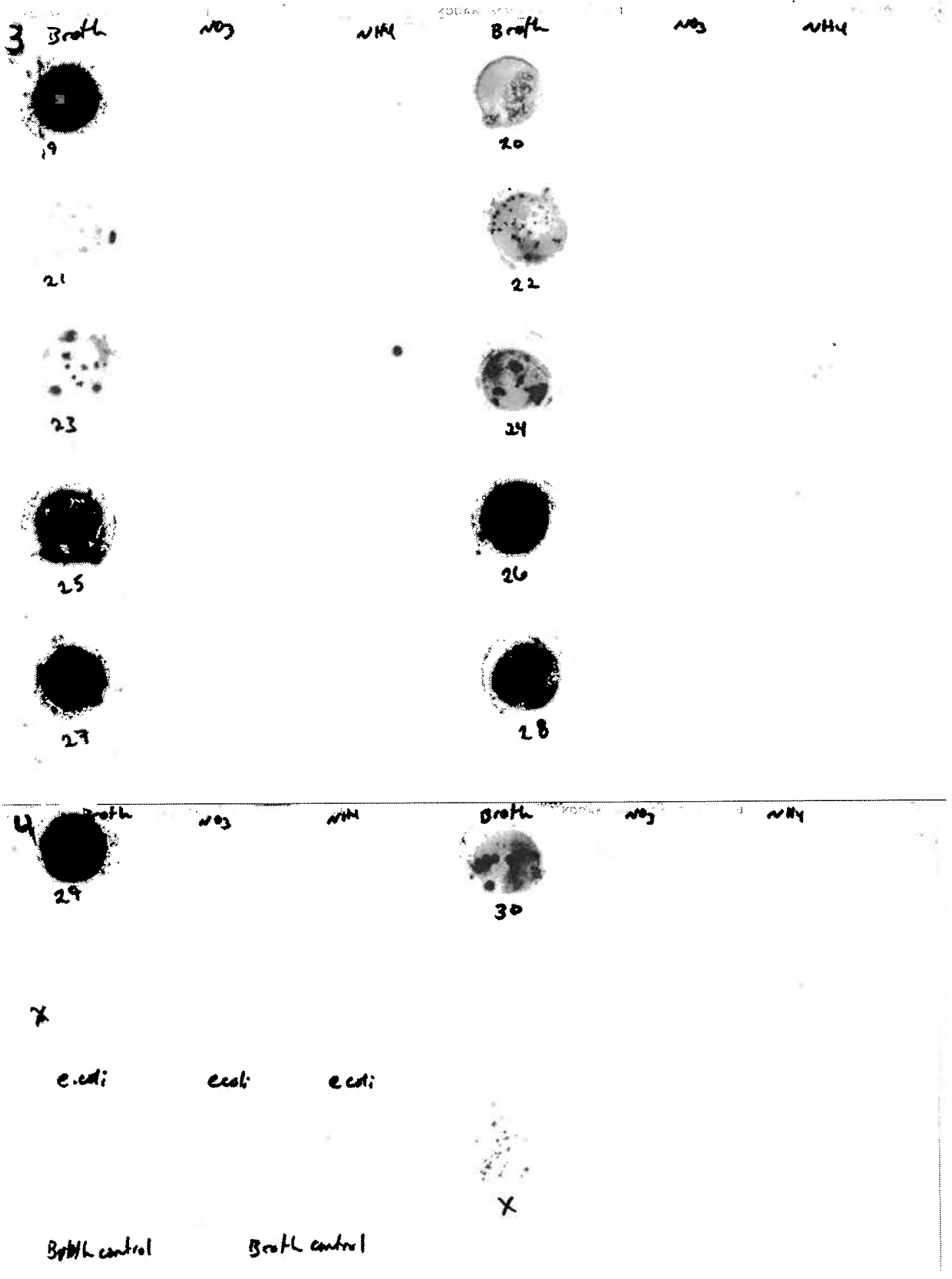


APPENDIX C: Characterizations of $\mathrm{CO}$ oxidizing isolates resulting from this study are excerpted from Bergey's Manual of Determinative Bacteriology, $9^{\text {th }}$ ed.

Genus Roseobacter are aerobic and phototrophic Purple Bacteria that grow heterotrophically in aerobic conditions but also synthesize Bacteriochlorophyll $a$ in the presence of oxygen. They form intracellular membranes and have reaction center complexes similar to those of other purple bacteria. Roseobacter cells are straight rods having $0.6-0.9 \mu \mathrm{m}$ diameter and $1.0-2.0 \mu \mathrm{m}$ length, are motile in liquid media and have polarly arranged flagella. Thiamine and niacin are required for growth, as well as $\mathrm{Na}^{+}$, biotin and nicotinic acid. The optimal $\mathrm{pH}$ for growth ranges from $7.0-8.0$, and the optimum temperature ranges from $20-30^{\circ} \mathrm{C}$. They are susceptible to chloramphenicol, penicillin, tetracycline, streptomycin, and polymyxin B.

Paracoccus are spherical cells $(0.5-0.9 \mu \mathrm{m}$ in diameter) or short rods $(0.9-1.2$ $\mu \mathrm{m}$ long), and occur singly, in pairs, or in clusters. No resting stages are known. Cells stain Gram negative. They are non-motile and aerobic, having a strictly respiratory type of metabolism; anaerobic growth can occur if nitrate, nitrite or nitrous oxide are present as terminal electron acceptor. Nitrate is reduced to nitrous oxide and molecular nitrogen under anaerobic conditions. One species ( $P$. dentrificans) can grow either autotrophically with $\mathrm{H}_{2}$ and $\mathrm{CO}_{2}$ or heterotrophically with a wide variety of organic compounds as sole carbon sources, though this species is not halophilic. A second species ( $P$. halodenitrificans) is not capable of autotrophic growth but is halophilic (requires at least $3 \% \mathrm{NaCl}$ for growth). Optimum temperature is $25-30^{\circ} \mathrm{C}$. They occur in soil and presumably in natural and artificial brines. 
Genus Halomonas are rod-shaped or pleomorphic. Rods are generally 0.6-0.8 $\mu \mathrm{m}$ $x$ 1.6-1.9 $\mu \mathrm{m}$. Elongated, flexuous filaments may be formed under certain conditions. Cells stain Gram negative. Motile or non-motile; motility is by means of several unsheathed lateral of polar flagella. They possess mainly a respiratory type of metabolism with oxygen as the terminal electron acceptor. Growth of some strains may occur anaerobically with nitrate. Colonies are white to yellow, never red. Carbohydrates, amino acids, and some polyols can serve as sole earbon sources in mineral media. Catalase and oxidase positive. Most strains reduce nitrate to nitrite. Chemoorganotrophic. Ammonium sulfate can serve as sole nitrogen source. Halotolerant, able to grow in $\mathrm{NaCl}$ concentrations ranging from $0-0.5-20 \%$ or more. Strains have been isolated form a solar salt facility, from a saline lake in Antarctica, and from an estuary in New Hampshire.

Genus Cyclobacterium contains only a single species, Cyclobacterium marinum. The genus consists of circle-shaped (ringlike) and horseshoe-shaped cells with an outer diameter of $0.8-1.5 \mu \mathrm{m}$ and a cell width of $0.3-0.7 \mu \mathrm{m}$. The cells have rounded (never tapered) ends. Coils, spiral forms, and some straight rods occur less frequently; filamentous or pleomorphic cells are rare. Stain is Gram-negative. Cells are encapsulated. They are non-flagellated and non-motile. No gas vesicles occur. No resting or life cycle stages occur. Optimum growth occurs at $20-25^{\circ} \mathrm{C}$ in media containing seawater or $3.0 \% \mathrm{NaCl}$. Aerobic, having a strictly respiratory type of metabolism. Convex, muciod, opaque, smooth, small $(<2-\mathrm{mm})$ pink colonies grow on modified Zobell marine agar or tryptone-glucose-yeast extract agar containing $3 \% \mathrm{NaCl}$. 
Oxidase and catalase positive. Habitat is marine environments. Cells are resistant to chlortetracycline, kanamycin, penicillin $\mathrm{G}, \quad$ streptomycin, and sulfmethoxazole/trimethoprim.

Genus Pseudomonas are straight or slightly curved rods, but not helical, $0.5-1.0$ $\mathrm{x}$ 1.5-5.0 $\mu \mathrm{m}$. They do not produce prosthecea and are not surrounded by sheaths. No resting stages are known. Cells stain Gram negative. Motility occurs by one or several polar flagella; they are rarely non-motile. Aerobic, having a strictly respiratory type of metabolism with oxygen as the terminal electron acceptor; in some cases nitrate can be used as an alternate electron acceptor, allowing growth to occur anaerobically. Most, if not all, species fail to grow under acidic conditions ( $\mathrm{pH} 4.5$ ). Most species do not require organic growth factors. Oxidase positive or negative. Catalase positive and chemoorganotrophic; some species are facultative chemolithotrophs, able to use $\mathrm{H}_{2}$ or $\mathrm{CO}$ as energy sources. Widely distributed in nature. Some species are pathogenic for human, animals, or plants. 
APPENDIX D: aligned 16S-rDNA sequences of CO oxidizing environmental isolates resulting from Chapter 3 isolation experiments (E. coli numbering).

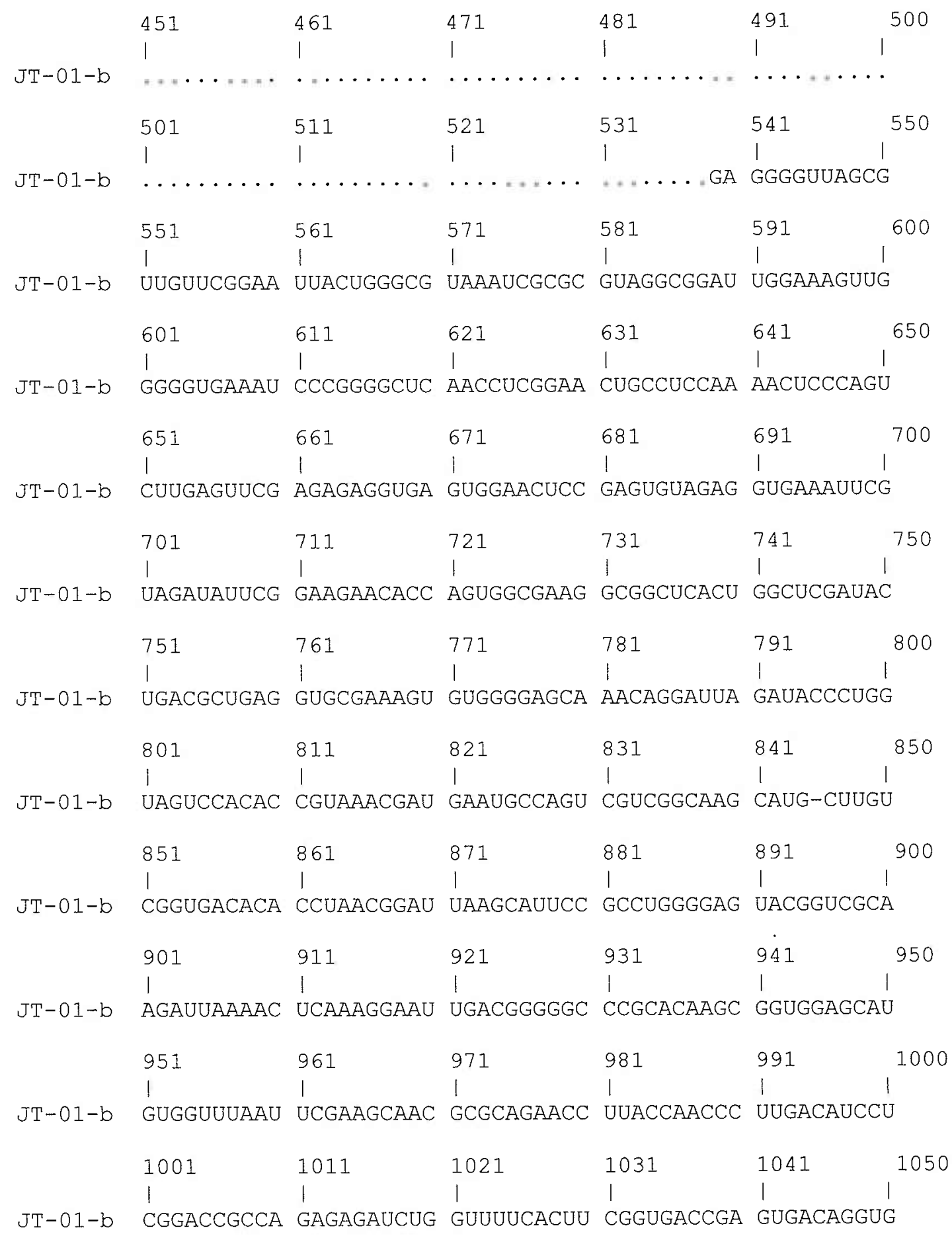




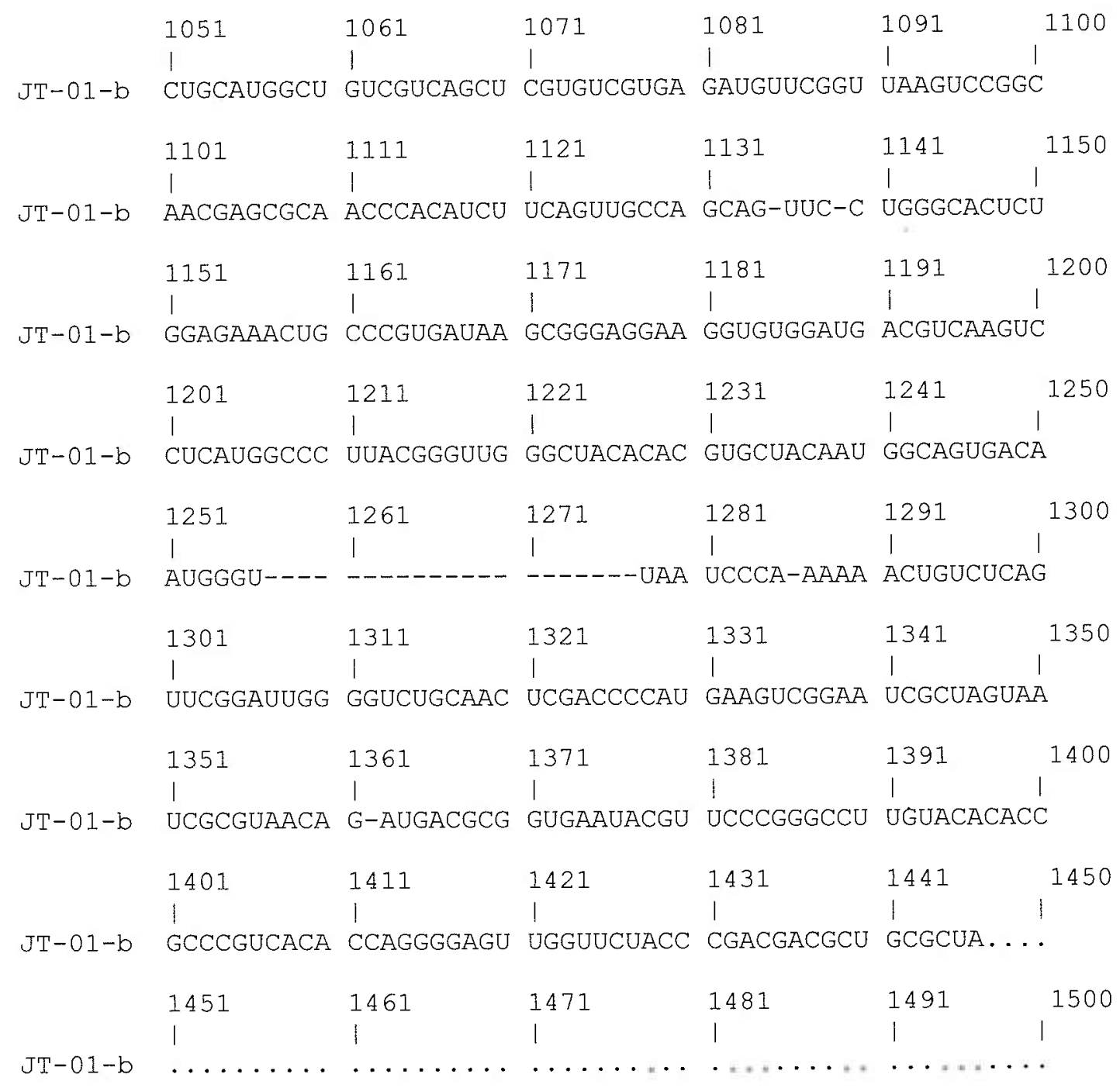




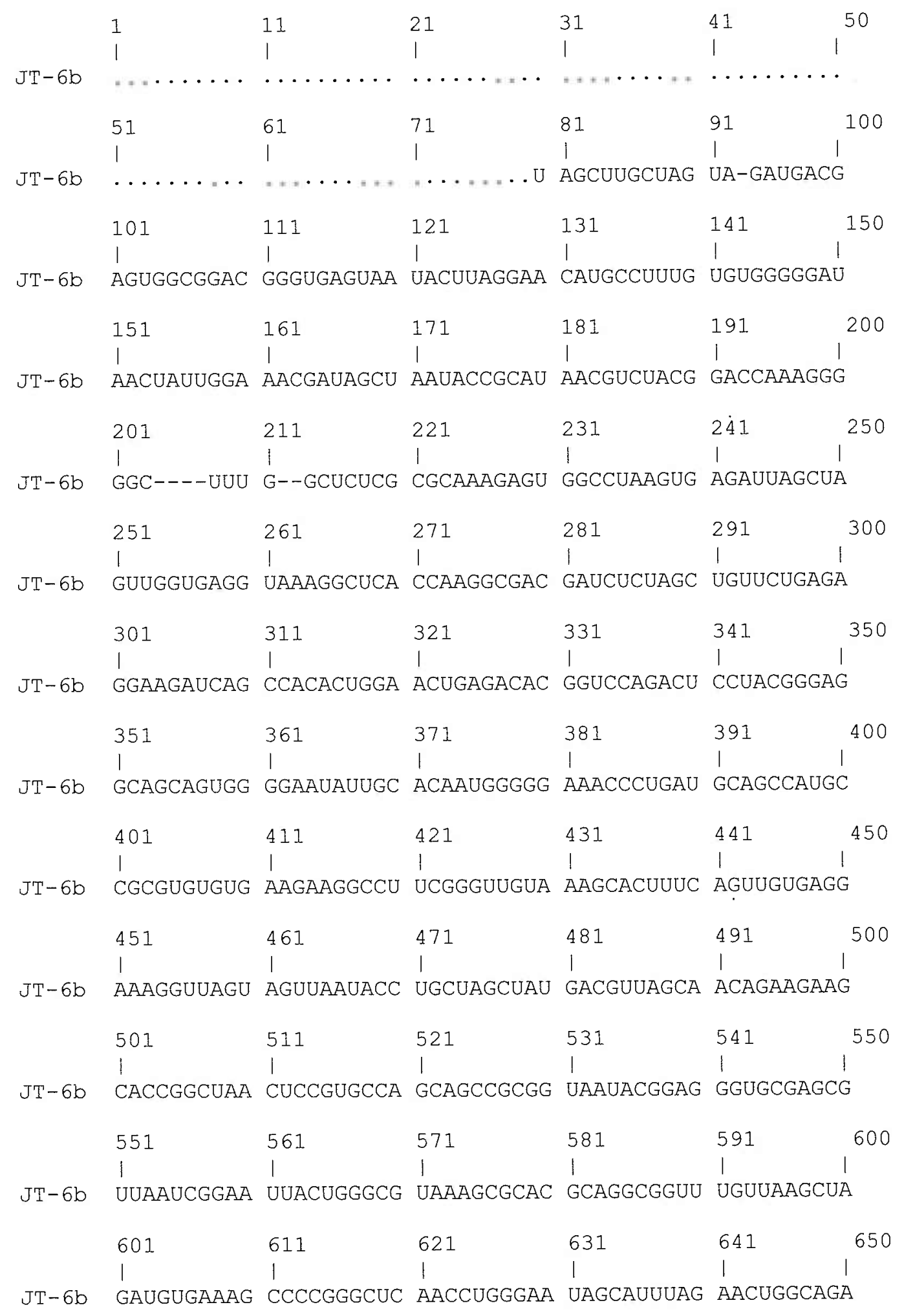


$\begin{array}{clllll}651 & 661 & 671 & 681 & 691 & 700 \\ \text { JT-6b } & \text { CUAGAGUCUUU } & \text { GGAGAGGGGA } & \text { GUGGAAUUCC } & \text { AGGUGUAGCG } & \text { GUGAAAUGCG }\end{array}$

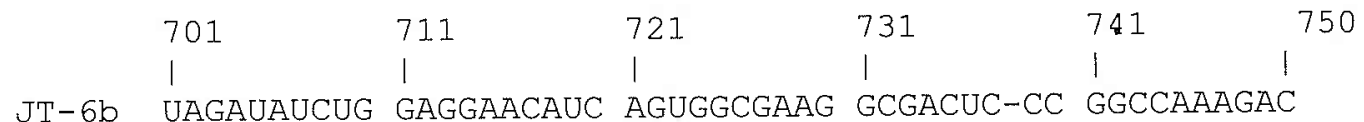

$\begin{array}{llllll}751 & 761 & 771 & 781 & 791 & 800\end{array}$

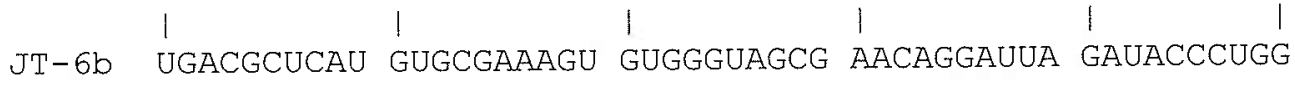

\begin{tabular}{cccccc}
801 & 811 & 821 & 831 & 841 & 850 \\
\hline & 1 & 1 & $\mid$ & $\mid$ & $\mid$
\end{tabular}

JT-6b UAgUCCACAC CGUAAACGCU GUCUACUAGC UgUUUgugua UUAUAUACGU

$\begin{array}{llllll}851 & 861 & 871 & 881 & 891 & 900\end{array}$

JT-6b GAgUAGCGAA GCUAACGCC- UAAGUAGACC GCCUGGgGAg UACGGCCGCA

$\begin{array}{clllll}901 & 911 & 921 & 931 & 941 & 950 \\ \text { I } & 1 & 1 & \mid & \mid & \mid \\ \text { JT-6b } & \text { AGGUUAAAAC } & \text { UCAAAUGAAU } & \text { UGACGGGGGC } & \text { CCGCACAAGC } & \text { GGUGGAGCAU }\end{array}$

$\begin{array}{llllll}951 & 961 & 971 & 981 & 991 & 1000\end{array}$

JT-6b GUGGUUUAAU UCGAUGCAAC GCGAAGAACC UUACCUACUC UUGACAUCCA

$\begin{array}{llllll}1001 & 1011 & 1021 & 1031 & 1041 & 1050\end{array}$

JT-6b GAAAAUUUGG CAGAGAUGCC UCAGUGCCUU CGGGAAUUCU GAGACAGGUG

$\begin{array}{llllll}1051 & 1061 & 1071 & 1081 & 1091 & 1100 \\ 1 & \mid & \mid & \mid & \mid & \mid\end{array}$

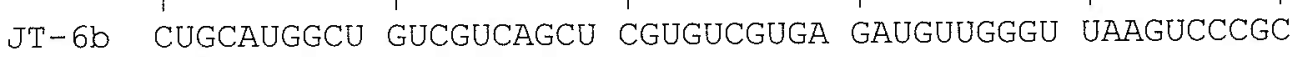

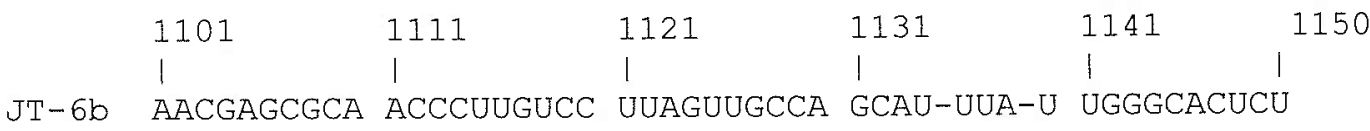

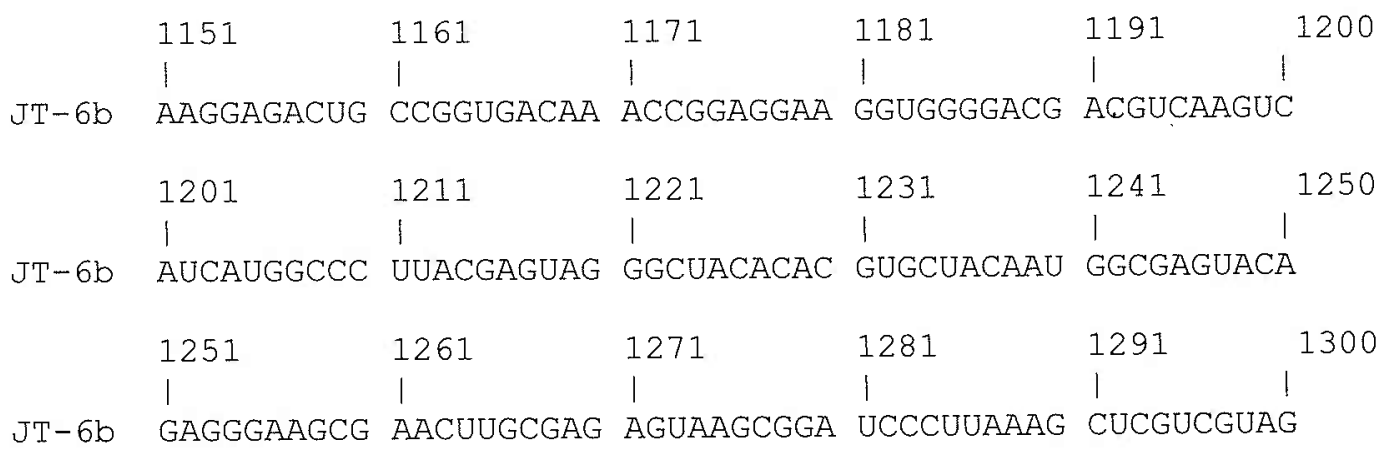




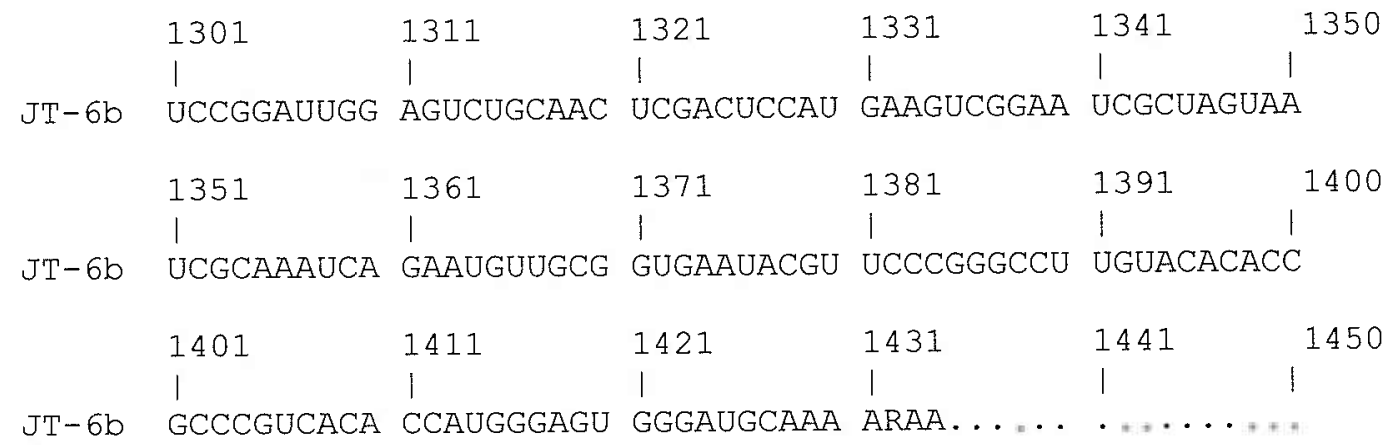




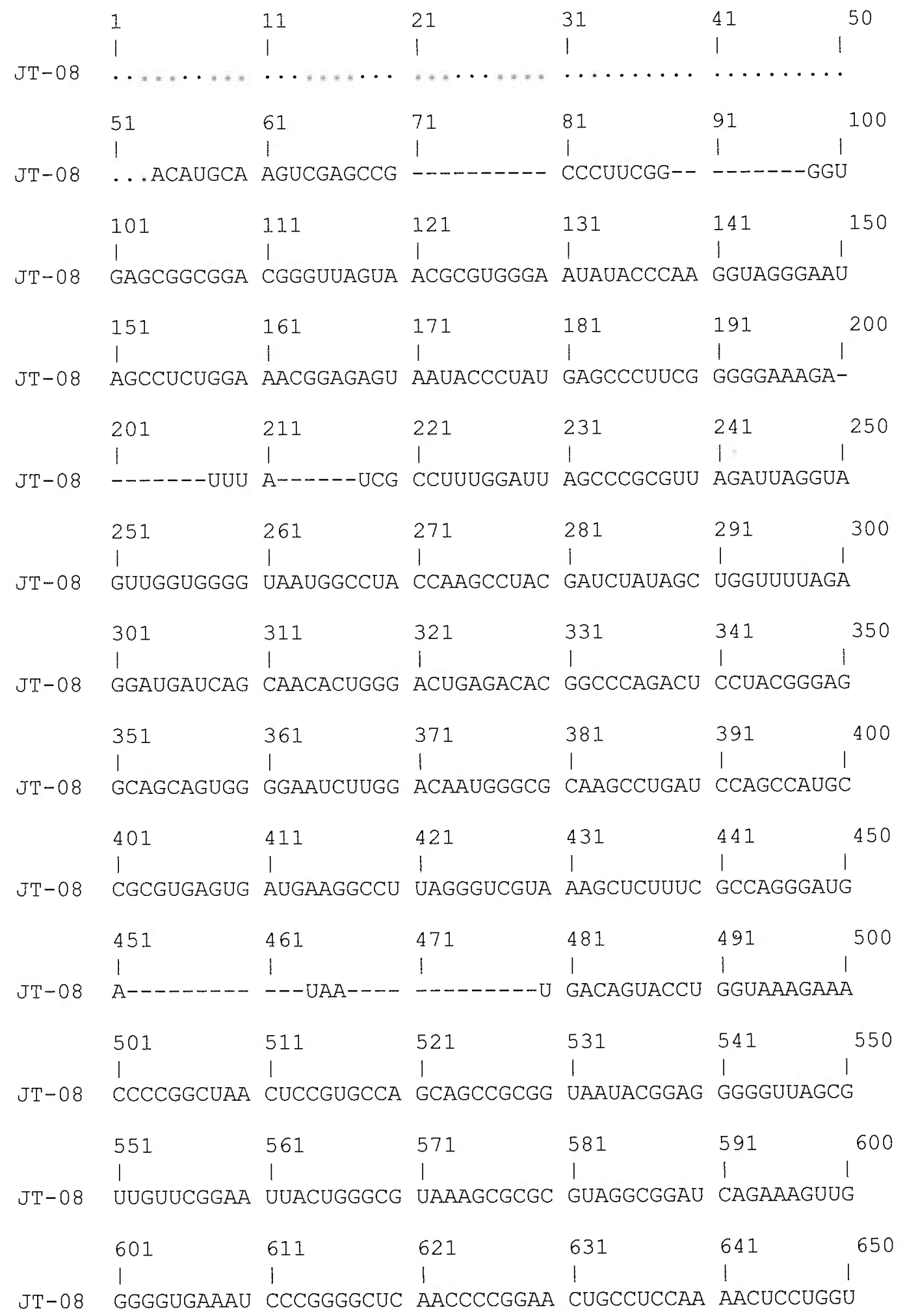




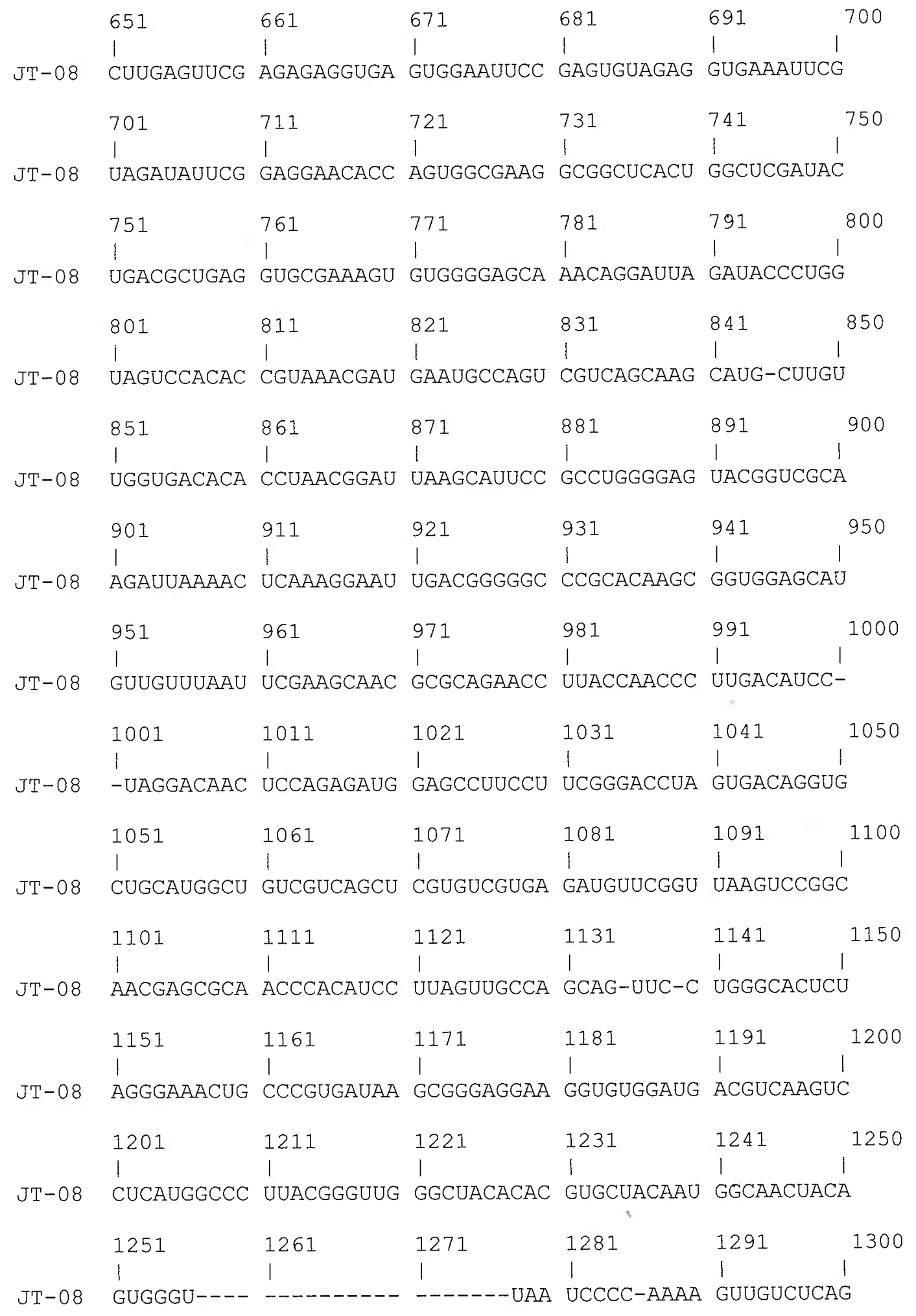




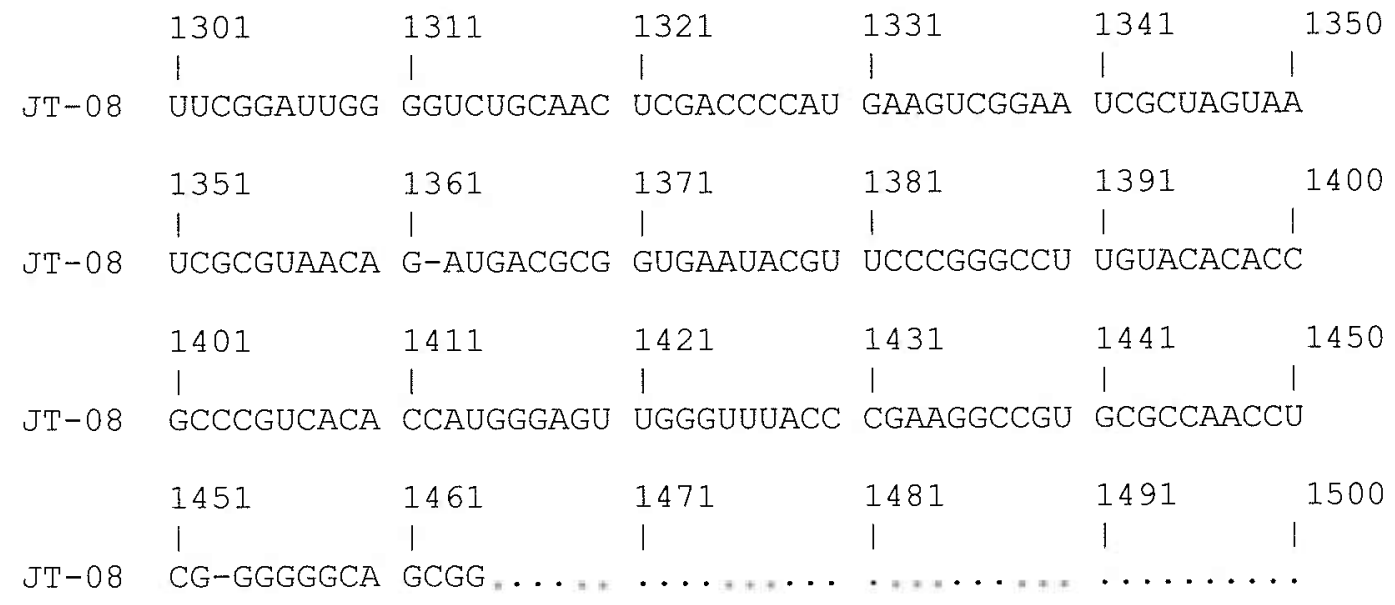




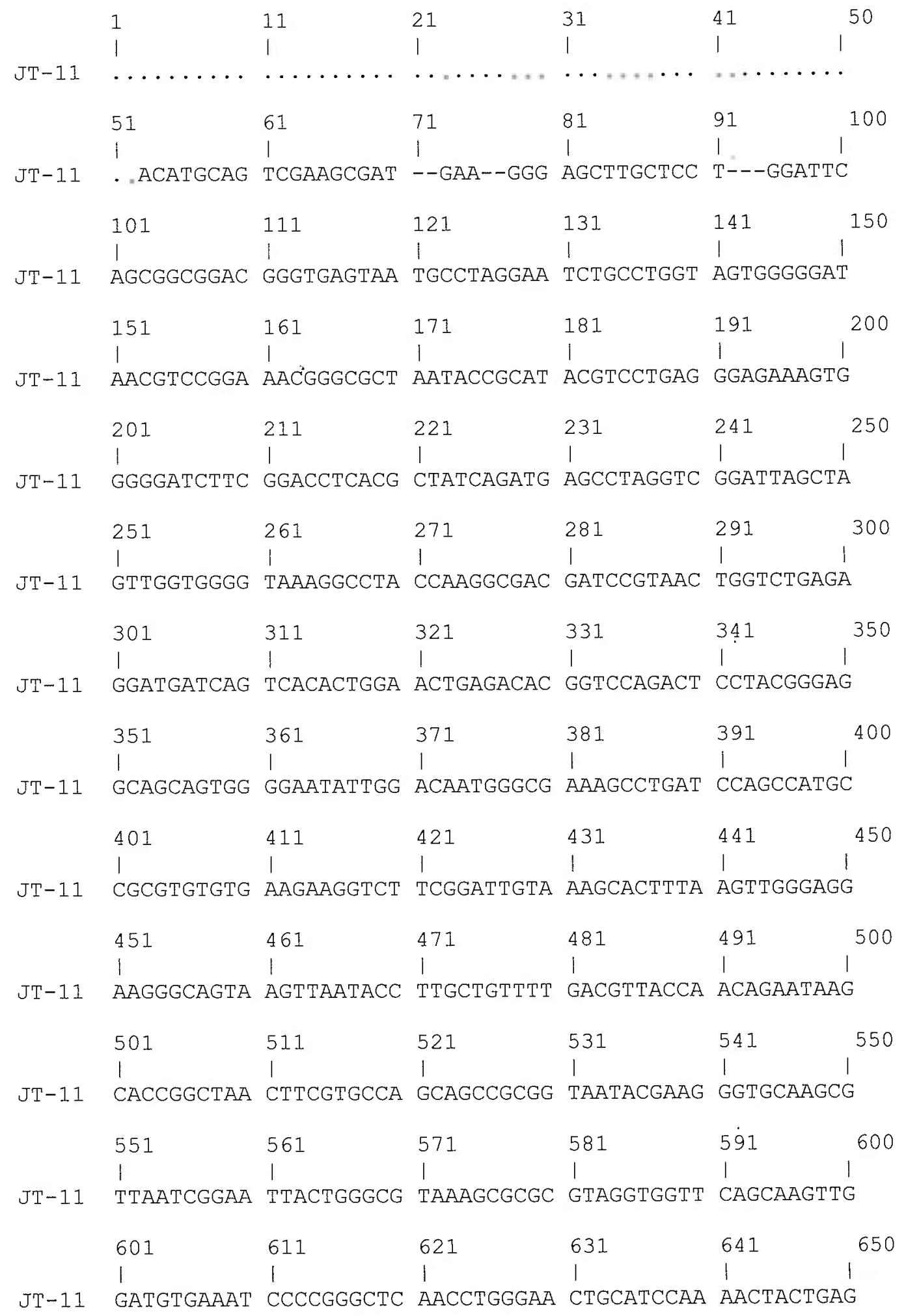




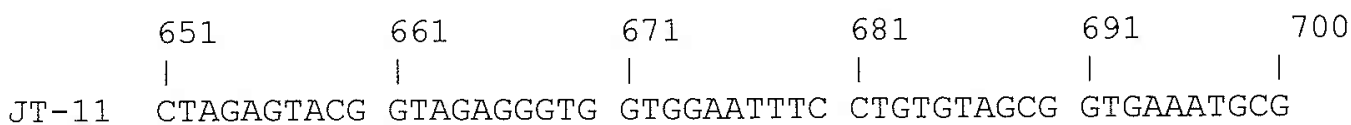

$\begin{array}{llllll}701 & 711 & 721 & 731 & 741 & 750\end{array}$

| 1 | | |

JT-11 TAGATATAgG AAGGAACACC AgtGGCGAAg GCGACCACCT GGACTGATAC

$\begin{array}{llllll}751 & 761 & 771 & 781 & 791 & 800\end{array}$

| 1 | 1

JT-11 TGACACTGAg GTGCGAAAgC GTGGgGAgCA AACAgGATtA GATACCCTGG

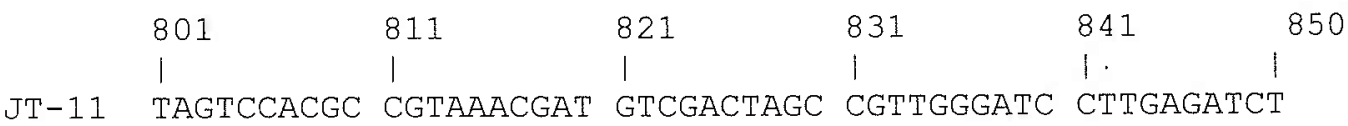

\begin{tabular}{clllll}
851 & 861 & 871 & 881 & 891 & 900 \\
\hline & 1 & 1 & 1 & 1 & $\mid$
\end{tabular}

JT-11 TAgtgGCGCA GCtAACGCGA tAAGtCGACC GCCTGgGgAg TACGgCCGCA

$\begin{array}{cccccc}901 & 911 & 921 & 931 & 941 & 950 \\ 1 & 1 & 1 & 1 & \mid & 1\end{array}$

JT-11 AgGTTAAAAC TCAAATGAAT TGACGGGgGC CCGCACAAGC GGTGGAGCAT

$\begin{array}{llllll}951 & 961 & 971 & 981 & 991 & 1000\end{array}$

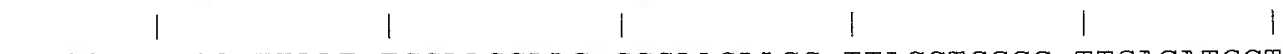

JT-11 GTGGTTTAAT TCGAAGCAAC GCGAAGAACC TTACCTGGCC TTGACATGCT

$\begin{array}{cllllll} & 1001 & 1011 & 1021 & 1031 & 1041 & 1050 \\ & \mid & 1 & \mid & \mid & \mid & \mid \\ \text { JT-11 } & \text { GAGAACTTTC } & \text { CAGAGATGGA } & \text { TTGGTGCCTT } & \text { CGGGACTCA } & \text { GACACAGGTG }\end{array}$

\begin{tabular}{clllll}
1051 & 1061 & 1071 & 1081 & 1091 & 1100 \\
\hline & 1 & $\mid$ & $\mid$ & $\mid$ & $\mid$
\end{tabular}

JT-11. CTGCATGgCT GTCGTCAgCt CGTGTCGTGA GATgtTgGgT TAAgtCCCGT

$\begin{array}{llllll}1101 & 1111 & 1121 & 1131 & 1141 & 1150\end{array}$

| 1 | | |

JT-11 AACGAGCGCA ACCCTTGTCC TTAGTTACCA GCACCTCGgG TGGGCACTCT

$\begin{array}{llllll}1151 & 1161 & 1171 & 1181 & 1191 & 1200\end{array}$

$\begin{array}{lllll}1 & \text { I } & \text { | } & \text { | }\end{array}$

JT-11 AAgGAgACTG CCGGTGACAA ACCGGAgGAA GGTGGgGATG ACGTCAAGTC

$\begin{array}{cllllll} & 1201 & 1211 & 1221 & 1231 & 1241 & 1250 \\ \text { JT-11 } & \text { ATCATGGCCC } & \text { TTACGGCCAG } & \text { GGCTACACAC } & \text { GTGCTACAAT } & \text { GGTCGGTACA }\end{array}$

$\begin{array}{cllllll} & 1251 & 1261 & 1271 & 1281 & 1291 & 1300 \\ \text { JT-11 } & \text { AAGGGTTGCC } & \text { AAGCCGCGAG } & \text { GTGGAGCTAA } & \text { TCCCATAAAA } & \text { CCGATCGTAG }\end{array}$ 


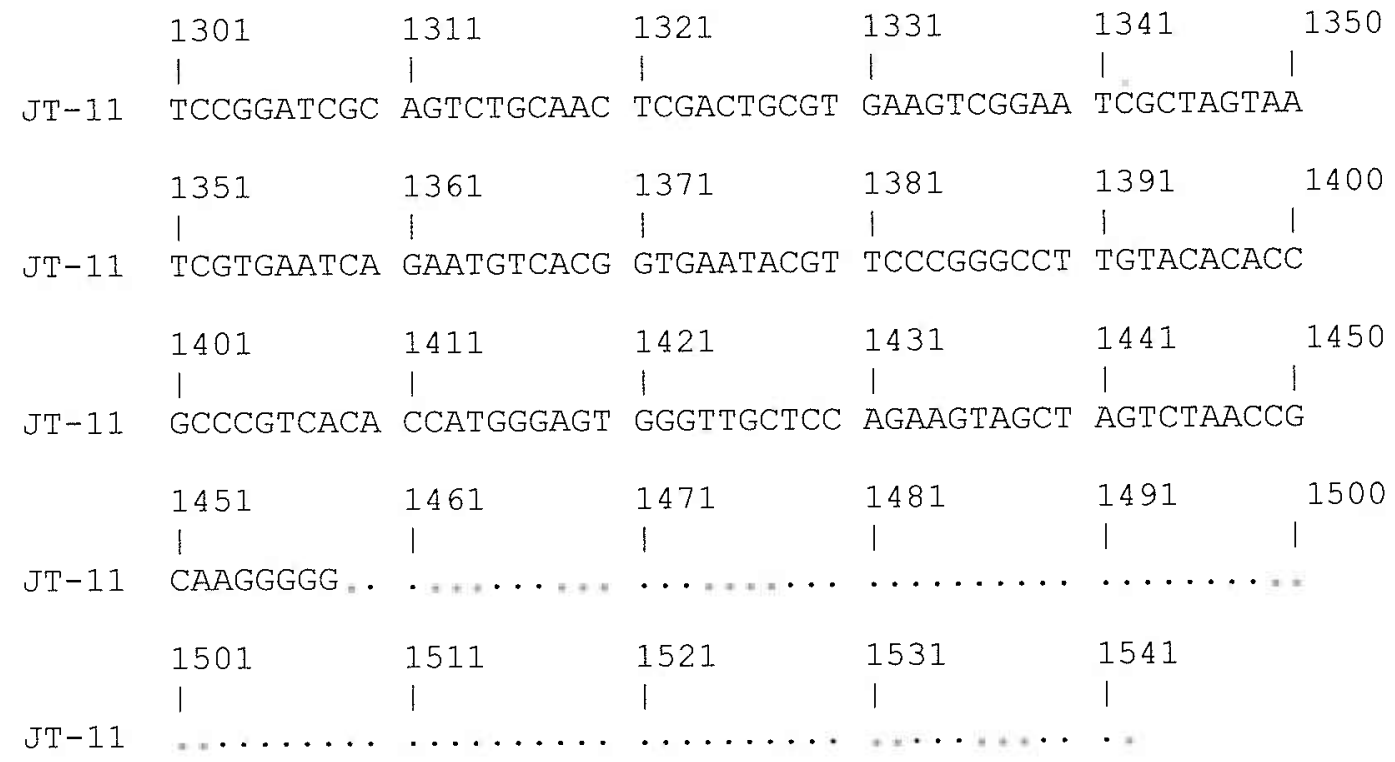




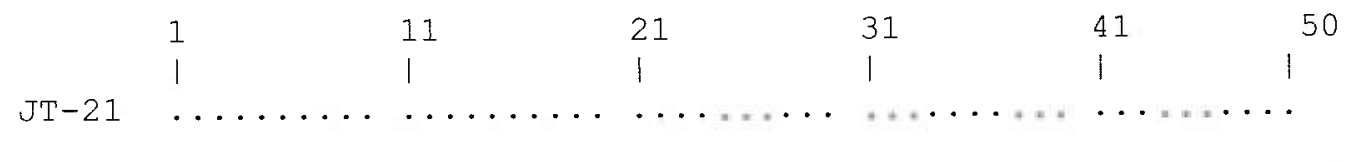

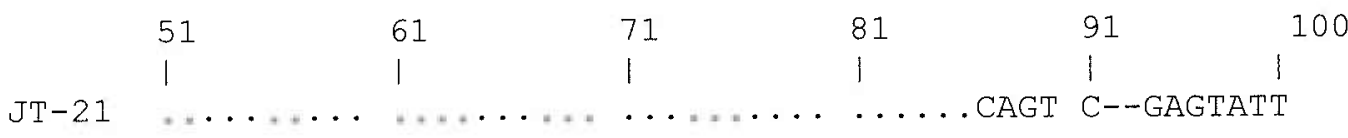

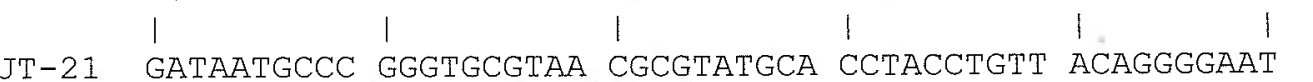

$\begin{array}{llllll}151 & 161 & 171 & 181 & 191 & 200\end{array}$
JT-21 AgCCCGgGga AACCCGgAtt AAtAtCCCAt AggActgCAt gGtTAAAgC-

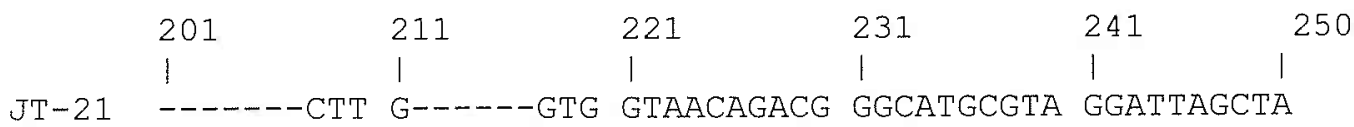

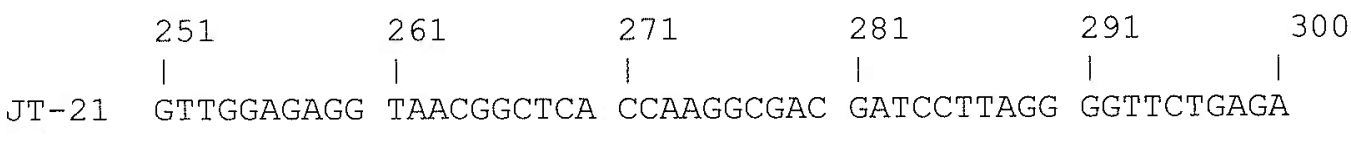
$\begin{array}{cllllll} & 301 & 311 & 321 & 331 & 341 & 350 \\ \text { JT-21 } & \text { GGAAGGTCCC } & \text { CCACACTGGC } & \text { ACTGAGATAC } & \text { GGGCCAGACT } & \text { CCTACGGGAG } \\ & & & & & & \\ 351 & 361 & 371 & 381 & 391 & 400 \\ & 1 & \mid & 1 & 1 & 1 & 1\end{array}$ JT-21 GCAgCAgtag GgAatattgg tCAAtgggcG AgAgCctgAa CCAgCCAtgC

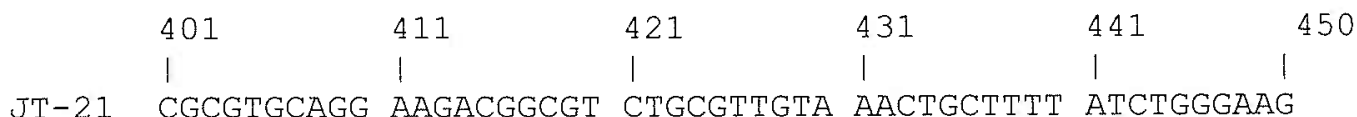
4512000

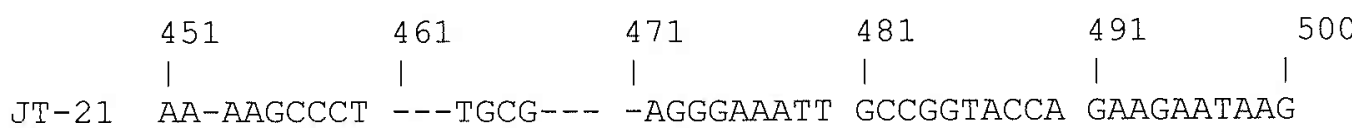
$\begin{array}{llllll}501 & 511 & 521 & 531 & 541 & 550\end{array}$

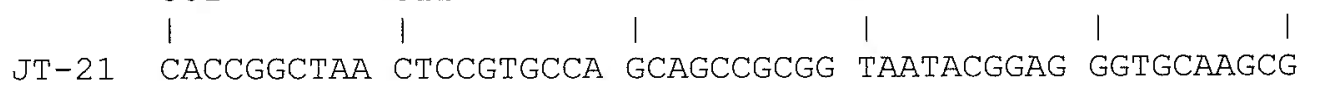
$\begin{array}{cllllll} & 551 & 561 & 571 & 581 & 591 & 600 \\ \text { JT-21 } & \text { I } & \text { TTGTCCGGAT } & \text { TTATTGGGTT } & \text { TAAAGGGTGC } & \text { GTAGGCGGCT } & \text { GATTAAGTCA }\end{array}$ $\begin{array}{cllllll} & 601 & 611 & 621 & 631 & 641 & 650 \\ & 1 & 1 & \mid & \mid & \mid & \mid \\ \text { JT-21 } & \text { GCGGTGAAAG } & \text { TTCTCGGCTC } & \text { AACCGAGAGA } & \text { CTGCCGTTGA } & \text { TACTGGTCAG }\end{array}$ 


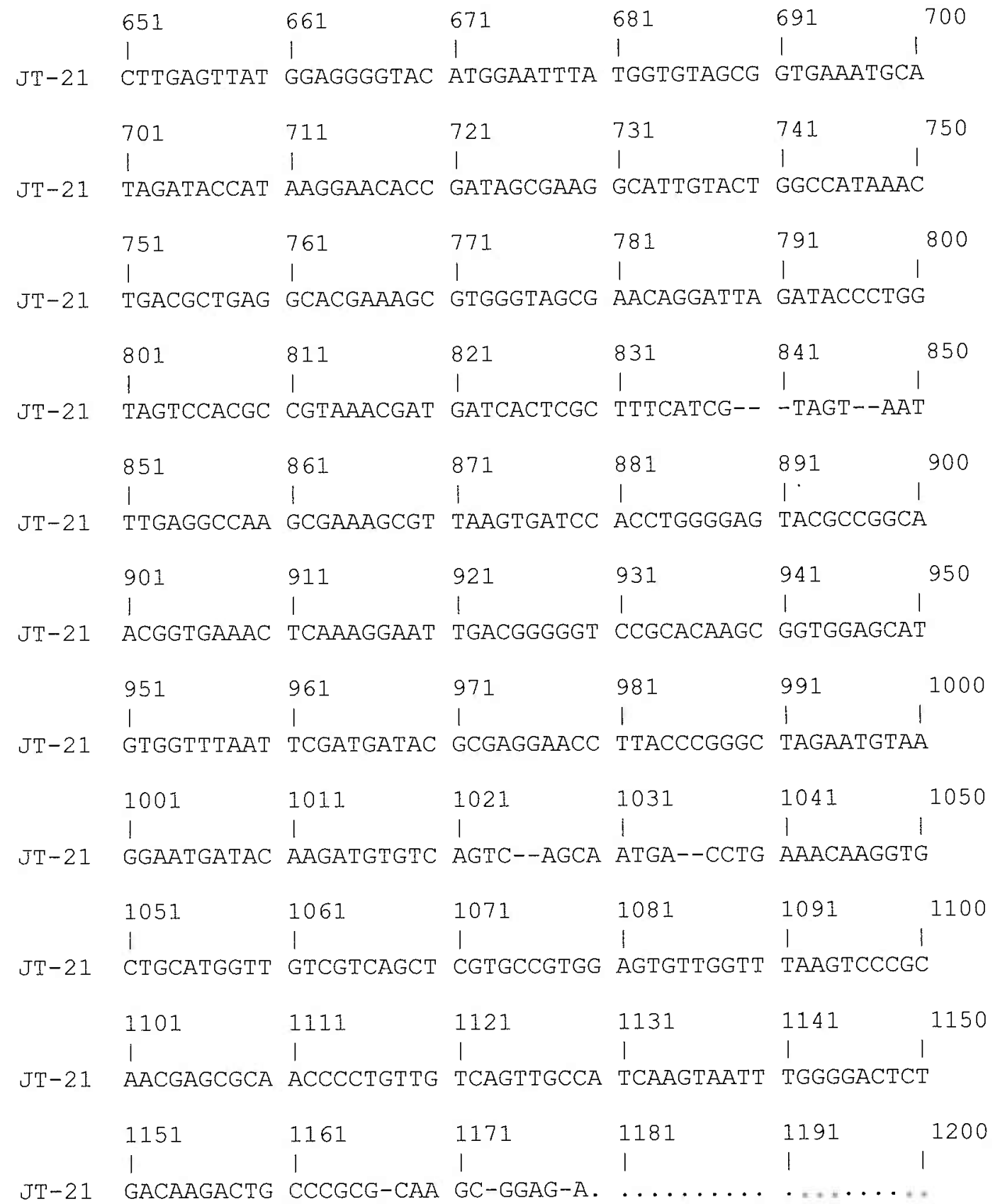




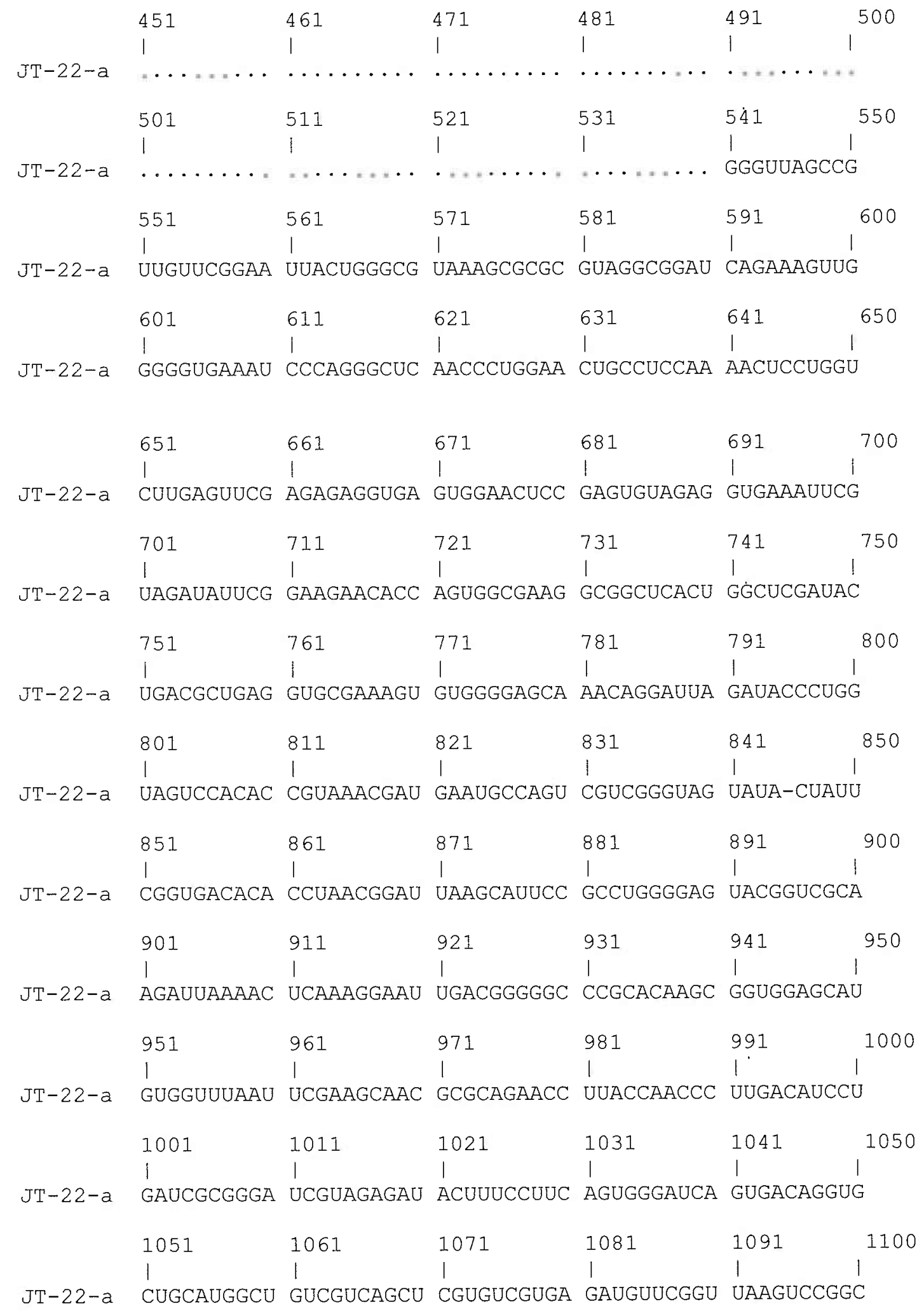




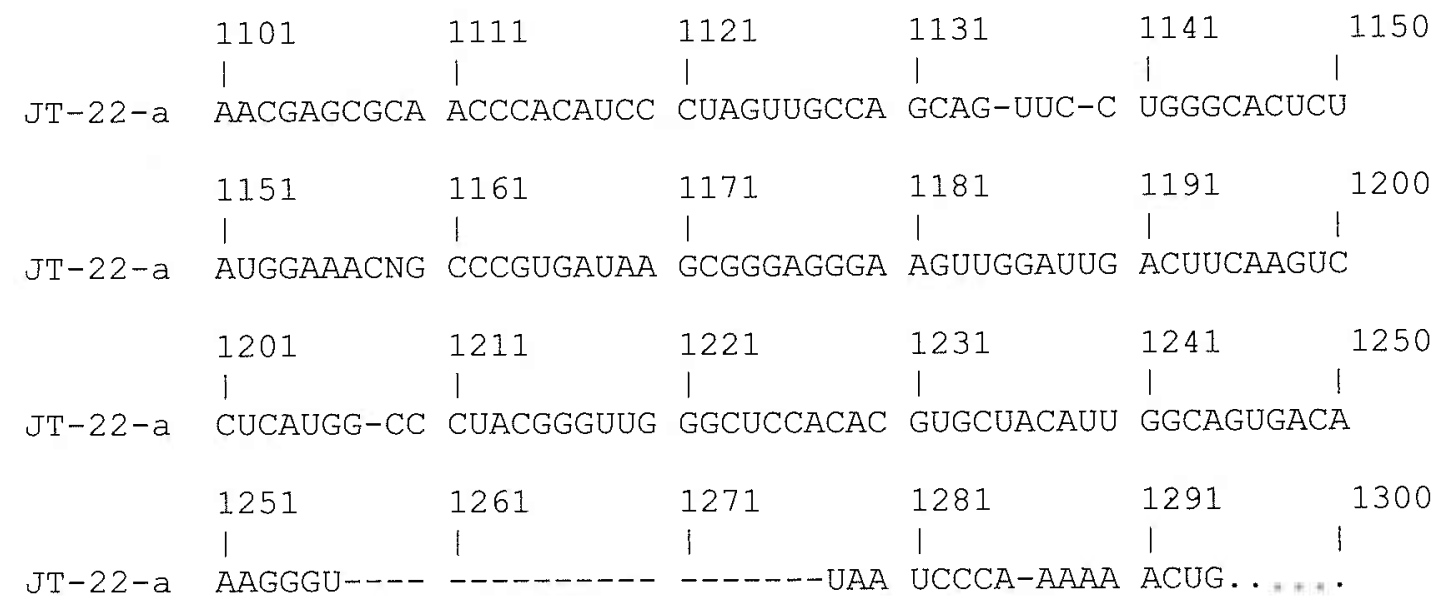




\begin{tabular}{|c|c|c|c|c|c|c|}
\hline & 1 & 11 & 21 & 31 & 41 & 50 \\
\hline & | & i & 1 & I & 1. & \\
\hline \multirow[t]{3}{*}{$\mathrm{JT}-23$} & $\ldots \ldots$ & $\ldots \ldots \ldots$ & $\cdots \ldots \ldots$ & $\ldots \ldots \ldots$ & $\ldots \ldots \ldots$ & \\
\hline & 51 & 61 & 71 & 81 & 91 & 100 \\
\hline & & 1 & 1 & 1 & 1 & \\
\hline \multirow[t]{3}{*}{$\mathrm{JT}-23$} & - CACATGCAA & GTCGAACGGT & GAACA-TGAA & AGACTTTCTT & TT-GATGACG & \\
\hline & 101 & 111 & 121 & 131 & 141 & 150 \\
\hline & । & | & I & I & 1 & \\
\hline \multirow[t]{3}{*}{ JT -23} & AGTGGCGGAC & GGGTGAGTAA & CACGTGGGAA & TCTACCGAGT & AGCGGGGGAT & \\
\hline & 151 & 161 & 171 & 181 & 191 & 200 \\
\hline & I & I & I & I & 1 & \\
\hline \multirow[t]{3}{*}{$\mathrm{JT}-23$} & AGCCCGGAGA & AATCCGGATT & AATACCGCAT & AAGCACTACG & GTGTAAAGGG & \\
\hline & 201 & 211 & 221 & 231 & 241 & 250 \\
\hline & 1 & I & I & 1 & 1 & \\
\hline \multirow[t]{2}{*}{$\mathrm{JT}-23$} & GGCCTTCTTG & AAAGCTTCCA & CTATTCGATG & AGCCTGCGTC & AGATTAGCTA & \\
\hline & $\begin{array}{l}251 \\
1\end{array}$ & $\begin{array}{l}261 \\
1\end{array}$ & $\begin{array}{l}271 \\
1\end{array}$ & 281 & $\begin{array}{l}291 \\
\mid\end{array}$ & 300 \\
\hline \multirow[t]{2}{*}{$\mathrm{JT}-23$} & GTTGGTGGGG & TAATGGCCTA & CCAAGGCGAC & GATCTGTAGC & TGGTCTGAGA & \\
\hline & $\begin{array}{l}301 \\
1\end{array}$ & $\begin{array}{l}311 \\
1\end{array}$ & $\begin{array}{l}321 \\
1\end{array}$ & $\begin{array}{l}331 \\
1\end{array}$ & $\begin{array}{l}341 \\
1\end{array}$ & \\
\hline \multirow[t]{2}{*}{$\mathrm{JT}-23$} & GGATGATCAG & CCACACTGGG & ACTGAGACAC & GGCCCAGACT & CCTACGGGAG & \\
\hline & $\begin{array}{l}351 \\
1\end{array}$ & $\begin{array}{l}361 \\
1\end{array}$ & $\begin{array}{l}37 \\
1\end{array}$ & $\begin{array}{l}381 \\
1\end{array}$ & $\begin{array}{l}391 \\
1\end{array}$ & \\
\hline \multirow[t]{2}{*}{$J T-23$} & GCAGCAGTGG & GGAATATTGG & ACAATGGGGG & CAACCCTGAT & CCAGCAATAC & \\
\hline & 401 & 411 & 421 & 431 & 441 & 450 \\
\hline \multirow[t]{3}{*}{ JT-23 } & CGCGTGTGTG & AAGAAGGCCT & TCGGGTTGTA & AAGCACTTTC & AGCGAGGAGG & \\
\hline & 451 & 461 & 471 & 481 & 491 & 500 \\
\hline & & I & 1 & 1 & & \\
\hline \multirow[t]{2}{*}{ JT-23 } & AAAAGCTAGT & AGTTAATACC & TCTGGCCTTT & GACGTTACTC & GCAGAAGAAG & \\
\hline & 501 & 511 & 521 & 531 & 541 & 50 \\
\hline \multirow[t]{3}{*}{ JT-23 } & CACCGGCTAA & CTCCGTGCCA & GCAGCCGCGG & TAATACGGAG & GGTGCCAGCG & \\
\hline & 551 & 561 & 571 & 581 & 591 & 600 \\
\hline & $I_{1}$ & 1 & 1 & I & 1 & \\
\hline \multirow{2}{*}{ JT -23} & TTAATCGGAA & TTACTGGGCG & TAAAGCGCGC & GTAGGCGGAT & GATTAAGTCA & \\
\hline & 601 & 611 & 621 & 631 & 641 & \\
\hline $5-23$ & GATGTGAAAG & CCCAGGGCTT & AACCTTG & CTGCATTTGA & TACTGGTCAT & \\
\hline
\end{tabular}




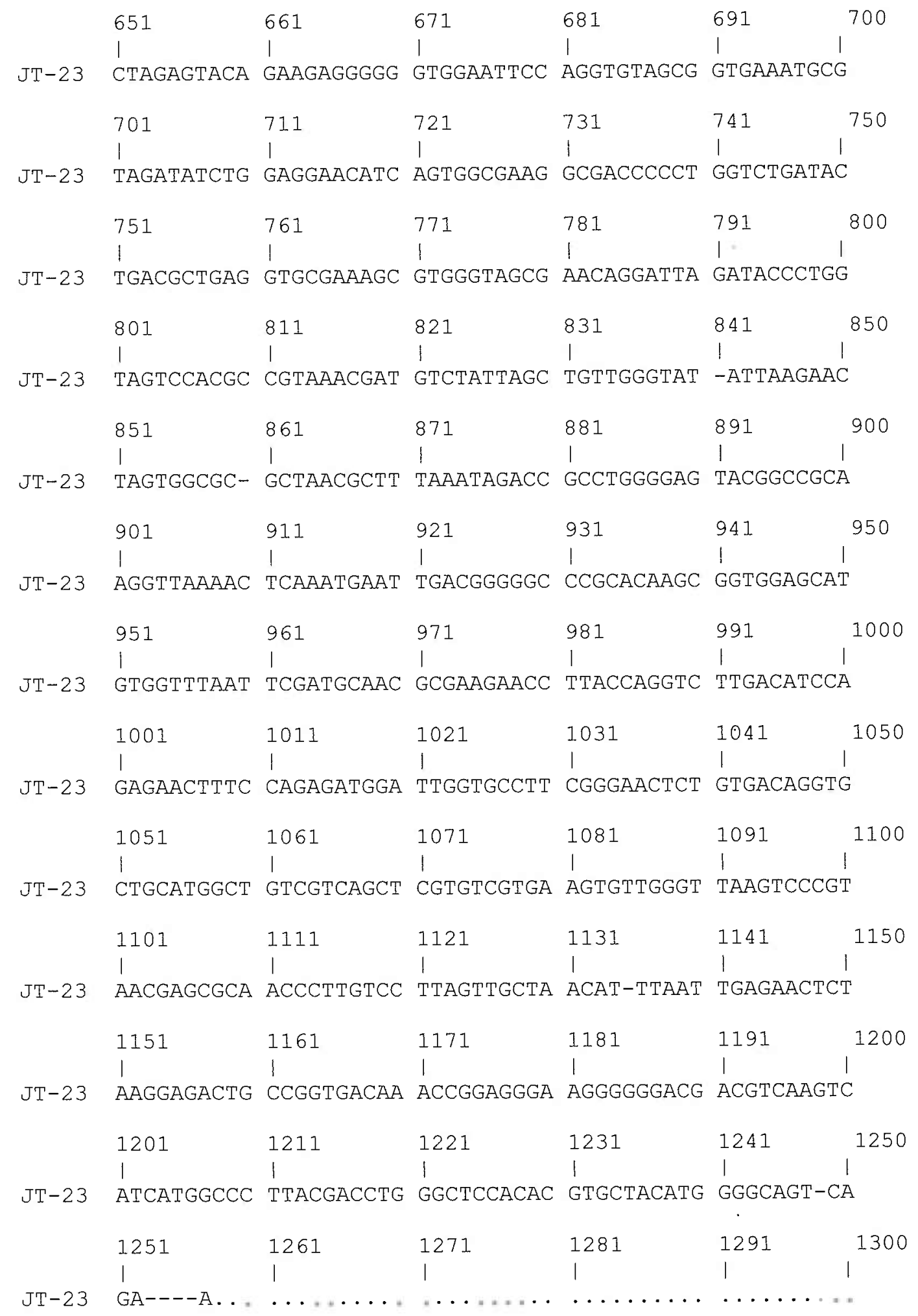




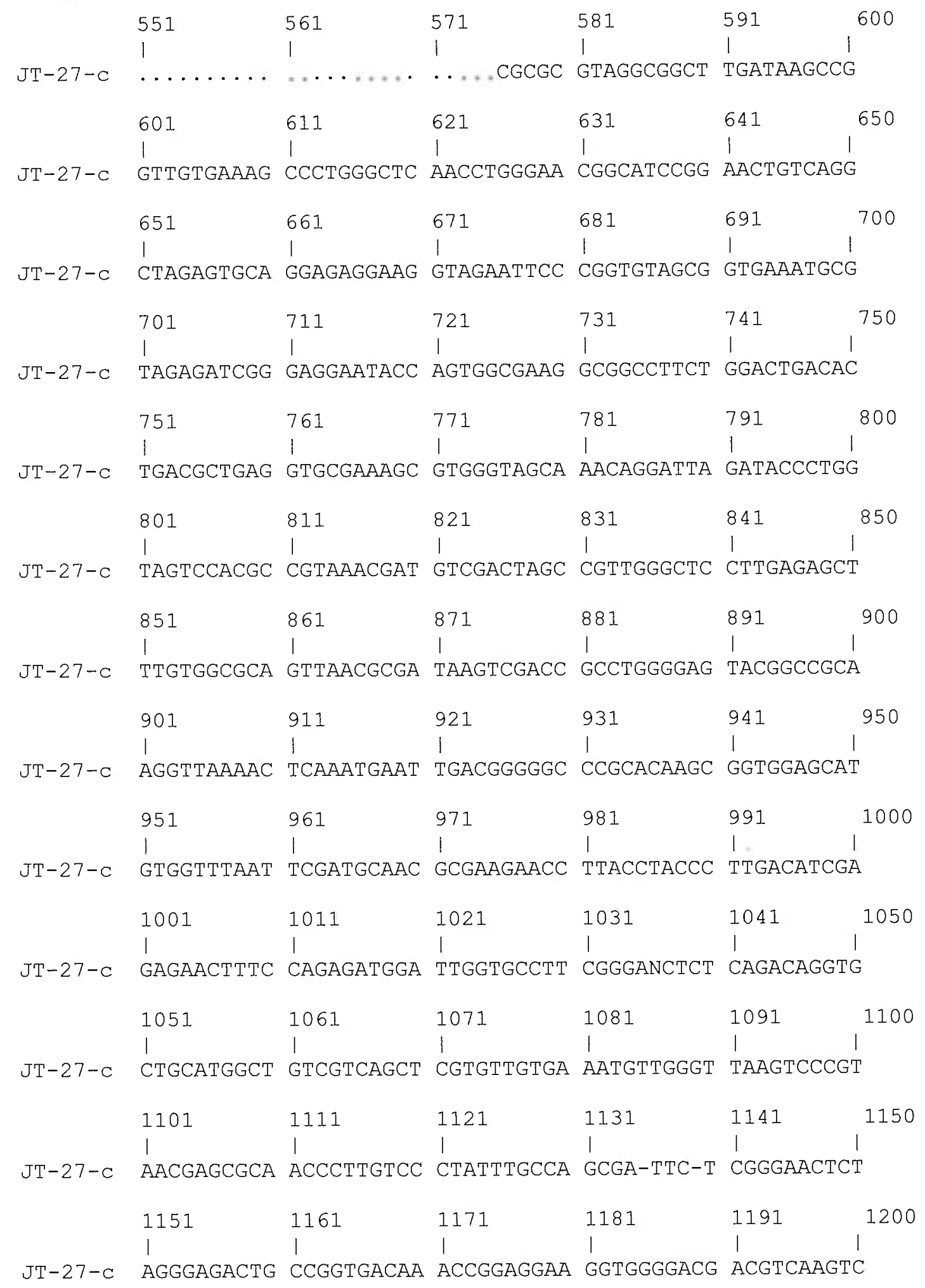




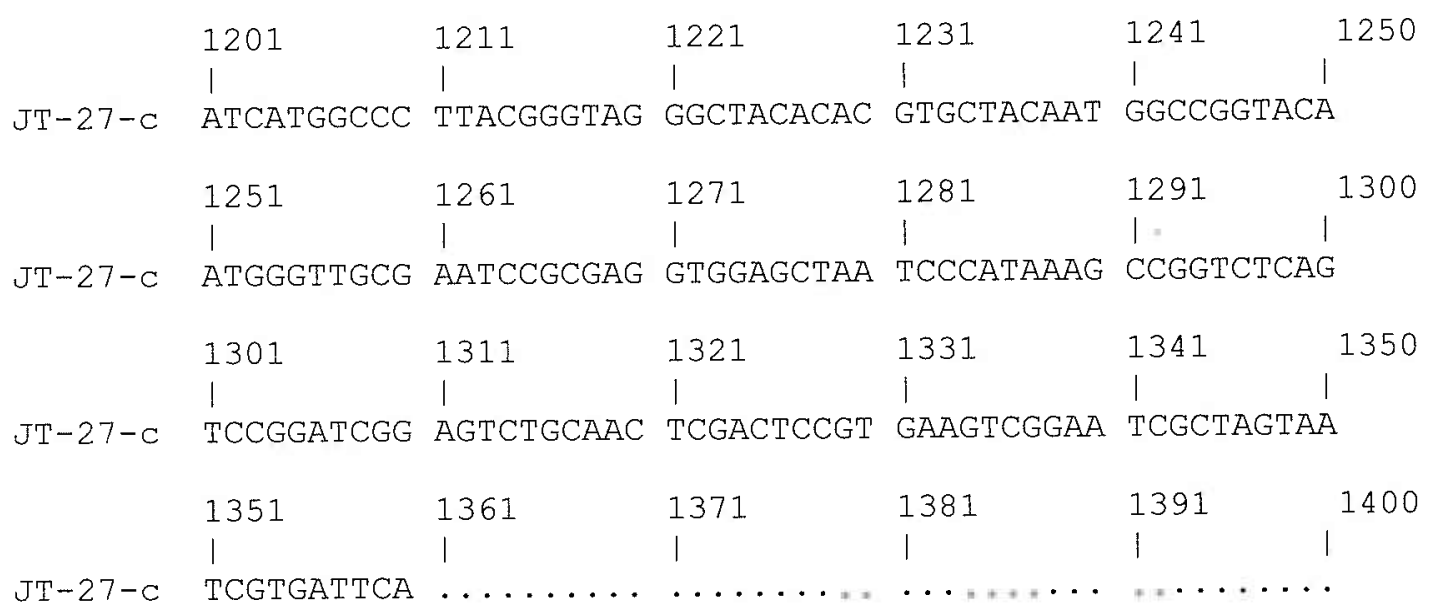




\begin{tabular}{|c|c|c|c|c|c|c|}
\hline & 1 & 1.1 & 21 & 31 & 41 & 50 \\
\hline & 1 & 1 & I & 1 & I & \\
\hline JT-29 & $\ldots \ldots \ldots$ & $\cdots \cdots \cdots$ & $\ldots \ldots \ldots$ & $\cdots \ldots$ & $\ldots \ldots \ldots$ & \\
\hline & 51 & 61 & 71 & 81 & 91 & 100 \\
\hline JT -29 & 1 & I & I & I & 1 & \\
\hline & $\ldots \ldots$ UGCAA & GUCGAGCCGA & AACGA-UUCU & $\mathrm{UU}$ & $A A-G G C G U C G$ & \\
\hline & $\begin{array}{l}101 \\
1\end{array}$ & 111 & 121 & 131 & 141 & 150 \\
\hline JT-29 & AGCGGCGGAC & I GGGUGAGUAA & 1 & & I & \\
\hline & $\begin{array}{l}151 \\
1\end{array}$ & $\begin{array}{l}161 \\
1\end{array}$ & $\begin{array}{l}171 \\
1\end{array}$ & 181 & $\begin{array}{l}191 \\
1\end{array}$ & \\
\hline $\mathrm{JT}-29$ & AACCUGGGGA & AACUCAGGCU & AAUACCGCAU & ACGUCCUACG & GGAGAAAGCA & \\
\hline & $\begin{array}{l}201 \\
1\end{array}$ & $\begin{array}{l}211 \\
1\end{array}$ & $\begin{array}{l}221 \\
1\end{array}$ & $\begin{array}{l}231 \\
1\end{array}$ & $\begin{array}{l}241 \\
1\end{array}$ & \\
\hline JT -29 & GGGGAUCUUC & GGACCUUGCG & CUAUCGGAUG & AGCCCAUGUC & GGAUUAGCUU & \\
\hline & $\begin{array}{l}251 \\
\mid\end{array}$ & $\begin{array}{l}261 \\
1\end{array}$ & $\begin{array}{l}2.71 \\
1\end{array}$ & $\begin{array}{l}281 \\
1\end{array}$ & $\begin{array}{l}291 \\
1\end{array}$ & \\
\hline JT -29 & GUUGGUGAGG & UAACGGCUCA & CCAAGGCGAC & GAUCCGUAGC & UGGUCUGAGA & \\
\hline & $\begin{array}{l}301 \\
1\end{array}$ & $\begin{array}{l}311 \\
1\end{array}$ & $\begin{array}{l}321 \\
1\end{array}$ & $\begin{array}{l}331 \\
1\end{array}$ & $\begin{array}{l}341 \\
1\end{array}$ & \\
\hline JT-29 & GGAUGAUCAG & CCACACUGGG & ACUGAGACAC & GGCCCAGACU & CCUACGGGAG & \\
\hline & $\begin{array}{l}351 \\
1\end{array}$ & $\begin{array}{l}361 \\
\mid\end{array}$ & $\begin{array}{l}371 \\
\mid\end{array}$ & $\begin{array}{l}381 \\
1\end{array}$ & $\begin{array}{l}391 \\
1\end{array}$ & 400 \\
\hline$J T-29$ & GCAGCAGUGG & GGAAUAUUGG & ACAAUGGGCG & AAAGCCUGAU & CCAGCCAUGC & \\
\hline & $\begin{array}{l}401 \\
1\end{array}$ & $\begin{array}{l}411 \\
\mid\end{array}$ & $\begin{array}{l}42 \\
1\end{array}$ & $\begin{array}{l}43 \\
1\end{array}$ & $\begin{array}{l}441 \\
1\end{array}$ & \\
\hline JT-29 & CGCGUGUGUG & AAGAAGGCCU & UCGGGUUGUA & AAGCACUUUC & AGCGAGGAAG & \\
\hline & $\begin{array}{l}451 \\
1\end{array}$ & $\begin{array}{l}461 \\
1\end{array}$ & $\begin{array}{l}471 \\
1\end{array}$ & $\begin{array}{l}48 \\
1\end{array}$ & $\begin{array}{l}491 \\
1\end{array}$ & 500 \\
\hline JT -29 & AACGCUUCGG & GAUUAAUACU & CCCGAGGAAA & GACAUCACUC & GCAGAAGAAG & \\
\hline & $\begin{array}{l}501 \\
1\end{array}$ & $\begin{array}{l}511 \\
1\end{array}$ & $\begin{array}{l}521 \\
1\end{array}$ & 531 & 541 & \\
\hline JT-29 & CACCGGCUAA & CUCCGUGCCA & GCAGCCGCGG & UAAUACGGAG & GGUGCAAGCG & \\
\hline$J T-29$ & UUAAUCGGAA & UUACUGGGCG & UAAAGCGCGC & GUAGGUGGCU & AAGUCAGCCA & \\
\hline & 60 & 611 & 62 & 63 & $6 \dot{4} 1$ & \\
\hline & 1 & $\begin{array}{l}\text { I } \\
\text { CCCCGGGCUC }\end{array}$ & $\begin{array}{l}1 \\
\text { AACCUGGGAA }\end{array}$ & $1_{\text {CGGCAUCUGG }}^{1}$ & $\begin{array}{l}\text { I } \\
\text { AACUGCUUGC }\end{array}$ & \\
\hline
\end{tabular}




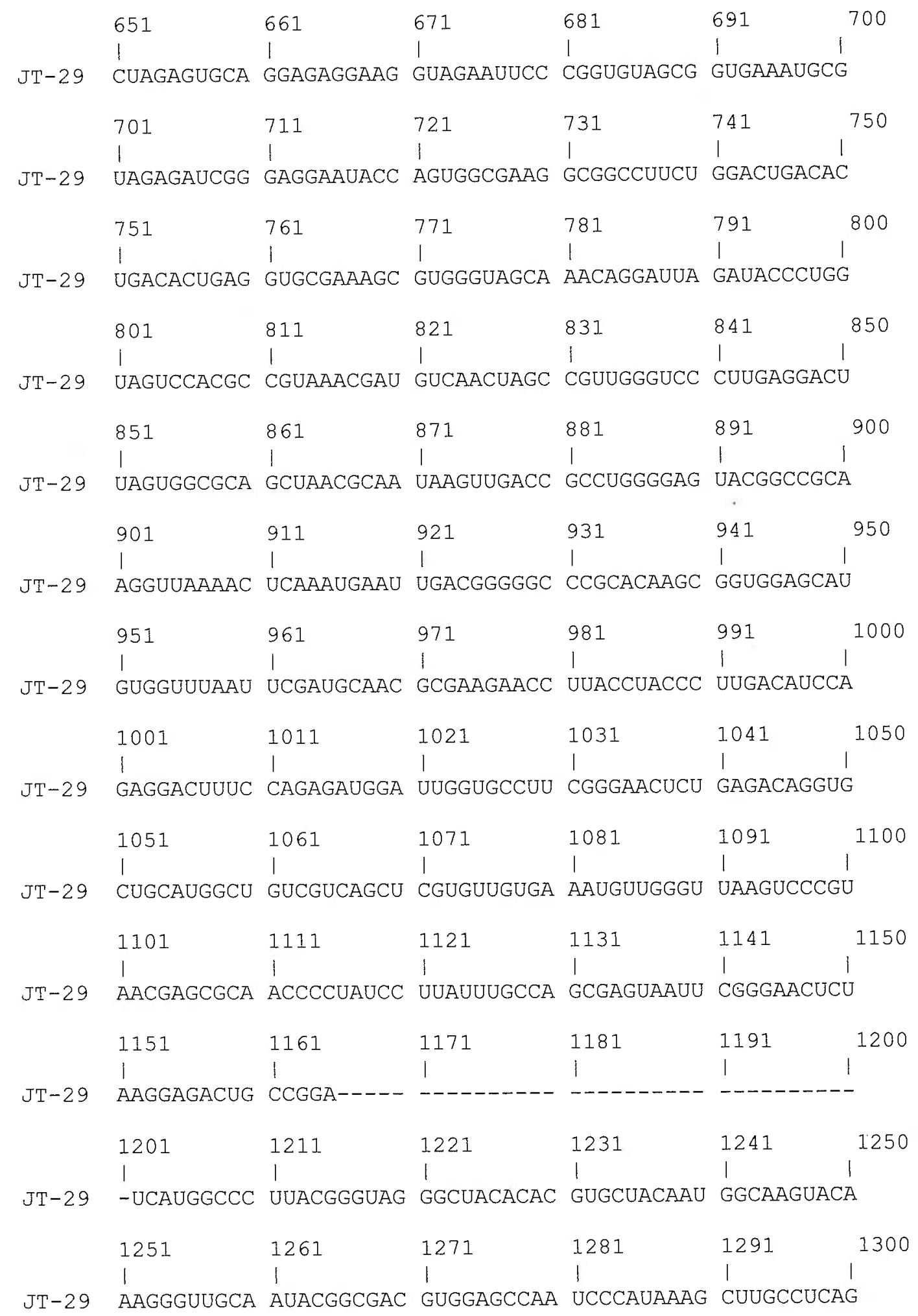




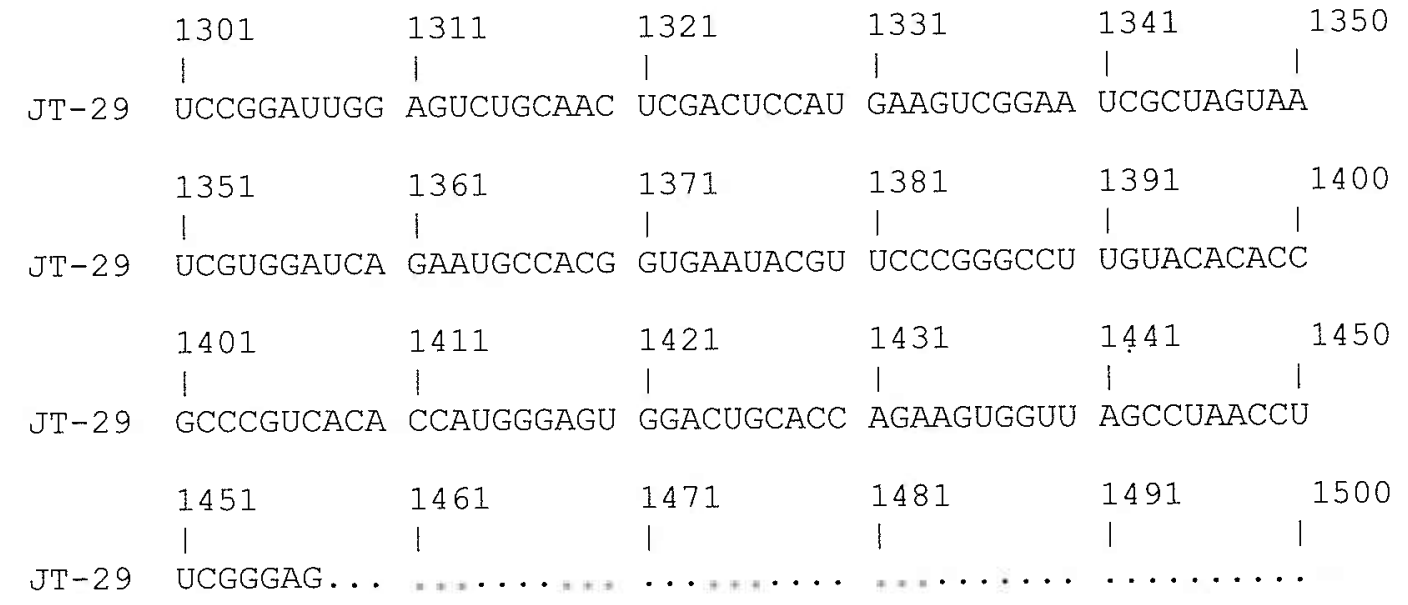

